\title{
Critical Buckling Strength Prediction of Pultruded GFRP Composite Columns
}

\author{
Mathew Marvin Blandford \\ West Virginia University
}

Follow this and additional works at: https://researchrepository.wvu.edu/etd

\section{Recommended Citation}

Blandford, Mathew Marvin, "Critical Buckling Strength Prediction of Pultruded GFRP Composite Columns" (2010). Graduate Theses, Dissertations, and Problem Reports. 2279.

https://researchrepository.wvu.edu/etd/2279

This Thesis is protected by copyright and/or related rights. It has been brought to you by the The Research Repository @ WVU with permission from the rights-holder(s). You are free to use this Thesis in any way that is permitted by the copyright and related rights legislation that applies to your use. For other uses you must obtain permission from the rights-holder(s) directly, unless additional rights are indicated by a Creative Commons license in the record and/ or on the work itself. This Thesis has been accepted for inclusion in WVU Graduate Theses, Dissertations, and Problem Reports collection by an authorized administrator of The Research Repository @ WVU. For more information, please contact researchrepository@mail.wvu.edu. 


\title{
Critical Buckling Strength Prediction of Pultruded GFRP Composite Columns
}

\section{Mathew Marvin Blandford}

\author{
Thesis submitted to the \\ College of Engineering and Mineral Resources at \\ West Virginia University in \\ partial fulfillment of the requirements \\ for the degree of
}

\section{Master of Science \\ in \\ Civil Engineering}

\author{
Approved by \\ Hota V. S. GangaRao, PhD, Chair \\ Ruifeng Liang, $\mathrm{PhD}$ \\ Udaya B. Halabe, PhD
}

\section{Department of Civil and Environmental Engineering}

\author{
Morgantown, West Virginia \\ 2010
}

Keywords: strain energy, eccentricity, GFRP, compression, pultrusion, column 


\section{ABSTRACT \\ Critical Buckling Strength Prediction of Pultruded GFRP Composite Columns \\ Mathew Blandford \\ Constructed Facilities Center, West Virginia University}

Fiber-reinforced polymeric (FRP) composites offer a unique addition to common construction materials utilized in Civil Engineering. However, unlike traditional construction materials (steel, timber, concrete, etc) FRP composites lack adequate design standards and or criteria. The need for appropriate design guidelines is subsequently required in order to ease the progression of the use FRP composites in construction. The present research investigates several previously proposed prediction models' ability to calculate failure of GFRP composite columns of varied length and cross section. Material properties were developed through testing specimens of the coupon and $1 \mathrm{ft}$ "pure" compression (component) levels. Furthermore, a strain-energy density failure model developed by researchers at WVU-CFC for GFRP coupons in tension and bending was manipulated to evaluate full-length samples in axial compression. Prediction of failure within the proposed models displayed a range of precision and accuracy. The strain energy density failure model commonly predicted the critical buckling load within $10 \%$ of experimental failure for each of the different column lengths tested (6ft, 8ft-6in, 9ft, 10ft). In conjunction with failure analysis, P- $\Delta$ effects enhanced by eccentricity due to loading and initial out-of-straightness were also investigated. Preliminary design guidelines have proposed a total eccentricity limit of $h / 220$ where ' $h$ ' is the column height in inches. The current research found this limit to be acceptable, however, the component due to initial imperfections along the column length $(h / 700)$, proved to be slightly too low and was commonly found to fall within the range of h/500-h/700. 


\section{ACKNOWLEDGEMENTS}

First and foremost I would like to thank Dr. Hota GangaRao, for not only serving as my advisor, but also as the chair of my review committee. I am very grateful for the opportunities presented to me at WVU none of which would have been possible without the aid of Dr. Hota. His encouragement and willingness to help made the transitions of this research translate extremely smoothly.

I would also like to thank Dr. Udaya Halabe and Dr. Ruifeng Liang for offering support throughout the course of my research and also for serving on my review committee.

The early stages of this project required hours of laboratory testing, none of which I would have survived without Jerry Nestor. Not only did he provide good company, but also assistance in the testing of EVERY column. His expertise as a technician created an efficient and safe work place for the both of us. I am extremely grateful for his assistance and this project is as much his as it is mine.

Additionally, I would like to thank Mark Skidmore and Dave Dittenber for their endless assistance in showing me the functionality of all the laboratory equipment as well as guidance in specimen preparation.

Finally, I would like to thank all of my friends far and near for their endless support during the course of the project. I would also like to thank my immediate family as well as my Moscow family for their unlimited acts of encouragement and kindness. 


\section{TABLE OF CONTENTS}

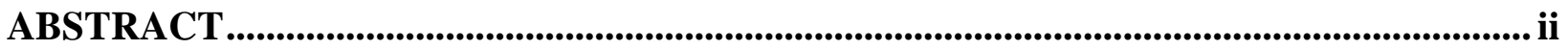

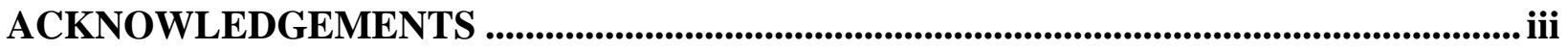

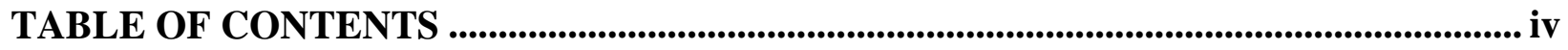

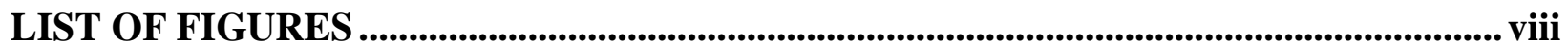

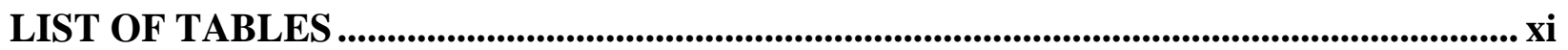

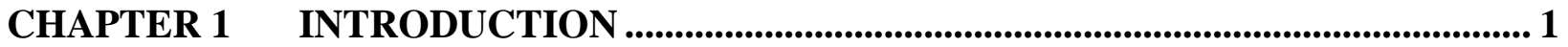

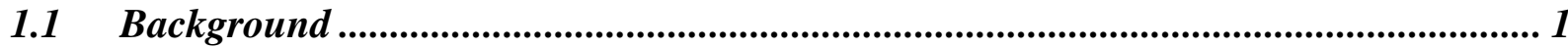

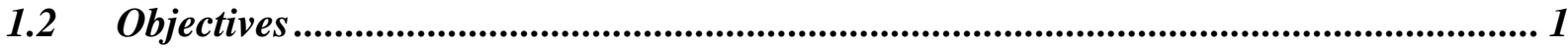

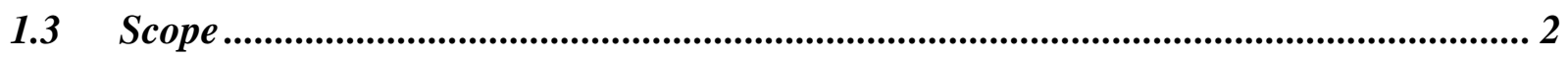

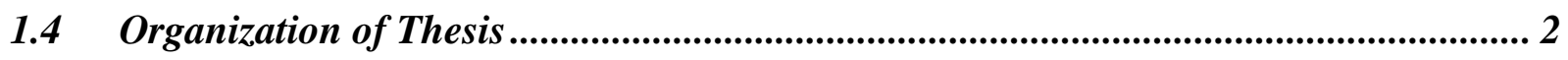

CHAPTER 2 LITERATURE REVIEW ..................................................................... 4

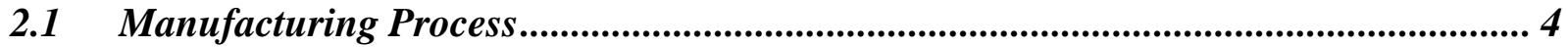

2.2 Buckling Effects .............................................................................................................. 5

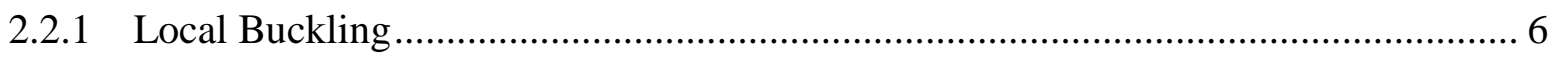

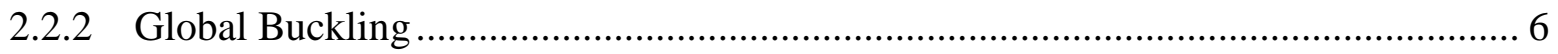

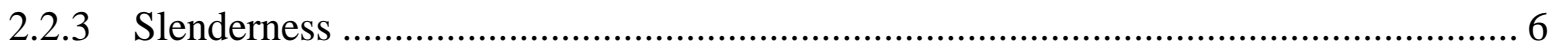

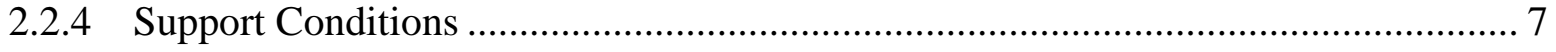

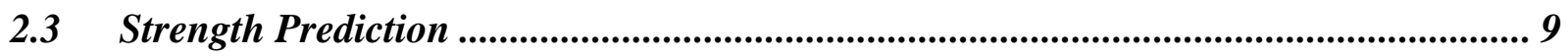

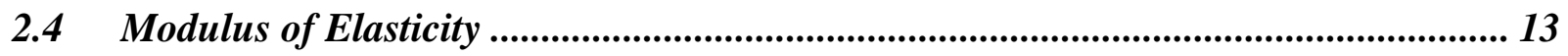




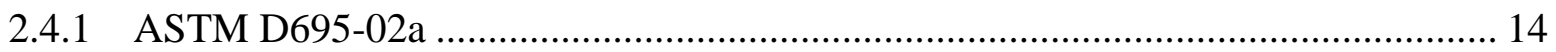

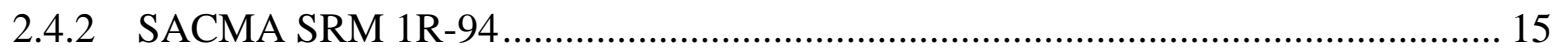

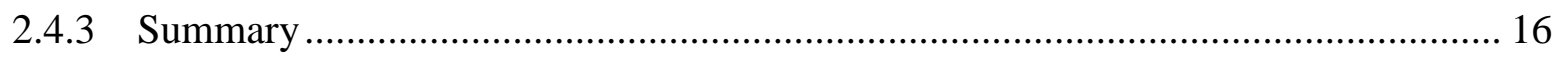

$2.5 \quad$ Strain Energy Failure Criteria …….................................................................................... 16

CHAPTER 3 LABORATORY TESTING/SPECIMEN IDENTIFICATION .................. 20

3.1 Introduction ......................................................................................................................... 20

$3.2 \quad$ Material Properties................................................................................................................ 20

3.3 Column Testing ................................................................................................................... 21

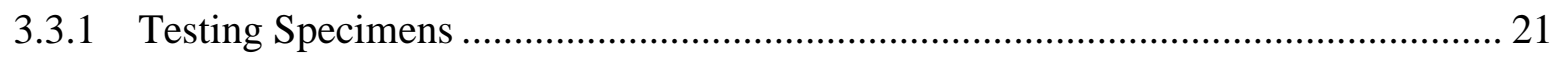

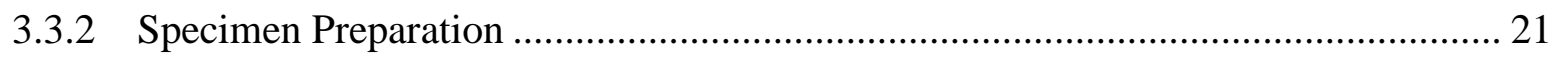

3.3.3 Testing Apparatus ………………………………………………………………... 23

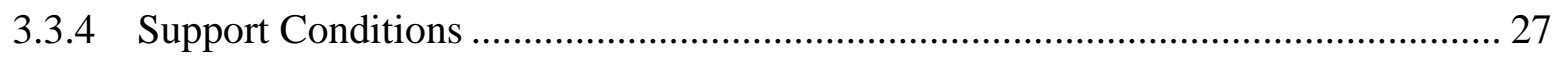

$3.4 \quad$ Pure Compression Testing (1ft Samples) ….......................................................................... 27

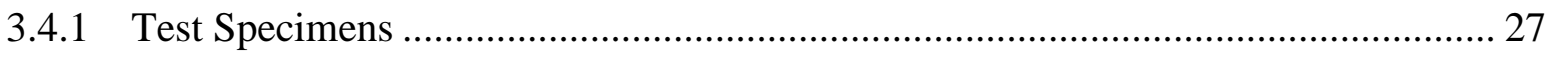

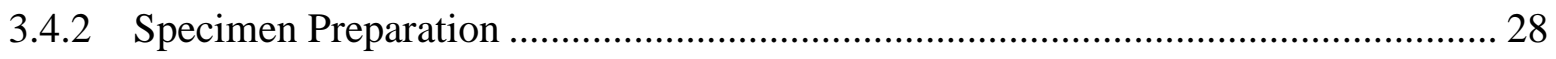

3.4.3 Testing Apparatus .......................................................................................... 28

3.5 Coupon Testing .............................................................................................................. 28

3.6 SACMA SRM 1R-94 (Modified ASTM D695) ................................................................ 29

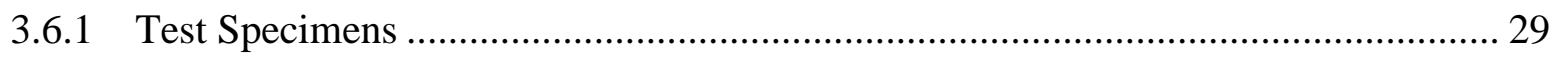

3.6.2 Specimen Preparation …………….................................................................. 29 


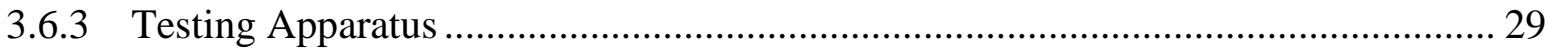

$3.7 \quad$ Modified ASTM D3410 ................................................................................................ 31

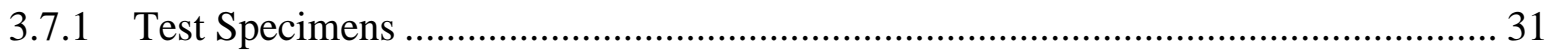

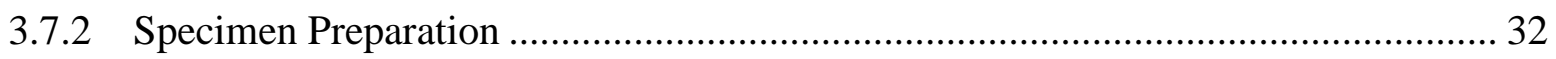

3.7.3 Testing Apparatus ................................................................................................ 32

CHAPTER 4 DATA ANALYSIS AND RESULTS................................................................... 33

4.1 Column Testing ................................................................................................................... 33

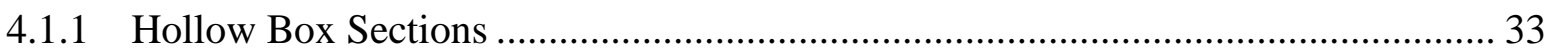

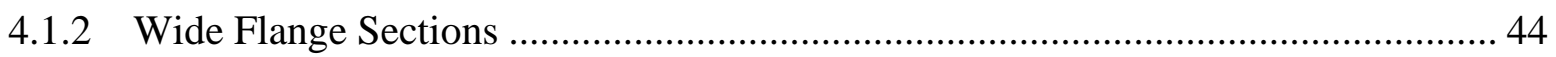

4.2 Pure Compression (1ft Samples) ....................................................................................... 50

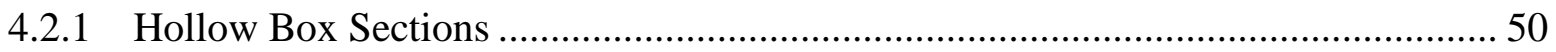

4.2.2 Wide Flange Sections ………………………....................................................... 56

4.3 Coupon Testing .................................................................................................................... 59

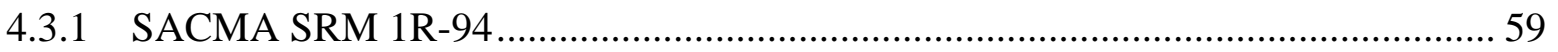

4.3.2 Modified ASTM D3410 ......................................................................................... 59

CHAPTER 5 EVALUATION/DISCUSSION OF RESULTS........................................... 62

$5.1 \quad$ Strength Prediction ..................................................................................................... 62

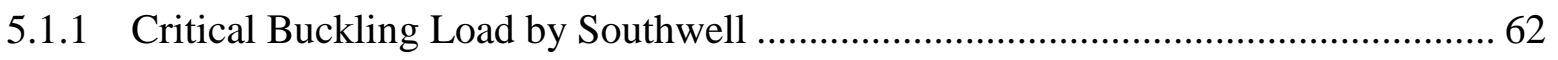

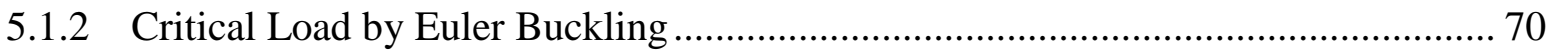

5.1.3 Critical Load Proposed by F. Engesser......................................................................... 72 
5.1.4 Empirical Approach to Strength Design (Puente) ............................................ 78

5.1.5 Strain Energy Failure Criteria ................................................................... 80

5.1.6 Predicted Strain Energy Failure (Hollow Box Sections) ....................................... 81

5.1.7 Predicted Strain Energy Failure (Wide Flange Sections) .................................... 93

5.2 Effect of Initial Imperfections (Along Length)................................................. 95

5.2.1 Full-Length Column Eccentricity Evaluation (Stress Analysis)........................... 97

5.2.2 Eccentricity due to Initial Imperfections (Southwell) ...................................... 101

5.3 Global vs. Local Buckling (LRFD Draft Spec) ................................................ 103

CHAPTER 6 Conclusions and Recommendations............................................................ 105

6.1 Evaluation of Mechanical Properties.............................................................................. 105

6.2 Commonalities within Data Analysis ................................................................... 106

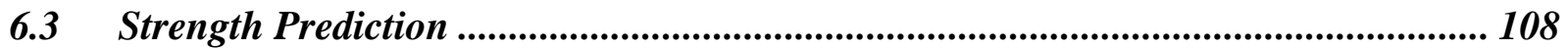

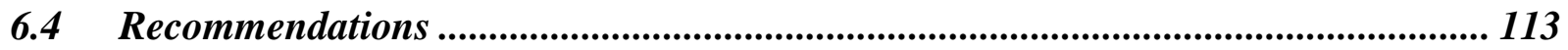

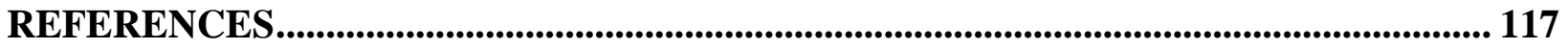

APPENDIX A - Data Analysis Figures ................................................................................ 120

APPENDIX B - Design Example................................................................................... 163 


\section{LIST OF FIGURES}

Figure 2-1 Pultrusion Manufacturing Process (Barbero E. J., 1998)......................................... 5

Figure 2-2 Effective Length Factors (Gere J. M., 2004) ........................................................ 8

Figure 2-3 Typical Stress-Strain Curve for Multidirectional Composites (Vadlamani, 2007)..... 18

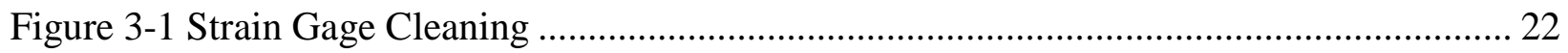

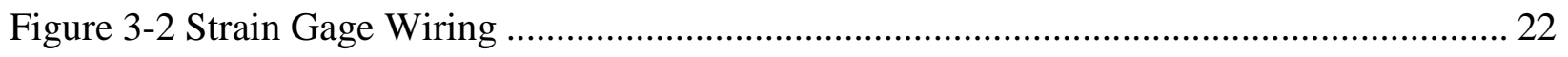

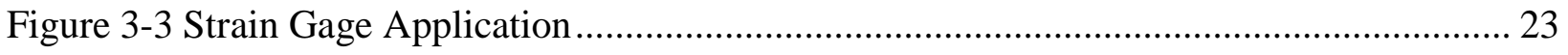

Figure 3-4 Top and Bottom Fixtures, Load Cell (Clockwise from Left)................................ 24

Figure 3-5 Modified Top Fixture (10ft Columns), Actuator Apparatus .................................. 25

Figure 3-6 Hydraulic Pump, Actuator, Data Acquisition, LVDT (Clockwise from Top Left) .... 26

Figure 3-7 SACMA SRM 1R-94 Testing Fixture............................................................ 30

Figure 3-8 Instron 8501 Universal Testing Machine ...................................................... 31

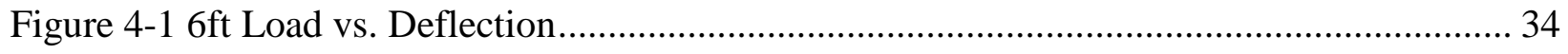

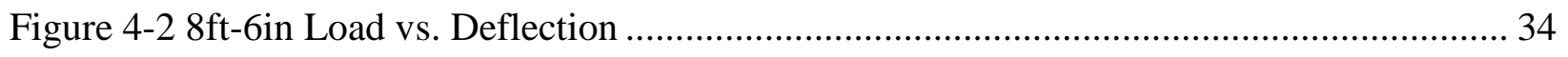

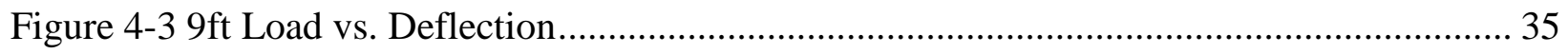

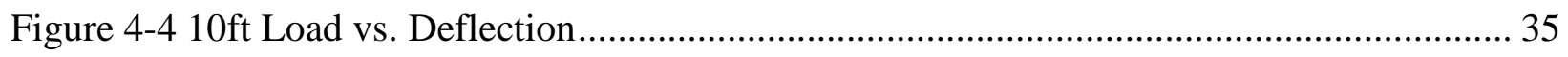

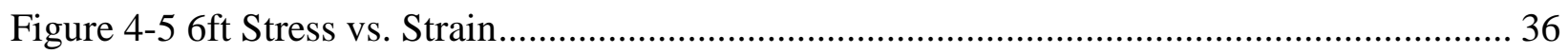

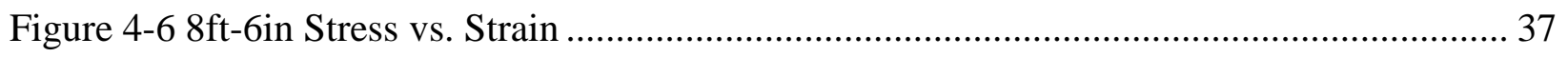

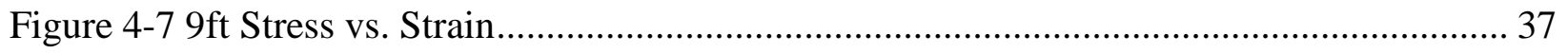

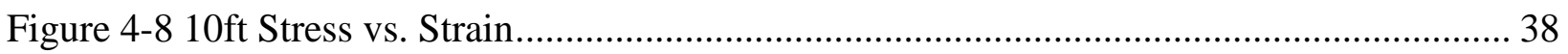

Figure 4-9 6ft failure, 8ft-6in failure, 6ft pure compression, 9ft failure (Clockwise from Left).. 40

Figure 4-10 Left: Excessive Bending (9ft Column) Right: Perfect Compression Failure (6ft

Column) 40 
Figure 4-11 3" W-Flange Load vs. Deflection ......................................................................... 45

Figure 4-12 6" W-Flange Load vs. Deflection .............................................................................. 46

Figure 4-13 3" W-Flange Stress vs. Strain ................................................................................ 46

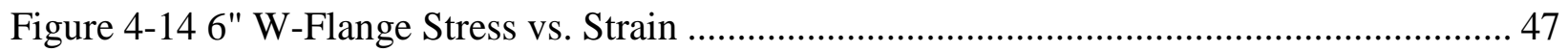

Figure 4-15 6" Flange Failure, 6" Flange Pure Compression, 3" Flange End Crushing (Clockwise

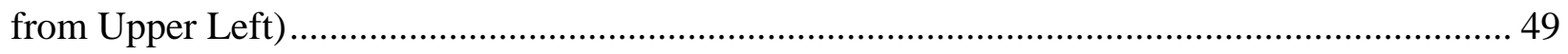

Figure 4-16 1ft Stress vs. Strain (8ft-6in Col. 2) ....................................................................... 51

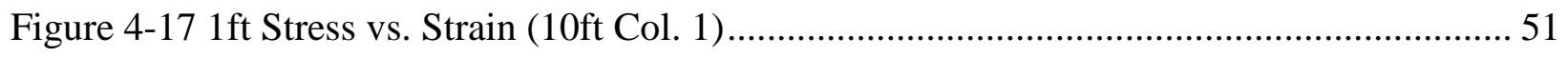

Figure 4-18 Local Buckling Failure (1ft Samples) ……………………………….................. 55

Figure 4-19 End Crushing (1ft Samples) ……………............................................................. 56

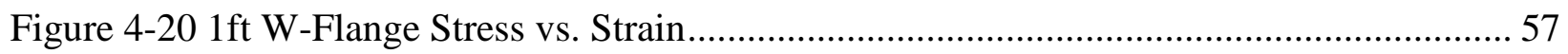

Figure 4-21 Local Buckling Failure (1ft W-Flange)..................................................................... 58

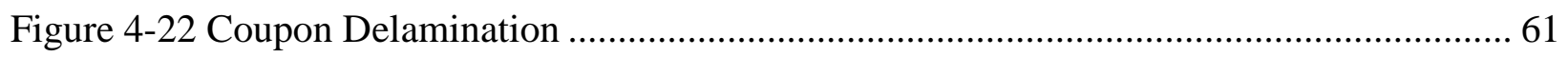

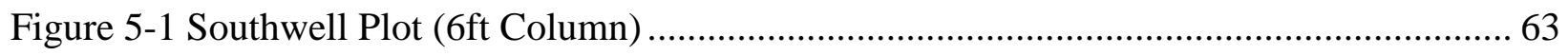

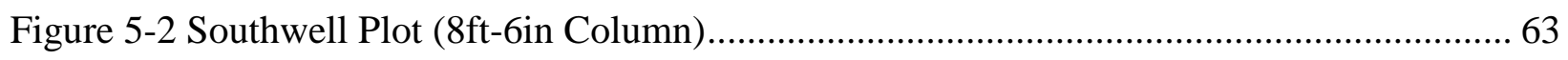

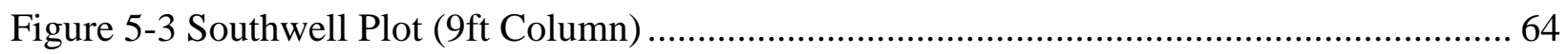

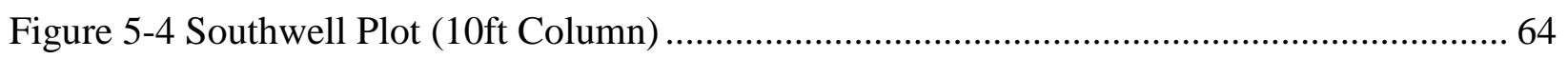

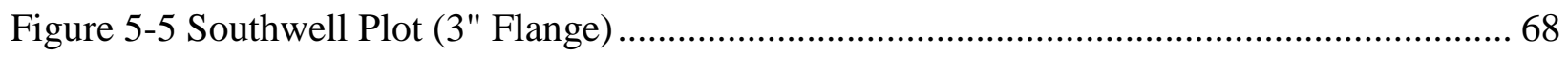

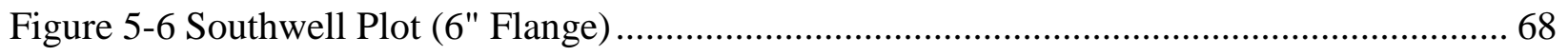

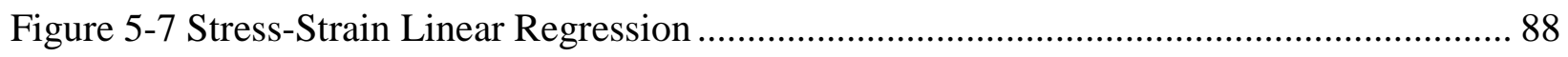

Figure 5-8 Column Initial Imperfection (Southwell) ................................................................ 102

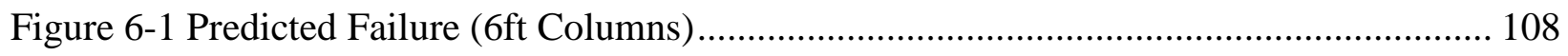

Figure 6-2 Predicted Failure (8ft-6in Columns) …………........................................................ 109 
Figure 6-3 Predicted Failure (9ft Columns)................................................................... 109

Figure 6-4 Predicted Failure (10ft Columns)................................................................ 110

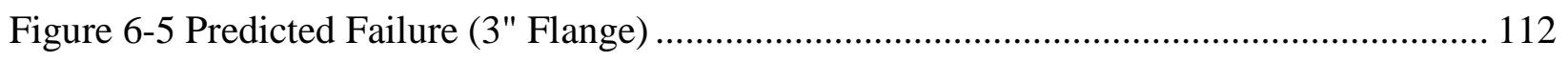




\section{LIST OF TABLES}

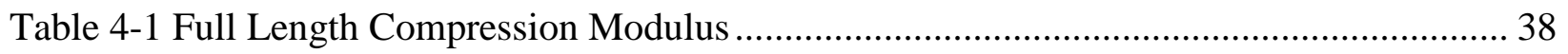

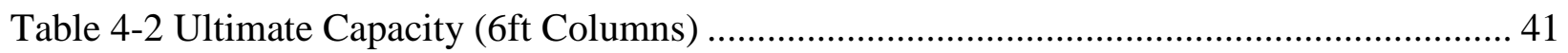

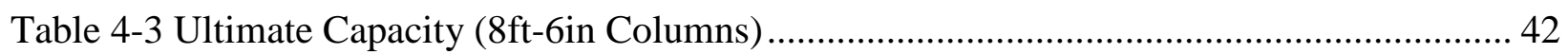

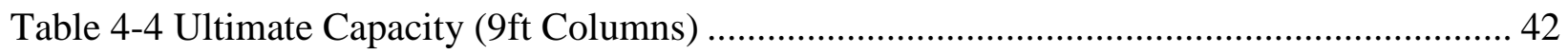

Table 4-5 Ultimate Capacity (10ft Columns) …………............................................................... 43

Table 4-6 Average Failure Data (Full Length Columns) ........................................................... 44

Table 4-7 Percent Difference of Average Values Between all Samples and Outliers................... 44

Table 4-8 Modulus of Elasticity (W-Flange Columns), ............................................................... 48

Table 4-9 Ultimate Capacity W-Flange Columns ............................................................ 50

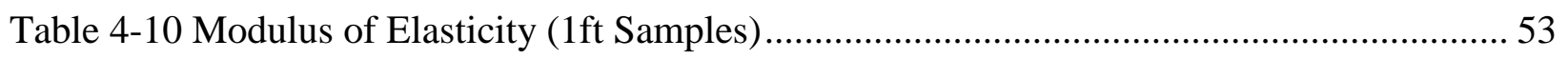

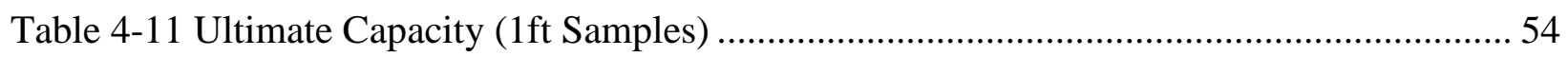

Table 4-12 Modulus of Elasticity (Coupon) ……………............................................................ 59

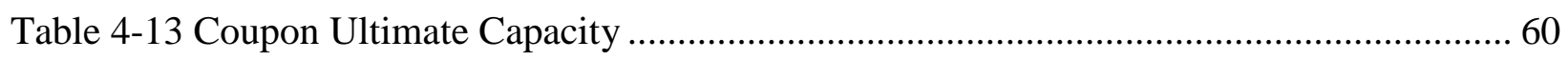

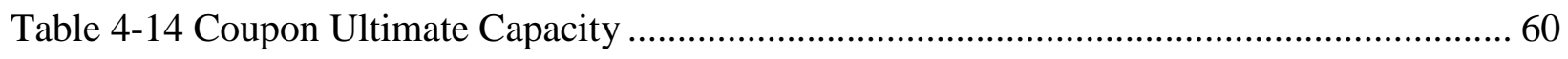

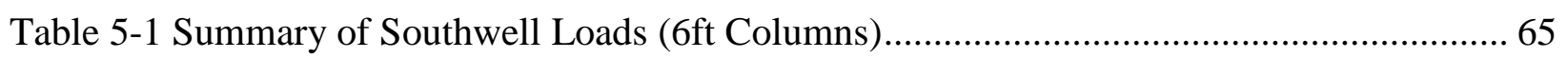

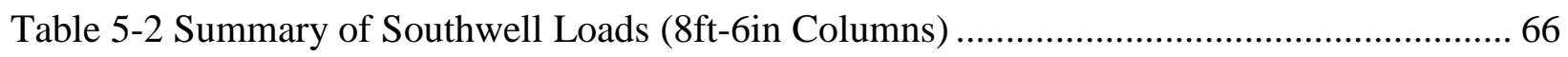

Table 5-3 Summary of Southwell Loads (9ft Columns).............................................................. 66

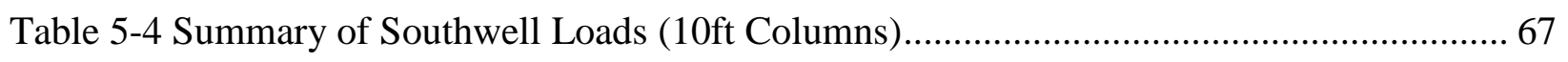

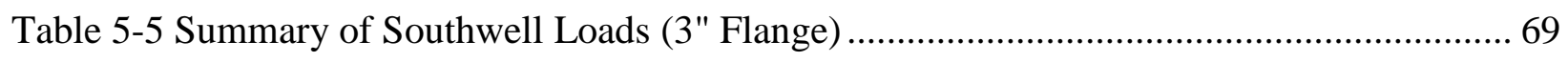

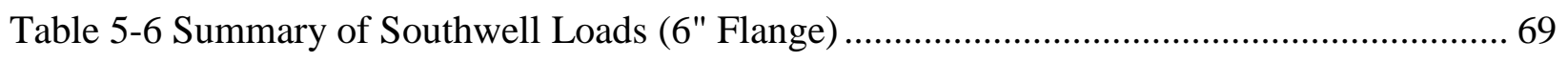

Table 5-7 Summary of Euler Buckling Loads ............................................................................. 71

Table 5-8 Summary of Euler Buckling Loads (3" W-Flange)..................................................... 72 


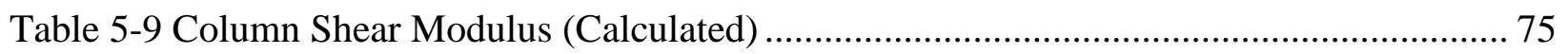

Table 5-10 Summary of Engesser Loads (Calculated Shear Modulus) ......................................... 75

Table 5-11 Summary of Engesser Loads (PMM Shear Modulus)................................................ 76

Table 5-12 Summary of Engesser Loads 3" W-Flange (Calculated Shear Modulus Eq. 5.5)...... 77

Table 5-13 Summary of Engesser Loads 3" W-Flange (PMM Shear Modulus Eq. 5.3)............... 77

Table 5-17 Puente Predicted Failure (Hollow Box Sections)........................................................ 79

Table 5-18 Puente Predicted Failure (W-Flange) ......................................................................... 80

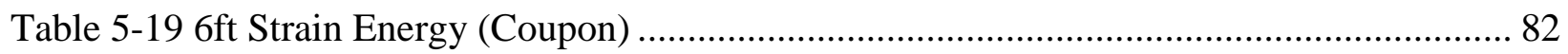

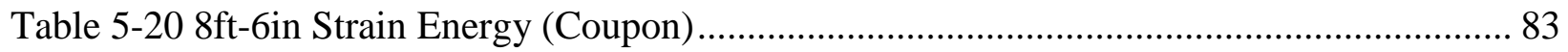

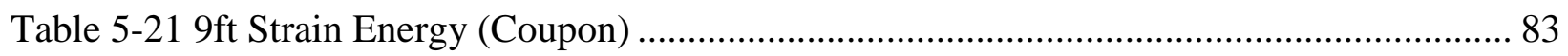

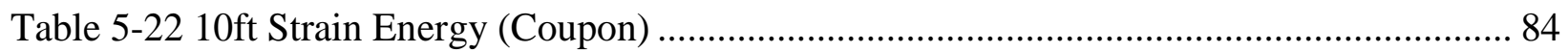

Table 5-23 Average Strain Energy Predicted Loads (Coupon) …………........................................ 84

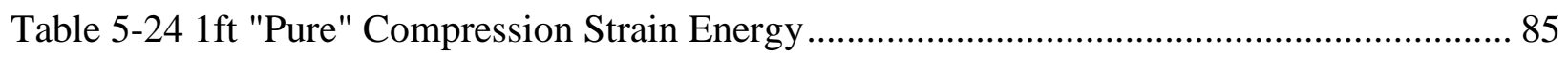

Table 5-25 Average Strain Energy Predicted Loads (1ft "Pure” Compression) ........................... 86

Table 5-26 Failure Strain (1ft "Pure" Compression) ....................................................................... 87

Table 5-27 Full Length Strain Energy Coefficients (6ft Columns) ............................................... 89

Table 5-28 Full Length Strain Energy Coefficients (8ft-6in Columns)......................................... 89

Table 5-29 Full Length Strain Energy Coefficients (9ft Columns) .............................................. 89

Table 5-30 Full Length Strain Energy Coefficients (10ft Columns) ............................................ 90

Table 5-31 Full Length Strain Energy (6ft Columns).................................................................. 92

Table 5-32 Full Length Strain Energy (8ft-6in Columns) ........................................................... 92

Table 5-33 Full Length Strain Energy (9ft Columns)................................................................... 93

Table 5-34 Full Length Strain Energy (10ft Columns)................................................................ 93 
Table 5-35 WF Strain Energy Failure (Single Strain Gage) .................................................. 94

Table 5-36 WF Strain Energy Failure (Double Strain Gage) ............................................... 95

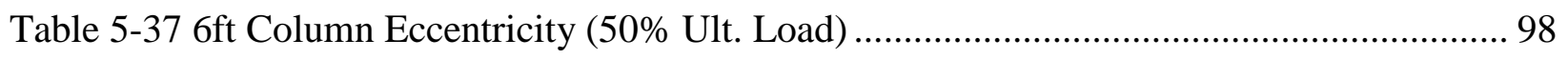

Table 5-38 8ft-6in Column Eccentricity (50\% Ult. Load).................................................. 98

Table 5-39 9ft Column Eccentricity (50\% Ult. Load) ...................................................... 98

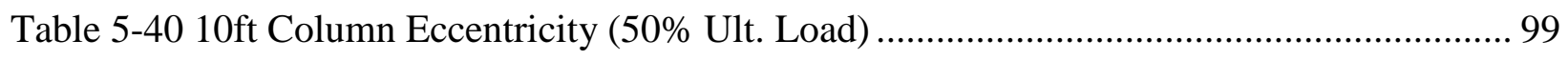

Table 5-41 6ft Column Eccentricity (25\% Ult. Load) ........................................................ 100

Table 5-42 8ft-6in Column Eccentricity (25\% Ult. Load).................................................. 100

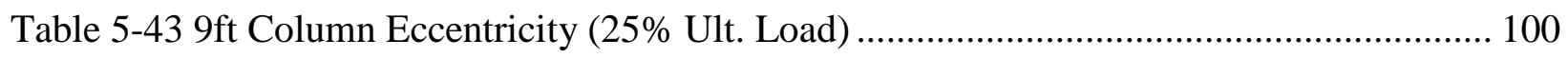

Table 5-44 10ft Column Eccentricity (25\% Ult. Load) ....................................................... 101

Table 5-45 Average Column Imperfections (Southwell) .................................................... 102

Table 5-46 Transition between Local and Global Buckling ............................................... 104

Table 6-1 Characteristic Values of Southwell Method (ASTM D7290-06)............................ 115

Table 6-2 Average \%Diff with Respect to Experimental Data (Hollow-Box)......................... 115

Table 6-3 Eccentricity Due Initial Imperfections (50\% Ult. Load) ..................................... 116 


\section{CHAPTER 1 INTRODUCTION}

\subsection{Background}

Fiber-reinforced polymeric (FRP) composites offer a unique addition to common construction materials utilized in Civil Engineering. Applications include: new construction, rehabilitation, and strengthening of existing structures (Zureick \& Scott, 1997). The increasing use of FRP in the civil industry is primarily due to their high strength to weight ratio, protection against environmental effects, and nonconductive material properties (Zureick \& Scott, 1997). Structural shapes often utilized in steel and timber construction are now being implemented in composites construction due to increased quality control and evolving manufacturing processes. However, unlike traditional construction materials (steel, timber, concrete, etc) FRP composites lack adequate design standards and or criteria. The need for appropriate design guidelines is subsequently needed in order to ease the progression of the use FRP composites in construction.

\subsection{Objectives}

The underlying objective of this research is to investigate the effects of pultruded FRP composite sections under compression pertaining to strain, deflection, buckling, and eccentricity. Specimens prepared consist of different shapes of cross-section and lengths. All test specimens were subjected to axial loading with "minimal eccentricity.” Research includes a comparison of full-length sections, samples under "pure" compression, and coupon level testing. The comparison will investigate: buckling effects, strain energy criteria, ultimate stress correlations, and modulus of elasticity variability induced by buckling effects. 


\subsection{Scope}

Laboratory testing conducted in the current research includes component, coupon, and $1 \mathrm{ft}$ "pure" compression specimens. Each test was used to generate a comparison between full-scale and coupon level analysis, based on ultimate strength, changes in strain energy, and failure modes including local and global buckling.

Several previously proposed theories for failure strength prediction of pultruded FRP composite columns are evaluated in terms of accuracy, consistency over a range of column lengths, and ability to predict strength of columns of both open and closed cross section.

\subsection{Organization of Thesis}

Presented in Chapter 2 is a review of published research on strength prediction of FRP composite columns. A brief description of the pultrusion manufacturing process is also outlined along with general mechanics theory of composites.

Chapter 3 offers a detailed description of test set up and procedure for each of the different laboratory tests conducted in the present research. Descriptions include coupon and component level analysis. Strain gage application and specimen preparation are also discussed as well as issues dealing with support conditions for the full length columns.

General data analyses for each experiment are outlined in Chapter 4. Stress-strain, loaddeflection, and modulus of elasticity relationships are all evaluated, with summaries for every level of testing form coupon to component level provided.

Chapter 5 consists of applying each of the investigated strength prediction models to the laboratory data obtained in the current research. Detailed analysis of each model is provided 
including comparisons between predicted and experimental failure. A strain energy density model is also developed and presented.

Finally, Chapter 6 draws conclusion on every phase of analysis and subsequent recommendations are formulated. 


\section{CHAPTER 2 LITERATURE REVIEW}

Compiled in this Chapter is a review of applicable literature obtained from various sources within the field of FRP composite research. Topics evaluated consist of FRP composite manufacturing methods, structural system mechanics including buckling and slenderness, strength prediction, laboratory testing guidelines, and finally strain energy density failure criteria.

\subsection{Manufacturing Process}

A wide variety of FRP manufacturing processes currently exist. Through decades of research and technical advances, these processes have been modified to develop a consistent means of production.

Out of the many manufacturing methods available, the pultrusion process is commonly implemented due to its high productivity-to-cost ratio (Zureick \& Scott, 1997). Pultrusion is also gaining popularity in civil applications primarily as a result of its ability to cast common structural shapes, frequently used in steel construction (W-Flange, Hollow Tubes, Hollow Box sections, etc). Through this continuous manufacturing process shapes of constant cross-section can be manufactured to any desired length. Both thermoplastic and thermoset matrices can be utilized, though the latter is more common. Due to their low cost glass fibers coupled with either polyesters or vinyl ester resins are typically used. Fibers are dominated by roving and continuous strand mat (CSM). Rotating winders can be implemented to apply fibers at an angle to provide reinforcement in the transverse direction; however the use of CSM often supplements the use of

angled reinforcement (Barbero E. J., 1998). Figure 2-1 Pultrusion Manufacturing Process, provides a general schematic outlining the process. 


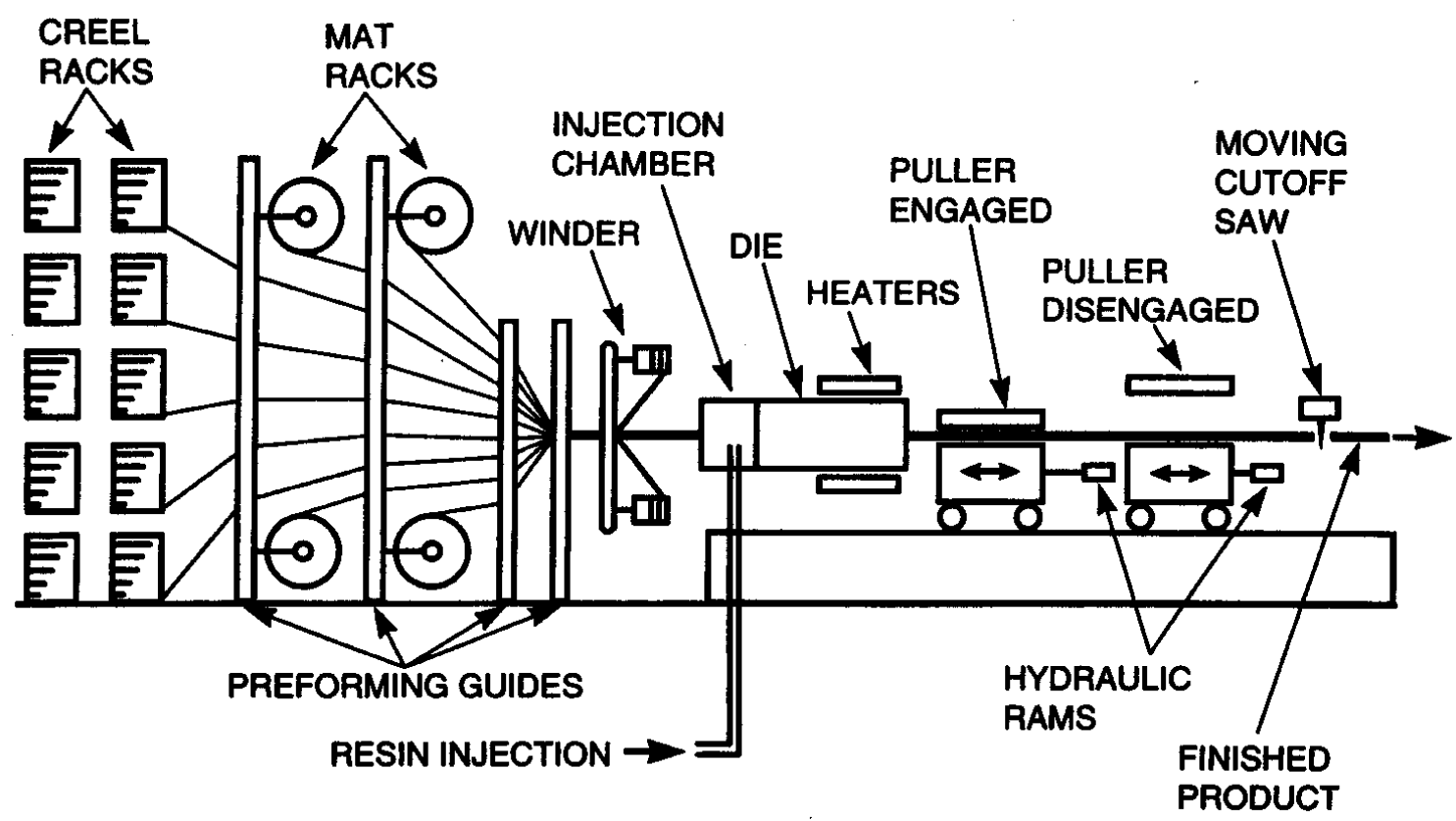

Figure 2-1 Pultrusion Manufacturing Process (Barbero E. J., 1998)

Steps:

1.) Roving and mat are pulled through performing guides

2.) Performing guides properly place roving and mats in appropriate location

3.) Reinforcement enters injection chamber where they are wetted with resin and then pulled through a heated die of the desired cross-section

4.) Curing is initiated while the sample is pulled through the die and is aided by in-line heaters.

5.) The cured product is then pulled by reciprocating pullers until a cut off saw cuts the final product at the desired length.

\subsection{Buckling Effects}

Column failure can be achieved in a variety of loading scenarios based upon: support conditions, slenderness, material properties, and type of loading. To gain a better understanding 
of column loading effects it is first important to fully understand the effect buckling has on a column and the parameters that influence buckling.

\subsubsection{Local Buckling}

Local buckling is often recognized as "the buckling of a compression element which may precipitate the failure of the whole structural member." From a mechanics of materials of approach it is referred to as: "buckling of thin elements of a column section in a series of waves or wrinkles.” Several definitions of local buckling exist, however the fundamental concept of local buckling deals on a columns "local” level, which relates to specific material and structural elements with the column. Bending effects are often not foreseen in local buckling due to the column acting in "pure” compression as a result of the applied axial loading.

\subsubsection{Global Buckling}

The structural phenomenon regarded as global buckling is defined as the structure buckling as unit rather than a localized failure of a compression region within the structure. Global buckling failure is driven by excessive deflection experienced by the column. Bending effects of the applied loading are often exhibited in global buckling failure, thus the mode of failure is often more common in columns of longer length. Most current structural design codes concerning column design are based on global buckling due to its prevalence in column failure over that of local buckling.

\subsubsection{Slenderness}

In the most basic sense slenderness is defined as the ratio of the length of a column ' $L$ ' to its radius of gyration ' $r$ ' (Gere J. M., 2004). Columns exhibiting high slenderness have a low 
corresponding critical stress/load. On the other hand columns with low slenderness (typically short with a high moment of inertia) require a high stress to induce buckling (Gere J. M., 2004).

Several slenderness parameters have been developed for use in the evaluation of pultruded FRP composites. Barbero and Tomblin (1994) proposed the following nondimensional slenderness defined as:

$$
\lambda=\frac{L_{c r}}{\pi} \sqrt{\frac{P_{L}}{E I}}
$$

where; $L_{c r}=$ critical length of specimen, $P_{L}=$ local buckling load, $E=$ bending modulus of elasticity in the direction of loading, and $I=$ moment of inertia. Zureick and Scott (1997) modified a classical nondimensional slenderness parameter;

$$
\lambda^{2}=\frac{F_{L}}{F_{e}}
$$

where $F_{L}=$ the average ultimate longitudinal compressive stress of coupon samples taken from structural member, $F_{e}=$ critical elastic stress, to produce the following slenderness equation for pultruded FRP composites;

$$
\lambda=\sqrt{\frac{1}{\pi^{2}}\left(\frac{L_{e f f}}{r}\right)^{2} \frac{F_{L}}{E_{L}}+\frac{n_{s} F_{L}}{G_{L T}}}
$$

where; $L_{\text {eff }}=$ effective length, $G_{L T}=$ shear modulus, and $n_{s}=$ shear factor depending on crosssection. Each of the aforementioned equations will be used to evaluate data obtained conducted in the present paper (Barbero \& Tomblin, 1994).

\subsubsection{Support Conditions}

Column support conditions play a vital role in the buckling strength. Ideal support conditions consist of a column pinned at each end. Pinned ends allow for the fundamental case of 
column buckling which is linked to the lowest critical buckling load ' $\mathrm{P}_{\mathrm{cr}}$ ' (Gere J. M., 2004). Critical loads for other support conditions are related to the critical load of pinned end columns by the concept of effective length. Effective length is defined as the equivalent length of a pinned end column required to produce a deflection curve that exactly matches that of the original column with varied support conditions (Gere J. M., 2004). Standard design practices frequently implement an effective length factor ' $K$ ', for varied support conditions. Figure 2-2 Effective Length Factors, below outlines different effective length factors for columns containing different support conditions.

\begin{tabular}{|c|c|c|c|}
\hline (a) Pinned-pinned column & (b) Fixed-free column & (c) Fixed-fixed column & (d) Fixed-pinned column \\
\hline$P_{\mathrm{cr}}=\frac{\pi^{2} E I}{L^{2}}$ & $P_{\mathrm{cr}}=\frac{\pi^{2} E I}{4 L^{2}}$ & $P_{\mathrm{cr}}=\frac{4 \pi^{2} E I}{L^{2}}$ & $P_{\mathrm{cr}}=\frac{2.046 \pi^{2} E I}{L^{2}}$ \\
\hline & & & \\
\hline
\end{tabular}

Figure 2-2 Effective Length Factors (Gere J. M., 2004) 


\subsection{Strength Prediction}

Buckling of FRP composites is an area of research under extensive evaluation. Previous researchers have proposed several means of calculating the critical buckling load for glass reinforced polymer composites (GFRP), however a specific criteria has yet to be accepted universally. The Euler buckling equation along with subsequent variations has been proposed with varied results. Equation 2.4 is the Euler buckling equation,

$$
P_{E}=\frac{\pi^{2} E_{L} I}{(K L)^{2}}
$$

where $I=$ moment of inertia about the minor principal axis; $L=$ length of sample; $K=$ effective length factor based on support conditions outlined in Figure 2-2. FRP composites differ from common construction materials in that they possess anisotropic material properties. As a result of this phenomenon the modulus of elasticity (MOE) differs in each direction. Therefore, the MOE in the longitudinal direction of loading $\left(E_{L}\right)$ is utilized in the Euler buckling equation.

Further investigation of glass and carbon fiber reinforced composites (GFRP/CFRP) by Lee and Hewson (1978) yielded the following estimation for the critical load of axially loaded members first proposed by Engesser in 1989 (Zureick \& Scott, 1997),

$$
P_{e}=\frac{P_{E}}{1+\left(\frac{n_{S} P_{E}}{A_{g} G_{L T}}\right)}
$$

where $P_{E}=$ Euler buckling load; $n_{s}=$ shear factor depending on cross-section; $A_{g}=$ gross area; $G_{L T}=$ shear modulus. Both equations were found to provide reasonable estimates for experimentally defined buckling loads.

Four sets of three pultruded FRP members composed of glass roving and woven fabrics were tested under axial compressive loading by Hashem (1993). Utilizing pinned end conditions Hashem compared a modified Euler buckling equation, which included a reduction factor for 
material nonlinearities, to the experimentally obtained ultimate load. Hashem concluded that the difference between the experimental data and the modified Euler buckling equation did not exceed $15.6 \%$. However, it must be clearly stated that the MOE value used by Hashem is not clearly defined. Coupon testing and short column tests were performed but the specific value used in the calculations was not clearly stated. In addition to uncertainties in the MOE calculation, effective length was not considered in the modified Euler buckling equation due to the pinned end conditions producing an effective length factor ' $\mathrm{K}$ ' equivalent to 1.0. True pinned boundary conditions are not likely, therefore the effective length would likely adjust the results due to the test fixtures used (Hashem, 1993). Despite these aforementioned uncertainties, Zureick (1997) proposed that Hashem's test data produced sufficient validation of the use of some modified form of the Euler buckling equation to predict the buckling load of pultruded FRP composites (Zureick \& Scott, 1997).

Southwell’s research (1932) of “The Analysis of Experimental Observations in Problems of Elastic Stability,” produced a technique to estimate the buckling load of a test specimen based on experimental results pertaining to load and deflection. Specimens must be tested in axial compression with minimal eccentricity. The corresponding relationship between load and deflection must also remain in a range where the elasticity of the material is not impaired. Southwell determined that when mid-point deflection is plotted against the same deflection divided by the corresponding load, a linear relationship exists. As a result, the slope of the linear curve is the taken as the buckling load.

Zureick (1997) tested Southwell’s theory on pultruded GFRP W-Flange and Hollow-Box sections of different length, resulting in an effective correlation between the ultimate experimental load, and the aforementioned Equations 2.4 and 2.5. The ratio for Southwell's 
predicted buckling load to Equations 2.4 and 2.5 for each section was commonly over $90 \%$. Variations of this ratio existed between cross-section and length, which will be further investigated in later Chapters of this research.

Puente, et al (2006) presented an empirical approach to design based upon Dutheil's empirical method of buckling. In conjunction with Dutheil's empirical approach, Puente, et al also incorporated Maquoi and Rondal's (1978) suggestion to include initial material imperfections into design. Empirical constants were developed for GFRP composites through extensive testing of pultruded hollow tubes of varied length. Subsequent empirical constants were incorporated into the following proposed equation for the critical buckling load

$$
P_{c r}=\frac{1}{y} x P_{L}
$$

where; $y=$ coefficient depending of reliability of manufacturer, $x=$ empirical coefficient based on slenderness ratio of column, and $P_{L}=$ local buckling load. Development of this simple empirical equation required evaluation of Dutheil's original equation for the critical buckling load, which is based on the superposition between local and global buckling. Dutheil (1966) incorporated both buckling effects by proposing a coefficient ' $\omega$ ' to decrease the local buckling load to a point where the resulting load is $\mathrm{P}_{\text {cr }}$ of global buckling.

$$
P_{c r}=\frac{P_{L}}{\omega}
$$

The coefficient ' $\omega$ ' is dependent upon the nondimensional slenderness ' $\lambda$ ' and the generalized initial imperfections ' $\mathrm{K}$ ' of the structural element in consideration. However, ' $\mathrm{K}$ ' takes into account parameters driven solely by nondimensional slenderness therefore, the coefficient ' $\omega$ ' is a function of only nondimensional slenderness both directly and indirectly. The 
coefficient ' $\mathrm{K}$ ' directly affects the critical stress versus nondimensional slenderness curves' shape, depending on the degree of the polynomial used (Puente, Insausti, \& Azkune, 2006).

Currently versions of the Eurocode incorporate ' $\mathrm{K}$ ' values for steel and wood structures as well a coefficient ' $x$ ' for verifying the stability of structural elements subjected to compressive loading. The coefficient ' $\mathrm{x}$ ' is simply the inverse of Dutheril's ' $\omega$ ', taken as 1.0 for nondimensional slenderness values less than 0.2 in steel and 0.5 in wood. For values greater than the specified lower limits ' $x$ ' is obtained from the following equation

$$
x=\frac{1}{\varphi+\sqrt{\varphi^{2}-\lambda^{2}}}
$$

where $\phi$ is based upon a cross-section classification coefficient ' $\alpha$ '. Puente's goal for this research was to adopt a method of calculation for ' $K$ ' and ' $\mathrm{x}$ ' specifically for GFRP composites. In order to determine the coefficient ' $K$ ' the value of ' $\alpha$ ' must first be determined. The value of ' $\alpha$ ' that minimizes the quadratic differences between experimental and theoretical values for the following polynomial

$$
K=\alpha\left(\lambda^{2}-.25\right)
$$

was based on experimental data obtained by Puente et al. for pultruded hollow tube sections. Puente concluded that based on experimental data $\alpha=.1205$, which fit well with values included in Eurocode 2003 for high strength steel $(\alpha=.13)$. Intuitively this makes sense since high strength steel presents a high yielding stress in relation to its MOE. Similar attributes are possessed in GFRP composites due to their low MOE resulting in a high stress-stiffness ratio. The resulting equation for calculating the coefficient ' $\mathrm{K}$ ' is therefore

$$
K=.12\left(\lambda^{2}-.25\right)
$$


With the appropriate ' $K$ ' coefficient found the corresponding value of ' $\mathrm{x}$ ' can then be determined yielding the following equation for pultruded GFRP composite columns

$$
\begin{gathered}
x=\frac{1}{\varphi+\sqrt{\varphi^{2}-\lambda^{2}}} \leq 1 \\
\varphi=.5\left[1+K+\lambda^{2}\right]
\end{gathered}
$$

The resulting equation for the critical buckling load is equivalent to the previously defined Equation 2.6

$$
P_{c r}=\frac{1}{y} x P_{L}
$$

where $y=1.2$ for decreased manufacturer reliability of pultruded composites compared to that of steel $(\mathrm{y}=1.0)$. It is important to note that Puente et al. also conducted testing on closed box sections in order to develop an appropriate comparison with previous researchers including the data described earlier provided by Zureick (1997). As a result Puente et al. concluded that the proposed equation fits the additional researcher’s data (Zureick \& Scott, 1997 and Barbero \& Tomblin, 1994) adequately and is an appropriate means of calculating the critical buckling load of pultruded GFRP composite columns (Puente, Insausti, \& Azkune, 2006).

\subsection{Modulus of Elasticity}

A key factor in the development of a universal load resistance factor design (LRFD) code for pultruded polymer composites is the standardization of consistent testing methods for determining material properties. Due to a wide variety of constituent materials and endless composite material configurations the adaptation of a single set of standards is a formidable task. 
Pultruded composites introduce additional complexity due an increased amount of reinforcement provided in the longitudinal direction. As a result, the axial strength differs greatly from the shear strength.

Adapting a standardized means of calculating compressive constituent properties for pultruded composites greatly affects the progression of their implementation into civil infrastructure applications. Lackey et al (2007) investigated several different methods for calculating the compressive strength of pultruded composites in an effort to promote a universal method of testing. Included in the investigation was the analysis of three common compressive test standards currently used by composite manufactures: ASTM D695-02a, ASTM D6641 (CLC), and SACMA SRM 1R-94. Each standard was evaluated based on its ability to calculate compressive strength and modulus of elasticity on the coupon level. Testing procedure including sample preparation and difficulty of test set-up was also considered. The comprehensive evaluation included test specimens comprised of varied fiber geometries and matrix type, including sample sets containing primarily unidirectional reinforcement. A statistical analysis comparing each test method enabled Lackey et al (2007) to recommend a proficient method (Lackey, Vaughan, Gupta, Rawls, \& Wimbrow, 2007).

\subsubsection{ASTM D695-02a}

ASTM D695-02A originated for use with rigid, unreinforced, and reinforced plastics. Supplemental provisions have incorporated the use of high strength composites (Lackey, Vaughan, Gupta, Rawls, \& Wimbrow, 2007). Testing requires the use of dog-bone shaped samples supported by a machined jig to avoid buckling effects. Samples are to be approximately 3.31" in length with a $1 \frac{1 / 2}{2}$ " gage length. The width of dog-bone is $3 / 4$ " and with a corresponding gage width of $1 / 2 ”$. The dog-bone shape of the coupon is credited with causing premature end 
crushing prior to valid compression failure in high strength composites. Premature failure also exists in composites comprised of primarily unidirectional reinforcement. Modulus of elasticity calculations are troublesome due to the inability of the use of strain gages caused lack of space provided by the support jig. Compressometers are therefore supplemented for modulus calculations.

\subsubsection{SACMA SRM 1R-94}

Despite its shortcomings (premature end crushing) the simplicity of ASTM D695-02a led researchers to form a modified version frequently used by composite engineers and manufacturers. The modified ASTM D695-02a has yet to be standardized by ASTM, however, Suppliers of Advanced Composite Materials Association (SACMA) standardized the test (SACMA SRM 1R-94) and used it frequently before disbanding in June 2000 (Lackey, Vaughan, Gupta, Rawls, \& Wimbrow, 2007).

SACMA SRM 1R-94 substitutes the use of dog-bone samples with straight edge samples of 3 5/16” length and $1 / 2$ ” width. Recommended specimen thickness is 0.120 ” however, $1 / 4$ ” thick samples have also supplied acceptable results. Sample preparation time is reduced with the

elimination of the precision required for dog-bones. A machined jig similar to that of ASTM D695-02a is utilized to prevent buckling; however, strain gages are permissible. Like ASTM D659-02a, SACMA SRM 1R-94 testing resulted in premature failure due to end crushing. This effect was nullified with the addition of tabs bonded to the sample at the ends. The addition of tabs resulted in adequate ultimate compression data and failure. When tabs are added, sufficient gage length for strain gages is compromised leading to the need for two separate samples: one for MOE calculations and a second for failure data. 


\subsubsection{Summary}

Based on sample preparation, accuracy of results and state of current ASTM standards, Lackey et al (2007) recommends the use of ASTM D6641-01 for generating design data. Adequate strength and MOE data can be obtained by both ASTM D6641-01 and SACMA SRM 1R-94; however the latter lacks standardization at this time. ASTM D695-02a has been found on numerous accounts to underestimate the compressive strength. All three methods can easily provide data of mat/roving composites, but encounter difficulties when faced with unidirectional composites primarily due to end crushing.

Acceptable failure modes for any compression coupon test shall be taken as: shear failure, local fiber buckling, longitudinal splitting, and delamination according to ISO 14126:1999(E). Global buckling and end crushing are not permissible (Lackey, Vaughan, Gupta, Rawls, \& Wimbrow, 2007).

Sample preparation plays a vital role in the acquisition of accurate results. Specimens shall be properly "sized" as the slightest amount of variation in height across the loading surface can cause premature failure. The use of tabs should be avoided when possible, but when their presence is required proper bonding is essential as goes for strain gages.

\subsection{Strain Energy Failure Criteria}

Developing strength prediction models that do not require extensive testing is essential to composite manufacturers and engineers. Such a model would limit both the time and cost spent on a particular design. In order to achieve a simple yet accurate model a thorough understanding of structural material is needed. Utilizing fundamental structural mechanics concepts such as strain energy such a model can be developed. 
Strain energy in its simplest form is the amount of energy absorbed by a material during loading. Furthermore from the theory of conservation of energy it is known that strain energy is equivalent to the amount of external work done on the specimen, with the underlying assumption being that no energy is lost due to heat transfer, damping, or friction (Gere J. M., 2004).

In terms of experimental analysis strain energy per unit volume can be obtained by simply taking the area under the stress-strain curve. This is also defined as strain-energy density. Changes in the slope of the stress-strain curve subsequently represent strength and stiffness variations within the test media, depending on material type these differences can range from having minor effects to defining specific failure mechanisms as in the case of GFRP composites.

Depending on fiber orientation GFRP composites commonly exhibit different stages of failure be it, delamination of fibers and matrix, matrix micro-cracking, fiber buckling, and fiber breakage. Specific failure mechanisms can only be theorized; however different stages are identified by the changing slope of the stress-strain curve which can be described as changes in strain energy. Vadlamani (2007) investigated this phenomenon by testing several GFRP coupons of varied fiber architecture, in tension and bending. Based on her experimental results a failure model was derived (Vadlamani, 2007).

The preliminary model is based off of several assumptions regarding: residual strain effects, void content of specimens, and neglecting bi-axial effects. It is also assumed that GFRP composites will follow a logical progression of failure. More specifically stress and stiffness changes caused by distress and damage can be directly correlated to changes in the strain energy.

Total strain-energy density was taken as the area under the stress-strain curve. A nonlinear relationship existed for the majority of fiber geometries, with the unidirectional composites exhibiting a nearly linear relationship up until ultimate stress. The following figure displays the 
typical stress-strain curve for multi-directional composites. Changes in slope are indentified and subsequently referenced in terms of the failure strain and stress $\left(\varepsilon_{\mathrm{p}}, \sigma_{\mathrm{p}}\right)$.

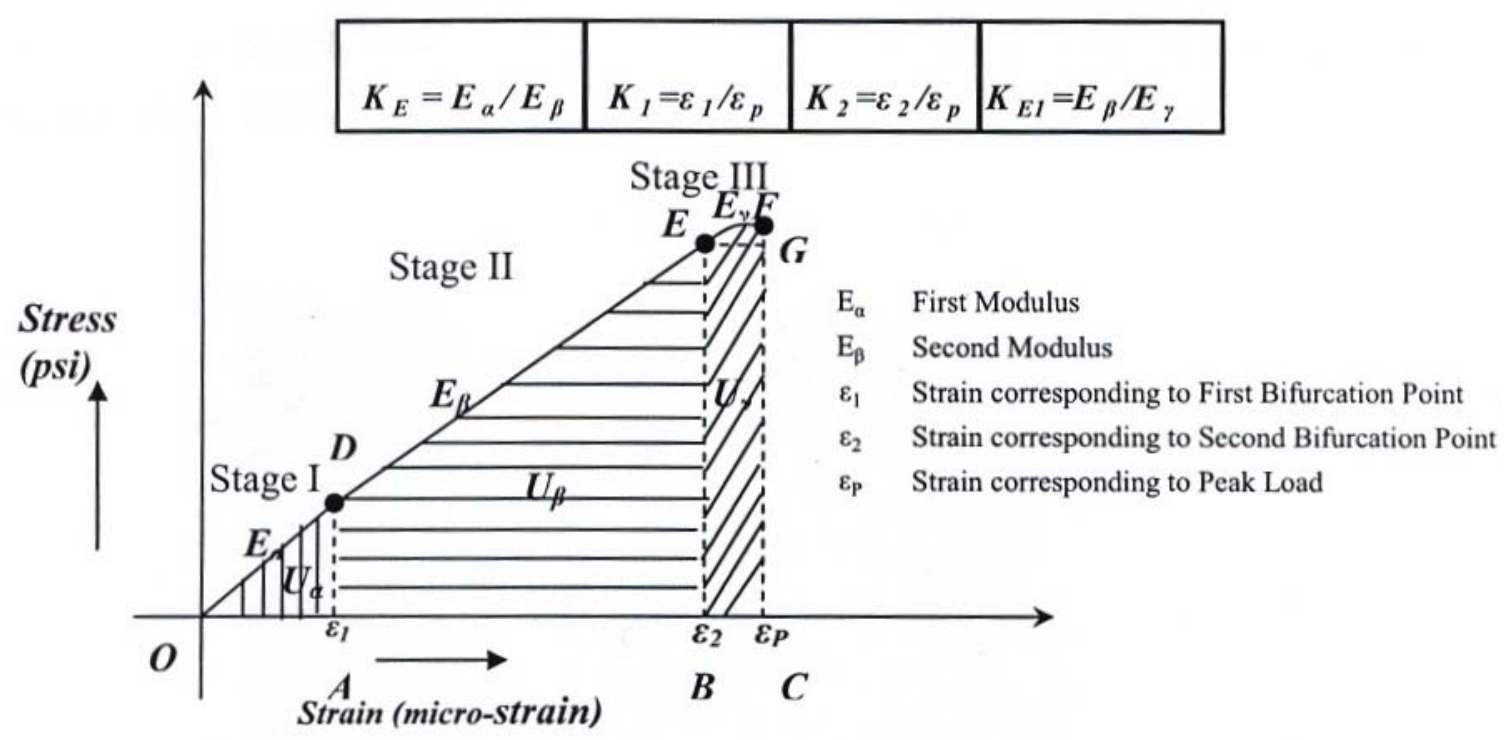

Figure 2-3 Typical Stress-Strain Curve for Multidirectional Composites (Vadlamani, 2007)

Assuming energy is completely conserved during loading the strain energy is differentiated with respect to stiffness in order to develop the following relationship for either bending or tension loading:

$$
C=U E
$$

where, ' $\mathrm{C}$ ' is an integration constant taken as a function of failure strain, fiber volume fraction, stacking sequence etc. ' $U$ ' is the total strain energy, and ' $E$ ' represents MOE. For stress-strain curves displaying nonlinear trends, Equation 2.14 can be rewritten in terms of superposition of the areas where changes in strain energy occur.

$$
C=U_{\alpha} E_{\alpha}+U_{\beta} E_{\beta}+U_{\gamma} E_{\gamma}
$$

where, ' $\alpha$ ', ' $\beta$ ', and ' $\gamma$ ' represent the three areas were changes in strain energy occur. Direct substitution of the strain energy for each of the loading areas in terms of the constants derived in Figure 2-3 yields the final equation for total strain-energy density. 


$$
C=E_{\alpha}^{2} \varepsilon_{p}^{2}\left(\frac{1}{2} K_{1}^{2}+\frac{1}{2}\left(\frac{K_{2}-K_{1}}{K_{E 1}}\right)\left(2 K_{1}+\frac{\left(K_{2}-K_{1}\right)}{K_{E 1}}\right)+\left(\frac{1-K_{2}}{K_{E 1} K_{E 2}}\right)\left(K_{1}+\frac{\left(K_{2}-K_{1}\right)}{K_{E 1}}\right)\right)
$$

This is more or less a universal representation of the total strain-energy for a test sample, limited to a stress-strain curve that exhibits three distinct slope changes. If the stress-strain diagram is linear as often is the case with unidirectional composites many of the terms can be eliminated resulting in a very simple estimation of strain energy.

Deriving means of predicting failure load of the coupon is achieved by setting the preceding equation equal to theoretical equations for strain energy developed from mechanics of materials principles. From a designer/manufacturer point of view, the variables $\left(\varepsilon_{\mathrm{p}}, \mathrm{K}_{1}, \mathrm{~K}_{2}, \mathrm{~K}_{\mathrm{E} 1}\right.$, etc.) would already be known and tabulated for given fiber geometries. Modulus of elasticity would be provided by the manufacturer or obtained theoretically via "Rule of Mixtures" or other commonly practiced methods. With the MOE accounted for; the only remaining unknown is the failure load.

Though the proposed model seems simplistic in nature, due to infinite combinations of fiber geometries, resin systems, fiber type, manufacturing processes, etc., a universally accepted means of prediction does not currently exist. Accuracy of the model proposed by Vadlamani (2007) will be tested on both the coupon and component level in the present research. Modifications are needed in applying it to the component level due to the presence of both bending and axial compression loading effects (Vadlamani, 2007). 


\section{CHAPTER 3 LABORATORY TESTING/SPECIMEN IDENTIFICATION}

\subsection{Introduction}

The primary focus of this research was to investigate buckling effects of pultruded GFRP composite columns in order to develop a plausible strength equation for design. Doing so required testing of full-length sections and subsequent coupon testing. Specimens varied in length in a range of $6 \mathrm{ft}$ to $10 \mathrm{ft}$. Hollow box cross sections were of primary focus; however WFlanged sections were also tested in an effort to evaluate the consistency of the prescribed strength prediction methods over different cross-sectional shapes. The effects of local and global buckling were evaluated by testing $1 \mathrm{ft}$ samples in "pure” compression for comparison with the full-length samples.

\subsection{Material Properties}

All test specimens were manufactured by Bedford Reinforced Plastics Inc. (BRP) of Bedford, Pennsylvania. Vinylester matrix containing flame retardant additives reinforced with Eglass roving and mats were used for the majority of test specimens. Wide-Flange sections substituted a polyester matrix in the place of vinylester. Regardless of matrix type this orientation of fiber architecture is defined as unidirectional. Both roving and matting were supplied by Owens Corning. Roving consisted of 366 Type 30 which was coupled with M-8643 Continuous Filament Matting. Both reinforcements contain primarily E-glass fibers and are designed specifically for purtrusion manufacturing. Bedford Reinforced Plastics typically manufactures products with a fiber volume fraction in the range of 38 to $42 \%$. Approximately 
$70 \%$ of this ratio is attributed to roving in the longitudinal direction with remaining $30 \%$ adding reinforcement in the transverse direction provided by continuous strand matting.

\subsection{Column Testing}

\subsubsection{Testing Specimens}

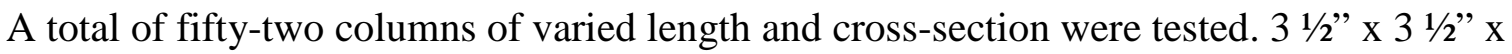
1/4" hollow box sections constituted the majority of the sections evaluated (46 total columns). Twelve of each of following lengths were used: $6 \mathrm{ft}$, 8ft-6in, and 9ft, with an additional ten $10 \mathrm{ft}$ long columns. Two different dimensioned W-Flange members (3ea 6” x 6” x 3/8”, 3ea 3" x 3" x $1 / 4$ ”) running $6 \mathrm{ft}$ in length accounted for the remaining columns.

\subsubsection{Specimen Preparation}

Bedford Reinforced Plastics provided each column factory cut to testing length. Therefore, specimen preparation was limited to the application of strain gages in the longitudinal direction. Strain gages were applied at mid-height of the column length and the center line of the cross section. In the case of the W-Flange sections gages were placed on the column's flange.

Special installation practices recommended by the gage manufacturer (Vishay MicroMeasurements) were used to ensure proper bonding. Light sanding allowed for the "degreasing” of the specimen. Meticulous cleaning followed with the use of M-Prep Conditioner (Phosphoric Acid) and a subsequent M-Prep Neutralizer (Ammonia Water). M-bond adhesive was used to ensure proper bonding. Set time was highly temperature dependent as a result samples were frequently left overnight to let the adhesive dry. Once bonded, manufactured tabs were used to 
solder wire to the strain gages in order to properly connect them to the data acquisition system. The following figures show the different steps of the strain gage installation process.

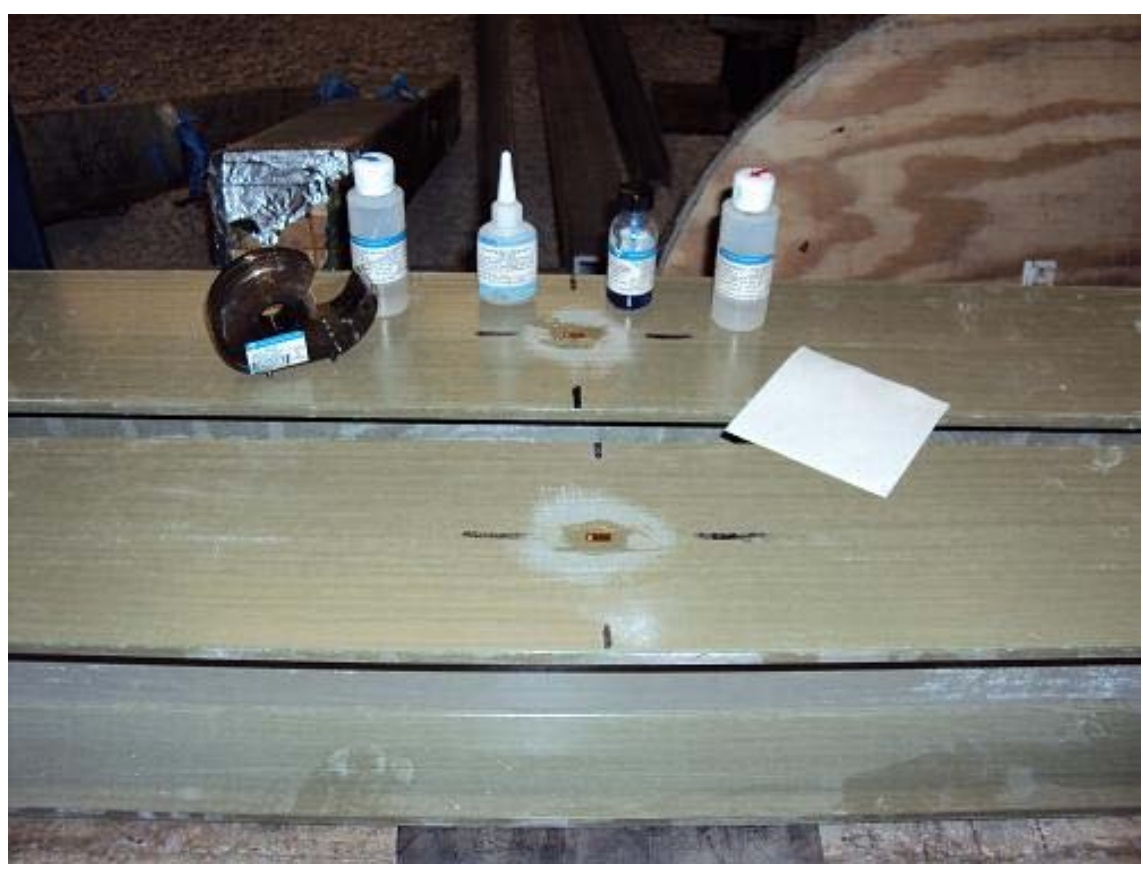

Figure 3-1 Strain Gage Cleaning

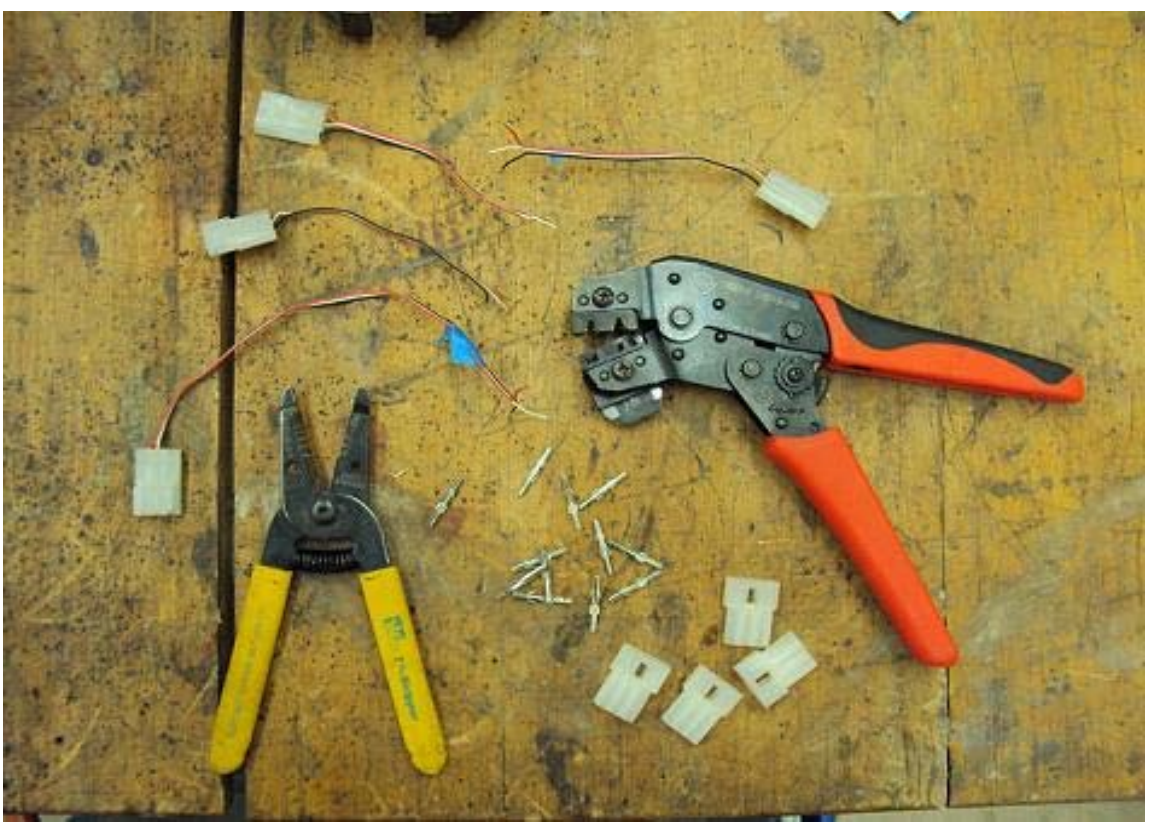

Figure 3-2 Strain Gage Wiring 


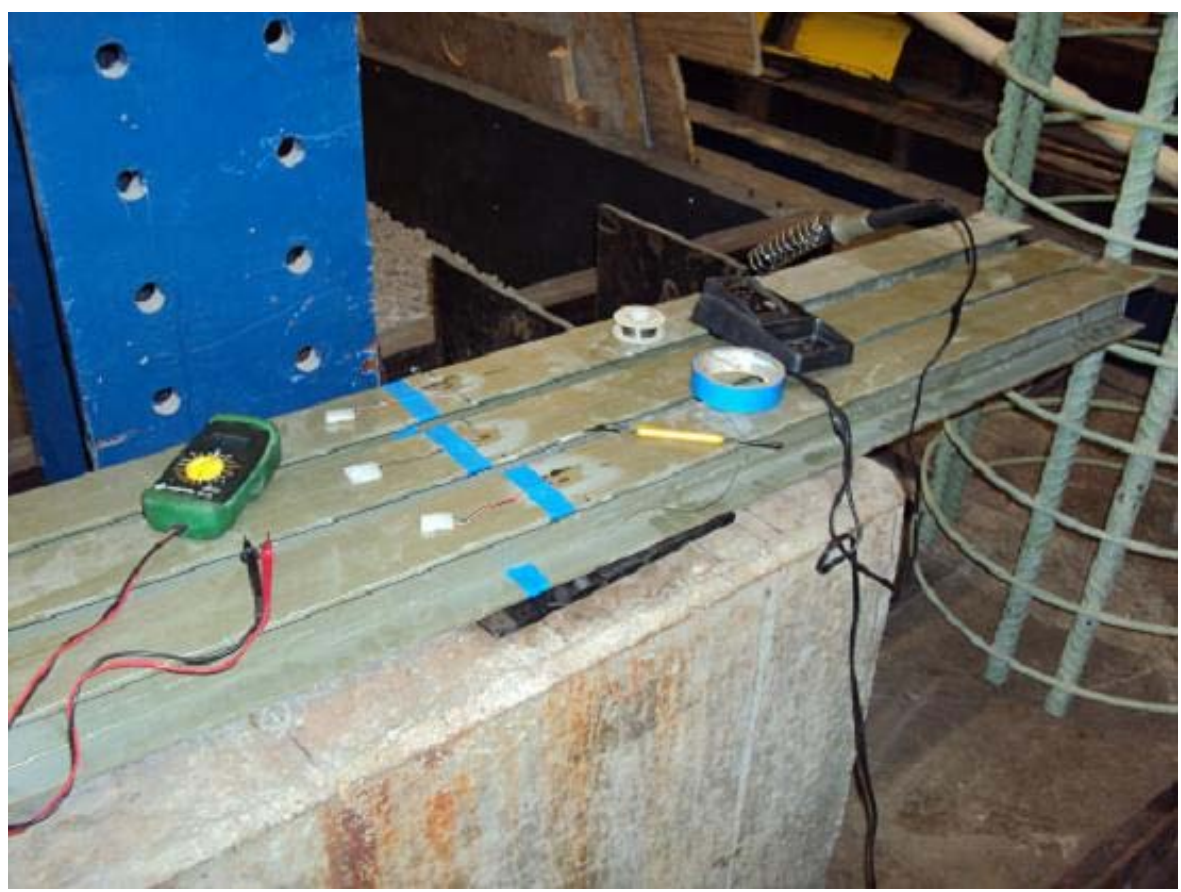

Figure 3-3 Strain Gage Application

A total of five specimens were fitted with strain gages for the hollow box sections of $6 \mathrm{ft}$, 8ft-6in, and 9ft length. Four of the 10ft long box sections and all of the W-Flange sections were equipped with gages.

\subsubsection{Testing Apparatus}

Each column test was run following the same procedure consisting of the same basic test apparatus. The following equipment was needed for each test to reduce variability of results:

- Top and bottom fixtures (Defining Support Conditions) (Figure 3-4 Top and Bottom Fixtures, Load Cell (Clockwise from Left))

- 100-200 Kip Load Cell

- Two Linear Variable Differential Transformers (LVDT’s)

- Manually operated hydraulic actuator and pump

- Data acquisition to record load, strain, and deflection 
The accompanying testing procedure is outlined below:

- Columns were roughly aligned with the actuator in order to properly place the fixtures

- After zeroing and calibrating the strain gages a small load was applied to the column to maintain its vertical position while it was plumbed with a level

- LVDT's were attached at mid-height on perpendicular axis's and then zeroed

- Utilizing a hydraulic pump, load was applied, while the corresponding strain and deflection were recorded continuously using a computer and data acquisition system

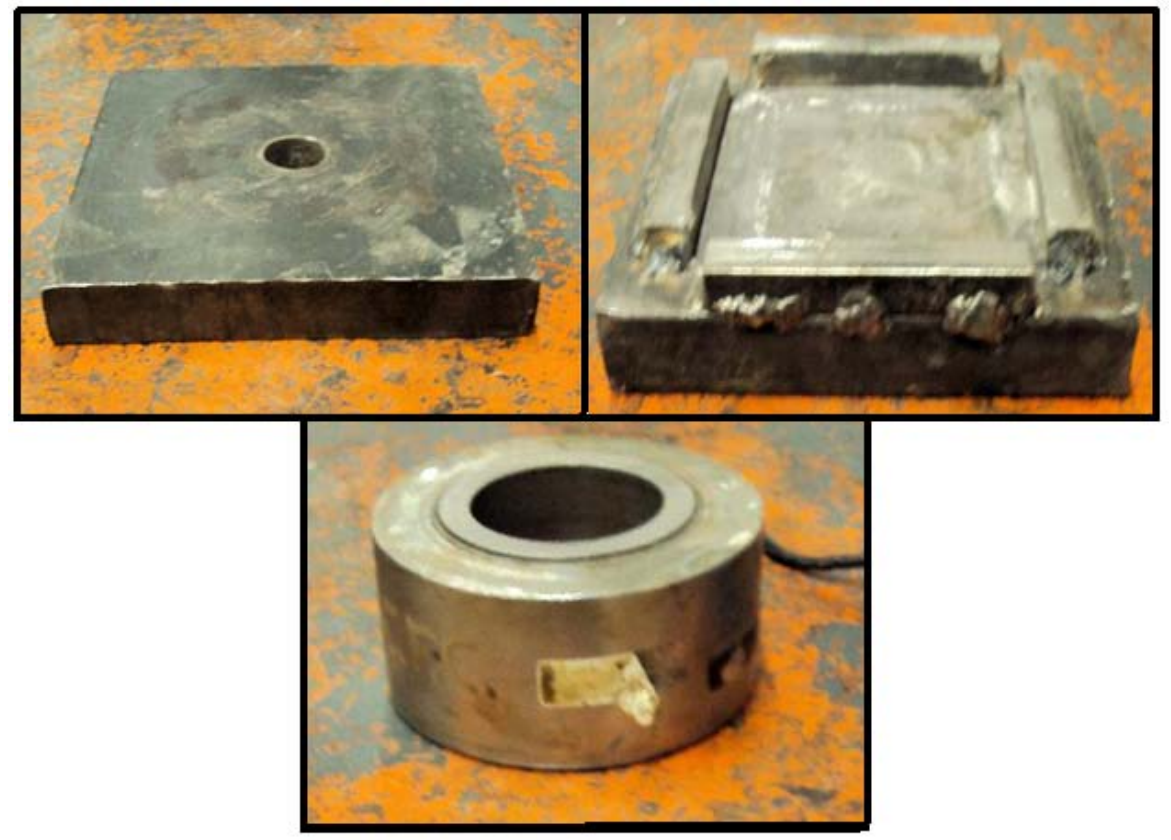

Figure 3-4 Top and Bottom Fixtures, Load Cell (Clockwise from Left) 


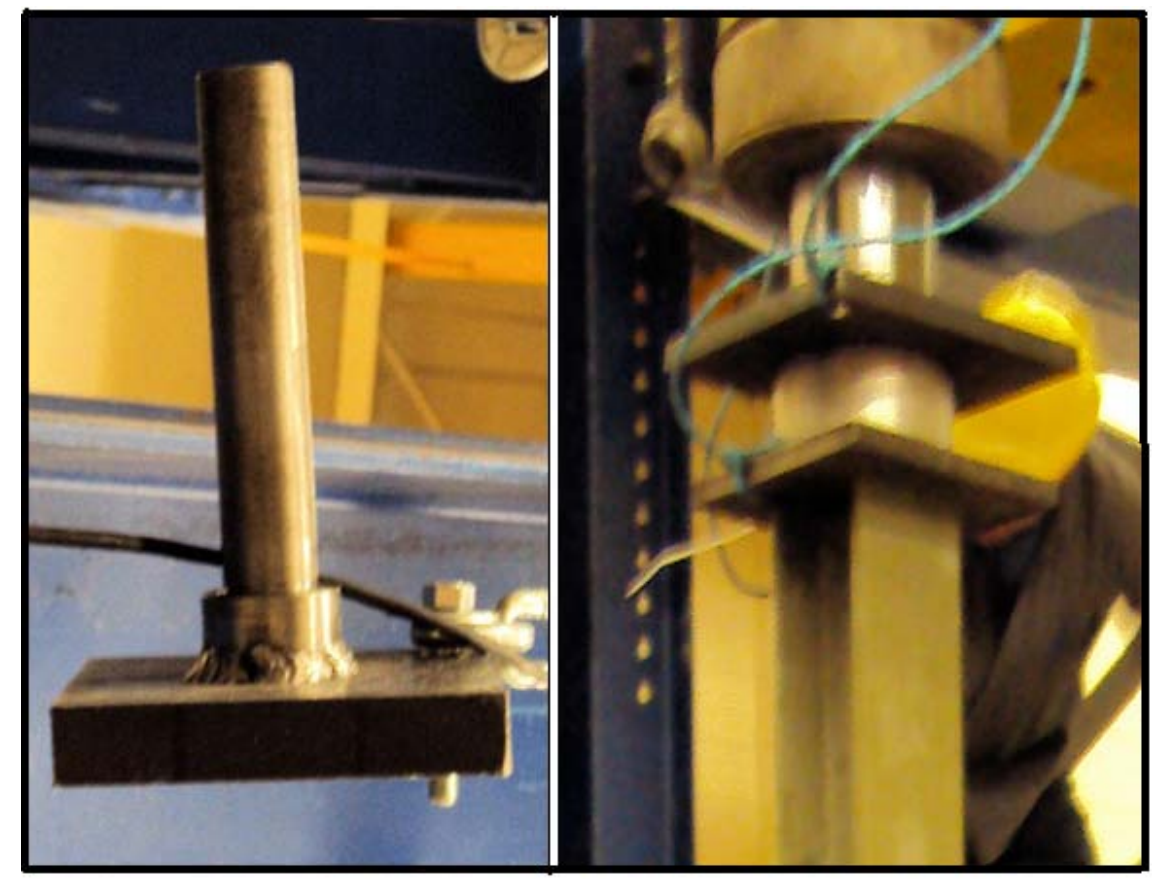

Figure 3-5 Modified Top Fixture (10ft Columns), Actuator Apparatus 


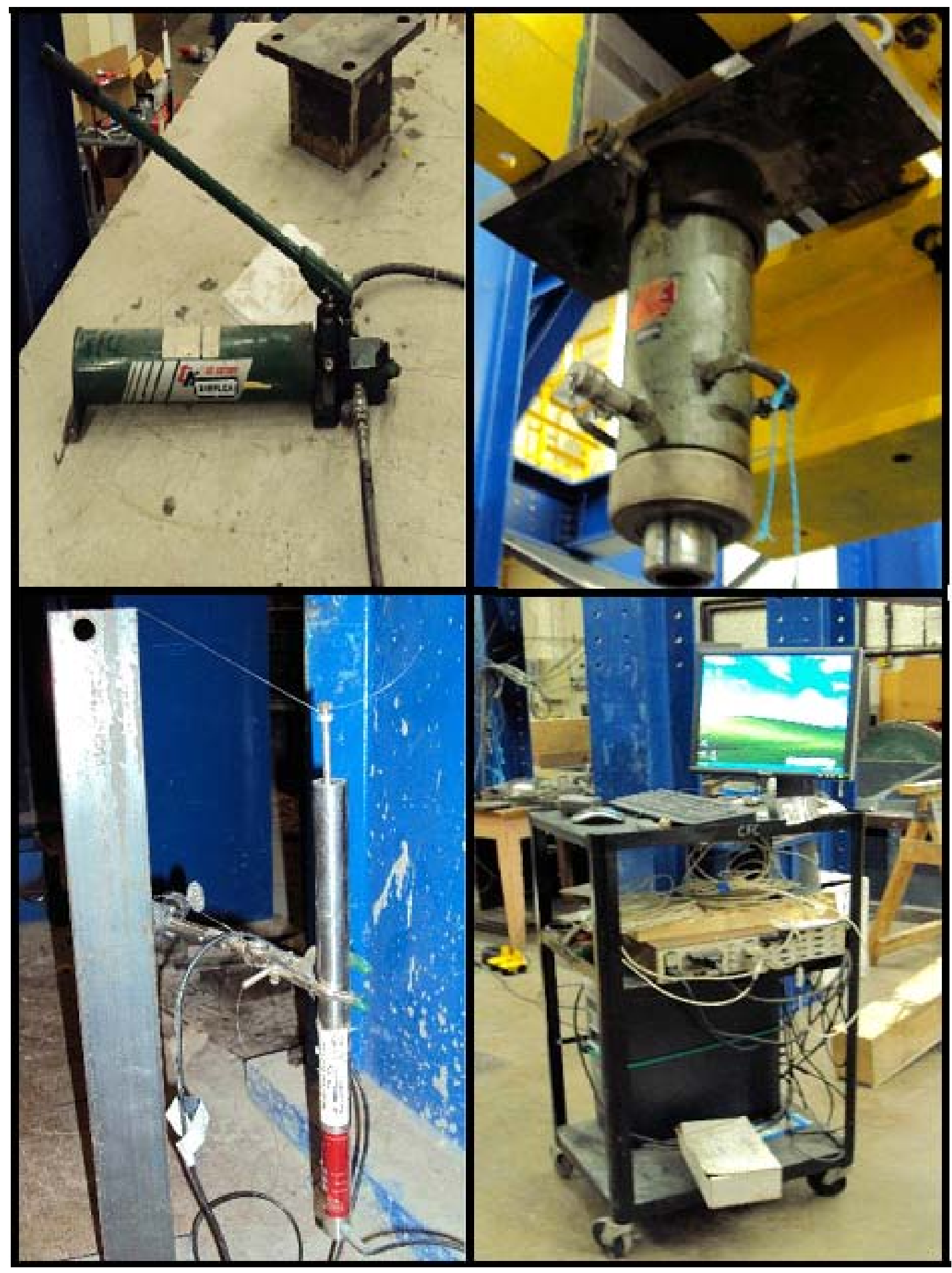

Figure 3-6 Hydraulic Pump, Actuator, Data Acquisition, LVDT (Clockwise from Top Left) 


\subsubsection{Support Conditions}

The support condition utilized during testing consisted of steel plates aligned between the floor, column and actuator. The corresponding support condition allowed partial rotation at the fixtures implying a condition in-between that of a fixed and pinned support (Figure 3-5 Modified Top Fixture (10ft Columns), Actuator Apparatus). An appropriate effective length factor ' $\mathrm{K}$ ' of this condition falls in the range of 0.5 to 1.0 , where $\mathrm{K}=1.0$ is designated as an ideal support condition corresponding to a column pinned at each end.

The addition of the steel plates allowed for uniform load transfer between the load cell and the column. Slipping of the load cell and column was also safely prevented due to the presence of the top and bottom fixtures. However, when testing the $10 \mathrm{ft}$ long columns slight modifications were required to prevent slipping of the specimen due to the increased length. Half inch tabs were welded to the steel plates at a cross section of 4 ” $\mathrm{x} 4$ ” to provide an additional "collar" to the ends of the column. The steel plate directly under actuator was also modified by welding a steel rod to its center to be inserted into the actuator (Figure 3-5 Modified Top Fixture (10ft Columns), Actuator Apparatus). These adjustments allowed for proper failure to occur without slipping.

\subsection{Pure Compression Testing (1ft Samples)}

\subsubsection{Test Specimens}

Local buckling loads were evaluated through testing eleven $1 \mathrm{ft}$ long box sections. The specimens used were cut directly from previously tested full-length samples and tested to failure. 


\subsubsection{Specimen Preparation}

One foot samples were cut directly from full-length columns at the Constructed Facilities Center (CFC) at West Virginia University. The use of a table saw with a diamond blade assured a flush testing surface. The samples were carefully selected from areas of the full-length columns that did not exhibit structural deficiencies from previous testing.

Strain gages were applied to seven of the eleven samples in a back to back fashion (on opposing faces of the cross section) to monitor any minimal bending that may occur during testing. Strain gage application followed the same procedure as that of the full length testing to promote consistency of results.

\subsubsection{Testing Apparatus}

A similar testing apparatus and procedure was used for both the full-length and $1 \mathrm{ft}$ long samples. The only differences included the use of a different actuator and testing location. Due to the relatively small size of the test specimens the samples were placed on a $2 \mathrm{ft}$ high concrete base rather than directly on the floor. This allowed for the actuator to successfully reach the sample for testing.

\subsection{Coupon Testing}

Two methods of coupon testing were employed for comparison with full-length column testing data. Both methods are commonly practiced within the composite industry (SACMA SRM 1R-94 (Modified ASTM D695) and Modified ASTM D3410. Significant differences in specimen preparation and testing apparatus were encountered between the two methods and are outlined below. 


\subsection{SACMA SRM 1R-94 (Modified ASTM D695)}

\subsubsection{Test Specimens}

Sixteen samples, four of each column length, were prepared for coupon testing following SACMA SRM 1R-94 specifications. A total of eight samples were fitted with strain gages for comparison purposes and MOE calculations.

\subsubsection{Specimen Preparation}

Coupons were cut out of full-length column samples using caution to avoid material damages experienced during previous testing. These straight edge samples registered $35 / 16$ ” x $1 / 2$ " in length and width and were cut using a diamond bladed table saw to ensure uniform edges.

Strain gages were applied following the same protocol outlined previously, however, extreme caution was taken in soldering electrical connections due limited gage length provided in the testing fixture (Figure 3-7).

\subsubsection{Testing Apparatus}

Testing following SACMA SRM 1R-94 specifications requires the use of a hardened steel machined fixture (Figure 3-7) to secure coupons to the extent where global buckling is prevented. Samples are centered within the fixture where the two grooved loading plates are then fitted by finger tightening nuts that hold them in place. The sample was now prepared for loading. 


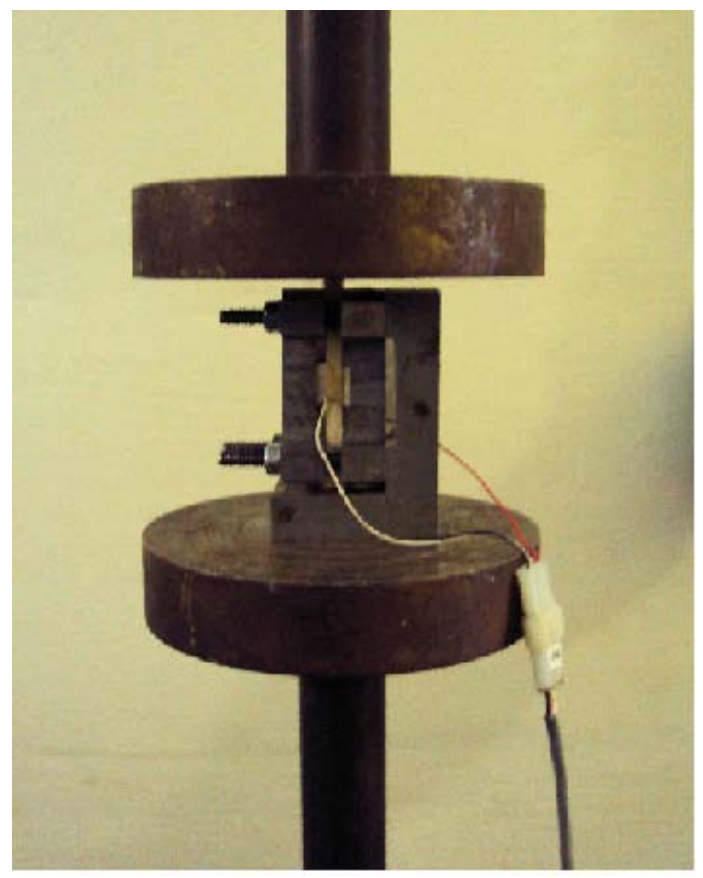

Figure 3-7 SACMA SRM 1R-94 Testing Fixture

All coupon testing was performed on an Instron 8501 Universal Testing Machine (Figure 3-8). Compression plates were positioned to appropriately accommodate the SACMA SRM 1R94 testing fixture. A load rate of $0.05 \mathrm{in} / \mathrm{min}$ was used until failure. Modulus of elasticity values were the desired result as determining the ultimate compressive stress requires the use of tabs for this particular method. 


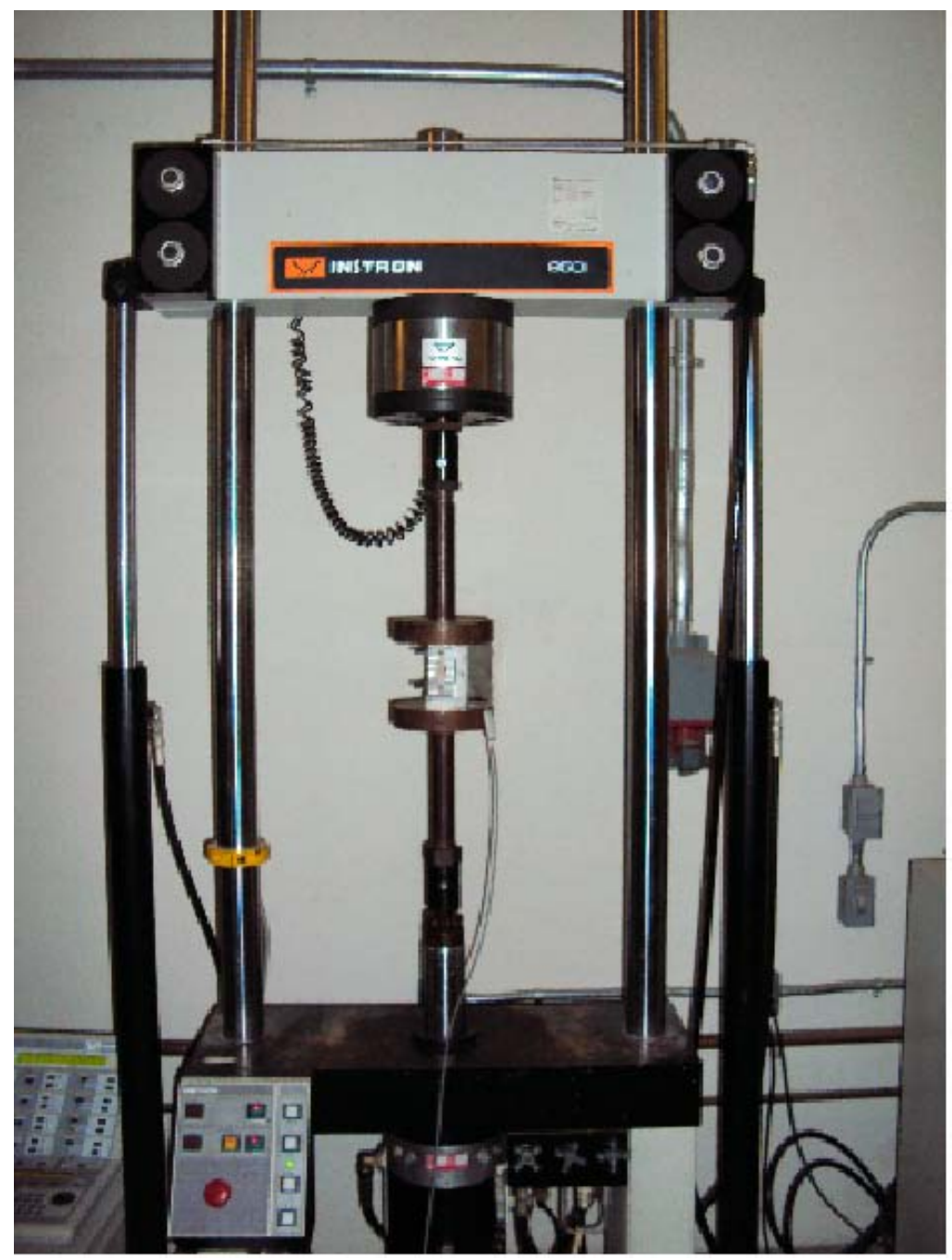

Figure 3-8 Instron 8501 Universal Testing Machine

\subsection{Modified ASTM D3410}

\subsubsection{Test Specimens}

Forty samples (10 of each column length) were prepared following ASTM D3410 specifications for testing. A total of twelve samples were fitted with strain gages for comparison purposes and MOE calculations. 


\subsubsection{Specimen Preparation}

Coupon preparation followed the same general procedure of the SACMA SRM 1R-94 samples outlined above, only the dimensions of the samples changed. One inch samples were used and tested in the direction of longitudinal reinforcement. Strain gages were applied to one face of the coupon.

\subsubsection{Testing Apparatus}

All coupon testing was performed on an Instron 8501 Universal Testing Machine. Compression plates were positioned to appropriately accommodate the samples. Unlike the SACMA SRM 1R-94 testing additional fixtures are not needed. A load rate of $0.05 \mathrm{in} / \mathrm{min}$ was used until failure. Ultimate failure stress is the primary desired result for testing within Modified ASTM D3410. 


\section{CHAPTER 4 DATA ANALYSIS AND RESULTS}

\subsection{Column Testing}

The following data represents different failure patterns for each of the targeted column lengths used (6ft, 8ft-6in, 9ft, 10ft). Loading was applied manually using a hydraulic pump and actuator. Failure was noted when the specimen would no longer take and sustain load. This failure was often identified through a deafening "pop” signifying energy released by the composite.

Load versus deflection and strain were recorded using a data accusation system at a time interval of 0.1 seconds. This continuous loading data was then used to develop a variety of plots. Tabulated values of average failure load, strain, and deflection for each column length have also been developed for comparison purposes.

In order to record load versus deflection for each of the tested specimens two LVDT's were attached at mid-height. The LVDT's were placed perpendicular to one another to account for bending in each direction.

\subsubsection{Hollow Box Sections}

Four different lengths (6ft, 8ft-6in, 9ft, 10ft) of hollow box sections of the same cross section ( 3 1/2” x 3 1/2” x 1/4") were tested under axial compressive loading. Testing results include load-deflection and stress-strain analysis. The following tables and figures provide an illustration

of the test results along with subsequent commentary. Experimental error due to slack and alignment of the specimen was eliminated by extending the linear portion of the desired curve until it reached the horizontal axis. This intersection is then taken as the corrected zero point. 


\subsubsection{Load vs. Deflection}

Deflection increased parabolicly with respect to load up until a point near the failure load for each of the tested column lengths. At this point the deflection leveled off and did not experience a substantial change. The "step" pattern observed in the diagrams can be attributed to load being applied manually by the hydraulic pump.

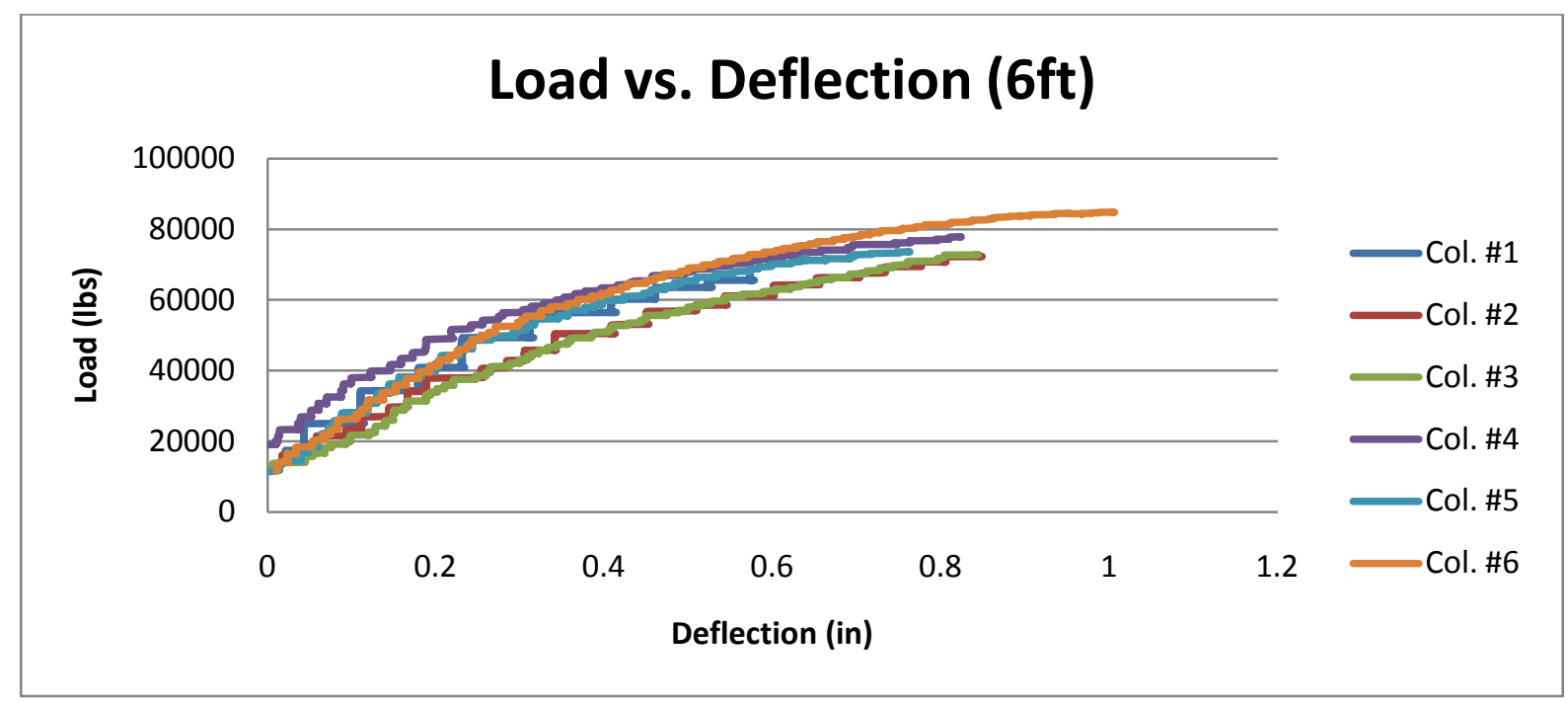

Figure 4-1 6ft Load vs. Deflection

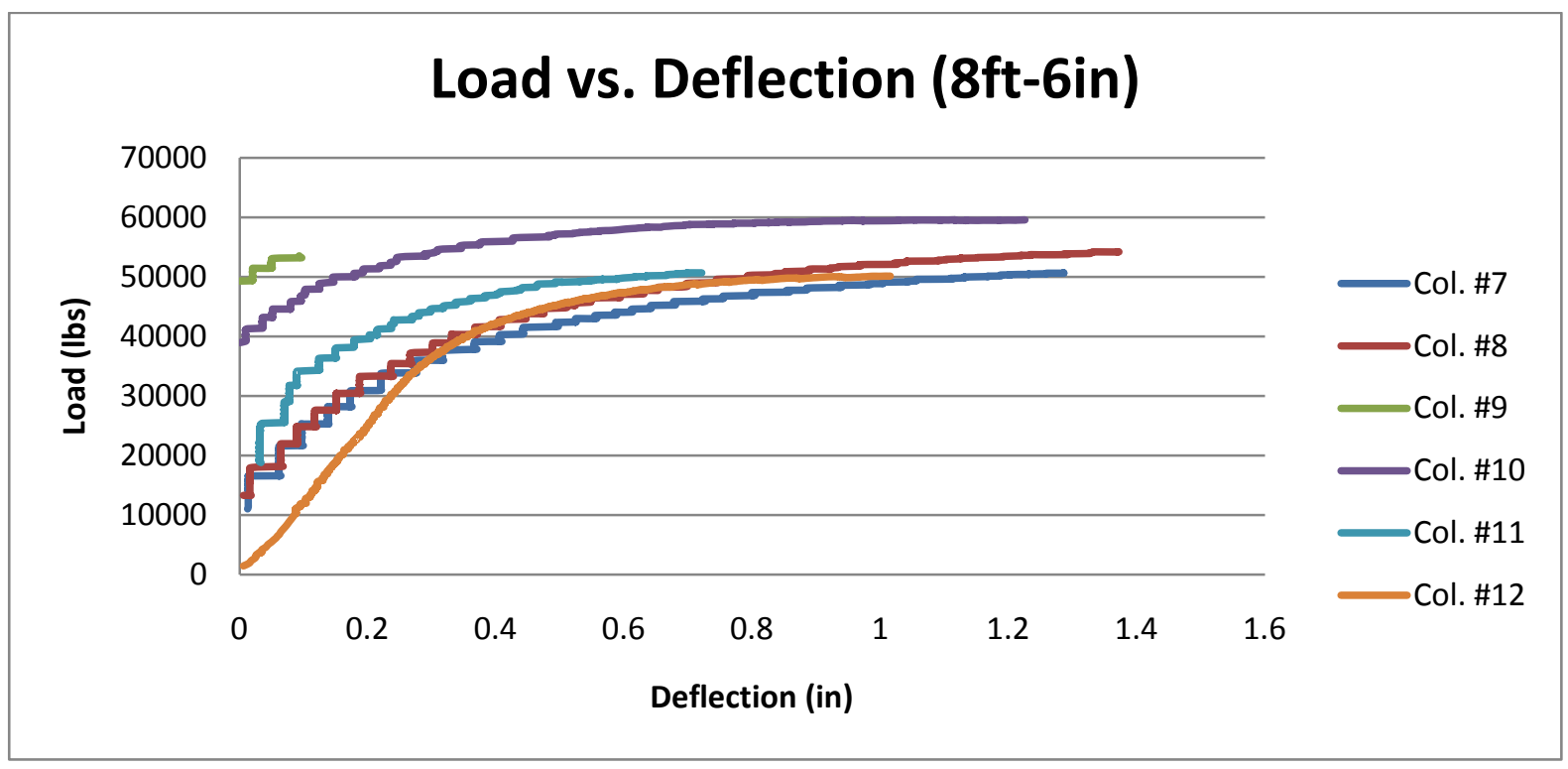

Figure 4-2 8ft-6in Load vs. Deflection 


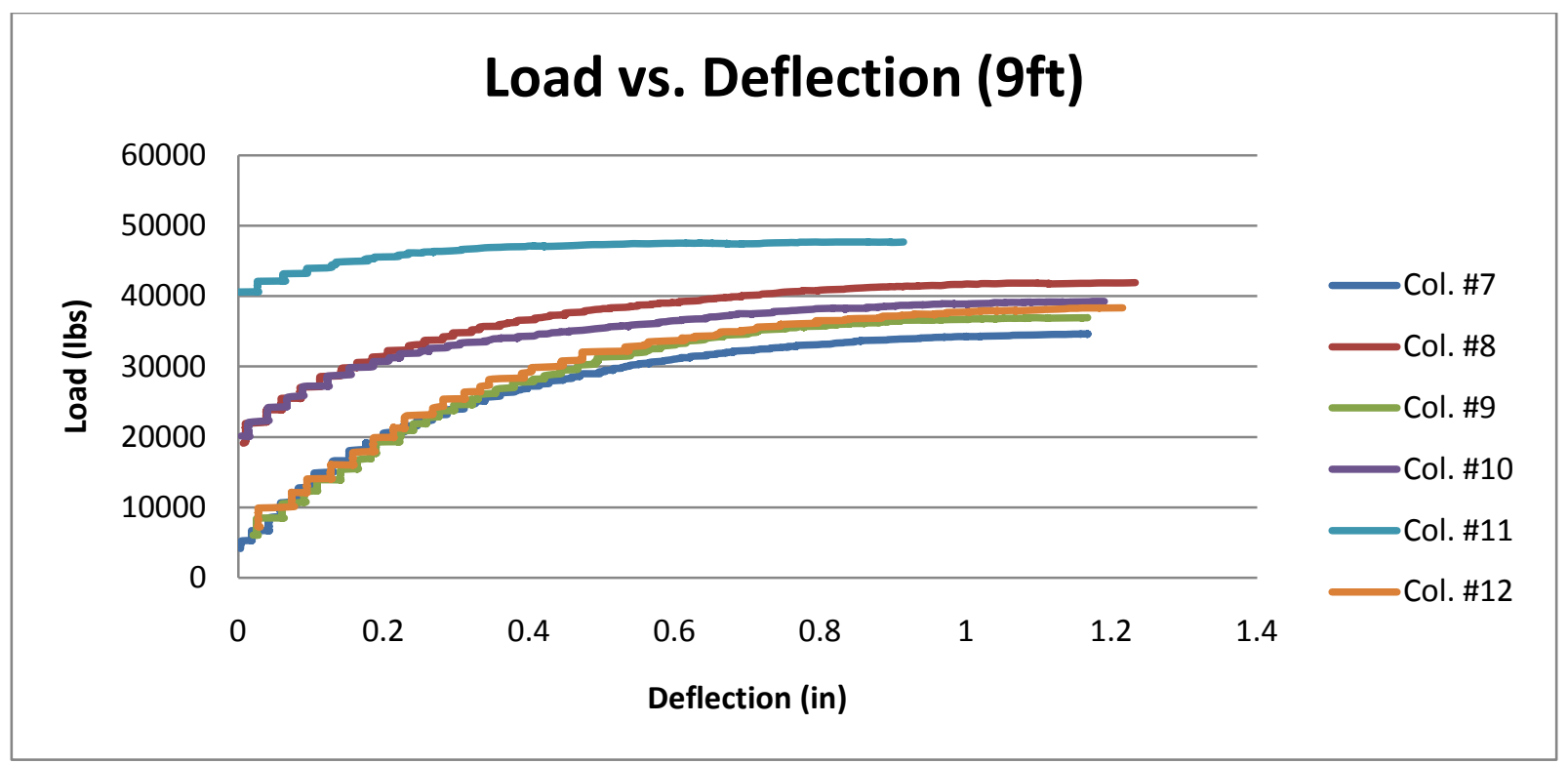

Figure 4-3 9ft Load vs. Deflection

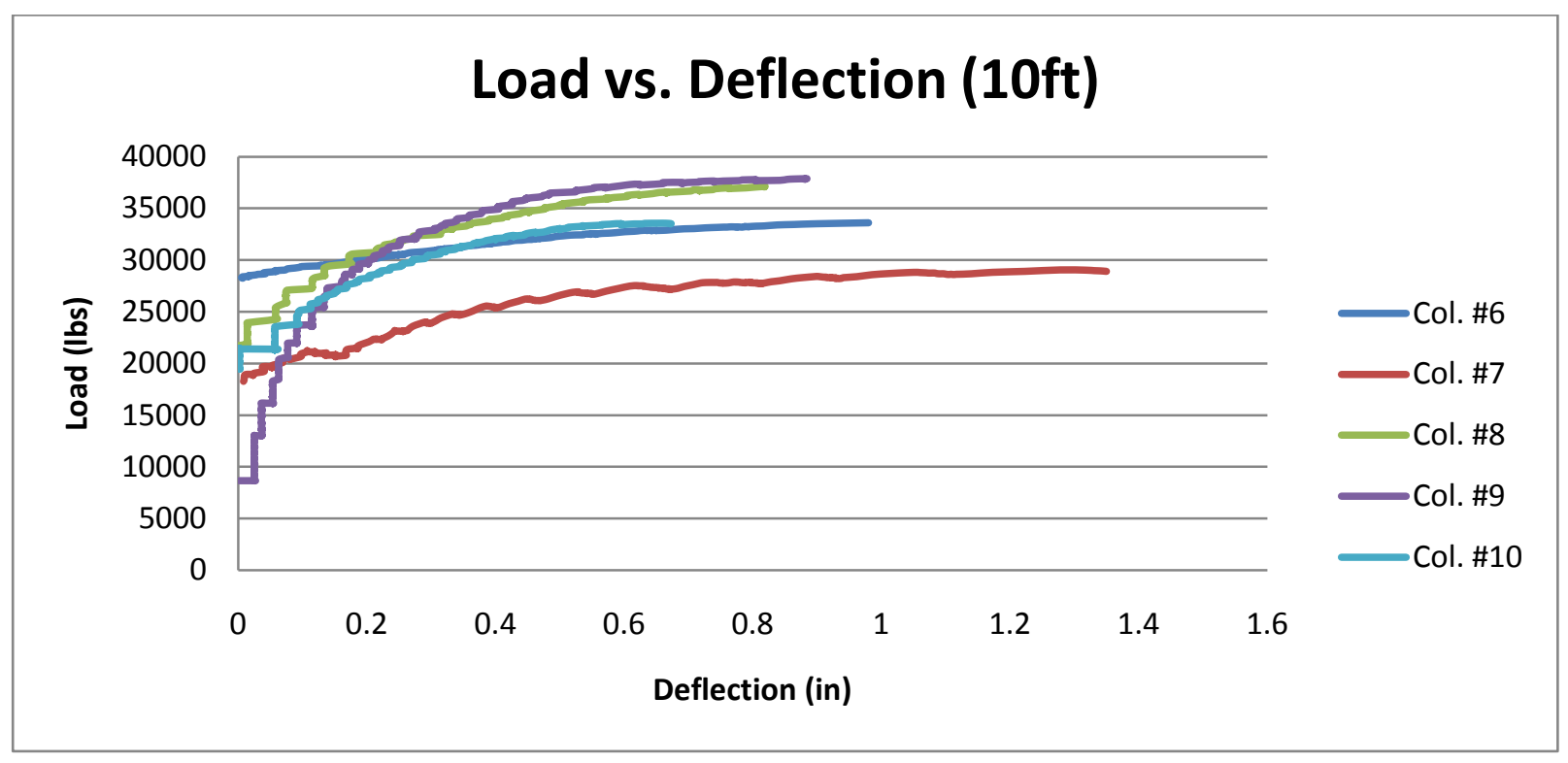

Figure 4-4 10ft Load vs. Deflection

At roughly 10kips the deflection began to increase with the prescribed loading for each of the column lengths. This point is noted as the instance where global buckling effects begin. The $10 \mathrm{ft}$ columns experienced this phenomenon at a later stage likely due to the minor adjustments made to the support conditions described in the previous chapter. 
The deflection diagrams shown here represent half of the total testing samples; the remaining figures can be found in the Appendix.

\subsubsection{Stress vs. Strain}

Longitudinal strain gages applied at mid-height enabled load or stress versus strain curves to be created for a selection of samples of each column length. For each of the targeted column lengths a trilinear response was observed. The $6 \mathrm{ft}$ columns produced the least amount of scatter within the sample media, which can be observed in the following figures. The reduced scatter is likely due to the shorter length coupled with a reduction in column buckling.

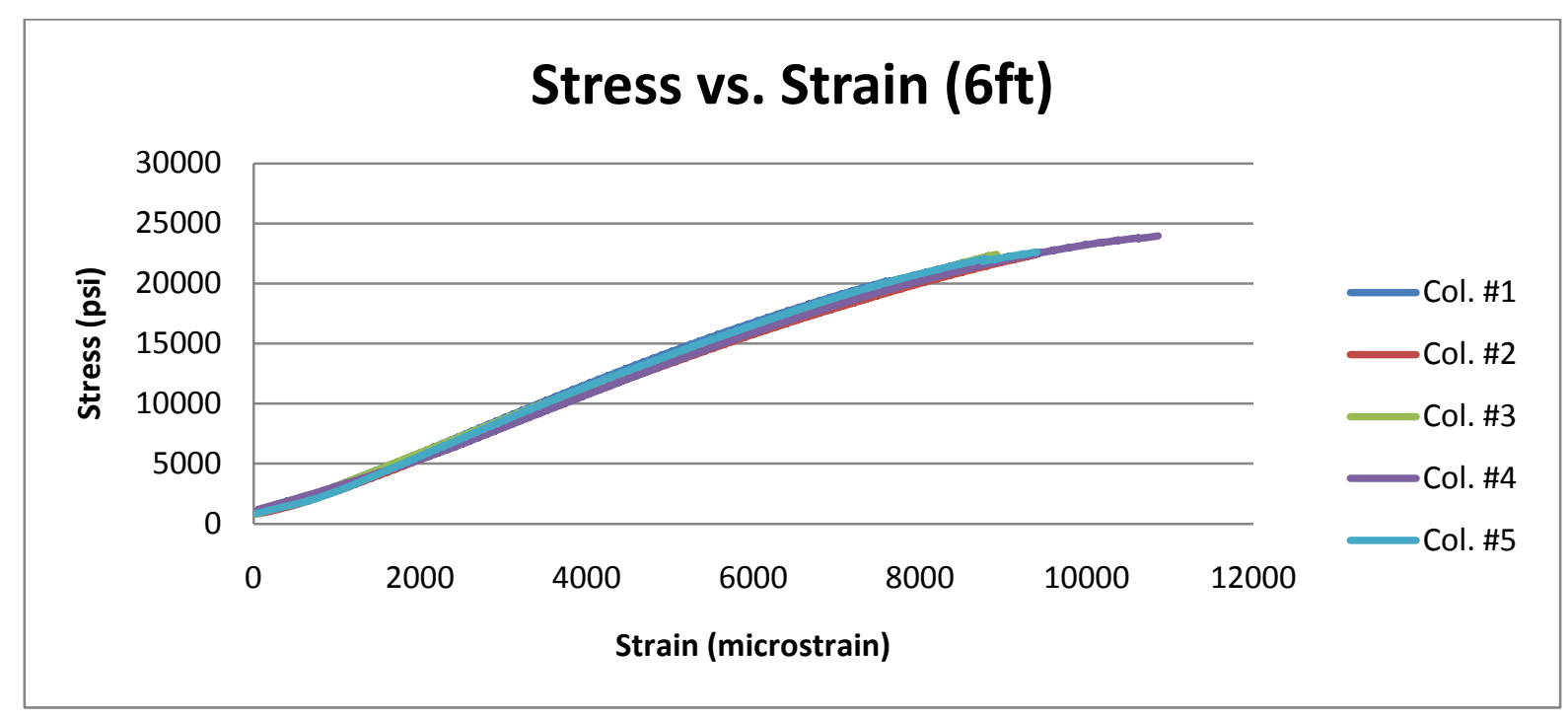

Figure 4-5 6ft Stress vs. Strain 


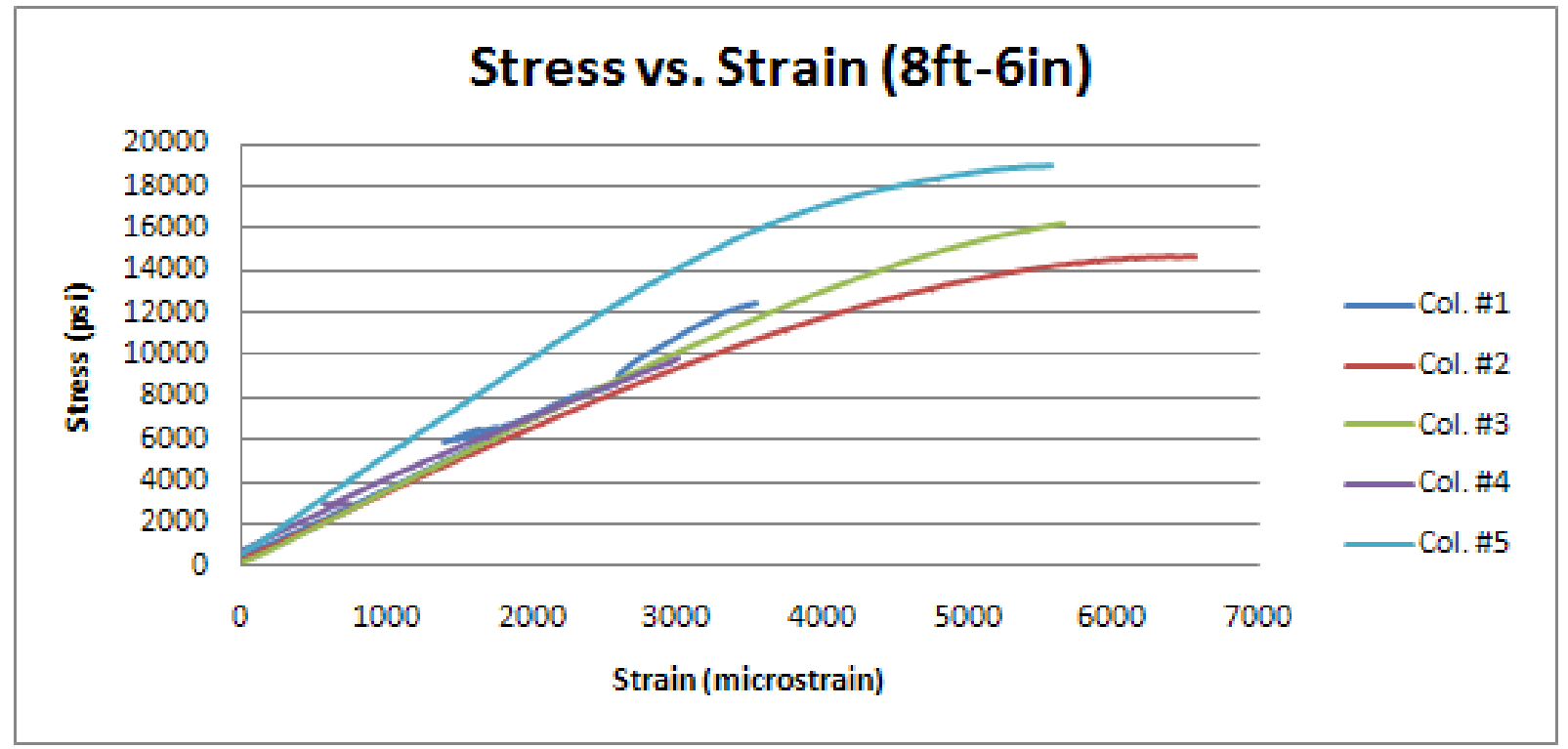

Figure 4-6 8ft-6in Stress vs. Strain

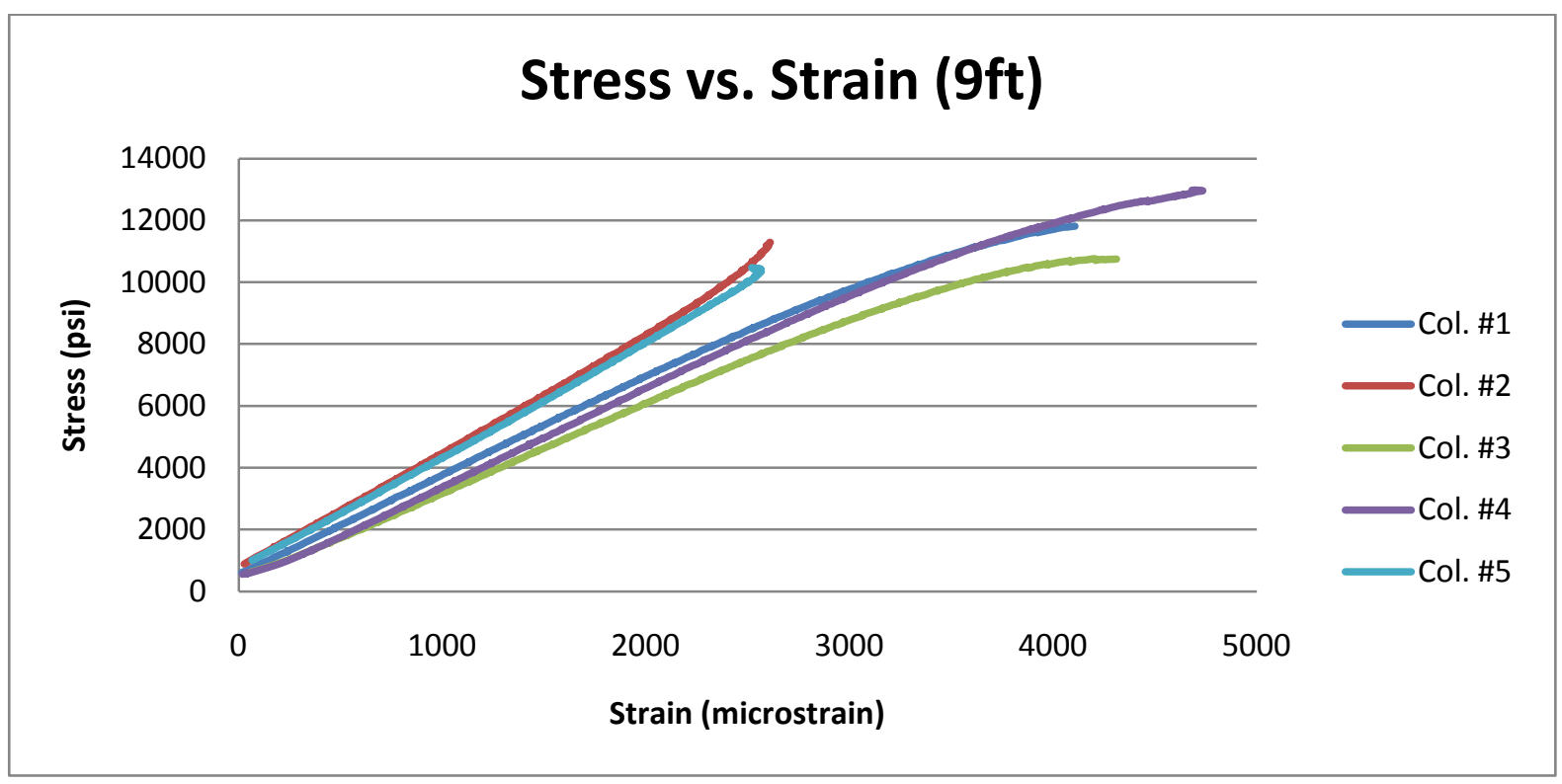

Figure 4-7 9ft Stress vs. Strain 


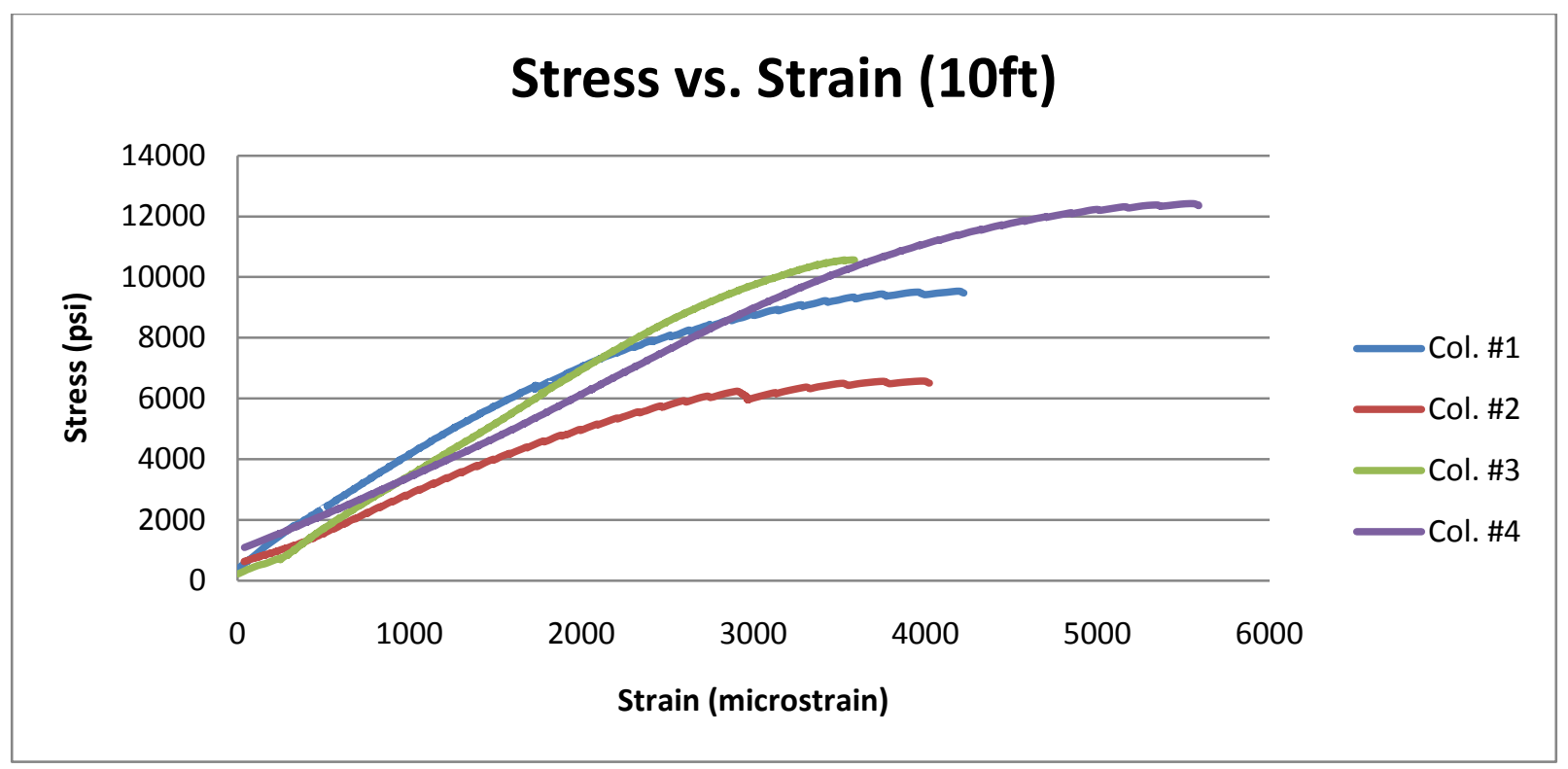

Figure 4-8 10ft Stress vs. Strain

At approximately 3,000 mircostrain a trilinear response was first identified for each of the testing lengths. This phenomenon is likely attributed to internal slipping or delamination of the continuous strand mats within the composite. Lower failure stresses were reached as the column length increased due to the effects of global buckling.

\subsubsection{Determination of Modulus of Elasticity}

Modulus of elasticity for each specimen was obtained by simply taking the slope of the linear portion of the stress-strain curve below 50\% of the failure load. Average values for each column length are tabulated below.

Table 4-1 Full Length Compression Modulus

\begin{tabular}{|l|c|}
\hline Sample ID & $\begin{array}{c}\text { Compression Modulus } \\
\text { E (msi) }\end{array}$ \\
\hline $6 \mathrm{ft}$ & 2.48 \\
\hline $8 \mathrm{ft}-6 \mathrm{in}$ & 3.20 \\
\hline 9ft & 3.02 \\
\hline 10ft & 2.83 \\
\hline AVERAGE & $\mathbf{2 . 8 8}$ \\
\hline
\end{tabular}


Typical MOE values for primarily unidirectional GFRP pultruded sections range from 3.0 - 3.5 msi (Zureick \& Scott, 1997). From the current research's data, the values displayed in Table 4-1 are slightly lower than the desired MOE; therefore additional testing is needed to accurately obtain “true” MOE data.

Intuitively the pattern of MOE decreasing with column length makes sense due to the effects of global buckling. However, the 6ft columns MOE is the lowest of all the tested column lengths leaving reason to believe that the material properties for the $6 \mathrm{ft}$ columns may vary compared to the other lengths. This assumption is further investigated within coupon and "pure" compression testing discussed later.

\subsubsection{Failure Modes}

Failure was noted when the specimen would no longer take and sustain load. This failure was often identified through a deafening "pop” released by the composite. Global buckling effects greatly contributed to failure and are evident in the provided pictures. In instances where end crushing did not occur, failure was taken as the point where increasing hydraulic pressure no longer resulted in an increased load. Deflection readings were then recorded and global buckling failure was noted. 


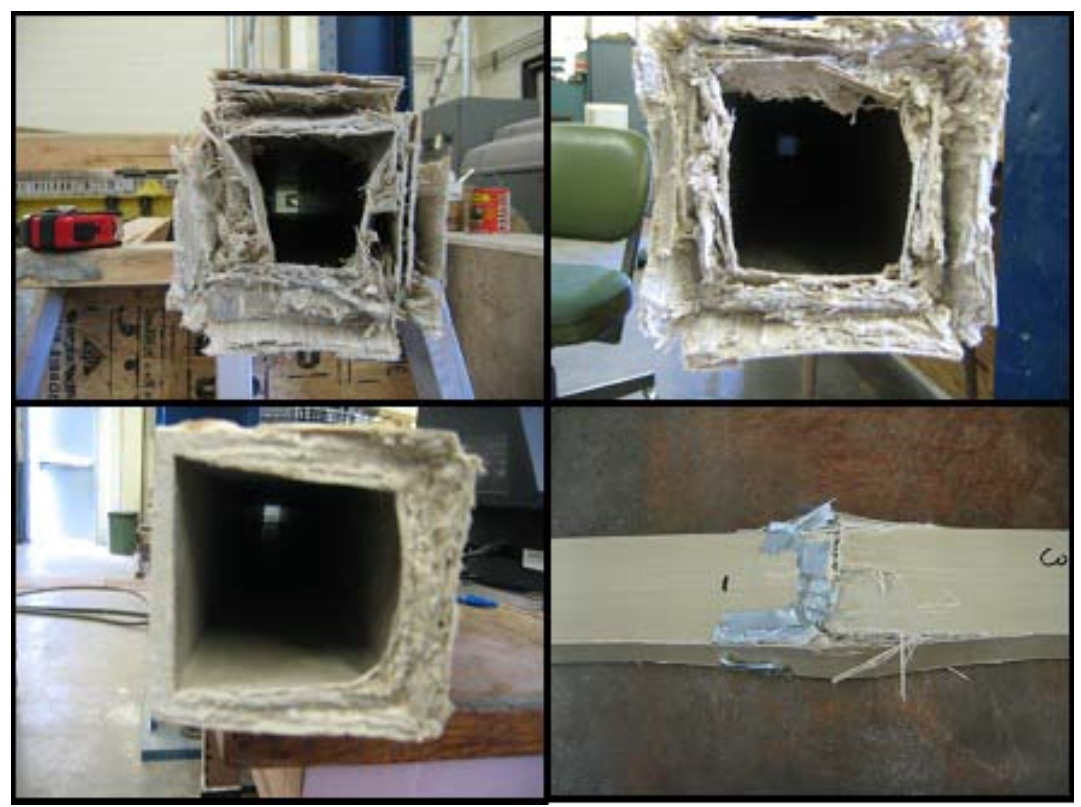

Figure 4-9 6ft failure, 8ft-6in failure, 6ft pure compression, 9ft failure (Clockwise from Left)
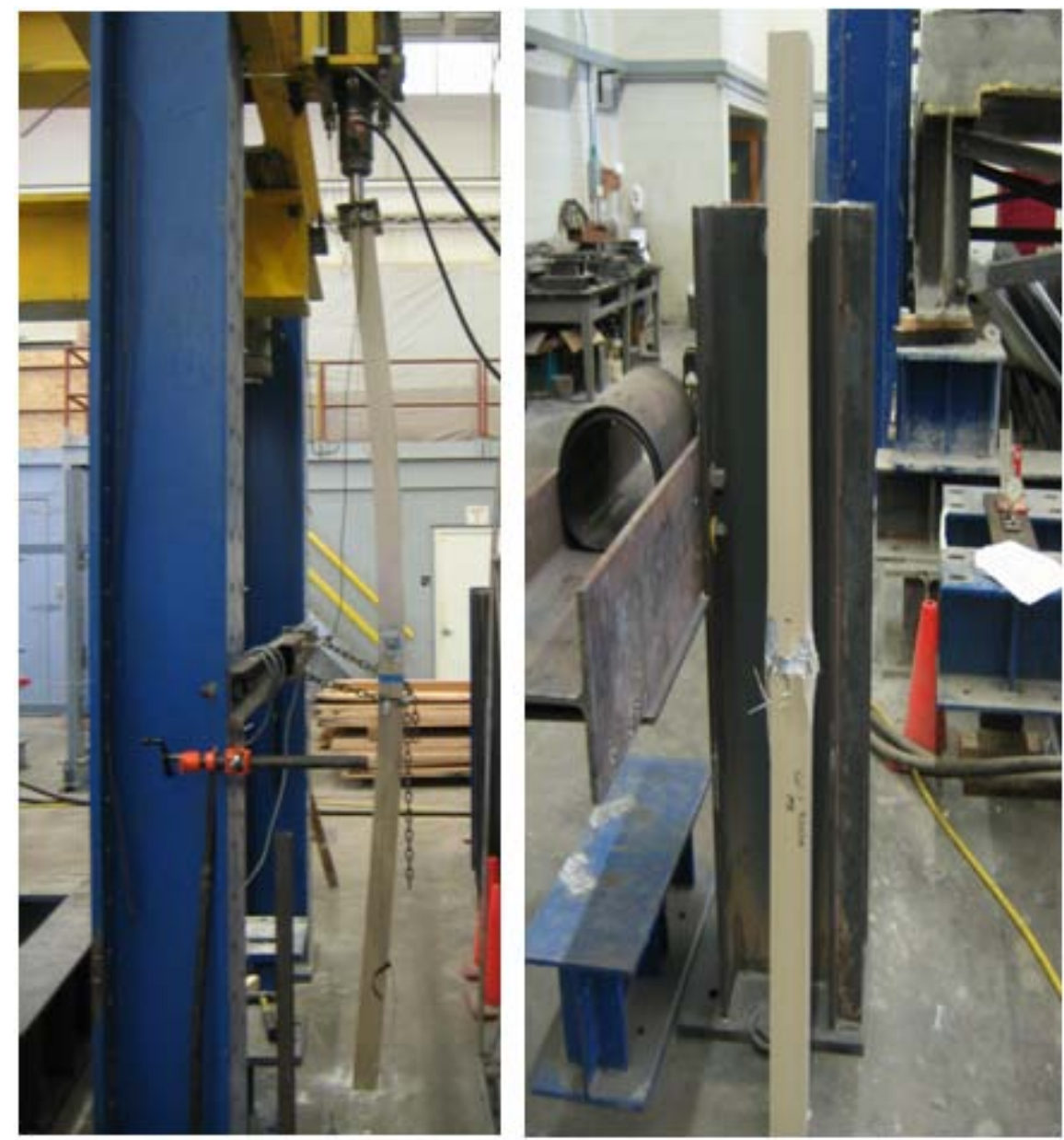

Figure 4-10 Left: Excessive Bending (9ft Column) Right: Perfect Compression Failure (6ft Column) 
Failure occurred along the steel fixtures used as supports in nearly all of the test specimens. At the ultimate load either the top or bottom of the columns were crushed and completely delaminated across at least one edge of the cross-section. In the cases where extreme deflection (Figure 4-10) was not observed the entire cross section crushed (Figure 4-9).

Complete compression failure existed in one of the $6 \mathrm{ft}$ columns displaying a "mushroom effect” of delamination at mid-height. This specimen also carried the greatest load at roughly 84 kips.

\subsubsection{Summary of Ultimate Capacity}

Failure data including: deflection, stress, strain, and load for each column length are outlined below.

Table 4-2 Ultimate Capacity (6ft Columns)

\begin{tabular}{|c|c|c|c|c|}
\hline Test Sample & $\begin{array}{c}\text { Ult. Load } \\
\text { (lbs) }\end{array}$ & Stress (psi) & $\begin{array}{c}\text { Ult. Strain } \\
\text { (microstrain) }\end{array}$ & $\begin{array}{c}\text { Ult. Deflection } \\
\text { (in) }\end{array}$ \\
\hline Column 1 & $67,867.51$ & $20,882.31$ & $8,568.44$ & 0.763 \\
\hline Column 2 & $72,795.26$ & $22,398.54$ & $14,550.52$ & 1.035 \\
\hline Column 3 & $72,841.96$ & $22,412.91$ & $9,434.46$ & 1.001 \\
\hline Column 4 & $77,839.78$ & $23,950.70$ & $11,357.90$ & 1.223 \\
\hline Column 5 & $73,612.66$ & $22,650.05$ & $9,910.15$ & 1.015 \\
\hline Column 6 & $\mathbf{8 4 , 8 2 2 . 7 0}$ & $\mathbf{2 6 , 0 9 9 . 2 9}$ & -- & $\mathbf{1 . 1 8 4}$ \\
\hline Column 7 & $80,245.27$ & $24,690.85$ & -- & 1.058 \\
\hline Column 8 & $67,447.13$ & $20,752.96$ & -- & 0.593 \\
\hline Column 9 & $\mathbf{5 7 , 4 0 4 . 7 9}$ & $\mathbf{1 7 , 6 6 3 . 0 1}$ & -- & $\mathbf{0 . 6 4}$ \\
\hline Column 10 & $64,317.66$ & $19,790.05$ & -- & 0.792 \\
\hline Column 11 & $64,878.16$ & $19,962.51$ & -- & 0.776 \\
\hline Column 12 & $\mathbf{5 0 , 4 9 1 . 9 3}$ & $\mathbf{1 5 , 5 3 5 . 9 8}$ & -- & $\mathbf{0 . 5 7 3}$ \\
\hline
\end{tabular}


Table 4-3 Ultimate Capacity (8ft-6in Columns)

\begin{tabular}{|c|c|c|c|c|}
\hline Test Sample & $\begin{array}{c}\text { Ult. Load } \\
\text { (lbs) }\end{array}$ & Stress (psi) & $\begin{array}{c}\text { Ult. Strain } \\
\text { (microstrain) }\end{array}$ & $\begin{array}{c}\text { Ult. Deflection } \\
\text { (in) }\end{array}$ \\
\hline Column 1 & $\mathbf{4 0 , 6 3 3 . 6 5}$ & $\mathbf{1 2 , 5 0 2 . 6 6}$ & $\mathbf{3 , 7 0 0 . 8 9}$ & $\mathbf{0 . 1 2 8}$ \\
\hline Column 2 & $\mathbf{4 7 , 8 9 2 . 7 1}$ & $\mathbf{1 4 , 7 3 6 . 2 2}$ & $\mathbf{7 , 0 3 3 . 0 8}$ & $\mathbf{1 . 0 1 5}$ \\
\hline Column 3 & $52,780.94$ & $16,240.29$ & $5,806.89$ & 0.439 \\
\hline Column 4 & $\mathbf{3 2 , 2 2 5 . 8 3}$ & $\mathbf{9 , 9 1 5 . 6 4}$ & $\mathbf{3 , 1 6 7 . 8 8}$ & $\mathbf{0 . 8 7 1}$ \\
\hline Column 5 & $61,608.56$ & $18,956.48$ & $8,327.52$ & 1.325 \\
\hline Column 6 & $54,158.55$ & $16,664.17$ & -- & 0.904 \\
\hline Column 7 & $50,702.12$ & $15,600.65$ & -- & 1.456 \\
\hline Column 8 & $54,228.61$ & $16,685.73$ & -- & 1.42 \\
\hline Column 9 & $53,527.98$ & $16,470.15$ & -- & 0.121 \\
\hline Column 10 & $59,553.39$ & $18,324.12$ & -- & 1.275 \\
\hline Column 11 & $50,655.41$ & $15,586.28$ & -- & 0.791 \\
\hline Column 12 & $50,141.31$ & $15,428.09$ & -- & 1.54 \\
\hline
\end{tabular}

Table 4-4 Ultimate Capacity (9ft Columns)

\begin{tabular}{|c|c|c|c|c|}
\hline Test Sample & $\begin{array}{c}\text { Ult. Load } \\
(\mathbf{l b s})\end{array}$ & Stress (psi) & $\begin{array}{c}\text { Ult. Strain }(\boldsymbol{\mu s}) \\
\text { Long. }\end{array}$ & $\begin{array}{c}\text { Ult. Deflection } \\
\text { (in) }\end{array}$ \\
\hline Column 1 & $38,394.42$ & $11,813.67$ & $4,493.55$ & 0.995 \\
\hline Column 2 & $38,744.73$ & $11,921.46$ & $2,929.11$ & 1.134 \\
\hline Column 3 & $\mathbf{3 4 , 9 3 7 . 9 9}$ & $\mathbf{1 0 , 7 5 0 . 1 5}$ & $\mathbf{4 , 9 2 5 . 3 5}$ & $\mathbf{1 . 0 9 1}$ \\
\hline Column 4 & $42,201.16$ & $12,984.97$ & $5,130.04$ & 1.2 \\
\hline Column 5 & $\mathbf{3 4 , 0 0 3 . 8 2}$ & $\mathbf{1 0 , 4 6 2 . 7 1}$ & $\mathbf{2 , 8 6 5 . 9 5}$ & $\mathbf{1 . 4 6 6}$ \\
\hline Column 6 & $40,893.33$ & $12,582.56$ & -- & 1.275 \\
\hline Column 7 & $\mathbf{3 4 , 6 3 4 . 3 8}$ & $\mathbf{1 0 , 6 5 6 . 7 3}$ & -- & $\mathbf{1 . 2 6 7}$ \\
\hline Column 8 & $41,897.56$ & $12,891.56$ & -- & 1.232 \\
\hline Column 9 & $36,969.81$ & $11,375.33$ & -- & 1.267 \\
\hline Column 10 & $39,258.53$ & $12,079.55$ & -- & $\mathbf{0 . 9 1 4}$ \\
\hline Column 11 & $\mathbf{4 7 , 6 8 9 . 4 2}$ & $\mathbf{1 4 , 6 7 3 . 6 7}$ & -- & 1.28 \\
\hline Column 12 & $38,324.36$ & $11,792.11$ & -- & \\
\hline
\end{tabular}


Table 4-5 Ultimate Capacity (10ft Columns)

\begin{tabular}{|c|c|c|c|c|}
\hline Test Sample & $\begin{array}{c}\text { Ult. Load } \\
\text { (lbs) }\end{array}$ & $\begin{array}{c}\text { Stress } \\
\text { (psi) }\end{array}$ & Ult. Strain $(\boldsymbol{\mu s}$ ) Long. & $\begin{array}{c}\text { Ult. Deflection } \\
\text { (in) }\end{array}$ \\
\hline Column 1 & $30,967.76$ & $9,528.54$ & $4,179.08$ & 1.674 \\
\hline Column 2 & $\mathbf{2 1 , 3 6 7 . 1 9}$ & $\mathbf{6 , 5 7 4 . 5 2}$ & $\mathbf{3 , 9 6 9 . 2 1}$ & $\mathbf{1 . 6 6}$ \\
\hline Column 3 & $34,343.43$ & $10,567.21$ & $3,572.40$ & 0.688 \\
\hline Column 4 & $\mathbf{4 0 , 3 5 5 . 8 4}$ & $\mathbf{1 2 , 4 1 7 . 1 8}$ & $\mathbf{5 , 5 5 6 . 3 8}$ & $\mathbf{1 . 6 6 5}$ \\
\hline Column 5 & $35,685.32$ & $10,980.10$ & -- & 0.537 \\
\hline Column 6 & $33,606.79$ & $10,340.55$ & -- & 1.016 \\
\hline Column 7 & $29,052.71$ & $8,939.30$ & -- & 1.278 \\
\hline Column 8 & $\mathbf{3 7 , 1 1 8 . 3 9}$ & $\mathbf{1 1 , 4 2 1 . 0 4}$ & -- & $\mathbf{0 . 8 1 9}$ \\
\hline Column 9 & $\mathbf{3 7 , 8 8 4 . 8 0}$ & $\mathbf{1 1 , 6 5 6 . 8 6}$ & -- & $\mathbf{0 . 8 8 4}$ \\
\hline Column 10 & $33,550.58$ & $10,323.26$ & -- & 0.665 \\
\hline
\end{tabular}

Consistency of results is based upon several factors including: material properties, proper alignment of column, boundary conditions, temperature, and rate of loading. Any number of these factors are responsible for variation within the testing results and are identified by the samples presented in bold in the accompanying figures. The inconsistent results, pertaining to a larger standard deviation exhibited between average values are referred to as "outliers" and shall not be considered adequate for use in developing a design aid.

Table 4-6 provides average load, stress, and deflection data with and without the proposed "outliers." Buckling effects are identified in that the failure load decreases as the column length increases. Once the "outliers" are removed deflection increases with column length, which was expected, however, the $10 \mathrm{ft}$ columns experienced slightly lower ultimate deflection likely a result of the modified support conditions. From Table 4-7 the percent difference between the two sets of data is presented. Through removal of the "outliers" the standard deviation is decreased significantly presenting a more consistent set of data. 
Table 4-6 Average Failure Data (Full Length Columns)

\begin{tabular}{|c|c|c|c|c|c|c|c|}
\hline \multirow{2}{*}{$\begin{array}{c}\text { Column } \\
\text { Length }\end{array}$} & \multirow{2}{*}{ Data } & \multicolumn{4}{|c|}{ Average Values } & \multicolumn{3}{c|}{ Standard Deviation } \\
\cline { 3 - 8 } & & $\begin{array}{c}\text { Load } \\
\text { (lbs) }\end{array}$ & $\begin{array}{c}\text { Stress } \\
\text { (psi) }\end{array}$ & $\begin{array}{c}\text { Def } \\
\text { (in) }\end{array}$ & $\begin{array}{c}\text { Load } \\
\text { (lbs) }\end{array}$ & $\begin{array}{c}\text { Stress } \\
\text { (psi) }\end{array}$ & $\begin{array}{c}\text { Def } \\
\text { (in) }\end{array}$ \\
\hline 6ft & All Samples & $69,547.07$ & $21,399.10$ & 0.888 & $9,636.16$ & $2,964.97$ & 0.227 \\
\hline & Outliers & $71,316.15$ & $21,943.43$ & 0.917 & $5,583.07$ & $1,717.87$ & 0.196 \\
\hline 8ft-6in & All Samples & $50,675.75$ & $15,592.54$ & 0.940 & $7,890.93$ & $2,427.98$ & 0.498 \\
\hline & Outliers & $54,150.76$ & $16,661.77$ & 1.030 & $3,988.48$ & $1,227.23$ & 0.499 \\
\hline 9ft & All Samples & $38,995.79$ & $11,998.70$ & 1.193 & $3,853.35$ & $1,185.65$ & 0.145 \\
\hline & Outliers & $39,585.49$ & $12,180.15$ & 1.197 & $1,873.21$ & 576.37 & 0.096 \\
\hline $10 \mathrm{ft}$ & All Samples & $33,393.28$ & $10,274.86$ & 1.089 & $5,355.21$ & $1,647.76$ & 0.447 \\
\hline & Outliers & $32,867.77$ & $10,113.16$ & 0.976 & $2,420.47$ & 744.76 & 0.436 \\
\hline
\end{tabular}

Table 4-7 Percent Difference of Average Values Between all Samples and Outliers

\begin{tabular}{|c|c|c|c|c|}
\hline \multirow{3}{*}{$\begin{array}{l}\text { Column } \\
\text { Length }\end{array}$} & \multicolumn{4}{|c|}{$\%$ Diff } \\
\hline & \multicolumn{2}{|c|}{ Average Values } & \multicolumn{2}{|c|}{ Standard Deviation } \\
\hline & $\begin{array}{c}\text { Load } \\
\text { (lbs) }\end{array}$ & $\begin{array}{l}\text { Def } \\
\text { (in) }\end{array}$ & $\begin{array}{l}\text { Load } \\
\text { (lbs) }\end{array}$ & Def (in) \\
\hline $6 \mathrm{ft}$ & 2.48 & 3.22 & -72.60 & -15.39 \\
\hline $8 f t-6 i n$ & 6.42 & 8.71 & -97.84 & 0.06 \\
\hline $9 \mathrm{ft}$ & 1.49 & 0.34 & -105.71 & -52.06 \\
\hline $10 \mathrm{ft}$ & -1.60 & -11.50 & -121.25 & -2.51 \\
\hline
\end{tabular}

\subsubsection{Wide Flange Sections}

Six 6ft W-Flange sections of varying cross-section (3ea 3” x 3” x 1/4”; 3ea 6” x 6” x 3/8”) were tested under axial compressive loading to produce failure data for a cross-section differing from the commonly used hollow-boxed section. Similar to the testing conducted on the closed sections; recorded data included load-deflection and load-strain analysis. Results and commentary are illustrated in the accompanying figures below. Data analysis mirrored that of the closed-section columns including modifications for experimental error with regard to test set-up. 


\subsubsection{Load vs. Deflection}

Load-deflection analysis for the W-Flange sections was consistent with the hollow box sections in that deflection increased parabolicly with respect to load up until a point near failure. The deflection presented in the following figures represents weak axis deflection. Biaxial deflection was not experienced due to the presence of a weak axis in bending.

The smaller sections (3in flange width) were affected by both local and global buckling, which is evident in large deflection at failure. At roughly 10 kips deflection began to increase more quickly with load. A similar trend was observed in the hollow box sections and is likely due to the initiation of global buckling. Due to the increased thickness (3/8” vs. 1/4”) and increased flange width (6”) the larger cross sectioned columns displayed minimal global buckling effects and as a result was able to carry a much larger load.

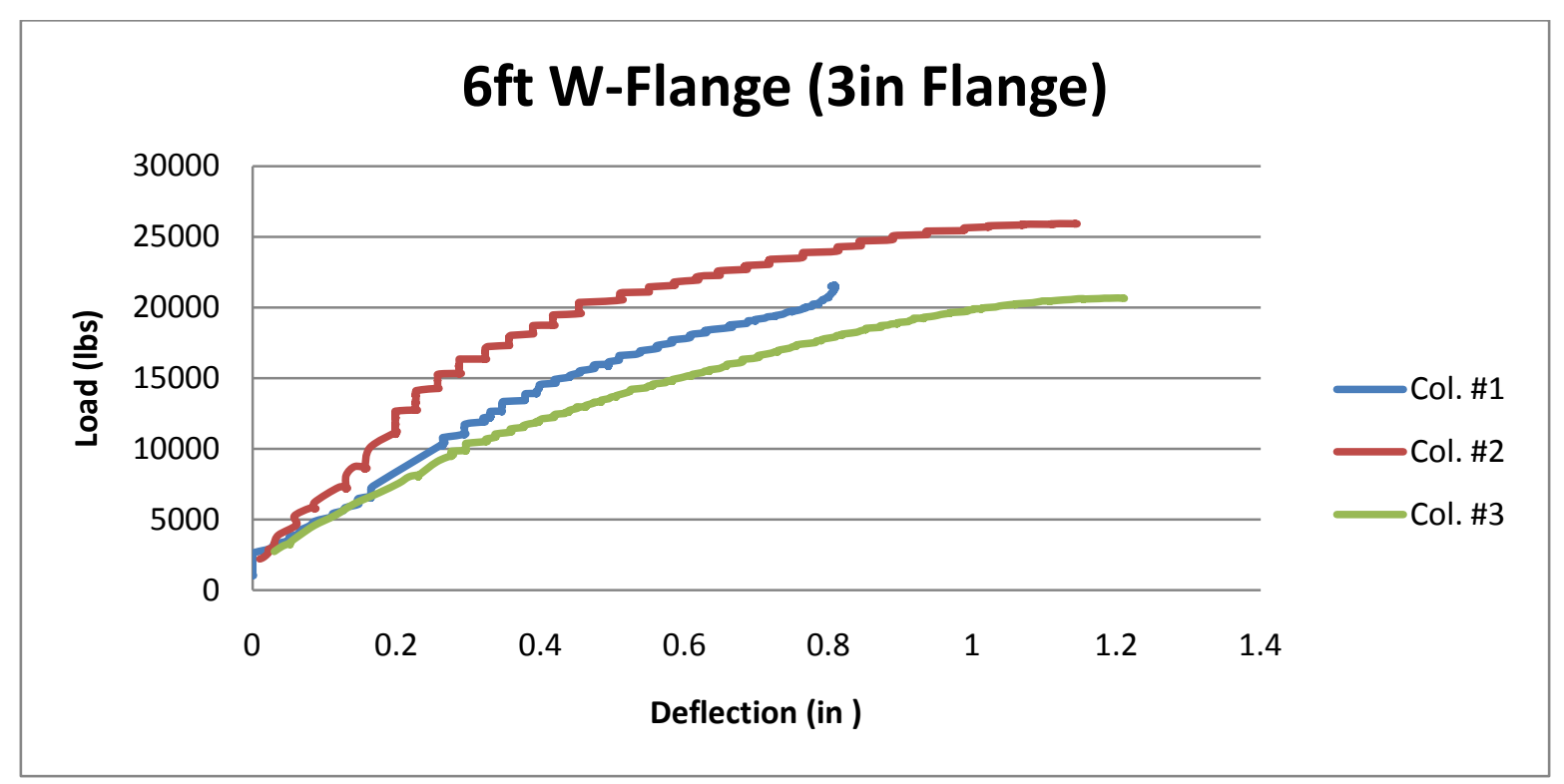

Figure 4-11 3" W-Flange Load vs. Deflection 


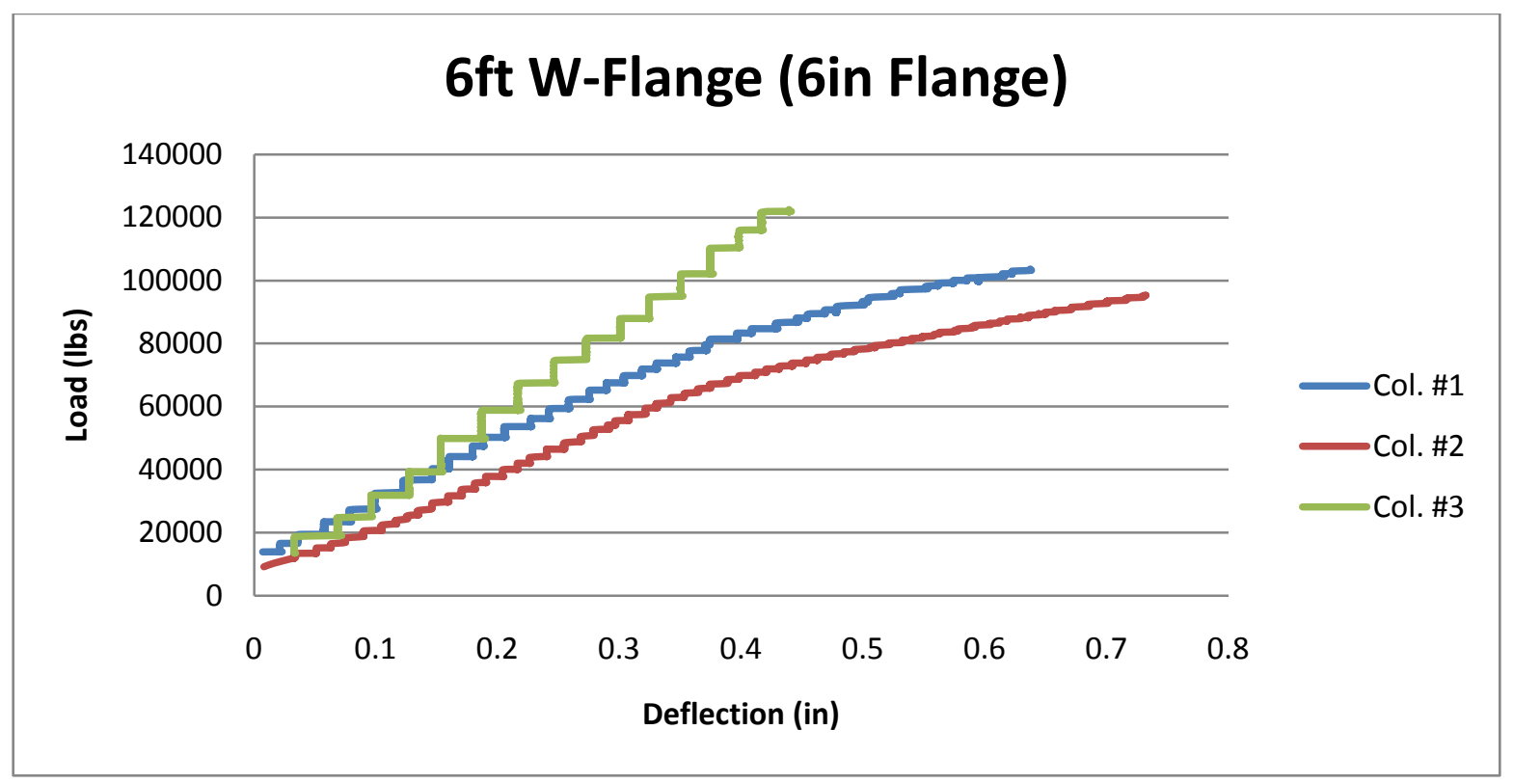

Figure 4-12 6" W-Flange Load vs. Deflection

\subsubsection{Stress vs. Strain}

Back to back strain gage configurations were used to monitor any possible "twisting" of the cross-section during loading. The resulting stress-strain diagrams provided evidence of this phenomenon.

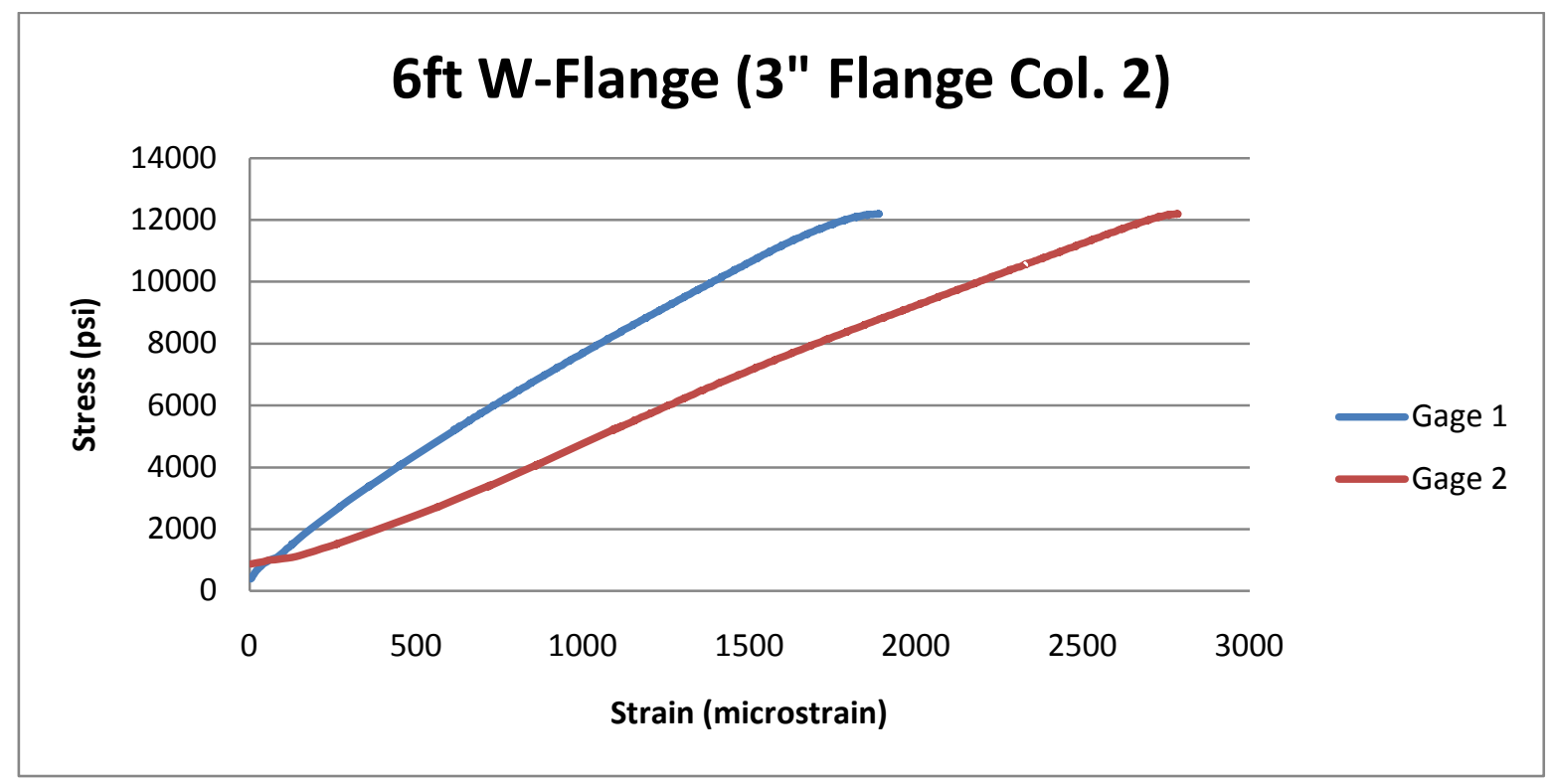

Figure 4-13 3" W-Flange Stress vs. Strain 


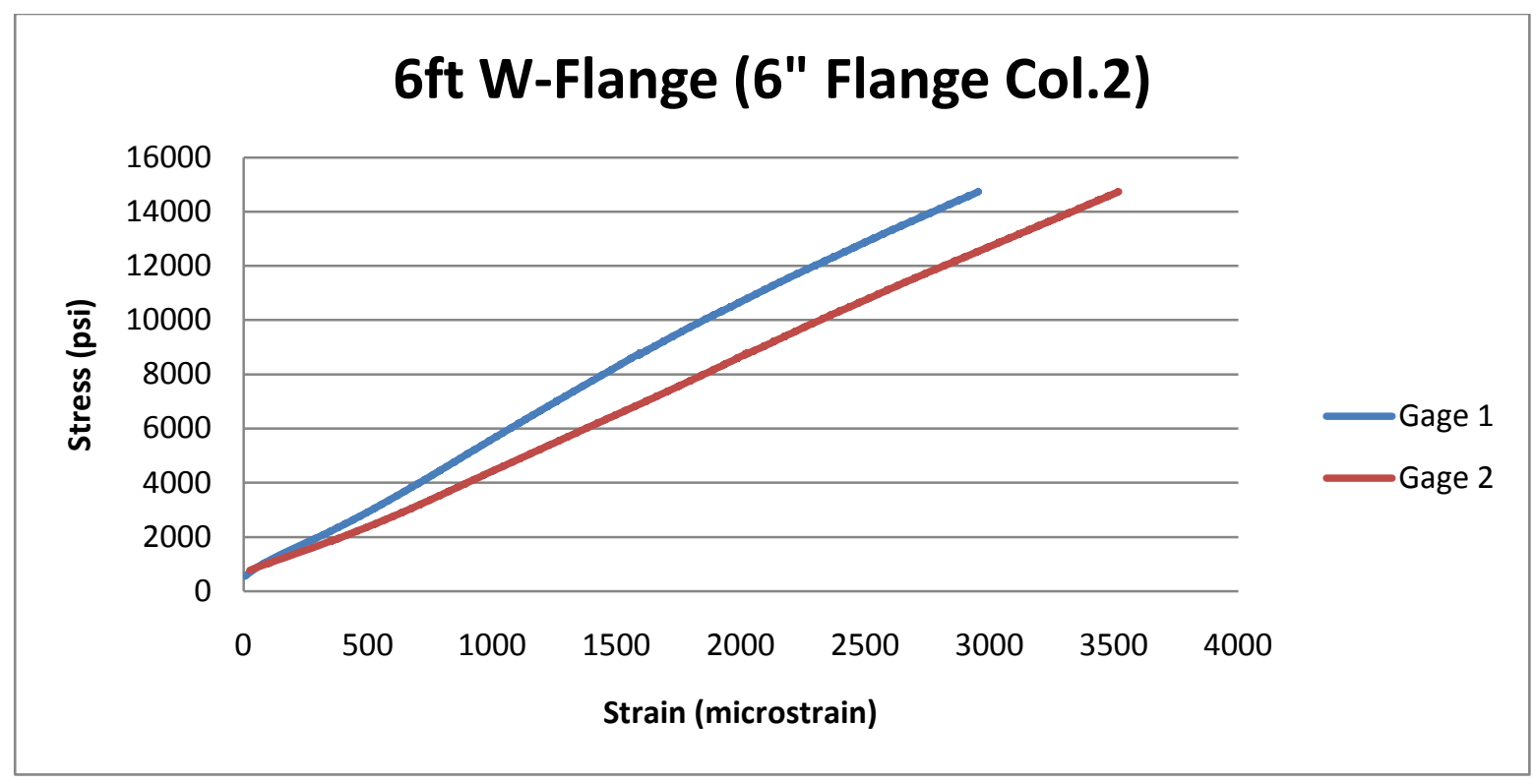

Figure 4-14 6" W-Flange Stress vs. Strain

In ideal conditions the strain recorded by gages 1 and 2 would be nearly equal, however, due to many factors including: fiber geometry, minimal loading eccentricity, and twisting of the cross section under axial loads, the recorded data varies. Twisting of the cross section is the dominant contributor to the divergent strain data, which is clearly shown in Figure 4-13 and Figure 4-14. As the flange width and thickness are increased, the recorded strain from the two parallel gages is closer to equivalency, meaning that twisting effects are not as extreme.

\subsubsection{Modulus of Elasticity}

Modulus of elasticity of the W-Flange sections was determined following the same steps outlined for the hollow-box sections, however due to the twisting effects observed during loading, significantly different values were obtained for each set of strain data. As a result further testing was conducted (1ft "pure” compression columns) in an effort to obtain an acceptable value. Table 4-8 below provides the different MOE values obtained from each set of strain data for the desired column. Gages were placed in a back to back configuration longitudinally on opposing flanges at mid-height. The two values for each column were then averaged for 
comparison purposes within the sample media. As noted in the table the average values for each flange width are relatively high when compared to the hollow box sections. This trend is further investigated in the succeeding chapters, although it is likely due to the different resin systems used by the two cross section types.

Table 4-8 Modulus of Elasticity (W-Flange Columns).

\begin{tabular}{|c|c|c|c|c|}
\hline Flange Width & $\begin{array}{c}\text { Test } \\
\text { Sample }\end{array}$ & MOE G.1 & MOE G.2 & Average \\
\hline (in) & $\#$ & (msi) & (msi) & (msi) \\
\hline & 1 & 5.42 & 3.35 & 4.39 \\
3 & 2 & 6.17 & 4.28 & 5.23 \\
& 3 & 5.08 & 3.34 & 4.21 \\
\hline \multirow{3}{*}{6} & 1 & 5.53 & 3.73 & 4.63 \\
& 2 & 4.87 & 4.11 & 4.49 \\
& 3 & 5.91 & 3.81 & 4.86 \\
\hline
\end{tabular}

\subsubsection{Failure Modes}

Failure was noted when the specimen would no longer take and sustain load. This failure was often identified through a deafening "pop” released by the composite. Global buckling was only observed in the 3" wide sections as is evident in the following pictures. The larger crosssections (6" Flanges) exhibited local buckling due to the greatly increased moment of inertia. Pure compression failure was observed in the third column tested producing a "mushroom" effect at mid-height. 


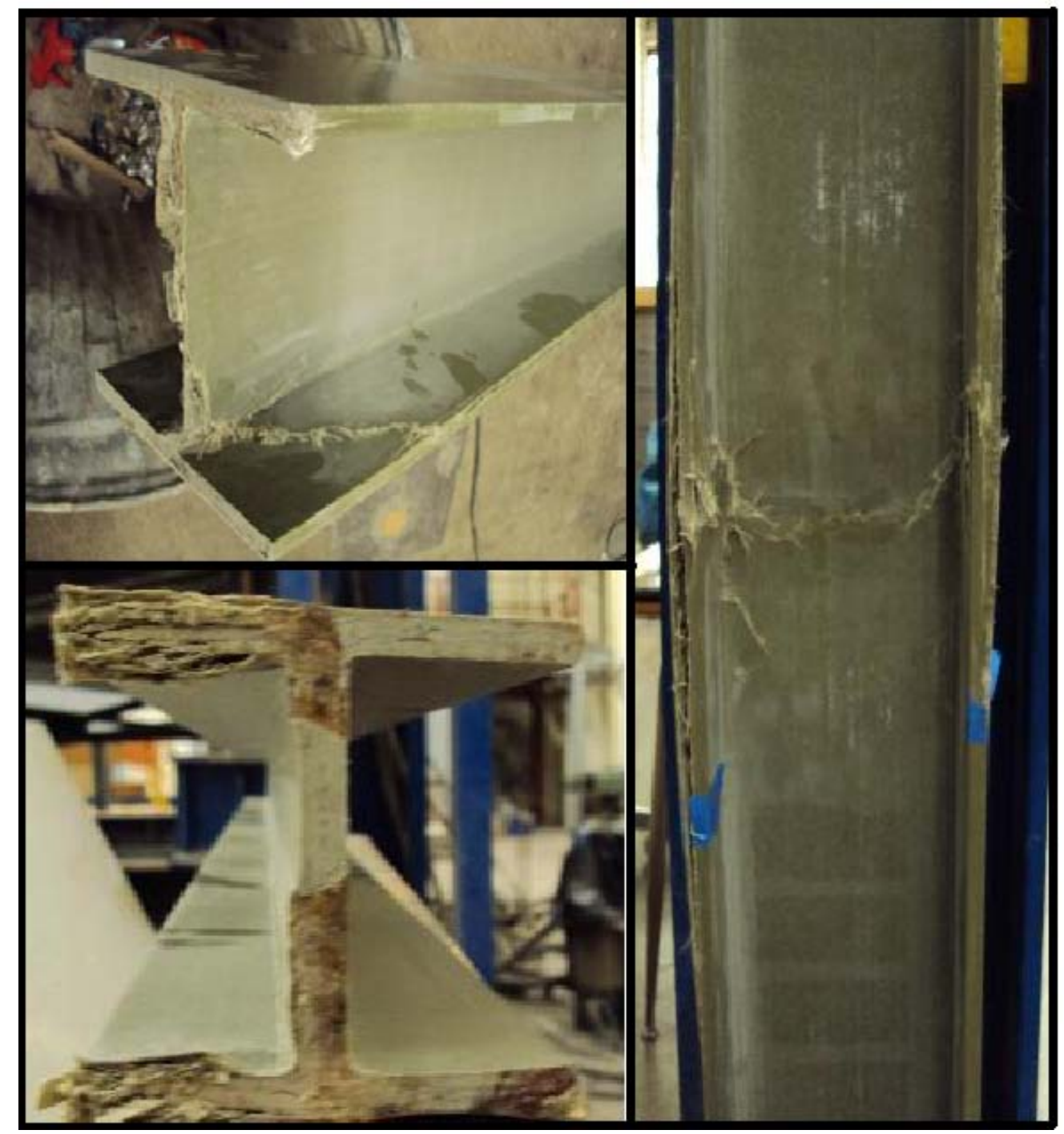

Figure 4-15 6" Flange Failure, 6" Flange Pure Compression, 3" Flange End Crushing (Clockwise from

Upper Left)

\subsubsection{Summary of Ultimate Capacity}

Failure data including: load, stress, strain, and deflection are provided in Table 4-9. Minimal scatter within the sample media was experienced. Twisting effects are presented in terms of varying strains among Gages 1 and 2. As the flange width increased from 3" to 6” the deflection decreased which was as expected, due buckling occurring on localized level for the 
larger cross sections. The 3" flanged sections were controlled by deflection, therefore failed much more rapidly (lower loading).

Table 4-9 Ultimate Capacity W-Flange Columns

\begin{tabular}{|c|c|c|c|c|c|c|}
\hline $\begin{array}{c}\text { Flange } \\
\text { Width }\end{array}$ & $\begin{array}{c}\text { Test } \\
\text { Sample }\end{array}$ & Ult. Load & Stress & $\begin{array}{c}\text { Ult. Strain } \\
\text { G.1 }\end{array}$ & $\begin{array}{c}\text { Ult. Strain } \\
\text { G.2 }\end{array}$ & $\begin{array}{c}\text { Ult. } \\
\text { Deflection }\end{array}$ \\
\hline (in) & $\#$ & (lbs) & (psi) & (microstrain) & (microstrain) & (in) \\
\hline \multirow{3}{*}{3} & 1 & $21,591.83$ & $10,160.86$ & $1,548.41$ & $3,150.84$ & 0.808 \\
& 2 & $25,939.26$ & $12,206.71$ & $1,887.05$ & $2,784.11$ & 1.142 \\
& 3 & $20,653.63$ & $9,719.35$ & $1,613.76$ & $2,764.31$ & 1.21 \\
\hline \multirow{3}{*}{6} & 1 & $103,690.98$ & $16,026.43$ & $2,775.81$ & $4,121.76$ & 0.637 \\
& 2 & $95,326.46$ & $14,733.61$ & $2,953.34$ & $3,517.48$ & 0.732 \\
& 3 & $122,534.28$ & $18,938.84$ & $3,086.74$ & $4,830.58$ & 0.439 \\
\hline
\end{tabular}

\subsection{Pure Compression (1ft Samples)}

Local buckling strength was evaluated through testing $1 \mathrm{ft}$ samples taken directly from fulllength columns. The corresponding failure load was deemed "failure due to local buckling," under the assumption that any minor global buckling effects were negligible. Therefore, deflection readings were not recorded. The results from localized testing at $1 \mathrm{ft}$ sample heights offers another view point for comparison further discussed in Chapter 5.

\subsubsection{Hollow Box Sections}

\subsubsection{Stress vs. Strain}

Stress-strain relationships were developed similarly to those of the full-length columns. However, the shorter length specimens provided a nearly linear response as illustrated below. 


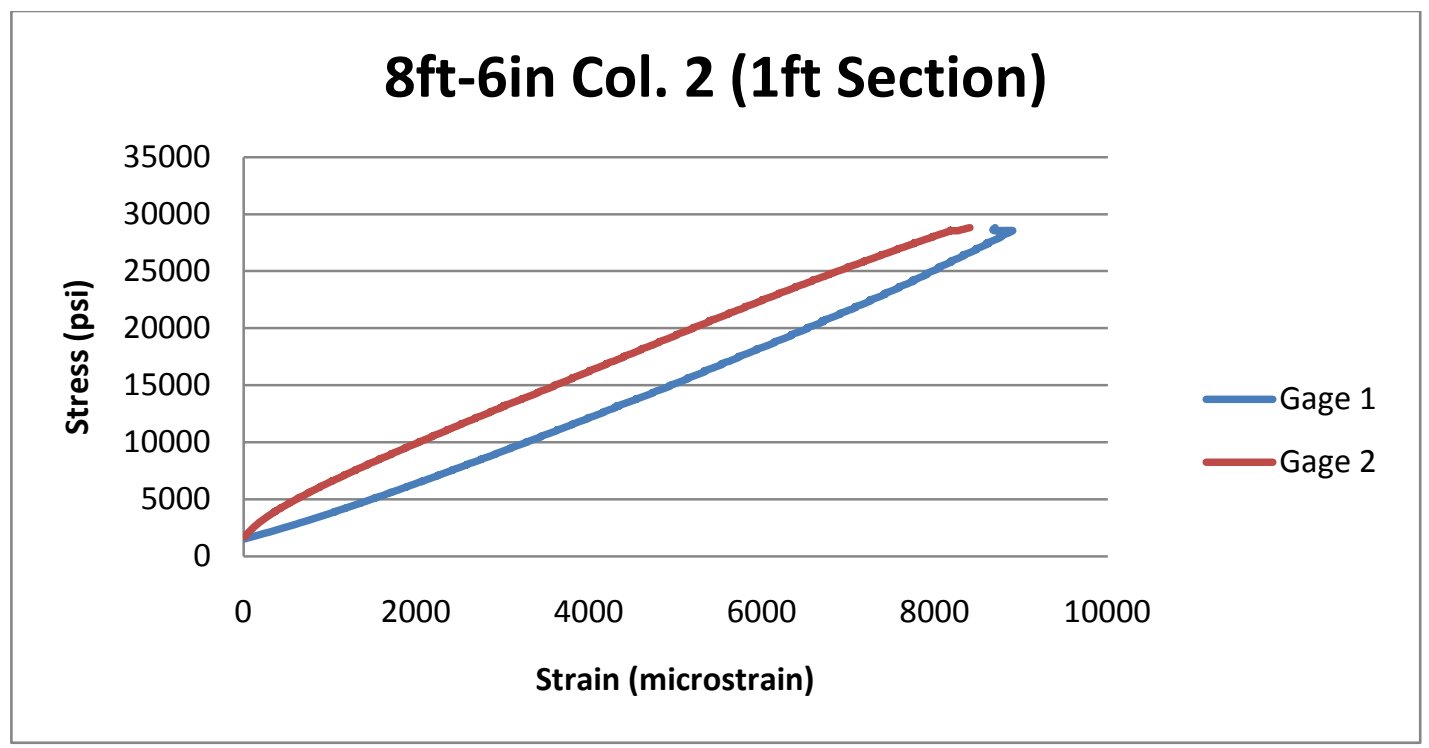

Figure 4-16 1ft Stress vs. Strain (8ft-6in Col. 2)

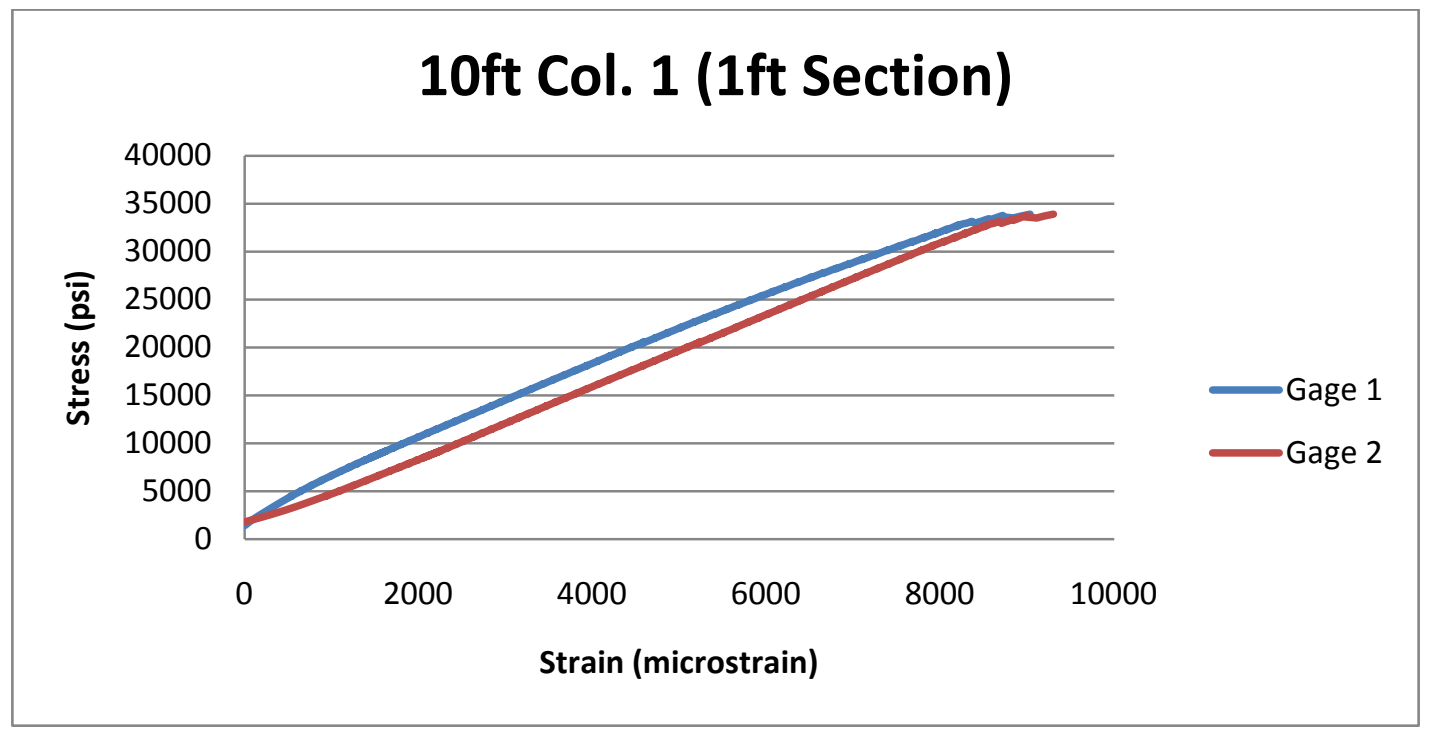

Figure 4-17 1ft Stress vs. Strain (10ft Col. 1)

The use of back to back strain gage configurations allowed for the effects of minor eccentricity of the set up to be analyzed, thus two sets of stress-strain data were obtained. An important trend between the two sets of data displayed is that at failure the stress and strain converge to yield approximately the same value, which is a direct result of minor bending during loading. (Note the remaining column lengths' 1ft “pure” compression stress-strain diagrams can be found in the Appendix) 


\subsubsection{Modulus of Elasticity}

In order to develop a "true” MOE a 4-Phase loading test was conducted. The specimen was loaded to approximately 20 kips in each phase to obtain adequate stress-strain data. The first phase consisted of applying the load to the sample under normal conditions with the position noted. During the second phase loading was repeated with the sample rotated 90 deg. The sample was then returned to its original position of phase 1 only flipped 360 deg in the longitudinal direction for phase 3 loading. Lastly, the flipped sample was then rotated 90 deg and loaded for the final time. Loading of the specimen in four different orientations allowed for average values of stress and strain to be taken from each strain gage. The underlying theory behind the loading configurations is to accurately account for any possible nonlinearity across the two ends of the specimen created during cutting.

Modulus of elasticity values were obtained by determining the effects of minor eccentricities encountered during set up, evident in the differences of the recorded strain data. These effects enabled a direct correlation between bending and axial stress allowing for a "true" modulus of elasticity to be calculated. Stress was calculated using Equation 4.1,

$$
\sigma=\frac{P}{A}+\frac{M c}{I}
$$

where both axial and bending stresses are evaluated. The corresponding load 'P', cross-sectional area 'A', moment of inertia ' $\mathrm{I}$ ', and distance to the neutral axis 'c' are all known parameters, with the only unknown lying in the bending moment, defined as the axial load ' $\mathrm{P}$ ' multiplied by “some” eccentricity 'e'. In order to accurately calculate the eccentricity, back to back strain gage configurations were used during testing in an effort to observe bending effects in the strain data. By simple substitution a direct correlation between the two sets of strain data was made. The stress was first redefined in terms of strain and MOE outlined in Equation 4.2. 


$$
\sigma=E \times \varepsilon
$$

Subsequent substitution into Equation 4.1 provided the following relationship

$$
E \varepsilon_{1}=\frac{P}{A}+\frac{P e c}{I}
$$

where, ' $\varepsilon_{1}$ ' corresponds to the first set of strain data. As a result of having two sets of strain data from each test a second equation mirroring Equation 4.3 was created

$$
E \varepsilon_{2}=\frac{P}{A}+\frac{P e c}{I}
$$

where, ' $\varepsilon_{2}$ ' corresponds to the second set of strain data. Based on the fact that MOE for a given test specimen is constant; Equations 4.3 and 4.4 can be equated to one another, where the value of ' $\mathrm{e}$ ' is then obtained.

$$
\frac{\frac{P}{A}+\frac{P e c}{I}}{\varepsilon_{1}}=\frac{\frac{P}{A}+\frac{P e c}{I}}{\varepsilon_{2}}
$$

After solving for the eccentricity 'e', the MOE was calculated by simply substituting the known value of ' $\mathrm{e}$ ' into either Equation 4.3 or 4.4. Average MOE values for each column length are tabulated below.

Table 4-10 Modulus of Elasticity (1ft Samples)

\begin{tabular}{|c|c|}
\hline Sample ID & $\begin{array}{c}\text { Compression Modulus } \\
\text { E (msi) }\end{array}$ \\
\hline $6 \mathrm{ft}$ & 3.65 \\
\hline $8 \mathrm{ft}-6 \mathrm{in}$ & 3.99 \\
\hline $9 \mathrm{ft}$ & 4.21 \\
\hline $10 \mathrm{ft}$ & 4.18 \\
\hline
\end{tabular}


The $6 \mathrm{ft}$ test specimens reported slightly lower values than the rest likely due to anomalies in the fiber configuration. This discrepancy will be further investigated in the ensuing chapters.

\subsubsection{Ultimate Strength}

Ultimate strength data including: stress, strain, and load for each sample are outlined below.

Table 4-11 Ultimate Capacity (1ft Samples)

\begin{tabular}{|c|c|c|c|c|}
\hline \multirow{2}{*}{ Sample } & Ult. Load & Ult. Stress & Ult. Strain G.1 & Ult. Strain G.2 \\
\cline { 2 - 5 } & (lbs) & (psi) & (microstrain) & (microstrain) \\
\hline 6ft \#1 & $96,429.78$ & $29,670.70$ & -- & -- \\
6ft \#2 & $93,790.74$ & $28,858.69$ & $11,594.78$ & $6,941.50$ \\
6ft \#3 & $\mathbf{6 0 , 9 0 7 . 9 3}$ & $\mathbf{1 8 , 7 4 0 . 9 0}$ & $\mathbf{7 , 1 0 3 . 0 9}$ & $\mathbf{3 , 4 3 9 . 0 0}$ \\
\hline 8ft-6in \#1 & $88,886.35$ & $27,349.65$ & -- & -- \\
8ft-6in \#2 & $85,173.02$ & $26,207.08$ & $8,273.83$ & $6,968.62$ \\
8ft-6in \#3 & $93,697.33$ & $28,829.95$ & $8,693.46$ & $8,404.84$ \\
\hline 9ft \#1 & $99,769.44$ & $30,698.29$ & -- & -- \\
9ft \#2 & $\mathbf{7 6 , 8 1 2 . 1 9}$ & $\mathbf{2 3 , 6 3 4 . 5 2}$ & $\mathbf{8 , 1 1 4 . 8 4}$ & $\mathbf{4 , 4 2 0 . 8 2}$ \\
\hline 10ft \#1 & $110,113.03$ & $33,880.93$ & $9,032.44$ & $9,303.32$ \\
10ft \#2 & $118,847.55$ & $36,568.48$ & $9,043.79$ & $8,133.73$ \\
10ft \#3 & $115,557.24$ & $35,556.07$ & -- & - \\
\hline
\end{tabular}

Failure stress is consistent within each group of column length, with the specimens cut from the $10 \mathrm{ft}$ columns having the highest failure stress and strain. The differences between the samples sets can be attributed to slight variations in fiber geometry and minor eccentricities in the loading due to test set-up. Strain values for both Gages 1 and 2 differ for each test specimen as a result of minor bending that occurs due to the minimal eccentricity of the applied load. Gages were applied in a back to back configuration longitudinally at mid-height. 


\subsubsection{Failure Modes}

Local buckling failure resulted in several failure modes including: delamination, fiber micro buckling, matrix cracking, and fiber debonding. Delamination was the most obvious and is clearly represented in Figure 4-18.

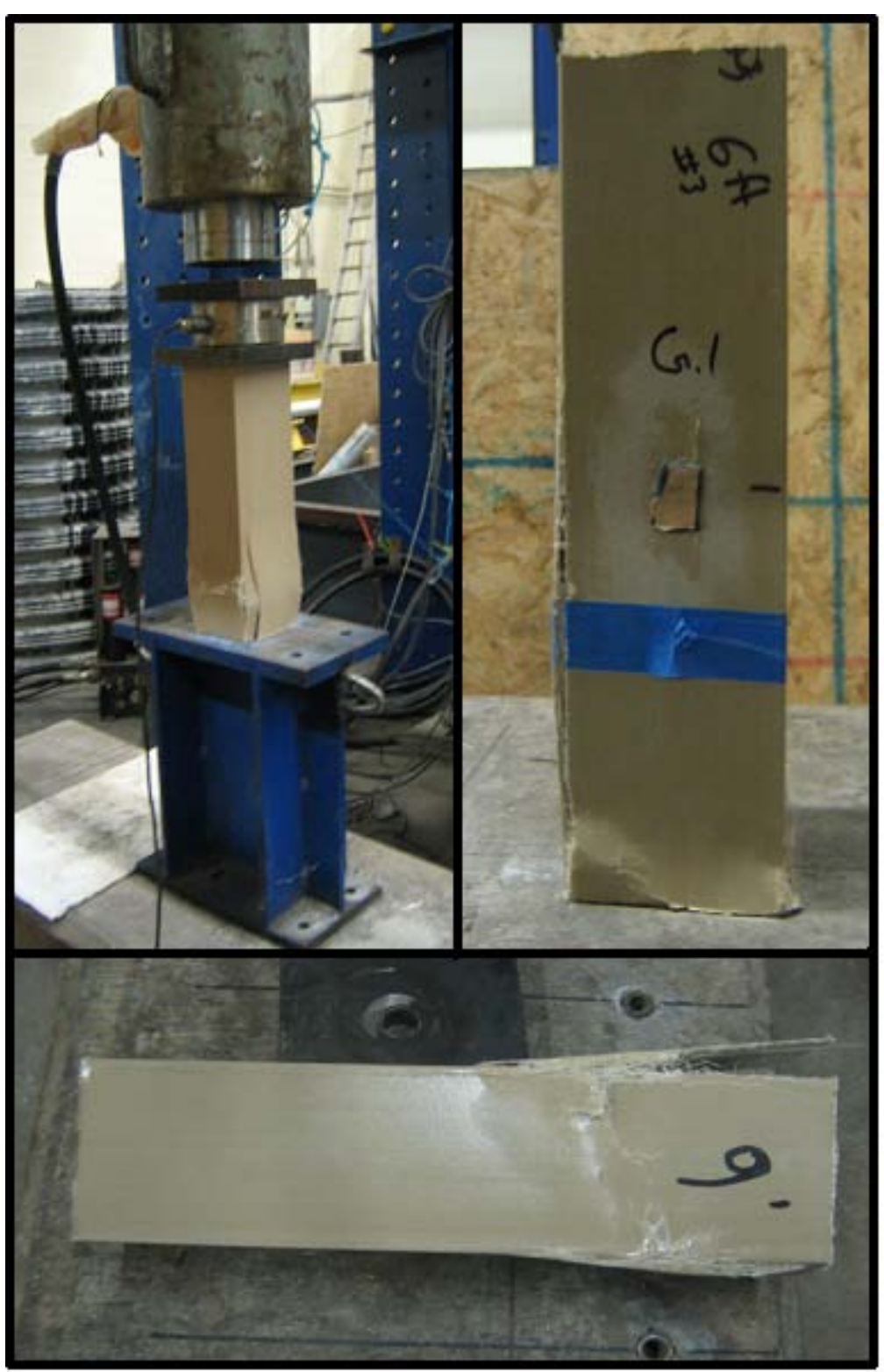

Figure 4-18 Local Buckling Failure (1ft Samples) 


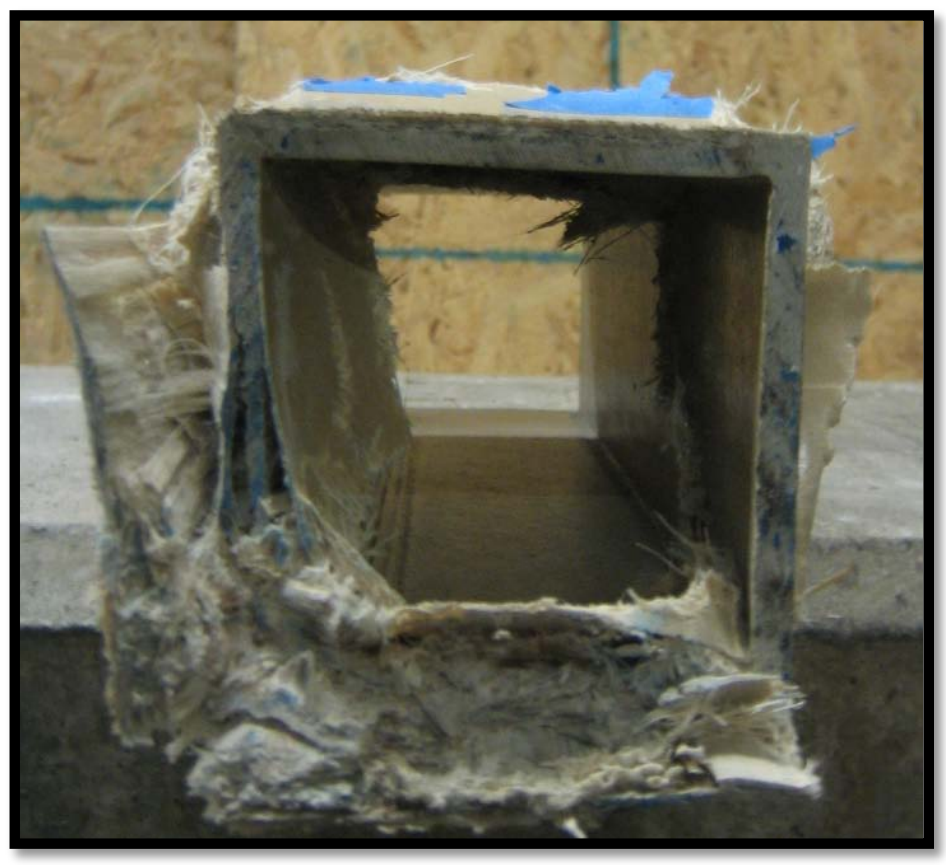

Figure 4-19 End Crushing (1ft Samples)

\subsubsection{Wide Flange Sections}

\subsubsection{Stress vs. Strain}

The primary difference between the full-length W-Flange columns and the $1 \mathrm{ft}$ samples was the minimization of the twisting of the cross-section during loading. Figure 4-20, below provides sufficient validation through displaying only minor discrepancies between the two sets of strain data. As a result of the reduction of twisting effects an appropriate MOE value could be obtained. Only the W-Flange sections with a flange width of 3" were tested in $1 \mathrm{ft}$ lengths due to the larger cross-sections showing local buckling failure in the full-length test. (Note additional W-Flange stress-strain diagrams are provided in the appendix.) 


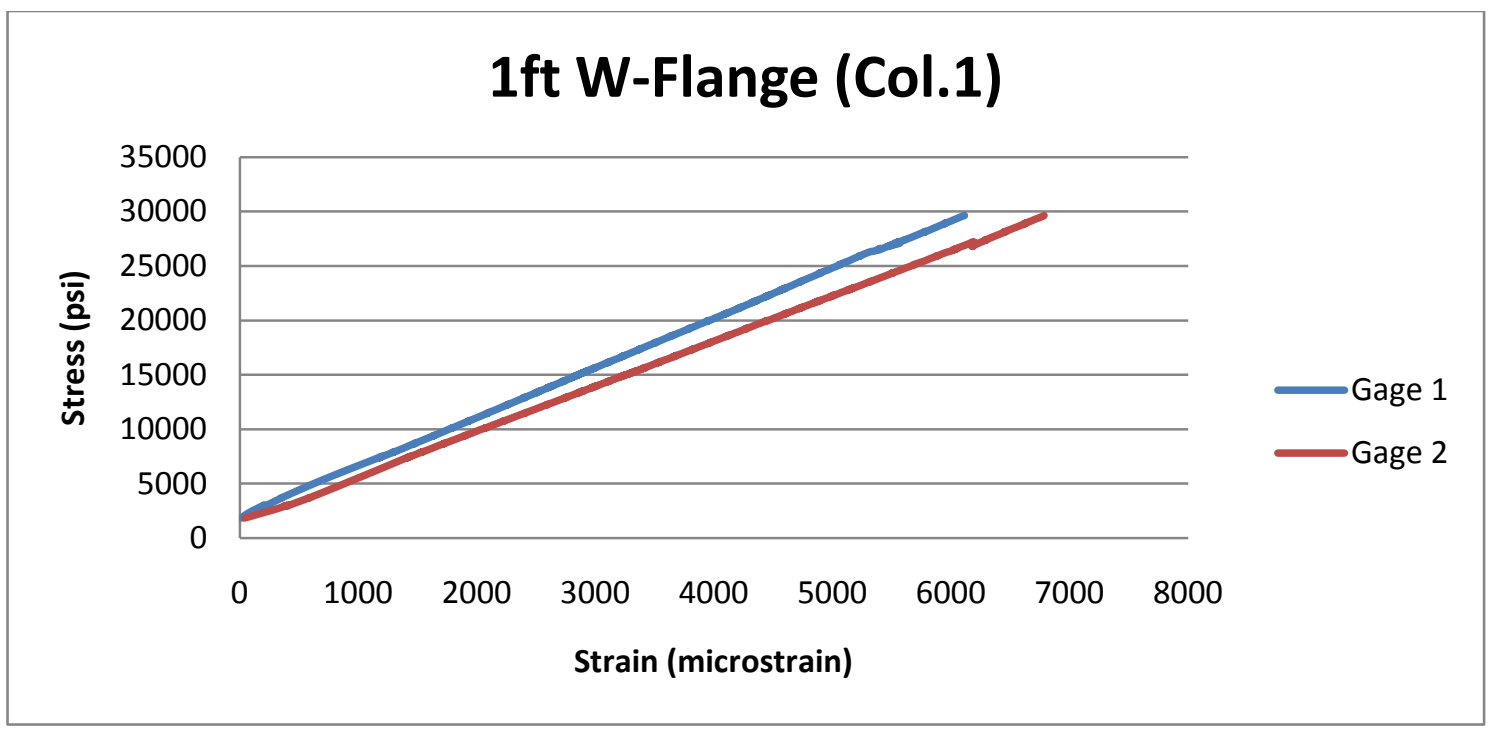

Figure 4-20 1ft W-Flange Stress vs. Strain

\subsubsection{Modulus of Elasticity}

Utilizing the 4-Phase loading test described previously, MOE values for the $1 \mathrm{ft}$ W-Flange test specimens were obtained. An average value of $4.40 \mathrm{msi}$ was obtained from the three test samples. The observed value is slightly higher than that of the hollow-box sections, which is likely a result of varied fiber geometry and the different resin system used during manufacturing.

\subsubsection{Ultimate Strength}

Failure was achieved at an average load of 61.3 kips (28.8 ksi) for the three samples tested. The significant reduction between failure load of the hollow box sections and W-Flange sections can be attributed to the reduction in moment of inertia. Strain at failure ranged from 5,100-6,100 microstrain for Gage 1 and 6,000-6,700 microstrain for Gage 2, which is comparable to ratio of strain to failure load of the hollow box sections. 


\subsubsection{Failure Modes}

Failure was driven by local buckling. Common failure patterns exhibited were: delamination, end crushing, and buckling of the web at mid-height. Figure 4-21 provides a representation of the three different test specimens and their subsequent failure modes.

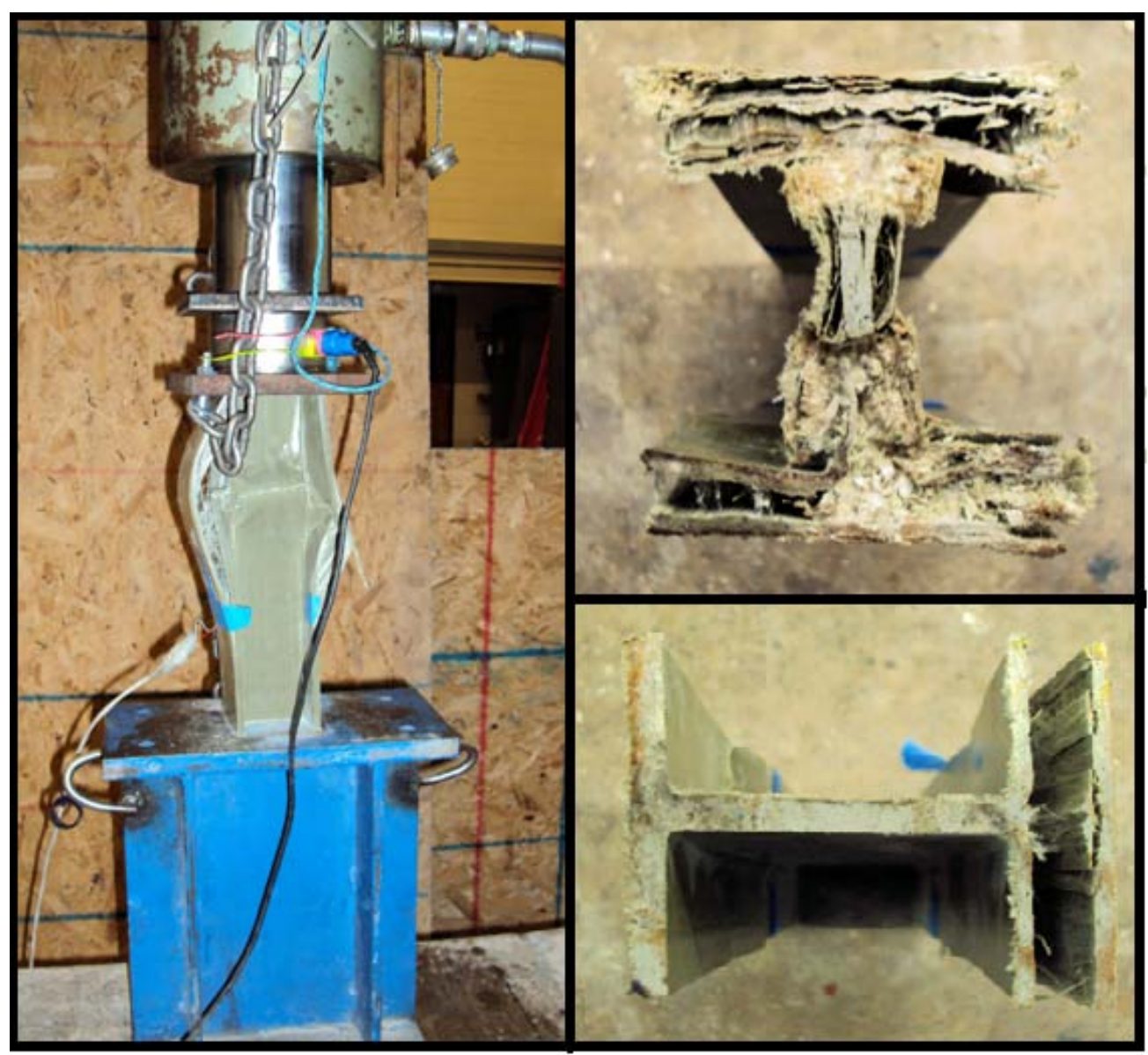

Figure 4-21 Local Buckling Failure (1ft W-Flange) 


\subsection{Coupon Testing}

\subsubsection{SACMA SRM 1R-94}

As previously stated the primary use of SACMA SRM 1R-94 testing is to produce a valid value of compressive MOE. Without the addition of tabs ultimate strength data is considered invalid, therefore ultimate strength was not investigated.

Obtaining the MOE for each specimen did not require loading to failure since only the slope of the linear portion of the stress-strain curve was needed. Modulus values for selected coupons of full-length columns are presented below.

Table 4-12 Modulus of Elasticity (Coupon)

\begin{tabular}{|c|c|}
\hline $\begin{array}{c}\text { Sample } \\
\text { ID }\end{array}$ & $\begin{array}{c}\text { Compression Modulus } \\
\text { E (msi) }\end{array}$ \\
\hline $6 \mathrm{ft}$ & 3.49 \\
\hline $8 \mathrm{ft}-6 \mathrm{in}$ & 4.03 \\
\hline $9 \mathrm{ft}$ & 4.21 \\
\hline $10 \mathrm{ft}$ & 4.16 \\
\hline
\end{tabular}

Modulus of elasticity values obtained from the coupon testing matched the "pure" compression data very closely providing sufficient evidence that the actual values of MOE for each column length are accurately represented in Table 4-12. These values also fall in the range of common MOE values for GFRP composites with primarily unidirectional reinforcement.

\subsubsection{Modified ASTM D3410}

Coupon level ultimate load and stress presented in Table 4-13 comes as a result of testing forty 1 x 1 ” $\mathrm{x}$ 1/4” samples (10 of each column length). 
Table 4-13 Coupon Ultimate Capacity

6ft Box Section

\begin{tabular}{|c|c|c|}
\hline \multicolumn{3}{|c|}{ Coupon Testing (No Fixture) } \\
\hline Sample & $\begin{array}{c}\text { Max Load } \\
\text { (lbs) }\end{array}$ & $\begin{array}{c}\text { Stress } \\
\text { (psi) }\end{array}$ \\
\hline 1 & $9,109.24$ & $36,436.95$ \\
\hline 2 & $8,132.49$ & $32,529.96$ \\
\hline 3 & $7,251.13$ & $29,004.52$ \\
\hline 4 & $7,077.50$ & $28,310.00$ \\
\hline 5 & $9,613.98$ & $38,455.92$ \\
\hline 6 & $8,563.69$ & $34,254.76$ \\
\hline 7 & $\mathbf{6 , 4 6 1 . 4 1}$ & $\mathbf{2 5 , 8 4 5 . 6 4}$ \\
\hline 8 & $10,375.60$ & $41,502.40$ \\
\hline 9 & $8,028.03$ & $32,112.12$ \\
\hline $\mathbf{1 0}$ & $\mathbf{6 , 1 9 9 . 3 5}$ & $\mathbf{2 4 , 7 9 7 . 4 0}$ \\
\hline AVERAGE & $\mathbf{8 , 5 1 8 . 9 6}$ & $\mathbf{3 4 , 0 7 5 . 8 3}$ \\
\hline STDD & $\mathbf{1 1 , 3 8 . 4 3}$ & $\mathbf{4 , 5 5 3 . 7 3}$ \\
\hline
\end{tabular}

8ft-6in Box Section

\begin{tabular}{|c|c|c|}
\hline \multicolumn{3}{|c|}{ Coupon Testing (No Fixture) } \\
\hline Sample & $\begin{array}{c}\text { Max Load } \\
\text { (lbs) }\end{array}$ & $\begin{array}{c}\text { Stress } \\
\text { (psi) }\end{array}$ \\
\hline $\mathbf{1}$ & $\mathbf{6 , 4 3 1 . 2 8}$ & $\mathbf{2 5 , 7 2 5 . 1 2}$ \\
\hline 2 & $9,541.12$ & $38,164.48$ \\
\hline 3 & $10,212.10$ & $40,848.40$ \\
\hline 4 & $11,726.00$ & $46,904.00$ \\
\hline 5 & $8,453.15$ & $33,812.60$ \\
\hline 6 & $9,711.52$ & 38846.08 \\
\hline 7 & $9,531.99$ & $38,127.96$ \\
\hline 8 & $9,547.89$ & $38,191.56$ \\
\hline 9 & $11,076.70$ & $44,306.80$ \\
\hline 10 & $10,093.00$ & $40,372.00$ \\
\hline AVERAGE & $\mathbf{9 , 9 8 8 . 1 6}$ & $\mathbf{3 9 , 9 5 2 . 6 5}$ \\
\hline STDD & $\mathbf{9 0 0 . 6 6}$ & $\mathbf{3 6 0 2 . 6 4}$ \\
\hline
\end{tabular}

Table 4-14 Coupon Ultimate Capacity

9ft Box Section

\begin{tabular}{|c|c|c|}
\hline \multicolumn{3}{|c|}{ Coupon Testing (No Fixture) } \\
\hline Sample & $\begin{array}{c}\text { Max Load } \\
\text { (lbs) }\end{array}$ & $\begin{array}{c}\text { Stress } \\
\text { (psi) }\end{array}$ \\
\hline 1 & $8,634.97$ & $34,539.88$ \\
\hline 2 & $9,014.07$ & $36,056.28$ \\
\hline 3 & $5,144.30$ & $\mathbf{2 0 , 5 7 7 . 2 0}$ \\
\hline 4 & $8,897.76$ & $35,591.04$ \\
\hline 5 & $\mathbf{6 , 9 6 2 . 6 9}$ & $\mathbf{2 7 , 8 5 0 . 7 6}$ \\
\hline 6 & $11,048.30$ & $44,193.20$ \\
\hline 7 & $8,312.08$ & $33,248.32$ \\
\hline $\mathbf{8}$ & $\mathbf{7 , 2 8 4 . 7 0}$ & $\mathbf{2 9 , 1 3 8 . 8 0}$ \\
\hline 9 & $8,285.44$ & $33,141.76$ \\
\hline 10 & $10,443.50$ & $41,774.00$ \\
\hline AVERAGE & $\mathbf{9 , 2 3 3 . 7 3}$ & $\mathbf{3 6 , 9 3 4 . 9 3}$ \\
\hline STDD & $\mathbf{1 , 2 1 5 . 8 7}$ & $\mathbf{4 , 8 6 3 . 4 9}$ \\
\hline
\end{tabular}

10ft Box Section

\begin{tabular}{|c|c|c|}
\hline \multicolumn{3}{|c|}{ Coupon Testing (No Fixture) } \\
\hline Sample & $\begin{array}{c}\text { Max Load } \\
\text { (lbs) }\end{array}$ & $\begin{array}{c}\text { Stress } \\
\text { (psi) }\end{array}$ \\
\hline 1 & $11,053.46$ & $44,213.85$ \\
\hline 2 & $10,021.87$ & $40,087.46$ \\
\hline 3 & $11,056.27$ & $44,225.06$ \\
\hline 4 & $10,730.15$ & $42,920.62$ \\
\hline 5 & $9,383.66$ & $37,534.64$ \\
\hline 6 & $10,880.60$ & $43,522.38$ \\
\hline 7 & $10,242.39$ & $40,969.55$ \\
\hline $\mathbf{8}$ & $\mathbf{7 , 9 3 5 . 4 7}$ & $\mathbf{3 1 , 7 4 1 . 8 7}$ \\
\hline 9 & $11,061.87$ & $44,247.49$ \\
\hline $\mathbf{1 0}$ & $\mathbf{7 , 3 7 5 . 2 8}$ & $\mathbf{2 9 , 5 0 1 . 1 4}$ \\
\hline AVERAGE & $\mathbf{1 0 , 5 5 3 . 7 8}$ & $\mathbf{4 2 , 2 1 5 . 1 3}$ \\
\hline STDD & $\mathbf{6 1 4 . 9 7}$ & $\mathbf{2 , 4 5 9 . 8 9}$ \\
\hline
\end{tabular}


For a given set of coupons taken from the desired column length the ultimate stress and load provided a reasonable standard deviation. Outliers, when present, were likely a result of the coupon not being placed exactly vertical during testing. When one set of coupons from a specific column length is compared to another column length there is a reasonable correlation if varied fiber geometry and minor imperfections of test set-up are considered. The range of failure stress for the entire thirty samples is $36.9-42.2 \mathrm{psi}$ (neglecting $6 \mathrm{ft}$ column data due to variances in MOE, which are further discussed in the ensuing Chapters).

Delamination coupled with fiber micro buckling was the prominent failure mode observed, noted in Figure 4-22 below.

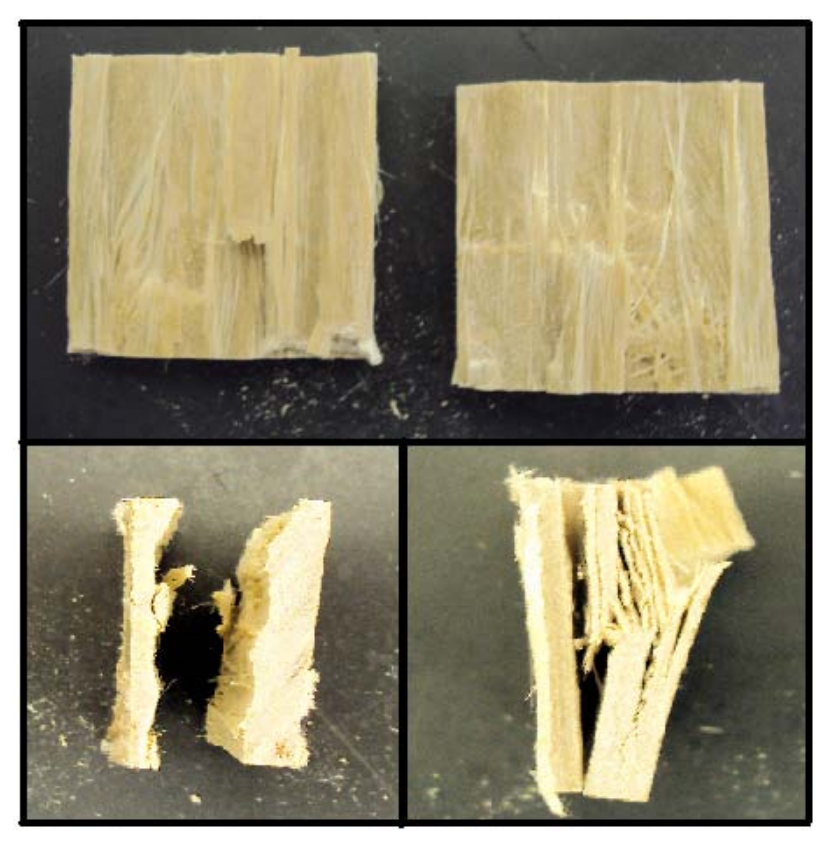

Figure 4-22 Coupon Delamination 


\section{CHAPTER 5 EVALUATION/DISCUSSION OF RESULTS}

\subsection{Strength Prediction}

Developing an appropriate and accurate strength prediction model for GFRP composite columns is essential for their subsequent progression into structural engineering industry. Included in this chapter are several proposed prediction methods. Each method is compared with experimental data to arrive at a simple yet accurate model for use in design.

\subsubsection{Critical Buckling Load by Southwell}

Applying Southwell's technique to estimate the buckling load of a test specimen based on experimental load and mid-point deflection to GFRP composite columns was previously attempted by Zureick (1997) with reasonable success. The predicted buckling load is obtained by taking the inverse slope of the linear portion of the graph created when mid-point deflection is plotted against the same deflection divided by the corresponding load (see Figure 5-1). In this research Southwell's technique has been applied to a range of column lengths for both of the tested cross-section types (Hollow Box and Wide Flange). Summarized below are comparisons between the experimental buckling load and the estimated critical buckling load provided by Southwell analysis. Graphical representations of the Southwell prediction model are also provided (Section 5.1.1.1).

\subsubsection{Hollow Box Sections}

Each of the four different lengths of hollow box sections tested (6ft, 8ft-6in, 9ft, 10ft) provided decent correlation $\left(\mathrm{R}^{2} \sim\right.$.998) between actual failure and predicted buckling load. 
Southwell plots for the four column lengths are presented below. Additional plots for each of the tested columns of different lengths are provided in the Appendix.

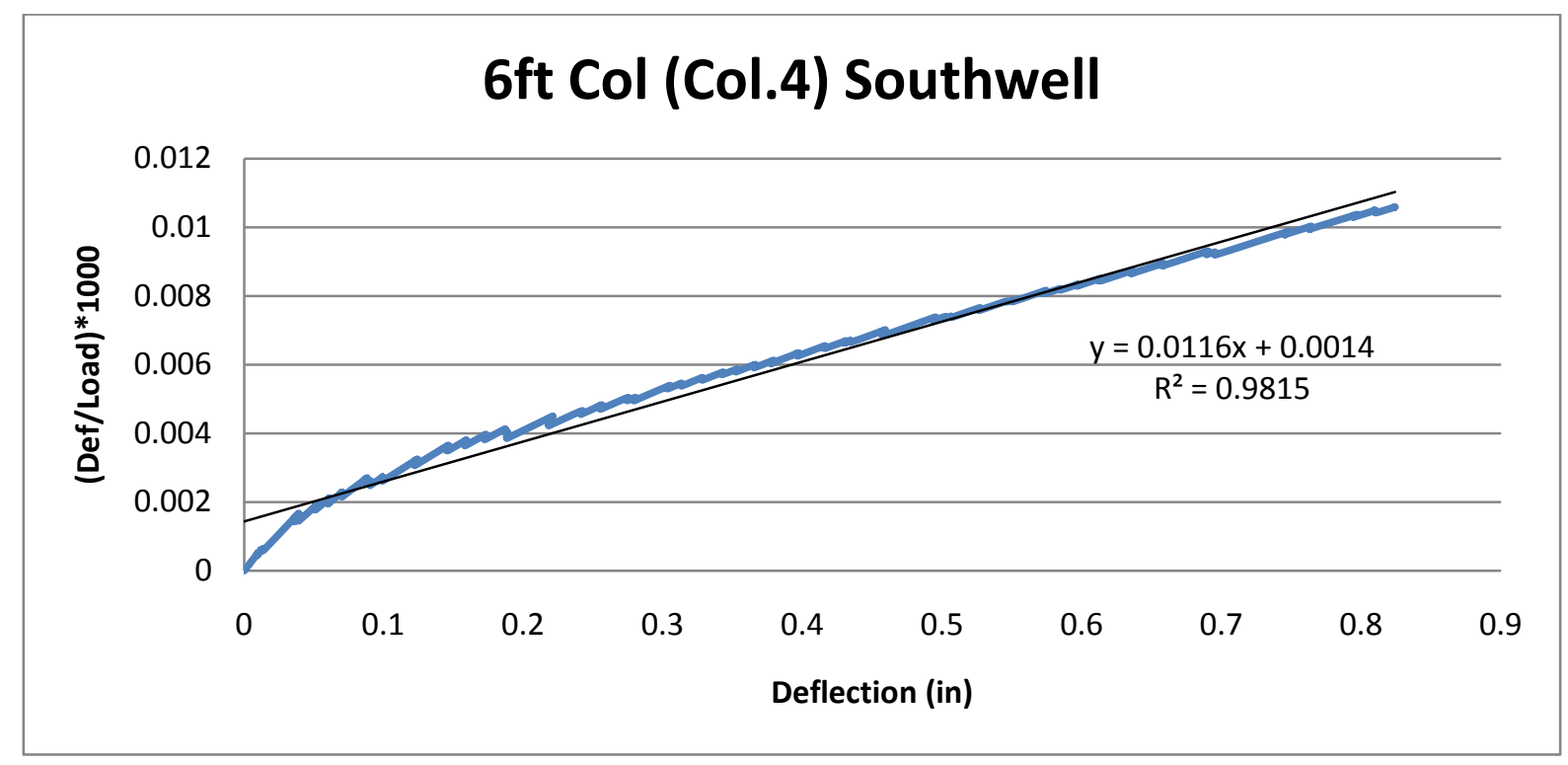

Figure 5-1 Southwell Plot (6ft Column)

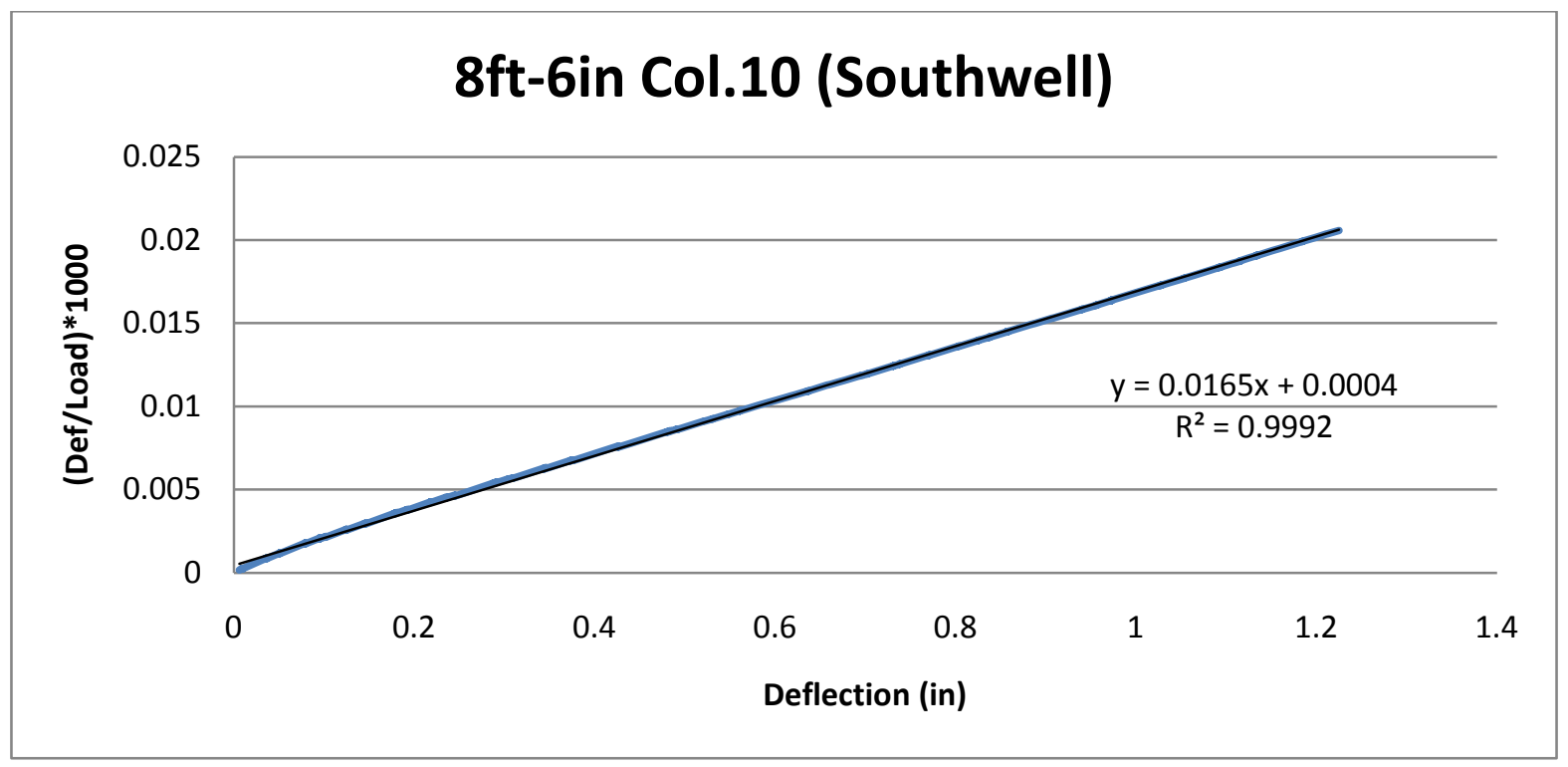

Figure 5-2 Southwell Plot (8ft-6in Column) 


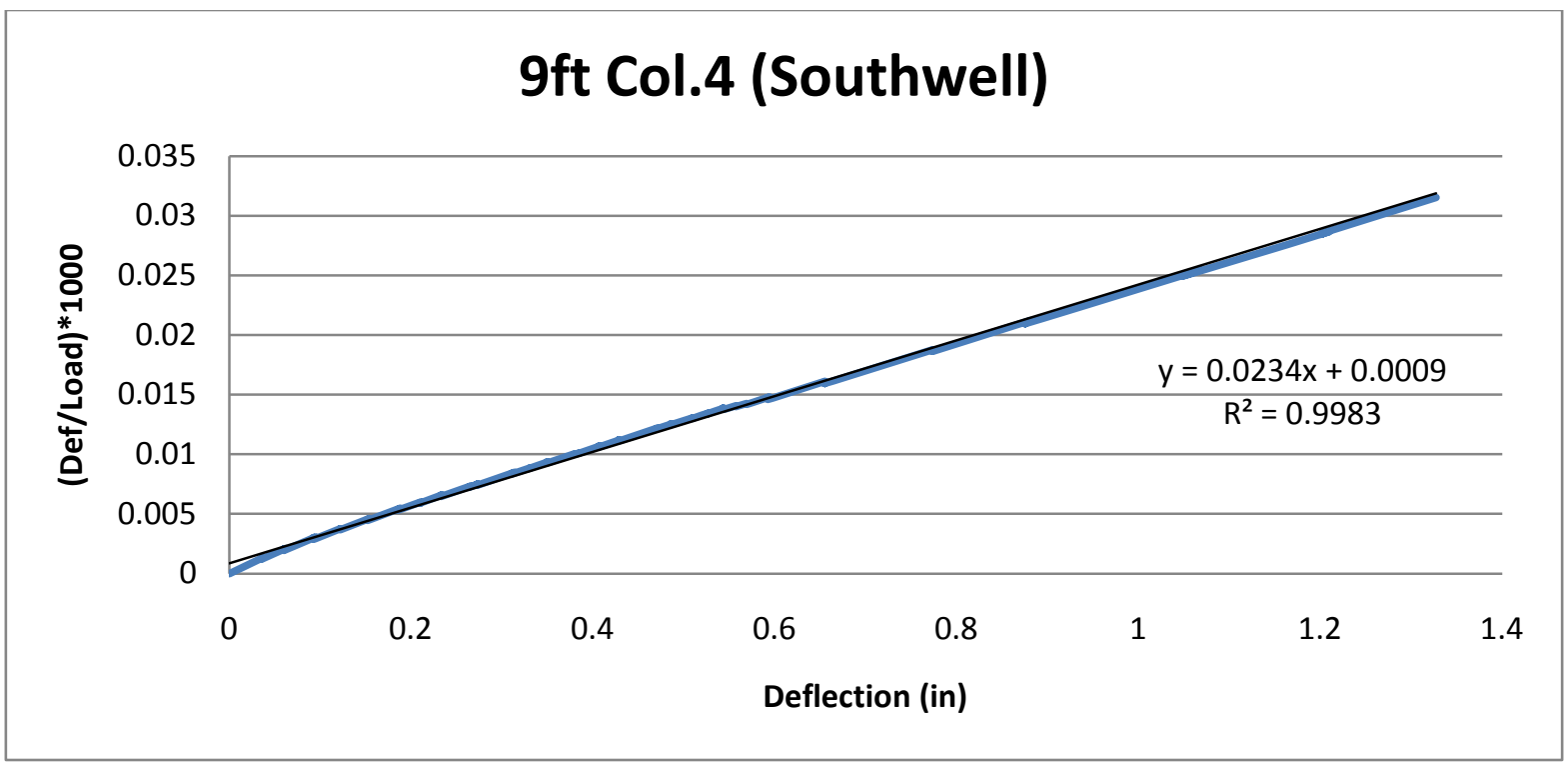

Figure 5-3 Southwell Plot (9ft Column)

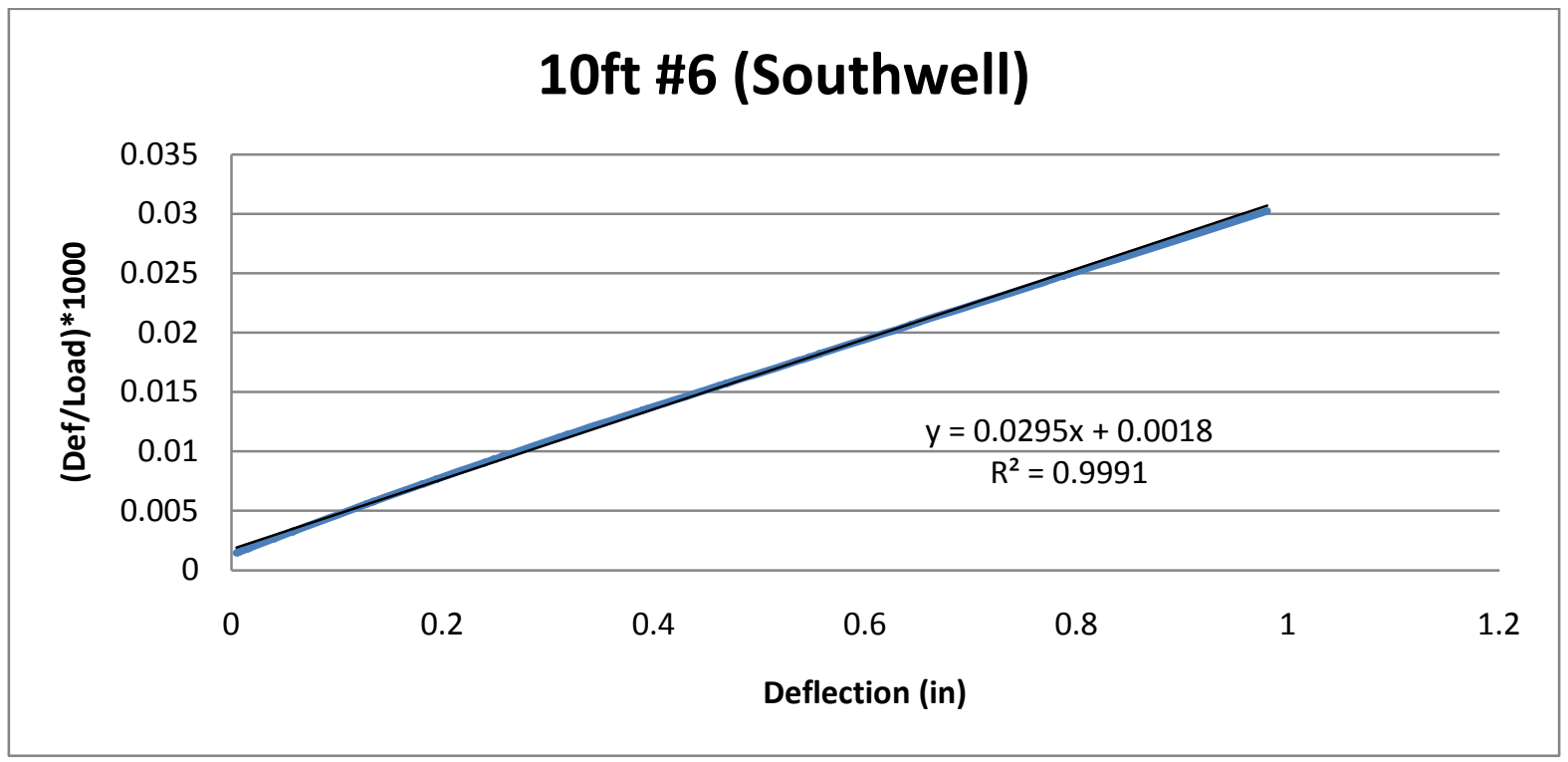

Figure 5-4 Southwell Plot (10ft Column)

As noted in Figures 5.1 to 5.4, a linear relationship between deflection versus deflection/load is apparent for each of the tested column lengths. Six foot columns provided the maximum scatter in relation to $8 \mathrm{ft}-6 \mathrm{in}, 9 \mathrm{ft}$, and $10 \mathrm{ft}$ lengths, potentially due to their shorter length preventing substantial global buckling coupled with a greater influence of boundary conditions. Minor eccentricities among the test samples created during test set-up play a 
significant role in the accuracy of the model and will be further investigated in Section 5.2; however it is worth noting that the $6 \mathrm{ft}$ columns experienced the greatest amount of average eccentricity of all the test samples (Section 5.2). Experimental error due to taking up slack and alignment of the test specimen also greatly impacts the linearity of the Southwell plot and subsequent modifications are needed in order to produce an acceptable prediction of the buckling load.

The ratio of predicted buckling load to the experimentally derived buckling load is consistent with previous research of GFRP composite columns. Typically the Southwell method, as expected, produces a critical buckling load slightly higher than the actual failure load since in theory at the point of global buckling a test specimen will undergo an increase in midpoint deflection while experiencing only slight change(s) in load. The failure load for each column length, both predicted and experimentally obtained is presented below, including the corresponding ratio of the two.

Table 5-1 Summary of Southwell Loads (6ft Columns)

\begin{tabular}{|c|c|c|c|}
\hline Sample \# & Southwell Load (kip) & $\begin{array}{c}\text { Max Load Exp. } \\
\text { (kip) }\end{array}$ & Exp. Load/Southwell \\
\hline 1 & 86.96 & 67.87 & 0.78 \\
2 & 90.91 & 72.80 & 0.80 \\
3 & 105.30 & $\mathbf{7 2 . 8 4}$ & $\mathbf{0 . 6 9}$ \\
4 & 86.20 & 77.84 & 0.90 \\
5 & 96.15 & 73.61 & 0.77 \\
6 & 105.30 & 84.82 & 0.81 \\
7 & 100.00 & 80.25 & 0.80 \\
8 & 78.84 & 67.45 & 0.86 \\
9 & 75.19 & 57.40 & 0.76 \\
10 & 86.21 & 64.32 & 0.75 \\
11 & 109.90 & $\mathbf{6 4 . 8 8}$ & $\mathbf{0 . 5 9}$ \\
12 & 54.50 & 50.49 & 0.93 \\
\hline AVERAGE & $\mathbf{8 6 . 0 3}$ & $\mathbf{6 9 . 6 8}$ & $\mathbf{0 . 8 1}$ \\
\hline
\end{tabular}


Table 5-2 Summary of Southwell Loads (8ft-6in Columns)

\begin{tabular}{|c|c|c|c|}
\hline Sample \# & Southwell Load (kip) & $\begin{array}{c}\text { Max Load Exp. } \\
\text { (kip) }\end{array}$ & Exp. Load/Southwell \\
\hline 1 & 42.37 & 40.63 & 0.96 \\
2 & 54.35 & 47.89 & 0.88 \\
3 & 56.18 & 52.78 & 0.94 \\
$\mathbf{4}$ & 43.10 & $\mathbf{3 2 . 2 3}$ & $\mathbf{0 . 7 5}$ \\
5 & 62.11 & 61.61 & 0.99 \\
6 & 55.56 & 54.16 & 0.97 \\
7 & 54.05 & 50.70 & 0.94 \\
8 & 58.14 & 54.23 & 0.93 \\
9 & 52.36 & 53.53 & 1.02 \\
10 & 60.61 & 59.55 & 0.98 \\
11 & 54.05 & 50.66 & 0.94 \\
12 & $\mathbf{8 1 . 9 7}$ & $\mathbf{5 0 . 1 4}$ & $\mathbf{0 . 6 1}$ \\
\hline AVERAGE & $\mathbf{5 4 . 9 8}$ & $\mathbf{5 2 . 5 7}$ & $\mathbf{0 . 9 6}$ \\
\hline
\end{tabular}

Table 5-3 Summary of Southwell Loads (9ft Columns)

\begin{tabular}{|c|c|c|c|}
\hline Sample \# & $\begin{array}{c}\text { Southwell Load } \\
\text { (kip) }\end{array}$ & $\begin{array}{c}\text { Max Load Exp. } \\
\text { (kip) }\end{array}$ & Exp. Load/Southwell \\
\hline 1 & 39.06 & 38.39 & 0.98 \\
2 & 44.44 & 38.74 & 0.87 \\
3 & 41.15 & 34.94 & 0.85 \\
4 & 42.74 & 42.20 & 0.99 \\
5 & 38.61 & 34.00 & 0.88 \\
6 & 48.54 & 40.89 & 0.84 \\
7 & 40.32 & 34.63 & 0.86 \\
8 & 41.32 & 41.90 & 1.01 \\
9 & 46.51 & 36.97 & 0.79 \\
10 & 38.61 & 39.26 & 1.02 \\
11 & 47.39 & 47.69 & 1.01 \\
12 & 46.73 & 38.32 & 0.82 \\
\hline AVERAGE & 42.95 & 39.00 & $\mathbf{0 . 9 1}$ \\
\hline
\end{tabular}


Table 5-4 Summary of Southwell Loads (10ft Columns)

\begin{tabular}{|c|c|c|c|}
\hline Sample \# & $\begin{array}{c}\text { Southwell Load } \\
\text { (kip) }\end{array}$ & $\begin{array}{c}\text { Max Load Exp. } \\
\text { (kip) }\end{array}$ & Exp. Load/Southwell \\
\hline 1 & 34.01 & 30.97 & 0.91 \\
2 & $\mathbf{2 2 . 4 2}$ & $\mathbf{2 1 . 3 7}$ & $\mathbf{0 . 9 5}$ \\
3 & $\mathbf{6 0 . 6 1}$ & $\mathbf{3 4 . 3 4}$ & $\mathbf{0 . 5 7}$ \\
4 & $\mathbf{5 5 . 8 7}$ & $\mathbf{4 0 . 3 6}$ & $\mathbf{0 . 7 2}$ \\
5 & 34.97 & 35.69 & 1.02 \\
6 & 33.90 & 33.61 & 0.99 \\
7 & 29.85 & 29.05 & 0.97 \\
8 & 38.17 & 37.12 & 0.97 \\
9 & 39.22 & 37.88 & 0.97 \\
10 & 34.13 & 33.55 & 0.98 \\
\hline AVERAGE & $\mathbf{3 4 . 8 9}$ & $\mathbf{3 3 . 9 8}$ & $\mathbf{0 . 9 7}$ \\
\hline
\end{tabular}

Typically the ratio of Southwell load to experimental failure load is above $90 \%$. As noted in the provided tables, the longer length columns (8ft-6in, $9 \mathrm{ft}$, 10ft) all conform to this trend. The 6ft columns present a lower ratio (.81), which is attributed to minimal global buckling effects present up until failure, as compared to other column lengths (8ft-6in, 9ft, 10ft).

\subsubsection{Wide Flange Sections}

Six foot W-Flange sections of two different flange widths (3" \& 6”) were evaluated using the Southwell prediction model. The columns with larger cross sections (6” Flange) provided an extremely poor correlation with the Southwell critical buckling load. This is a direct result of the columns failing due to local buckling. The presence of experimental error affected the open section columns much more greatly than the closed sectioned columns, which is evident in a larger discrepancy between actual and predicated failure load. The following figures present a graphical representation of Southwell's method for the W-Flange sections. 


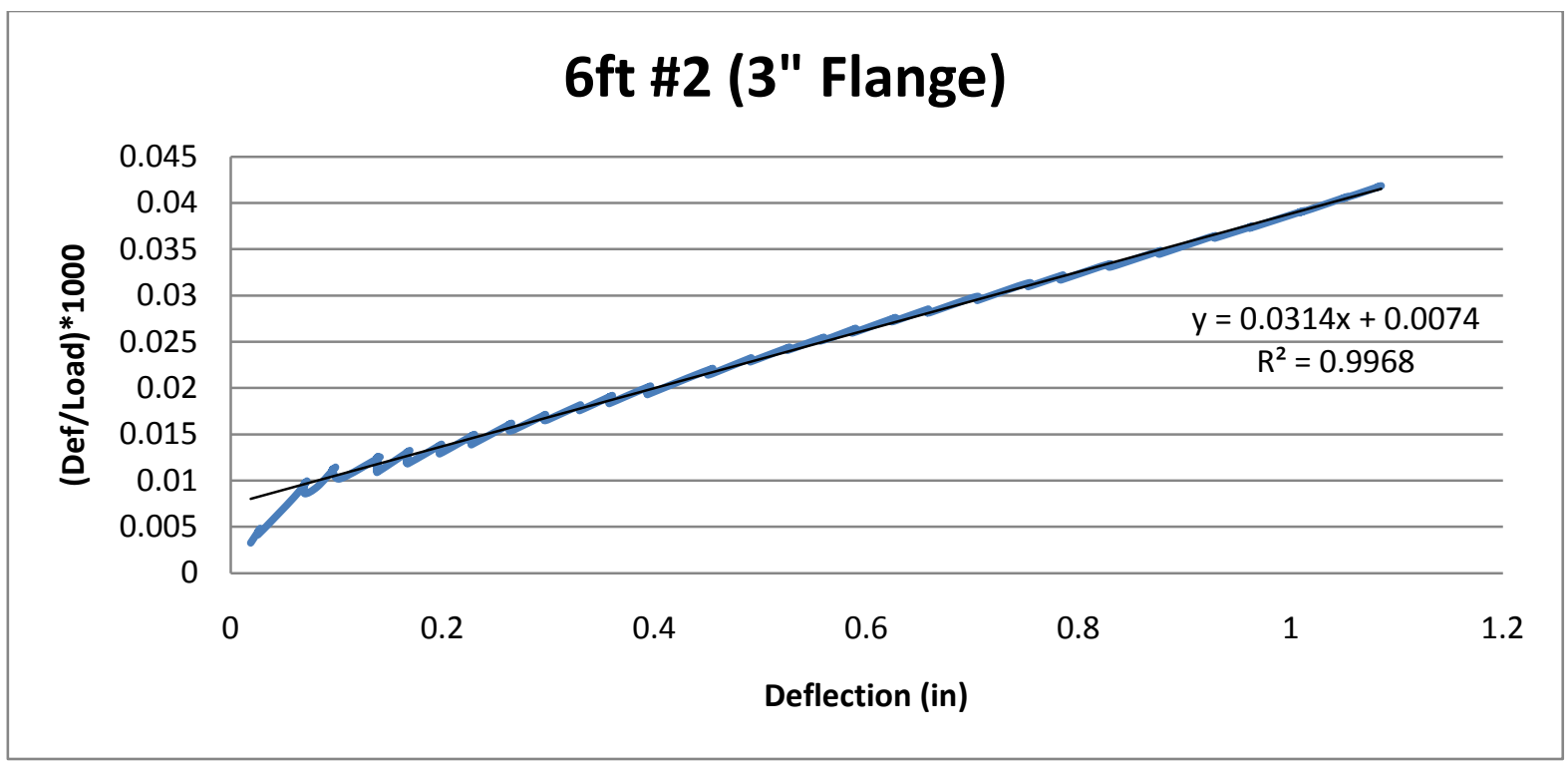

Figure 5-5 Southwell Plot (3" Flange)

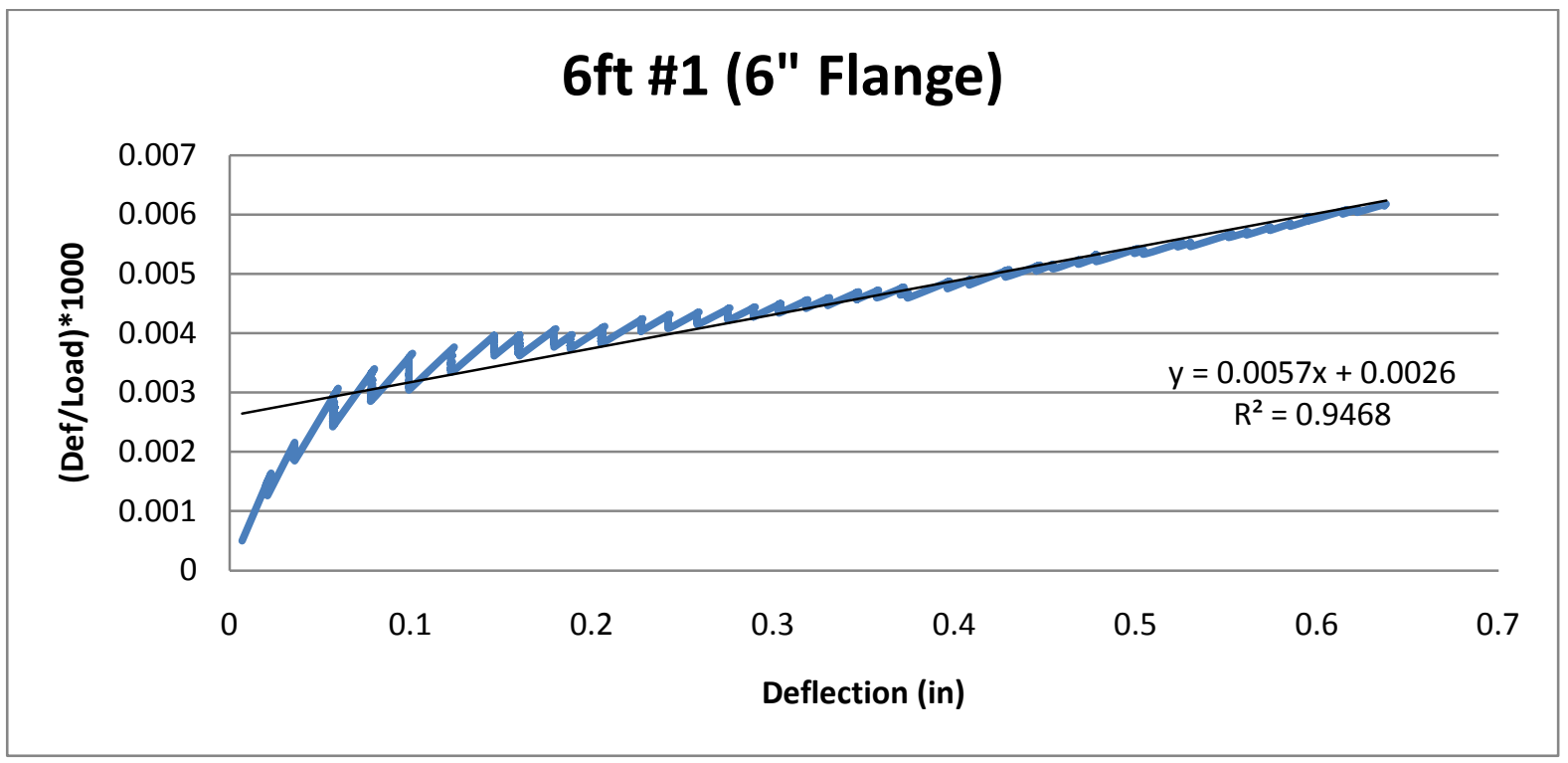

Figure 5-6 Southwell Plot (6" Flange)

The ratio of experimental load to predicted load for the W-Flange sections was significantly lower than the ideal range (.85-1.0). The columns with a 3" flange provided a reasonable representation however; the 6” flanged sections failed to accurately derive the critical buckling load. As previously stated this is a direct result of local buckling failure (Figure 4-15). 
Table 5-5 Summary of Southwell Loads (3" Flange)

\begin{tabular}{|c|c|c|c|}
\hline Sample \# & $\begin{array}{c}\text { Southwell Load } \\
\text { (kip) }\end{array}$ & $\begin{array}{c}\text { Max Load Exp. } \\
\text { (kip) }\end{array}$ & Exp. Load/Southwell \\
\hline 1 & 25.84 & 21.59 & 0.84 \\
2 & 31.85 & 25.94 & 0.81 \\
3 & 26.81 & 20.65 & 0.77 \\
\hline AVERAGE & $\mathbf{2 8 . 1 7}$ & $\mathbf{2 2 . 7 3}$ & $\mathbf{0 . 8 1}$ \\
\hline
\end{tabular}

Table 5-6 Summary of Southwell Loads (6" Flange)

\begin{tabular}{|c|c|c|c|}
\hline Sample \# & $\begin{array}{c}\text { Southwell Load } \\
\text { (kip) }\end{array}$ & $\begin{array}{c}\text { Max Load Exp. } \\
\text { (kip) }\end{array}$ & Exp. Load/Southwell \\
\hline 1 & 175.44 & 103.69 & 0.59 \\
2 & 200 & 95.33 & 0.48 \\
3 & 1111 & 122.53 & $\mathbf{0 . 1 1}$ \\
\hline AVERAGE & $\mathbf{1 8 7 . 7 2}$ & $\mathbf{9 9 . 5 1}$ & $\mathbf{0 . 5 3 5}$ \\
\hline
\end{tabular}

Overall, Southwell's method has proven to effectively calculate the critical buckling load of GFRP composite columns comprised of closed cross sections. Hollow box sectioned columns of lengths exceeding 6ft showed the least deviation between predicted and actual failure. Wide flange sections exhibited a larger scatter between the two loads, primarily in the case of larger flange widths.

Although Southwell's method provided fairly accurate results, it is limited in terms of a prediction model due to the necessity of experimental results required for its implementation. Experimental error in the initial loading stages coupled with minor eccentricities in column alignment during test set-up greatly impacts the final results, therefore experience in appropriate data reduction methods is needed. 


\subsubsection{Critical Load by Euler Buckling}

Critical buckling load of GFRP composite columns using the standard Euler Buckling equation was first attempted by Goodman and Gilksman (1969) and further investigated by Hewson (1978). Due to an initial poor correlation between predicted failure and experimentally determined failure, Hewson proposed modifying the MOE value utilized in the equation to represent the MOE of the test specimen only in the longitudinal direction of loading. This slight deviation produced a 5-11\% difference between predicted and actual experimental failure loads, which is a much more reasonable standard deviation. The Euler buckling equation is presented below,

$$
P_{E}=\frac{\pi^{2} E_{L} I}{(K L)^{2}}
$$

where $I=$ moment of inertia about the minor principal axis; $L=$ length of sample; $K=$ effective length factor based on support conditions.

\subsubsection{Hollow Box Sections}

Average experimental failure for each of the four tested column lengths was tabulated and compared to the predicted Euler buckling failure load. Modulus of elasticity values were obtained from the $1 \mathrm{ft}$ "Pure" compression tests utilizing the 4-Phase loading technique outlined previously. Effective length factors ' $K$ ' were estimated to be within the range of 0.5-1.0, signifying that support conditions of our test setup were somewhere between fully restrained and pinned-pinned. The 10ft columns' effective length factor was slightly reduced due to minor modifications made to the loading fixture (Figure 3-4). The failure load for each column length, both predicted and experimental is presented below, which includes the ratio of the two. 
Table 5-7 Summary of Euler Buckling Loads

\begin{tabular}{|c|c|c|c|c|c|}
\hline $\begin{array}{c}\text { Column } \\
\text { Length } \\
\text { (ft) }\end{array}$ & $\begin{array}{c}\text { E } \\
\text { (msi) }\end{array}$ & $\begin{array}{c}\text { Eff. Length } \\
\text { Factor } \\
\text { (K) }\end{array}$ & $\begin{array}{c}\text { Euler Buckling } \\
\text { (Eq. 5.1) } \\
\text { (kip) }\end{array}$ & $\begin{array}{c}\text { Max Exp. } \\
\text { Load } \\
\text { (kip) }\end{array}$ & $\begin{array}{c}\text { Exp. } \\
\text { Load/Euler }\end{array}$ \\
\hline $6 \mathrm{ft}$ & 3.66 & 0.75 & 71.35 & 69.55 & 0.97 \\
$8 \mathrm{ft}-6 \mathrm{in}$ & 3.99 & 0.70 & 44.49 & 50.68 & 1.14 \\
$9 \mathrm{ft}$ & 4.21 & 0.70 & 41.88 & 39.00 & 0.93 \\
$10 \mathrm{ft}$ & 4.18 & 0.68 & 35.69 & 33.98 & 0.95 \\
\hline
\end{tabular}

The Euler buckling load is highly dependent upon the effective length factor ' $\mathrm{K}$ ' and MOE ' $E$ ' which is highlighted in differences between the ratio of predicted Euler buckling load to maximum experimental load. The ratio is above $90 \%$ for each of the column lengths, with the 8ft-6in columns having a ratio above 1.0. If the effective length factor of 0.70 is reduced further the 8ft-6in columns would follow the trends observed by the other column lengths. However, this is not practical due to the fact that as the column length increases the support conditions move further away from a fully restrained response which is quantified by an increase in the effective length factor ' $\mathrm{K}$ '.

\subsubsection{Wide Flange Sections}

Six foot wide flange sections were also evaluated using the standard Euler buckling equation. Due to a minimal amount of global buckling experienced in short columns with a large cross section the 6" flanged columns were deemed inappropriate for comparison with the Euler buckling equation, therefore only the response of the 3” flanged columns is presented herein.

Unlike the hollow box sections which maintained a constant cross section across each principal axis, the W-Flange sections contained both weak and strong axis in bending. Due to excessive bending stress and deflection about the weak axis during loading, defining the appropriate failure mode based on support conditions is not easy. Therefore, a range of effective 
length factors were attempted in the Euler buckling analysis, as noted below, to theoretically evaluate the buckling load and compare with experimental data.

Table 5-8 Summary of Euler Buckling Loads (3" W-Flange)

\begin{tabular}{|c|c|c|c|c|c|}
\hline $\begin{array}{c}\text { Column } \\
\text { Length } \\
(\mathrm{ft})\end{array}$ & $\begin{array}{c}\mathrm{E} \\
(\mathrm{msi})\end{array}$ & $\begin{array}{c}\text { Eff. Length } \\
\text { Factor } \\
(\mathrm{K})\end{array}$ & $\begin{array}{c}\text { Euler } \\
\text { Buckling } \\
(\text { kip) }\end{array}$ & $\begin{array}{c}\text { Max Exp. } \\
\text { Load } \\
(\mathrm{kip})\end{array}$ & $\begin{array}{c}\text { Exp. } \\
\text { Load/Euler }\end{array}$ \\
\hline $6 \mathrm{ft}$ & 4.40 & 0.65 & 22.37 & 22.73 & 1.02 \\
$6 \mathrm{ft}$ & 4.40 & 0.70 & 19.28 & 22.73 & 1.18 \\
$6 \mathrm{ft}$ & 4.40 & 0.75 & 16.80 & 22.73 & 1.35 \\
$6 \mathrm{ft}$ & 4.40 & 0.80 & 14.76 & 22.73 & 1.54 \\
$6 \mathrm{ft}$ & 4.40 & 0.85 & 13.08 & 22.73 & 1.74 \\
$6 \mathrm{ft}$ & 4.40 & 0.90 & 11.67 & 22.73 & 1.95 \\
\hline
\end{tabular}

As noted in Table 5-8, the relationship between predicted load and maximum experimental load became more accurate with the decrease in effective length factor. This implies that under the given loading conditions the 3" W-Flange columns were acting more like a fixed-fixed system versus a fully pinned system. A similar trend was observed within the data obtained from the $6 \mathrm{ft}$ closed sectioned columns tested previously.

Modulus of elasticity values used in the analysis were obtained from the aforementioned 4Phase "pure" compression loading test. The maximum experimental failure load is the average value of the three full length column tests.

\subsubsection{Critical Load Proposed by F. Engesser}

Further investigation of glass and carbon fiber reinforced composites (GFRP/CFRP) by Lee and Hewson (1978), yielded the following estimation for the critical load of axially loaded members first proposed by Engesser in 1989, 


$$
P_{e}=\frac{P_{E}}{1+\left(\frac{n_{S} P_{E}}{A_{g} G_{L T}}\right)}
$$

where $P_{E}=$ Euler buckling load; $n_{s}=$ shear shape factor depending on cross-section (Zureick \& Scott, 1997); $A_{g}=$ gross area; $G_{L T}=$ shear modulus. The inclusion of parameters pertaining to shear deformation is of significance because of the high $E_{L} / G_{L T}$ ratio that polymer composites typically display (Zureick \& Scott, 1997).

Shear modulus was calculated by two different methods for comparison purposes. Utilizing a mechanics of materials approach the Periodic Microstructure Model (PMM) shown below, was implemented (Barbero, 1998).

$$
G_{12}=G_{m}\left[1+\frac{V_{f}\left(1-G_{m} / G_{f}\right)}{G_{m} / G_{f}+S_{3}\left(1-G_{m} / G_{f}\right)}\right]
$$

where,

$$
S_{3}=.49247-.47603 V_{f}-.02748 V_{f}^{2}
$$

Where, $V_{f}=$ fiber volume fraction, $G_{m}=$ shear modulus of matrix, and $G_{f}=$ shear modulus of fiber. All test specimens were provided by Bedford Reinforced Plastics Inc. with Type E Glass fibers and roving $\left(V_{\mathrm{f}}=.41 \mathrm{G}_{\mathrm{f}}=4300 \mathrm{ksi}\right)$ and a vinyl ester matrix $\left(\mathrm{G}_{\mathrm{m}}=179 \mathrm{ksi}\right)$ yielding a shear modulus ' $\mathrm{G}_{\mathrm{LT}}$ ' of $396 \mathrm{ksi}$.

Experimental flexural and transverse shear properties of pultruded GFRP profiles were determined by performing three point bending tests of $4 \mathrm{ft}$ sections cut from full length columns. Utilizing the following relationship developed by Roberts and Masri, the transverse shear modulus was obtained (Roberts \& Masri, 2003).

$$
\frac{w_{3}}{P a}=\frac{a^{2}}{6 E_{b} I}+\frac{1}{2 G_{t} K A}
$$


Where, ' $\mathrm{w}_{3}$ ' is the central deflection, ' $\mathrm{A}$ ' is the area of the cross-section, ' $\mathrm{K}$ ' is the shear coefficient, 'a' is the distance from the support to the applied load, 'I' is the moment of inertia, ' $\mathrm{E}_{\mathrm{b}}$ ' is the flexural MOE, and ' $\mathrm{G}_{\mathrm{t}}$ ' is the transverse shear modulus.

Based on the assumption that the MOE of pultruded GFRP composites differs in flexural versus compression, further investigation was needed in order to accurately calculate the MOE in flexure. Nagaraj and GangaRao (1997) proposed a relationship for determining the flexural rigidity of GFRP composites based on central deflection of three point bending tests, where the total deflection is a function of bending and shear deflection.

$$
\Delta=\frac{P L^{3}}{48 E I}+\frac{P a^{2}}{K L A G}
$$

where, ' $\mathrm{P}$ ' is the applied load and ' $\mathrm{L}$ ' is the total specimen length. The total deflection for a given applied load was recorded by an LVDT allowing for the flexural MOE to be back calculated through substitution. The transverse shear modulus used for substitution was determined by PMM (396ksi). The shear coefficient ' $K$ ' was obtained by applying the following equation by Gere and Timoshenko (1984).

$$
K=\frac{2\left(d_{w}+2 t_{f}\right) t_{w}}{2 d_{w} t_{w}+2 b_{f} t_{f}}
$$

Where, ' $\mathrm{d}_{\mathrm{w}}$ ' is the depth of the web, ' $\mathrm{b}_{\mathrm{f}}$ ' is the width of section, ' $\mathrm{t}_{\mathrm{f}}$ ' is the flange thickness, and ' $t_{\mathrm{w}}$ ' is the web thickness. The original equation was developed for wide flange sections and has been modified for hollow box sections by multiplying the numerator by two. All other variables were known based on cross sectional properties and experimental set up.

Now that the only unknown variable ' $\mathrm{E}_{\mathrm{b}}$ ' from Equation 5.5 is known, the shear modulus for each column cross section type was calculated and are tabulated below. 
Table 5-9 Column Shear Modulus (Calculated)

\begin{tabular}{|c|c|c|}
\hline $\begin{array}{c}\text { Column Length } \\
\text { (ft) }\end{array}$ & Cross Section & $\begin{array}{c}\text { G } \\
\text { (Apparent) } \\
\text { (ksi) }\end{array}$ \\
\hline $6 \mathrm{ft}$ & Hollow Box & 490 \\
$8 \mathrm{ft}-6 \mathrm{in}$ & Hollow Box & 331 \\
$9 \mathrm{ft}$ & Hollow Box & 308 \\
$10 \mathrm{ft}$ & Hollow Box & 266 \\
$6 \mathrm{ft}$ & 3" W-Flange & 337 \\
\hline
\end{tabular}

As expected the values decreased slightly with length which is likely due to an increase in internal damage due to the presence of a greater amount of global buckling during the initial compression tests (each $4 \mathrm{ft}$ test specimen was cut directly from a previously tested full length column).

\subsubsection{Hollow Box Sections}

Average experimental failure load for each of the four tested column lengths was tabulated (Table 5-10) and compared to the predicted failure load as defined by Engesser (1989). Each of the two different methods of calculating shear modulus is properly represented in terms of failure load. The shear coefficient $\left(\mathrm{n}_{\mathrm{s}}\right.$ in Equation 5.2) based on cross section type defined by Zureick (1997) is 2. Using the previously obtained Euler buckling load coupled with corrections for shear deformation the following relationship was derived.

Table 5-10 Summary of Engesser Loads (Calculated Shear Modulus)

\begin{tabular}{|c|c|c|c|c|c|c|}
\hline $\begin{array}{c}\text { Column } \\
\text { Length } \\
\text { (ft) }\end{array}$ & $\begin{array}{c}\text { E } \\
\text { (msi) }\end{array}$ & $\begin{array}{c}\text { G } \\
\text { (apparent) } \\
\text { (ksi) }\end{array}$ & $\begin{array}{c}\text { Eff. Length } \\
\text { Factor } \\
\text { (K) }\end{array}$ & $\begin{array}{c}\text { Engesser } \\
\text { Load } \\
\text { (kip) }\end{array}$ & $\begin{array}{c}\text { Max Exp. } \\
\text { Load } \\
\text { (kip) }\end{array}$ & $\begin{array}{c}\text { Exp. } \\
\text { Load/Engesser }\end{array}$ \\
\hline $6 \mathrm{ft}$ & 3.66 & 490 & 0.75 & 65.48 & 69.55 & 1.06 \\
$8 \mathrm{ft}-6 \mathrm{in}$ & 3.99 & 331 & 0.70 & 41.09 & 50.68 & 1.23 \\
$9 \mathrm{ft}$ & 4.21 & 308 & 0.70 & 38.64 & 39.00 & 1.01 \\
$10 \mathrm{ft}$ & 4.18 & 266 & 0.68 & 32.96 & 33.98 & 1.03 \\
\hline
\end{tabular}


Table 5-11 Summary of Engesser Loads (PMM Shear Modulus)

\begin{tabular}{|c|c|c|c|c|c|c|}
\hline $\begin{array}{c}\text { Column } \\
\text { Length } \\
\text { (ft) }\end{array}$ & $\begin{array}{c}\mathbf{E} \\
\text { (msi) }\end{array}$ & $\begin{array}{c}\text { G } \\
\text { (ksi) }\end{array}$ & $\begin{array}{c}\text { Eff. Length } \\
\text { Factor } \\
\text { (K) }\end{array}$ & $\begin{array}{c}\text { Engesser } \\
\text { Load } \\
\text { (kip) }\end{array}$ & $\begin{array}{c}\text { Max Exp. } \\
\text { Load } \\
\text { (kip) }\end{array}$ & $\begin{array}{c}\text { Exp. } \\
\text { Load/Engesser }\end{array}$ \\
\hline $6 \mathrm{ft}$ & 3.66 & 396.00 & 0.75 & 64.23 & 69.55 & 1.08 \\
$8 \mathrm{ft}-6 \mathrm{in}$ & 3.99 & 396.00 & 0.70 & 41.62 & 50.68 & 1.22 \\
$9 \mathrm{ft}$ & 4.21 & 396.00 & 0.70 & 39.32 & 39.00 & 0.99 \\
$10 \mathrm{ft}$ & 4.18 & 396.00 & 0.68 & 33.81 & 33.98 & 1.01 \\
\hline
\end{tabular}

Engesser's equation typically under predicted the actual buckling load obtained from testing. Little deviation between the predicted failure loads was observed between the two different methods of calculating the shear modulus, leaving reason to believe that shear deformations have only minor effects ( $10 \%$ of total effect) on the overall failure of the columns. Effective length factors and MOE values were all identical to those used in the Euler Buckling analysis.

\subsubsection{W-Flange Sections}

Similar to the Euler buckling analysis, 3" W-Flange sections were evaluated using the technique generated by Engesser (1989). Once again the 6" flanged sections were not considered due to minor global buckling effects present during loading. A comparison of predicted load utilizing both methods for calculating shear modulus is presented, for a range of effective length factors. 
Table 5-12 Summary of Engesser Loads 3" W-Flange (Calculated Shear Modulus Eq. 5.5)

\begin{tabular}{|c|c|c|c|c|c|c|}
\hline $\begin{array}{c}\text { Column } \\
\text { Length } \\
(\mathrm{ft})\end{array}$ & $\mathrm{E}$ & $\mathrm{G}$ & $\begin{array}{c}\text { Eff. Length } \\
\text { Factor } \\
(\mathrm{K})\end{array}$ & $\begin{array}{c}\text { Engesser } \\
\text { Load } \\
(\mathrm{kip})\end{array}$ & $\begin{array}{c}\text { Max Exp. } \\
\text { Load } \\
(\mathrm{kip})\end{array}$ & $\begin{array}{c}\text { Exp. } \\
\text { Load/Engesser }\end{array}$ \\
\hline $6 \mathrm{ft}$ & 4.40 & 337 & 0.65 & 20.22 & 22.73 & 1.12 \\
$6 \mathrm{ft}$ & 4.40 & 337 & 0.70 & 17.67 & 22.73 & 1.29 \\
$6 \mathrm{ft}$ & 4.40 & 337 & 0.75 & 15.56 & 22.73 & 1.46 \\
$6 \mathrm{ft}$ & 4.40 & 337 & 0.80 & 13.80 & 22.73 & 1.65 \\
$6 \mathrm{ft}$ & 4.40 & 337 & 0.85 & 12.31 & 22.73 & 1.85 \\
$6 \mathrm{ft}$ & 4.40 & 337 & 0.90 & 11.05 & 22.73 & 2.06 \\
\hline
\end{tabular}

Table 5-13 Summary of Engesser Loads 3" W-Flange (PMM Shear Modulus Eq. 5.3)

\begin{tabular}{|c|c|c|c|c|c|c|}
\hline $\begin{array}{c}\text { Column } \\
\text { Length } \\
(\mathrm{ft})\end{array}$ & $\begin{array}{c}\mathrm{E} \\
(\mathrm{msi})\end{array}$ & $\begin{array}{c}\mathrm{G} \\
(\mathrm{ksi})\end{array}$ & $\begin{array}{c}\text { Eff. Length } \\
\text { Factor } \\
(\mathrm{K})\end{array}$ & $\begin{array}{c}\text { Engesser } \\
\text { Load } \\
(\mathrm{kip})\end{array}$ & $\begin{array}{c}\text { Max Exp. } \\
\text { Load } \\
\text { (kip) }\end{array}$ & $\begin{array}{c}\text { Exp. } \\
\text { Load/Engesser }\end{array}$ \\
\hline $6 \mathrm{ft}$ & 4.40 & 396.00 & 0.65 & 20.51 & 22.73 & 1.11 \\
$6 \mathrm{ft}$ & 4.40 & 396.00 & 0.70 & 17.89 & 22.73 & 1.27 \\
$6 \mathrm{ft}$ & 4.40 & 396.00 & 0.75 & 15.73 & 22.73 & 1.45 \\
$6 \mathrm{ft}$ & 4.40 & 396.00 & 0.80 & 13.93 & 22.73 & 1.63 \\
$6 \mathrm{ft}$ & 4.40 & 396.00 & 0.85 & 12.42 & 22.73 & 1.83 \\
$6 \mathrm{ft}$ & 4.40 & 396.00 & 0.90 & 11.14 & 22.73 & 2.04 \\
\hline
\end{tabular}

The differences between predicted load and experimental load for the different shear moduli, are minor which implies shear deformation has little effect on the actual failure of the columns. A similar trend was observed in the closed sectioned columns.

Utilizing a range of effective length factors once again proved significant in developing an accurate model of predicted failure versus experimental failure. With higher effective length factors Engesser's equation decreased in accuracy when compared to the experimental results. It should also be noted that in the case of the closed section columns Engesser's equation slightly underestimated the failure load, which is evident in the case of the W-Flange columns, for each effective length factor used. This reinforces an earlier assumption that the W-Flange sections behaved under a system more closely resembling fully fixed. 


\subsubsection{Empirical Approach to Strength Design (Puente)}

Puente, et al (2006) presented an empirical approach to design based upon Dutheil's empirical method of buckling. In conjunction with Dutheil's empirical approach, Puente, et al also incorporated Maquoi and Rondal's (1978) suggestion to include initial material imperfections into design. Empirical constants were developed for GFRP composites through extensive testing of pultruded hollow tubes of varied length. Subsequent empirical constants were incorporated into the following proposed equation for the critical buckling load

$$
P_{c r}=\frac{1}{y} x P_{L}
$$

where; $y=$ coefficient depending of reliability of manufacturer, $x=$ empirical coefficient based on slenderness ratio of column, and $P_{L}=$ local buckling load.

In the current research average local buckling failure loads were obtained from the $1 \mathrm{ft}$ "pure” compression tests evaluated previously. The empirical coefficient ' $x$ ' was derived based of off the nondimensional slenderness for each column length, which was computed using the following equation proposed by Barbero and Tomblin (1994).

$$
\lambda=\frac{L_{c r}}{\pi} \sqrt{\frac{P_{L}}{E I}}
$$

where; $L_{c r}=$ critical length of specimen, $P_{L}=$ local buckling load, $E=$ bending modulus of elasticity in the direction of loading, and $I=$ moment of inertia about weak axis.

Manufacturer reliability ' $y$ ' was taken as 1.2 for possible imperfections along the column length developed during the pultrusion process. Three point bending tests were conducted in order to quantify the bending MOE for each column length. 


\subsubsection{Hollow Box Sections}

Predicted and experimental failure data for the range of column lengths tested is provided below.

Table 5-14 Puente Predicted Failure (Hollow Box Sections)

\begin{tabular}{|c|c|c|c|c|c|}
\hline $\begin{array}{c}\text { Column } \\
\text { Length } \\
\text { (ft) }\end{array}$ & $\begin{array}{c}\text { Slenderness } \\
(\boldsymbol{\lambda})\end{array}$ & $\begin{array}{c}\text { Local } \\
\text { Buckling } \\
\text { (kip) }\end{array}$ & $\begin{array}{c}\text { Puente } \\
\text { Load } \\
(\text { kip) }\end{array}$ & $\begin{array}{c}\text { Max Exp. } \\
\text { Load } \\
(\text { kip) }\end{array}$ & $\begin{array}{c}\text { Exp. } \\
\text { Load/Puente }\end{array}$ \\
\hline $6 \mathrm{ft}$ & 0.90 & 95.11 & 65.57 & 69.55 & 1.06 \\
$8 \mathrm{ft}-6 \mathrm{in}$ & 1.23 & 89.25 & 40.48 & 50.68 & 1.25 \\
$9 \mathrm{ft}$ & 1.40 & 99.77 & 35.72 & 39.00 & 1.09 \\
$10 \mathrm{ft}$ & 1.62 & 114.84 & 31.27 & 33.98 & 1.09 \\
\hline
\end{tabular}

The predicted critical load underestimates experimental results in both the current research and the research data provided by Puente. Percent difference between the failure load ranges from 5.7-20\%. Effective length factors once again play a vital role in the accuracy of the model more specifically in calculating the slenderness as described by Barbero and Tomblin (1994). Adjusting the effective length alters the corresponding slenderness, and as a result the predicted critical buckling load is affected. If modifications are made to the effective length factor used for the 8ft-6in columns, the percent difference between the predicted and experimental failure loads would reduce from $20 \%$. However, a further reduction in effective length would define fixed end boundary conditions, which is an inaccurate assumption for the prescribed support conditions used during testing.

\subsubsection{Wide Flange Sections}

Three inch W-Flange sections were also evaluated using the prediction model presented by Puente et al (2006). Due to the presence of a weak-axis, and a reduction in cross sectional area, failure occurred under lower stress. Effective length factors ranged from $0.65-0.75$ to account for 
support conditions more likely resembling fully fixed due to the shorter column length (6ft). Nondimensional slenderness values for each effective length factor have been provided for comparison purposes and are noted below.

Table 5-15 Puente Predicted Failure (W-Flange)

\begin{tabular}{|c|c|c|c|c|c|}
\hline $\begin{array}{c}\text { Column } \\
\text { Length } \\
(\mathrm{ft})\end{array}$ & $\begin{array}{c}\text { Eff. Length } \\
\text { Factor } \\
(\mathrm{K})\end{array}$ & $\begin{array}{c}\text { Slenderness } \\
(\lambda)\end{array}$ & $\begin{array}{c}\text { Puente } \\
\text { Load } \\
(\mathrm{kip})\end{array}$ & $\begin{array}{c}\text { Max Exp. } \\
\text { Load } \\
(\mathrm{kip})\end{array}$ & $\begin{array}{c}\text { Exp. } \\
\text { Load/Puente }\end{array}$ \\
\hline $6 \mathrm{ft}$ & 0.65 & 1.39 & 22.23 & 22.73 & 1.02 \\
$6 \mathrm{ft}$ & 0.70 & 1.50 & 19.39 & 22.73 & 1.17 \\
$6 \mathrm{ft}$ & 0.75 & 1.61 & 17.02 & 22.73 & 1.34 \\
\hline
\end{tabular}

The average percent difference between the predicted and experimentally derived critical loads for the range of effective lengths used is $14 \%$, which matches the closed sectioned columns quite well.

The 6in W-Flange sections were not evaluated using Puente's prediction model due to insignificant global buckling effects present during loading, signifying a failure mode more closely resembling local buckling. Unlike the 3" W-Flange sections the 6" W-Flange columns failed at a more localized mode shape with limited load induced lateral deflection observed.

\subsubsection{Strain Energy Failure Criteria}

Strain energy based failure was predicted utilizing a model first described by Vadlamani (2007). In this model strain energy density is taken as the area under the stress-strain curve developed during testing. Changes in the slope of the curve signify initial damage to the test specimen, and are therefore implemented in the model for predicting the ultimate load. Correlating the predicted load to the strain energy achieved during experimentation required the use of theoretical equations for strain energy developed from mechanics of materials principles 
outlined below. Axial strain energy of specimens loaded in tension or compression for isotropic materials is defined as:

$$
U=\frac{P^{2} L}{2 A E}
$$

where, ' $\mathrm{P}$ ' is the applied loading, ' $\mathrm{L}$ ' is the specimen length, ' $\mathrm{A}$ ' is the cross-sectional area, and 'E' corresponds to the MOE. Specimens subjected to bending yield the following equation for strain energy:

$$
U=\int_{0}^{L} \frac{(P e)^{2} d x}{2 E I}
$$

where, 'e' is the eccentricity of the loading, and ' $\mathrm{I}$ ' is the moment of inertia. It should be noted that the aforementioned equations were derived from mechanics of materials theory based on the loading of a prismatic bar under linear stress distribution (Gere J. M., 2004).

Equating the experimentally obtained strain energy density to the theoretical equations (Equations 5.10 and 5.11) while simultaneously substituting in the appropriate cross sectional properties, results in the only remaining unknown being the load ' $\mathrm{P}$ ' from the theoretical equation. Therefore, by back solving for 'P' a prediction for failure can be made. This model was used to predict failure of samples ranging from coupon, $1 \mathrm{ft}$ "pure" compression, and full scale components.

\subsubsection{Predicted Strain Energy Failure (Hollow Box Sections)}

\subsubsection{Strain Energy Failure (Coupon)}

Forty 1” x 1" x 1/4" coupons, i.e., ten from each column length, were tested in compression to determine ultimate strength. Due to primarily unidirectional fibers present, the subsequent stress-strain relationship achieved during loading is linear. This linearity allows for 
many of the terms in the strength prediction model presented by Vadlamani (2007) to be disregarded (see Equation 2.16), resulting in the following equation for strain energy density.

$$
U=\frac{1}{2} \varepsilon_{p} E_{R O M} V
$$

Where ' $\varepsilon_{\mathrm{p}}$ ' is $95 \%$ of the strain at failure to prevent accounting for nonlinear effects near failure (lower MOE), ' $E_{\mathrm{ROM}}$ ' is the MOE from rule-of-mixtures ${ }^{1}$, and ' $\mathrm{V}$ ' corresponds to the sample's volume. Equating Equation 5.12 to Equation 5.10 allows for the theoretical load to be back calculated. Both experimental and predicted failure loads are tabulated below (Tables 5-19 - 522) for the coupons cut from each of the different column lengths.

Table 5-16 6ft Strain Energy (Coupon)

\begin{tabular}{|c|c|c|c|c|c|}
\hline Sample & $\begin{array}{c}\text { Max Load } \\
\text { (lb) }\end{array}$ & Stress (psi) & $\varepsilon_{p}$ & $\begin{array}{c}\text { Predicted } \\
\text { P (Ib) }\end{array}$ & \\
\hline 1 & $9,109.24$ & $36,436.95$ & $9,483.59$ & $7,966.22$ & \\
\hline 2 & $8,132.49$ & $32,529.96$ & $8,466.70$ & $7,112.03$ & \\
\hline 3 & $7,251.13$ & $29,004.52$ & $7,549.12$ & $6,341.26$ & \\
\hline 4 & $7,077.50$ & $28,310.00$ & $7,368.36$ & $6,189.42$ & \\
\hline 5 & $9,613.98$ & $38,455.92$ & $10,009.08$ & $8,407.62$ & \\
\hline 6 & $8,563.69$ & $34,254.76$ & $8,915.62$ & $7,489.12$ & \\
\hline 7 & $6,461.41$ & $25,845.64$ & $6,726.95$ & $5,650.64$ & \\
\hline 8 & $10,375.60$ & $41,502.40$ & $10,801.99$ & $9,073.68$ & \\
\hline 9 & $8,028.03$ & $32,112.12$ & $8,357.95$ & $7,020.68$ & $P_{\text {exp }} / P_{\text {pred }}$ \\
\hline 10 & 6,199.35 & $24,797.40$ & $6,454.12$ & $5,421.46$ & (lb) \\
\hline AVERAGE & $8,253.72$ & $33,014.89$ & $8,592.92$ & $7,218.05$ & 1.14 \\
\hline STDD & 924.90 & 3699.59 & 962.91 & 808.84 & 0.00 \\
\hline
\end{tabular}

\footnotetext{
${ }^{1}$ For $6 \mathrm{ft}$ columns $\mathrm{MOE}=3.36 \mathrm{msi}\left(\mathrm{V}_{\mathrm{f}}=.33\right)$, subsequently for 8ft-6in, 9ft, and 10ft columns MOE $=4.11 \mathrm{msi}\left(\mathrm{V}_{\mathrm{f}}\right.$ $=.41)$
} 
Table 5-17 8ft-6in Strain Energy (Coupon)

\begin{tabular}{|c|c|c|c|c|c|}
\hline Sample & $\begin{array}{l}\text { Max Load } \\
\text { (lb) }\end{array}$ & Stress (psi) & $\varepsilon_{\mathrm{p}}$ & $\begin{array}{l}\text { Predicted } \\
\qquad \mathrm{P}(\mathrm{lb})\end{array}$ & \\
\hline 1 & $6,431.28$ & $25,725.12$ & $6,125.03$ & $6,293.47$ & \\
\hline 2 & $9,541.12$ & $38,164.48$ & $9,086.78$ & $9,336.67$ & \\
\hline 3 & $10,212.10$ & $40,848.40$ & $9,725.81$ & $9,993.27$ & \\
\hline 4 & $11,726.00$ & $46,904.00$ & $11,167.62$ & $11,474.73$ & \\
\hline 5 & $8,453.15$ & $33,812.60$ & $8,050.62$ & $8,272.01$ & \\
\hline 6 & $9,711.52$ & $38,846.08$ & $9,249.07$ & $9,503.42$ & \\
\hline 7 & $9,531.99$ & $38,127.96$ & $9,078.09$ & $9,327.73$ & \\
\hline 8 & $9,547.89$ & $38,191.56$ & $9,093.23$ & $9,343.29$ & \\
\hline 9 & $11,076.70$ & $44,306.80$ & $10,549.24$ & $10,839.34$ & $P_{\text {exp }} / P_{\text {pred }}$ \\
\hline 10 & $10,093.00$ & $40,372.00$ & $9,612.38$ & $9,876.72$ & (lb) \\
\hline AVERAGE & $9,770.93$ & $39,083.74$ & $9,305.65$ & $9,561.56$ & 1.02 \\
\hline STDD & 746.72 & 2986.87 & 711.16 & 730.72 & 0.00 \\
\hline
\end{tabular}

Table 5-18 9ft Strain Energy (Coupon)

\begin{tabular}{|c|c|c|c|c|c|}
\hline Sample & Max Load (lb) & Stress (psi) & $\varepsilon_{\mathrm{p}}$ & $\begin{array}{l}\text { Predicted } \\
\text { P (lb) }\end{array}$ & \\
\hline 1 & $8,634.97$ & $34,539.88$ & $7,794.03$ & $8,008.37$ & \\
\hline 2 & $9,014.07$ & $36,056.28$ & $8,136.22$ & $8,359.96$ & \\
\hline 3 & $5,144.30$ & $20,577.20$ & $4,643.31$ & $4,771.00$ & \\
\hline 4 & $8,897.76$ & $35,591.04$ & $8,031.23$ & $8,252.09$ & \\
\hline 5 & $6,962.69$ & $27,850.76$ & $6,284.61$ & $6,457.44$ & \\
\hline 6 & $11,048.30$ & $44,193.20$ & $9,972.34$ & $10,246.58$ & \\
\hline 7 & $8,312.08$ & $33,248.32$ & $7,502.59$ & $7,708.91$ & \\
\hline 8 & $7,284.70$ & $29,138.80$ & $6,575.26$ & $6,756.08$ & \\
\hline 9 & $8,285.44$ & $33,141.76$ & $7,478.54$ & $7,684.20$ & $P_{\text {exp }} / P_{\text {pred }}$ \\
\hline 10 & $10,443.50$ & $41,774.00$ & $9,426.44$ & $9,685.66$ & (lb) \\
\hline AVERAGE & $8,696.07$ & $34,784.30$ & $7,849.19$ & $8,065.04$ & 1.08 \\
\hline STDD & 958.04 & 3832.17 & 864.74 & 888.52 & 0.00 \\
\hline
\end{tabular}


Table 5-19 10ft Strain Energy (Coupon)

\begin{tabular}{|c|c|c|c|c|c|}
\hline Sample & Max Load (lb) & Stress (psi) & $\varepsilon_{\mathrm{p}}$ & $\begin{array}{c}\text { Predicted } \\
\text { P (Ib) }\end{array}$ & \\
\hline 1 & $11,053.46$ & $44,213.85$ & $10,048.60$ & $10,324.94$ & \\
\hline 2 & $10,021.87$ & $40,087.46$ & $9,110.79$ & $9,361.33$ & \\
\hline 3 & $11,056.27$ & $44,225.06$ & $10,051.15$ & $1,0327.56$ & \\
\hline 4 & $10,730.15$ & $42,920.62$ & $9,754.69$ & $1,0022.94$ & \\
\hline 5 & $9,383.66$ & $37,534.64$ & $8,530.60$ & $8,765.19$ & \\
\hline 6 & $10,880.60$ & $43,522.38$ & $9,891.45$ & $1,0163.46$ & \\
\hline 7 & $10,242.39$ & $40,969.55$ & $9,311.26$ & $9,567.32$ & \\
\hline 8 & $7,935.47$ & $31,741.87$ & $7,214.06$ & $7,412.45$ & \\
\hline 9 & $11,061.87$ & $44,247.49$ & $10,056.25$ & $10,332.79$ & $P_{\text {exp }} / P_{\text {pred }}$ \\
\hline 10 & $7,375.28$ & $29,501.14$ & $6,704.80$ & 6,889.19 & (Ib) \\
\hline AVERAGE & $10,553.78$ & $42,215.13$ & $9,594.35$ & $9,858.19$ & 1.07 \\
\hline STDD & 614.97 & 2459.89 & 559.06 & 574.44 & 0.00 \\
\hline
\end{tabular}

Failure strain used in the prediction model was back calculated from the failure stress and MOE obtained from the $1 \mathrm{ft}$ "pure" compression test. Neglecting bending effects, stress was simply taken as that of an axial loaded member $(\sigma=\mathrm{P} / \mathrm{A})$. Utilizing these assumptions the prediction model showed reasonable correlation between predicted and experimental failure, as noted in the table below.

Table 5-20 Average Strain Energy Predicted Loads (Coupon)

\begin{tabular}{|c|c|c|c|}
\cline { 2 - 3 } \multicolumn{1}{c|}{} & \multicolumn{2}{c|}{ Average } & \multicolumn{1}{c|}{} \\
\hline Sample & $\begin{array}{c}\text { Exp. Load } \\
(\mathrm{lb})\end{array}$ & $\begin{array}{c}\text { Pred. Load } \\
(\mathrm{lb})\end{array}$ & \% Diff. \\
\hline $6 \mathrm{ft}$ & $8,253.72$ & $7,218.05$ & -14.35 \\
$8 \mathrm{tf}-6 \mathrm{in}$ & $9,770.93$ & $9,561.56$ & -2.19 \\
$9 \mathrm{ft}$ & $8,696.07$ & $8,065.04$ & -7.82 \\
$10 \mathrm{ft}$ & $10,553.78$ & $9,858.19$ & -7.06 \\
\hline
\end{tabular}

The coupons taken from the $6 \mathrm{ft}$ columns showed the most amount of scatter between predicted and experimental failure load. This phenomenon is in conjunction with the trend observed by the previously discussed prediction models. 


\subsubsection{Strain Energy Based Failure Prediction (1ft "Pure" Compression)}

Several 1ft samples were cut from full-length columns in order to evaluate local buckling strength. Subsequently strength prediction by strain energy density was implemented to gain a better understanding of the model's accuracy for test samples of varied length and cross section.

Failure was predicted using two methods for calculating failure strain. Back to back strain gage configurations were used providing two sets of strain data for each test. Due to a relatively wide range between predicted failure and experimental failure, failure strain was also back calculated following the same procedure utilized in the coupon testing. However, the MOE used corresponded to coupon testing rather than the $1 \mathrm{ft}$ "pure" compression tests.

For the case where strain data was readily available via strain gages, Equation 5.12 (same as coupon) was equated to the theoretical formulation for axial strain energy. Due to the relatively short length of the test specimens, bending effects are minute, however, they were still incorporated. Table 5-24 offers a summary of the predicted and experimental failure loads for each set of strain data, using the MOE corresponding to coupon testing.

Table 5-21 1ft "Pure" Compression Strain Energy

\begin{tabular}{|c|c|c|c|c|}
\hline Sample & $\begin{array}{c}\text { Max Load } \\
\text { (kip) }\end{array}$ & Stress (ksi) & $\begin{array}{c}\text { Predicted } \\
\mathrm{P}(\mathrm{kip})\end{array}$ & $\begin{array}{c}\mathrm{P}_{\text {exp }} / \mathrm{P}_{\text {pred }} \\
\text { (lb) }\end{array}$ \\
\hline 6ft \#2 & 93.79 & 28.86 & 78.73 & 1.19 \\
6ft \#3 & $\mathbf{6 0 . 9 1}$ & $\mathbf{1 8 . 7 4}$ & $\mathbf{3 9 . 0 1}$ & $\mathbf{1 . 5 6}$ \\
8ft-6in \#2 & 85.17 & 26.21 & 91.27 & 0.93 \\
8ft-6in \#3 & 93.70 & 28.83 & 110.08 & 0.85 \\
9ft \#2 & $\mathbf{7 6 . 8 1}$ & $\mathbf{2 3 . 6 3}$ & $\mathbf{6 0 . 4 9}$ & $\mathbf{1 . 2 7}$ \\
10ft \#1 & 110.11 & 33.88 & 125.78 & 0.88 \\
10ft \#2 & 118.85 & 36.57 & 109.97 & 1.08 \\
\hline AVERAGE & 100.32 & 30.87 & 103.17 & 0.99 \\
STDD & 13.74 & 4.23 & 18.33 & 0.15 \\
\hline
\end{tabular}


As noted in Table 5-24 a wider range between predicted and experimental failure is expressed when compared to the coupon level testing. This is likely due to minor eccentricity in the test set up between the actuator and test specimen, as well as, eccentricity in terms of fiber architecture in the specimens themselves at the time of manufacturing. Consequently, this minimal eccentricity leads to differences between the predicted and experimentally defined critical load. As a result the second method of determining failure strain based on simple mechanics of materials principles (see section 5.1.7.1), provided the following relationship between experimental and predicted failure.

Table 5-22 Average Strain Energy Predicted Loads (1ft “Pure” Compression)

\begin{tabular}{|c|c|c|c|c|c|}
\hline Sample & Max Load (kip) & Stress (ksi) & $\begin{array}{c}\varepsilon_{\mathrm{p}} \\
\text { (microstrain) }\end{array}$ & $\begin{array}{c}\text { Predicted } \\
\mathrm{P}(\mathrm{kip})\end{array}$ & $\begin{array}{c}\mathrm{P}_{\text {exp }} / \mathrm{P}_{\text {pred }} \\
\text { (lb) }\end{array}$ \\
\hline 6ft \#2 & 93.79 & 28.86 & $7,855.52$ & 85.78 & 1.09 \\
6ft \#3 & $\mathbf{6 0 . 9 1}$ & $\mathbf{1 8 . 7 4}$ & $\mathbf{5 , 1 0 1 . 3 9}$ & $\mathbf{5 5 . 7 1}$ & $\mathbf{1 . 0 9}$ \\
8ft-6in \#2 & 85.17 & 26.21 & $6,177.85$ & 82.52 & 1.03 \\
8ft-6in \#3 & 93.70 & 28.83 & $6,796.14$ & 90.78 & 1.03 \\
9ft \#2 & $\mathbf{7 6 . 8 1}$ & $\mathbf{2 3 . 6 3}$ & $\mathbf{5 , 3 3 3 . 2 1}$ & $\mathbf{7 1 . 2 4}$ & $\mathbf{1 . 0 8}$ \\
10ft \#1 & 110.11 & 33.88 & $7,737.23$ & 103.35 & 1.07 \\
10ft \#2 & 118.85 & 36.57 & $8,350.97$ & 111.55 & 1.07 \\
\hline AVERAGE & 91.33 & 28.10 & $6,764.62$ & 85.85 & 1.06 \\
STDD & 19.56 & 6.02 & $1,278.87$ & 18.81 & 0.03 \\
\hline
\end{tabular}

Of the two methods for determining failure strain, the mechanics of materials approach provided less scatter between predicted and experimental failure as noted in Table 5-26. 
Table 5-23 Failure Strain (1ft "Pure" Compression)

\begin{tabular}{|c|c|c|}
\hline \multicolumn{3}{|c|}{ Failure Strain Obtained By: } \\
\hline \multirow{2}{*}{ Sample } & Strain Gages & Mech. Of Mat. \\
\cline { 2 - 3 } & \% Diff & \% Diff \\
\hline 6ft \#2 & -19.12 & -9.34 \\
6ft \#3 & -56.15 & -9.34 \\
8ft-6in \#2 & 6.68 & -3.21 \\
8ft-6in \#3 & 14.88 & -3.21 \\
9ft \#2 & -26.99 & -7.82 \\
10ft \#1 & 12.46 & -6.54 \\
10ft \#2 & -8.07 & -6.54 \\
\hline AVERAGE & 1.36 & -5.77 \\
\hline
\end{tabular}

The trend observed within the coupon testing pertaining to the largest discrepancy between predicted and experimental failure lying within the samples cut from the $6 \mathrm{ft}$ columns once again is prevalent. Further conclusions detailing this phenomenon will be discussed later in Chapter 6.

\subsubsection{Strain Energy Failure (Full- Length Columns)}

Application of the strain energy based failure model to full-length columns required the use of additional parameters due to the presence of bending during loading. As a result, the prediction of failure strength was not as straight forward as in the cases of the coupon and $1 \mathrm{ft}$ local buckling samples. Stress-strain relationships were no longer primarily linear to failure; instead a three step representation with three distinct slope changes was indentified. This occurrence mirrored that of coupon samples with multi-directional fibers tested in tension and bending by Vadlamani (2007), therefore Equation 2.16 for strain energy density derived from Figure 2-3 held true. 


$$
C=E_{\alpha}^{2} \varepsilon_{p}^{2}\left(\frac{1}{2} K_{1}^{2}+\frac{1}{2}\left(\frac{K_{2}-K_{1}}{K_{E 1}}\right)\left(2 K_{1}+\frac{\left(K_{2}-K_{1}\right)}{K_{E 1}}\right)+\left(\frac{1-K_{2}}{K_{E 1} K_{E 2}}\right)\left(K_{1}+\frac{\left(K_{2}-K_{1}\right)}{K_{E 1}}\right)\right)
$$

Taking ' $\mathrm{E}_{\alpha}$ ' as the MOE obtained from coupon testing, the remaining terms were attained from the stress-strain plots for each of the tested columns equipped with strain gages. The following figure shows a typical stress curve with trend lines exhibiting the three distinct stages experienced during loading.

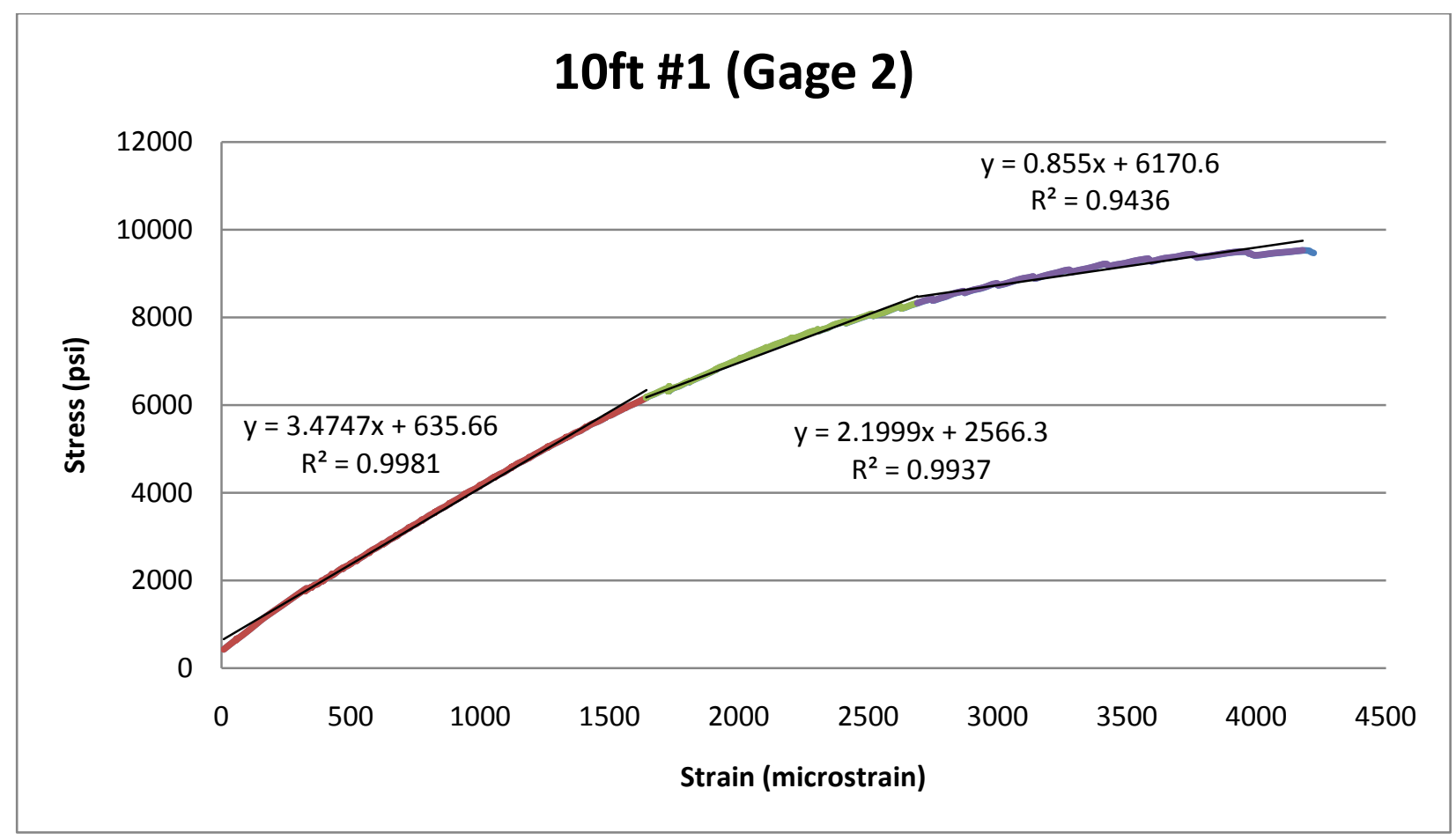

Figure 5-7 Stress-Strain Linear Regression

At the points where a slope change occurred, the different variables $\left(\mathrm{K}_{1}, \mathrm{~K}_{2}, \mathrm{~K}_{\mathrm{E} 1}{ }^{2}{ }^{2}\right.$ etc. $)$ from Equation 5.13 are obtained. The following tables offer a summary of these variables for each of the tested column lengths.

\footnotetext{
${ }^{2}$ See Figure 2-3 for derivation of $\mathrm{K}_{\mathrm{E} 1}$ and $\mathrm{K}_{\mathrm{E} 2}$
} 
Table 5-24 Full Length Strain Energy Coefficients (6ft Columns)

\begin{tabular}{|c|c|c|c|c|c|c|c|c|c|c|}
\hline Column & $\mathrm{E}_{1}$ (msi) & $\mathrm{E}_{2}$ (msi) & $\mathrm{E}_{\mathrm{p}}$ (msi) & $\varepsilon_{1}$ & $\varepsilon_{2}$ & $\varepsilon_{\mathrm{p}}$ & $\begin{array}{c}\mathrm{K}_{1}= \\
\varepsilon_{1} / \varepsilon_{\mathrm{p}}\end{array}$ & $\begin{array}{c}\mathrm{K}_{2}= \\
\varepsilon_{2} / \varepsilon_{\mathrm{p}}\end{array}$ & $\mathrm{K}_{\mathrm{E} 1}$ & $\mathrm{~K}_{\mathrm{E} 2}$ \\
\hline 1 & 2.80 & 2.26 & 1.51 & $5,279.98$ & $7,510.78$ & $8,067.51$ & 0.65 & 0.93 & 1.24 & 1.49 \\
2 & 2.66 & 2.11 & 1.65 & $5,680.40$ & $8,378.66$ & $9,385.74$ & 0.61 & 0.89 & 1.26 & 1.28 \\
3 & 2.69 & 2.19 & 1.83 & $5,423.70$ & $8,326.82$ & $8,917.18$ & 0.61 & 0.93 & 1.23 & 1.20 \\
4 & 2.62 & 2.19 & 1.31 & $5,639.22$ & $8,058.70$ & $10,854.18$ & 0.52 & 0.74 & 1.20 & 1.67 \\
5 & 2.82 & 2.28 & 1.34 & $5,411.01$ & $7,674.21$ & $9,398.94$ & 0.58 & 0.82 & 1.24 & 1.70 \\
\hline AVG & 2.72 & 2.21 & 1.53 & $5,486.86$ & $7,989.83$ & $9,324.71$ & 0.59 & 0.86 & 1.23 & 1.47 \\
STDD & 0.09 & 0.07 & 0.22 & 168.24 & 386.84 & $1,011.82$ & 0.05 & 0.08 & 0.02 & 0.23 \\
\% COV & 3.17 & 3.04 & 14.16 & 3.07 & 4.84 & 10.85 & 8.38 & 9.55 & 1.85 & 15.40 \\
\hline
\end{tabular}

Table 5-25 Full Length Strain Energy Coefficients (8ft-6in Columns)

\begin{tabular}{|c|c|c|c|c|c|c|c|c|c|c|}
\hline Column & $\mathrm{E}_{1}$ (msi) & $\mathrm{E}_{2}$ (msi) & $\mathrm{E}_{\mathrm{p}}(\mathrm{msi})$ & $\varepsilon_{1}$ & $\varepsilon_{2}$ & $\varepsilon_{\mathrm{p}}$ & $\begin{array}{c}\mathrm{K}_{1}= \\
\varepsilon_{1} / \varepsilon_{\mathrm{p}}\end{array}$ & $\begin{array}{c}\mathrm{K}_{2}= \\
\varepsilon_{2} / \varepsilon_{\mathrm{p}}\end{array}$ & $\mathrm{K}_{\mathrm{E} 1}$ & $\mathrm{~K}_{\mathrm{E} 2}$ \\
\hline 1 & 3.63 & 3.53 & 2.25 & $1,544.91$ & $3,278.15$ & $3,550.89$ & 0.44 & 0.92 & 1.03 & 1.57 \\
2 & 2.96 & 1.85 & 0.51 & $3,222.44$ & $5,443.72$ & $6,569.04$ & 0.49 & 0.83 & 1.60 & 3.60 \\
3 & 3.31 & 2.60 & 1.37 & $2,955.95$ & $5,100.30$ & $5,649.34$ & 0.52 & 0.90 & 1.27 & 1.89 \\
4 & 3.23 & -- & 2.81 & $1,667.67$ & -- & $3,016.92$ & -- & -- & 1.15 & -- \\
5 & 4.58 & 3.08 & 0.97 & $2,486.44$ & $4,495.07$ & $5,585.33$ & 0.45 & 0.80 & 1.49 & 3.17 \\
\hline AVG & 3.54 & 2.77 & 1.58 & $2,375.48$ & $4,579.31$ & $4,874.30$ & 0.47 & 0.86 & 1.31 & 2.56 \\
STDD & 0.63 & 0.72 & 0.93 & 751.24 & 951.97 & $1,514.90$ & 0.04 & 0.06 & 0.23 & 0.98 \\
\% COV & 17.73 & 25.95 & 59.06 & 31.62 & 20.79 & 31.08 & 8.66 & 6.59 & 17.93 & 38.29 \\
\hline
\end{tabular}

Table 5-26 Full Length Strain Energy Coefficients (9ft Columns)

\begin{tabular}{|c|c|c|c|c|c|c|c|c|c|c|}
\hline Column & $\mathrm{E}_{1}(\mathrm{msi})$ & $\mathrm{E}_{2}(\mathrm{msi})$ & $\mathrm{E}_{\mathrm{p}}(\mathrm{msi})$ & $\varepsilon_{1}$ & $\varepsilon_{2}$ & $\varepsilon_{\mathrm{p}}$ & $\begin{array}{c}\mathrm{K}_{1}= \\
\varepsilon_{1} / \varepsilon_{\mathrm{p}}\end{array}$ & $\begin{array}{c}\mathrm{K}_{2}= \\
\varepsilon_{2} / \varepsilon_{\mathrm{p}}\end{array}$ & $\mathrm{K}_{\mathrm{E} 1}$ & $\mathrm{~K}_{\mathrm{E} 2}$ \\
\hline 1 & 3.12 & 2.05 & 1.11 & $3,089.47$ & $3,869.16$ & $4,105.62$ & 0.75 & 0.94 & 1.52 & 1.85 \\
2 & 3.74 & 4.36 & 9.57 & $1,924.61$ & $2,525.54$ & $2,434.31$ & 0.79 & 1.04 & 0.86 & 0.46 \\
3 & 2.88 & 2.06 & 0.61 & $2,689.11$ & $3,908.27$ & $4,310.36$ & 0.62 & 0.91 & 1.40 & 3.40 \\
4 & 3.15 & 2.44 & 1.43 & $2,811.68$ & $3,982.40$ & $4,680.68$ & 0.60 & 0.85 & 1.29 & 1.71 \\
5 & 3.66 & 3.85 & 6.25 & $1,988.76$ & $2,485.43$ & $2,519.53$ & 0.79 & 0.99 & 0.95 & 0.62 \\
\hline AVG & 3.31 & 2.95 & 3.79 & $2,500.72$ & $3,354.16$ & $3,610.10$ & 0.71 & 0.94 & 1.20 & 1.61 \\
STDD & 0.37 & 1.08 & 3.95 & 517.88 & 775.93 & $1,055.21$ & 0.09 & 0.07 & 0.29 & 1.18 \\
\% COV & 11.23 & 36.50 & 104.12 & 20.71 & 23.13 & 29.23 & 12.95 & 7.60 & 23.83 & 73.66 \\
\hline
\end{tabular}


Table 5-27 Full Length Strain Energy Coefficients (10ft Columns)

\begin{tabular}{|c|c|c|c|c|c|c|c|c|c|c|}
\hline Column & $\mathrm{E}_{1}(\mathrm{msi})$ & $\mathrm{E}_{2}(\mathrm{msi})$ & $\mathrm{E}_{\mathrm{p}}(\mathrm{msi})$ & $\varepsilon_{1}$ & $\varepsilon_{2}$ & $\varepsilon_{\mathrm{p}}$ & $\begin{array}{c}\mathrm{K}_{1}= \\
\varepsilon_{1} / \varepsilon_{\mathrm{p}}\end{array}$ & $\begin{array}{c}\mathrm{K}_{2}= \\
\varepsilon_{2} / \varepsilon_{\mathrm{p}}\end{array}$ & $\mathrm{K}_{\mathrm{E} 1}$ & $\mathrm{~K}_{\mathrm{E} 2}$ \\
\hline 1 & 3.47 & 2.20 & 0.86 & $1,642.71$ & $2,689.47$ & $4,179.08$ & 0.39 & 0.64 & 1.58 & 2.57 \\
2 & 2.39 & 1.41 & 0.67 & $1,821.07$ & $2,932.44$ & $3,969.21$ & 0.46 & 0.74 & 1.70 & 2.10 \\
3 & 3.53 & 3.26 & 1.80 & $1,732.16$ & $2,609.85$ & $3,606.76$ & 0.48 & 0.72 & 1.08 & 1.81 \\
4 & 2.50 & 2.81 & 1.15 & $1,380.35$ & $3,394.33$ & $5,656.69$ & 0.24 & 0.60 & 0.89 & 2.44 \\
\hline AVG & 2.97 & 2.42 & 1.12 & $1,644.07$ & $2,906.52$ & $4,352.93$ & 0.39 & 0.68 & 1.31 & 2.23 \\
STDD & 0.61 & 0.80 & 0.49 & 190.30 & 352.96 & 900.75 & 0.11 & 0.07 & 0.39 & 0.34 \\
\% COV & 20.56 & 33.11 & 44.16 & 11.57 & 12.14 & 20.69 & 27.07 & 9.74 & 29.47 & 15.46 \\
\hline
\end{tabular}

As noted in the Tables 5-27 thru 5-30 a decent correlation is made between each of the sample media for a specified column length. More specifically the changes in slope in the stressstrain plots occurred near the same strain and corresponding stress. Ideally each of the defined variables would be tabulated for a specific fiber architecture, resin system, manufacturing process, cross-section type, and column length, enabling a designer to quickly select the appropriate parameter. Obviously, such a table does not currently exist, so for the present research each of the defined variables will be selected directly from the test data presented. Rather than using the average values for each column length, the individual values are used in the following equations for predicting the failure strength, giving a more accurate representation of the strain energy density model's ability to calculate failure.

Before failure strength prediction can be made, bending during loading has to be accounted for, since the theoretical equations previously used in the coupon and $1 \mathrm{ft}$ "pure" compression testing for axial strain energy are no longer accurate for computations of full length columns. In order to compensate for bending energy, Equation 5.11 for strain energy developed under bending loads is added to the strain energy induced under axial loading. Defined in 
Equation 5.14 below is a representation of the total theoretical strain energy for the full length columns.

$U_{\text {total }}=U_{\text {axial }}+U_{\text {bending }}=\frac{P^{2} L}{2 A E}+\frac{(P e)^{2} L}{2 E I}$

Where ' $\mathrm{e}$ ' is defined as the eccentricity causing bending and ' $E$ ' is taken as the MOE from coupon testing. The eccentricity of the loading was determined in a fashion similar to that of the method used in the 4-Phase loading technique for determining MOE of the 1ft "pure" compression tests discussed earlier. Utilizing simple mechanics of materials, stress was redefined in terms of MOE and strain, resulting in the following representation of total stress of a sample subjected to both axial compression and bending.

$$
E \varepsilon=\frac{P}{A}+\frac{P e c}{I}
$$

If ' $\mathrm{E}$ ' is taken as the MOE from coupon testing and ' $\mathrm{P}$ ' and ' $\varepsilon$ ' are measured experimental values, the only remaining unknown is the eccentricity, which is easily attained through substitution and rearrangement of the stress equation. With eccentricity known, the percent of the ultimate stress due to bending effects is easily computed.

Now that a theoretical representation of strain energy has been created, calculating the predicted failure load is established by simply equating the theoretical equation to the strain energy density model. In order to simplify the process in terms of unit conversion the theoretical equation must first be multiplied by MOE obtained from coupon testing. The strain energy density model needs to be multiplied by the representative volume of each column sample in an effort to transfer it to solely strain energy. The result is the following equation for predicted failure, where ' $U$ ' is the strain energy from the failure model (Equation 5.13) and ' $V$ ' is column volume. 


$$
P_{\text {pred }}=\frac{\sqrt{2} A I \sqrt{\frac{L U V\left(I+A e^{2}\right)}{A I}}}{I L+A L e^{2}}
$$

Application of prediction equation yields the following results for the selected column lengths tested.

Table 5-28 Full Length Strain Energy (6ft Columns)

\begin{tabular}{|c|c|c|c|c|c|c|c|}
\hline Sample & $\begin{array}{c}\text { Max Load } \\
\text { (kip) }\end{array}$ & Stress (psi) & $\begin{array}{c}\text { Vadlamani } \\
\text { U*E } \text { (psi }^{2} \text { ) }\end{array}$ & e (in) & \% Bending & P $_{\text {pred }}$ (kip) & \% Diff \\
\hline $6 f t \# 1$ & 65.06 & $26,212.63$ & $3.31 \mathrm{E}+08$ & 0.313 & 23.63 & 81.41 & 20.08 \\
$6 \mathrm{ft} \mathrm{\# 2}$ & 67.38 & $29,241.53$ & $4.32 \mathrm{E}+08$ & 0.416 & 29.10 & 91.19 & 26.11 \\
$6 \mathrm{ft} \mathrm{\# 3}$ & 69.34 & $29,060.59$ & $4.07 \mathrm{E}+08$ & 0.367 & 26.58 & 89.38 & 22.42 \\
$6 \mathrm{ft} \mathrm{\# 4}$ & 77.84 & $37,881.09$ & $4.87 \mathrm{E}+08$ & 0.589 & 36.77 & 92.75 & 16.08 \\
$6 \mathrm{ft} \mathrm{\# 5}$ & 73.61 & $32,802.31$ & $3.91 \mathrm{E}+08$ & 0.454 & 30.95 & 86.01 & 14.41 \\
\hline AVG & $\mathbf{7 0 . 6 5}$ & $\mathbf{3 1 , 0 3 9 . 6 3}$ & $\mathbf{4 . 1 0 E + 0 8}$ & $\mathbf{0 . 4 2 8}$ & $\mathbf{2 9 . 4 1}$ & $\mathbf{8 8 . 1 5}$ & $\mathbf{1 9 . 8 2}$ \\
\hline
\end{tabular}

Table 5-29 Full Length Strain Energy (8ft-6in Columns)

\begin{tabular}{|c|c|c|c|c|c|c|c|}
\hline Sample & $\begin{array}{c}\text { Max Load } \\
\text { (kip) }\end{array}$ & Stress (psi) & $\begin{array}{c}\text { Vadlamani } \\
\text { U*E (psi2) }\end{array}$ & e (in) & \% Bending & P $_{\text {pred }}$ (kip) & \% Diff \\
\hline $8.5 \mathrm{ft} \mathrm{\# 1}$ & 40.63 & $14,310.09$ & $9.34 \mathrm{E}+07$ & 0.146 & 12.63 & 44.16 & 7.99 \\
$8.5 \mathrm{ft} \mathrm{\# 2}$ & 47.75 & $26,473.22$ & $1.87 \mathrm{E}+08$ & 0.812 & 44.51 & 53.72 & 11.12 \\
$8.5 \mathrm{ft} \mathrm{\# 3}$ & 52.78 & $22,766.84$ & $1.92 \mathrm{E}+08$ & 0.407 & 28.67 & 60.97 & 13.43 \\
$8.5 \mathrm{ft} \mathrm{\# 4}$ & 32.23 & $12,158.19$ & -- & 0.229 & 18.45 & -- & - \\
$8.5 \mathrm{ft} \mathrm{\# 5}$ & 61.61 & $22,508.89$ & $1.34 \mathrm{E}+08$ & 0.190 & 15.78 & 52.63 & -17.06 \\
\hline AVG & $\mathbf{4 7 . 0 5}$ & $\mathbf{2 1 , 1 8 3 . 3 8}$ & $\mathbf{1 . 5 2 E}+\mathbf{0 8}$ & $\mathbf{0 . 4 5 5}$ & $\mathbf{2 8 . 6 0}$ & $\mathbf{5 2 . 9 5}$ & $\mathbf{1 0 . 8 4}$ \\
\hline
\end{tabular}


Table 5-30 Full Length Strain Energy (9ft Columns)

\begin{tabular}{|c|c|c|c|c|c|c|c|}
\hline Sample & $\begin{array}{c}\text { Max Load } \\
\text { (kip) }\end{array}$ & Stress (psi) & $\begin{array}{c}\text { Vadlamani } \\
\text { U*E (psi2) }\end{array}$ & e (in) & \% Bending & P pred (kip) & \% Diff \\
\hline 9ft \#1 & 38.35 & $17,284.65$ & $1.20 E+08$ & 0.471 & 31.72 & 47.53 & 19.30 \\
9ft \#2 & 38.74 & $10,248.43$ & $4.97 E+07$ & 0.142 & 16.33 & 32.23 & -20.21 \\
9ft \#3 & 34.91 & $18,146.61$ & $1.18 E+08$ & 0.698 & 40.80 & 44.16 & 20.94 \\
9ft \#4 & 42.18 & $19,705.64$ & $1.44 E+08$ & 0.525 & 34.14 & 51.22 & 17.65 \\
9ft \#5 & 34.00 & $10,607.26$ & $5.85 E+07$ & 0.014 & 1.36 & 35.16 & 3.29 \\
\hline AVG & $\mathbf{3 7 . 6 4}$ & $\mathbf{1 5 , 1 9 8 . 5 2}$ & $\mathbf{9 . 8 0 E + 0 7}$ & $\mathbf{0 . 3 7 0}$ & $\mathbf{2 4 . 8 7}$ & $\mathbf{4 2 . 0 6}$ & $\mathbf{8 . 1 9}$ \\
\hline
\end{tabular}

Table 5-31 Full Length Strain Energy (10ft Columns)

\begin{tabular}{|c|c|c|c|c|c|c|c|}
\hline Sample & $\begin{array}{c}\text { Max Load } \\
\text { (kip) }\end{array}$ & Stress (psi) & $\begin{array}{c}\text { Vadlamani } \\
\text { U*E (psi2) }\end{array}$ & e (in) & \% Bending & P $_{\text {pred }}$ (kip) & \% Diff \\
\hline $10 \mathrm{ft} \mathrm{\# 1}$ & 30.97 & $17,384.96$ & $6.06 \mathrm{E}+07$ & 0.835 & 45.19 & 30.30 & -2.20 \\
$10 \mathrm{ft} \mathrm{\# 2}$ & 21.37 & $16,511.93$ & $6.45 \mathrm{E}+07$ & 1.531 & 60.18 & 24.22 & 11.78 \\
$10 \mathrm{ft} \# 3$ & 34.34 & $14,861.17$ & $7.85 \mathrm{E}+07$ & 0.412 & 28.89 & 38.91 & 11.74 \\
$10 \mathrm{ft} \mathrm{\# 4}$ & 40.36 & $23,114.54$ & $1.81 \mathrm{E}+08$ & 0.872 & 46.28 & 51.66 & 21.88 \\
\hline AVG & $\mathbf{3 1 . 7 6}$ & $\mathbf{1 7 , 9 6 8 . 1 5}$ & $\mathbf{9 . 6 0 E + 0 7}$ & $\mathbf{0 . 9 1 3}$ & $\mathbf{4 5 . 1 4}$ & $\mathbf{3 6 . 2 7}$ & $\mathbf{1 0 . 8 0}$ \\
\hline
\end{tabular}

In most instances the predicted failure exceeded the experimental failure for each of the tested column lengths. Percent difference between the two ranged from 8-19\%, however if the 6ft columns are not included it is roughly $10 \%$. This is of significance due to the fact that similar trends have been observed within the other prediction models, clearly showing that the $6 \mathrm{ft}$ columns possibly have a slightly different material make up. The consistency of the results among the column lengths ranging from $8 \mathrm{ft}-6 \mathrm{in}$ to $10 \mathrm{ft}$ provides substantial validation for the creation of a prediction model based of off strain energy.

\subsubsection{Predicted Strain Energy Failure (Wide Flange Sections)}

Predicting failure for the 6ft 3" flanged columns followed the same procedure outlined in the previous section for hollow box columns. Bending along with axial effects were incorporated 
into the theoretical strain energy calculations that were then equated to the strain energy produced by stress-strain data. One major difference between the two different types of cross sections existed in that, the hollow box columns exhibited a stress-strain relationship with three distinct slope changes where as the wide flange section presented a nearly linear response. This phenomenon allows for the variables defined in Tables 5-27 thru 5-30 to be eliminated. Therefore, strain energy was calculated in a method similar to the coupon and $1 \mathrm{ft}$ "pure" compression tests.

The percentage of the total stress attributed to bending was solved utilizing two different methods due to the presence of back to back strain gages placed longitudinally at mid-height on opposing flanges. Previously, while evaluating the full length hollow box columns only a single set of strain data was available for eccentricity calculations, negating the effects of biaxial bending. In order to generate a comparison between the accuracy of each method's ability to calculate eccentricity induced bending, both single and double strain gage data was utilized yielding the following results for predicted failure.

Table 5-32 WF Strain Energy Failure (Single Strain Gage)

\begin{tabular}{|c|c|c|c|c|c|}
\hline Sample & $\begin{array}{c}\text { E } \\
\text { (msi) }\end{array}$ & $\begin{array}{c}\text { Max Load } \\
\text { (kip) }\end{array}$ & e (in) & P $_{\text {pred }}$ (kip) & \% Diff \\
\hline $6 \mathrm{ft} \mathrm{\# 1}$ & $\mathbf{4 . 4 0}$ & 21.59 & 0.114 & 24.393 & 11.49 \\
$6 \mathrm{ft} \mathrm{\# 2}$ & $\mathbf{4 . 4 0}$ & 25.94 & 0.001 & 21.825 & -18.85 \\
$6 \mathrm{ft} \# 3$ & $\mathbf{4 . 4 0}$ & 20.65 & 0.089 & 22.183 & 6.91 \\
\hline AVG & $\mathbf{4 . 4 0}$ & $\mathbf{2 2 . 7 3}$ & $\mathbf{0 . 0 7}$ & $\mathbf{2 2 . 8 0}$ & $\mathbf{- 0 . 1 5}$ \\
\hline
\end{tabular}


Table 5-33 WF Strain Energy Failure (Double Strain Gage)

\begin{tabular}{|c|c|c|c|c|c|}
\hline Sample & $\begin{array}{c}\mathbf{E} \\
\text { (msi) }\end{array}$ & $\begin{array}{c}\text { Max Load } \\
\text { (kip) }\end{array}$ & e (in) & $\mathbf{P}_{\text {pred }}$ (kip) & \% Diff \\
\hline $6 \mathrm{ft} \mathrm{\# 1}$ & $\mathbf{4 . 4 0}$ & 21.59 & 0.116 & 24.382 & 11.44 \\
$6 \mathrm{ft} \mathrm{\# 2}$ & $\mathbf{4 . 4 0}$ & 25.94 & 0.068 & 21.731 & -19.37 \\
$6 \mathrm{ft} \# 3$ & $\mathbf{4 . 4 0}$ & 20.65 & 0.093 & 22.168 & 6.83 \\
\hline AVG & $\mathbf{4 . 4 0}$ & $\mathbf{2 2 . 7 3}$ & $\mathbf{0 . 0 9}$ & $\mathbf{2 2 . 7 6}$ & $\mathbf{- 0 . 3 6}$ \\
\hline
\end{tabular}

As noted in Tables 5-35 and 5-36 the percent difference between the predicted and experimental failure is consistent between the two methods for obtaining eccentricity data. This provides assurance in regard to the predicted failure calculated for the hollow boxed sectioned columns where only one set of strain data was utilized. Consequently, it can be concluded that the effects of biaxial bending were not prevalent within the hollow box columns.

Although the two different methods for calculating eccentricity yielded similar results in terms of predicted failure, further evaluation of open cross sections at varied length is needed to judge the consistency of this particular strain energy model.

Modulus of elasticity used in the calculations pertains to the value obtained from the 4Phase loading technique previously described for the $1 \mathrm{ft}$ "pure” compression samples.

\subsection{Effect of Initial Imperfections (Along Length)}

In order to ensure that both strength and serviceability limit states are accommodated Zureick (1998) proposed that initial imperfections along the length of a compression member resulting in minor eccentricities be limited to a maximum mid-height lateral deflection of $h / 700$, where ' $h$ ' is the column length in inches. The minor eccentricities that result from initial out of straightness can have adverse effects on the amount of bending experienced by the column during loading. The current research evaluates the consistency of the experimental data with the 
h/700 limit proposed by Zureick (1998) reported by Zarghamee (2010) in an effort to determine if a correlation can be made.

Eccentricity during loading of axial compression members can be divided into two categories, one pertaining to initial imperfections derived during the manufacturing process (e.g. residual stresses, fiber misalignment) and a second inherited directly from mid-height lateral deflection as a consequence of loading. The total eccentricity is the summation of the two. Currently, the AISC Code for steel construction requires the designer to account for an initial out of straightness of $h / 1000$. Furthermore, according to Winter (1960) P- $\Delta$ effects are amplified by two sources, out-of-straightness and eccentricity of the load. Winter (1960) recommends that each source may be considered equal in magnitude and subsequently fall in a range of $h / 500$ to $h / 1000$, resulting in a combined value of $h / 250$ to $h / 500$. Zarghamee (2010) suggests that a combined eccentricity affect greater than $h / 300$ shall require justification so that strength and stability (including aesthetics) of a member are not compromised. Additionally, in conjunction with Winter's (1960) analysis of steel columns, Zarghamee (2010) suggests the initial out-ofstraightness requirement of $h / 700$ for pultruded FRP composites be coupled with an account for eccentricity of loading of equal value, which results in total eccentricity enhancing P- $\Delta$ effects of h/350. Furthermore, under the assumption that creep effects reduce the MOE to 2/3 of the initial value, P- $\Delta$ effects are further magnified resulting an in increased eccentricity limit of $h / 220$. This limit on eccentricity pertains to a service load for design of $2 / 7 \mathrm{P}_{\mathrm{cr}}$. Based on concern over aesthetic issues of having overly deflected columns, Zarghamee (2010) recommends against increasing this service load even if strength permits. 


\subsubsection{Full-Length Column Eccentricity Evaluation (Stress Analysis)}

Total eccentricity can be found from mechanics of materials principles regarding the relationship between pure axial compressive stress and stress attributed to bending from a specific load phase utilizing strain gage data. Following a similar process previously outlined in section 5.1.6.3 Strain Energy Failure (Full Length Columns), the total eccentricity and corresponding percent of stress due to bending was attained. Lateral deflection at mid-height was recorded continuously throughout the course of loading. Therefore, remaining portion of the total eccentricity due to initial imperfections along the length is easily obtained by substitution.

Understanding the different phases of the loading process becomes essential in evaluating the correct stage at which to determine the total eccentricity of the test specimen. If the desired load is selected too early in the loading phase, results become inaccurate due to the specimen taking up slack in the initial loading. Selection of loads near failure results in relatively high midheight lateral deflections signifying second order mode shapes and the deflection entering a nonlinear response. Therefore, total eccentricity was calculated using both $25 \%$ and $50 \%$ of the ultimate load and the corresponding strains. The following tables provide a numerical representation of each of the three values of eccentricity discussed and the corresponding $h / 700$ (out-of-straightness) ratio for each of the tested columns lengths. The $h / 220$ limit for total eccentricity, after creep effects are incorporated, is also provided. Supplemental tables can be found in the Appendix, providing the same data derived from multiple stages of loading (10-20\% of ultimate, $50-60 \%$ of ultimate, and failure). 
Table 5-34 6ft Column Eccentricity (50\% Ult. Load)

\begin{tabular}{|c|c|c|c|c|c|c|}
\hline 6ft Samples & $\begin{array}{c}50 \% \text { Ult. } \\
\text { Load }\end{array}$ & $\begin{array}{c}\mathbf{e}_{\text {total }}=\mathbf{e}_{\text {def }}+ \\
\mathbf{e}_{\text {imp }}\end{array}$ & $\mathbf{e}_{\text {def }}$ & $\mathbf{e}_{\text {imp }}$ & $\mathbf{h} / \mathbf{7 0 0}$ & $\mathbf{h} / \mathbf{2 2 0}$ \\
\hline Sample ID & (kip) & (in) & (in) & (in) & (in) & (in) \\
\hline $6 \mathrm{ft} \mathrm{\# 1}$ & 33.980 & 0.259 & 0.110 & 0.149 & 0.103 & 0.327 \\
$6 \mathrm{ft} \mathrm{\# 2}$ & 36.409 & 0.364 & 0.188 & 0.176 & 0.103 & 0.327 \\
$6 \mathrm{ft} \mathrm{\# 3}$ & 36.456 & 0.288 & 0.220 & 0.068 & 0.103 & 0.327 \\
$6 \mathrm{ft} \mathrm{\# 4}$ & $\mathbf{3 8 . 9 5 4}$ & $\mathbf{0 . 3 6 8}$ & $\mathbf{0 . 1 2 2}$ & $\mathbf{0 . 2 4 6}$ & $\mathbf{0 . 1 0 3}$ & $\mathbf{0 . 3 2 7}$ \\
$6 \mathrm{ft} \# 5$ & 36.853 & 0.282 & 0.156 & 0.126 & 0.103 & 0.327 \\
\hline \multicolumn{2}{|c|}{ Average } & $\mathbf{0 . 2 9 8}$ & $\mathbf{0 . 1 6 7}$ & $\mathbf{0 . 1 3 0}$ & $\mathbf{0 . 1 0 3}$ & $\mathbf{0 . 3 2 7}$ \\
\hline
\end{tabular}

Table 5-35 8ft-6in Column Eccentricity (50\% Ult. Load)

\begin{tabular}{|c|c|c|c|c|c|c|}
\hline $\begin{array}{c}\mathbf{8 . 5 f t} \\
\text { Samples }\end{array}$ & $\begin{array}{c}\mathbf{5 0 \%} \text { Ult. } \\
\text { Load }\end{array}$ & $\begin{array}{c}\mathbf{e}_{\text {total }}=\mathbf{e}_{\text {def }}+ \\
\mathbf{e}_{\text {imp }}\end{array}$ & $\mathbf{e}_{\text {def }}$ & $\mathbf{e}_{\text {imp }}$ & $\mathbf{h} / \mathbf{7 0 0}$ & $\mathbf{h} / \mathbf{2 2 0}$ \\
\hline Sample ID & (kip) & (in) & (in) & (in) & (in) & (in) \\
\hline $8.5 \mathrm{ft} \mathrm{\# 1}$ & 20.347 & 0.134 & 0.000 & 0.134 & 0.146 & 0.464 \\
$8.5 \mathrm{ft} \mathrm{\# 2}$ & 23.989 & 0.223 & 0.063 & 0.160 & 0.146 & 0.464 \\
$8.5 \mathrm{ft} \mathrm{\# 3}$ & 26.372 & 0.160 & 0.000 & 0.160 & 0.146 & 0.464 \\
$8.5 \mathrm{ft} \mathrm{\# 4}$ & 16.106 & 0.017 & 0.113 & -0.096 & 0.146 & 0.464 \\
$8.5 \mathrm{ft} \# 5$ & 30.827 & 0.196 & 0.016 & 0.180 & 0.146 & 0.464 \\
\hline \multicolumn{2}{|c|}{ Average } & $\mathbf{0 . 1 7 8}$ & $\mathbf{0 . 0 3 8}$ & $\mathbf{0 . 1 5 9}$ & $\mathbf{0 . 1 4 6}$ & $\mathbf{0 . 4 6 4}$ \\
\hline
\end{tabular}

Table 5-36 9ft Column Eccentricity (50\% Ult. Load)

\begin{tabular}{|c|c|c|c|c|c|c|}
\hline 9ft Samples & $\begin{array}{c}\mathbf{5 0 \%} \text { Ult. } \\
\text { Load }\end{array}$ & $\begin{array}{c}\mathbf{e}_{\text {total }}=\mathbf{e}_{\text {def }}+ \\
\mathbf{e}_{\text {imp }}\end{array}$ & $\mathbf{e}_{\text {def }}$ & $\mathbf{e}_{\text {imp }}$ & $\mathbf{h} / \mathbf{7 0 0}$ & $\mathbf{h} / \mathbf{2 2 0}$ \\
\hline Sample ID & (kip) & (in) & (in) & (in) & (in) & (in) \\
\hline 9ft \#1 & 19.220 & 0.190 & 0.024 & 0.166 & 0.154 & 0.491 \\
9ft \#2 & 19.313 & 0.015 & 0.120 & -0.105 & 0.154 & 0.491 \\
9ft \#3 & 17.445 & 0.381 & 0.132 & 0.249 & 0.154 & 0.491 \\
9ft \#4 & $\mathbf{2 1 . 1 1 2}$ & $\mathbf{0 . 2 8 2}$ & $\mathbf{0 . 0 0 0}$ & $\mathbf{0 . 2 8 2}$ & $\mathbf{0 . 1 5 4}$ & $\mathbf{0 . 4 9 1}$ \\
9ft \#5 & 17.095 & 0.010 & 0.156 & -0.146 & 0.154 & 0.491 \\
\hline \multicolumn{2}{|c|}{ Average } & $\mathbf{0 . 2 8 4}$ & $\mathbf{0 . 1 0 8}$ & $\mathbf{0 . 2 0 8}$ & $\mathbf{0 . 1 5 4}$ & $\mathbf{0 . 4 9 1}$ \\
\hline
\end{tabular}


Table 5-37 10ft Column Eccentricity (50\% Ult. Load)

\begin{tabular}{|c|c|c|c|c|c|c|}
\hline $\begin{array}{c}10 \mathrm{ft} \\
\text { Samples }\end{array}$ & $\begin{array}{c}50 \% \text { Ult. } \\
\text { Load }\end{array}$ & $\begin{array}{c}\mathbf{e}_{\text {total }}=\mathbf{e}_{\text {def }}+ \\
\mathbf{e}_{\text {imp }}\end{array}$ & $\mathbf{e}_{\text {def }}$ & $\mathbf{e}_{\mathrm{imp}}$ & $h / 700$ & $h / 220$ \\
\hline Box Section & (kip) & (in) & (in) & (in) & (in) & (in) \\
\hline $10 \mathrm{ft} \# 1$ & 15.553 & 0.288 & 0.175 & 0.113 & 0.171 & 0.545 \\
\hline $10 \mathrm{ft} \# 2$ & 10.505 & 0.275 & 0.133 & 0.142 & 0.171 & 0.545 \\
\hline $10 \mathrm{ft} \# 3$ & 17.099 & 0.213 & 0.172 & 0.041 & 0.171 & 0.545 \\
\hline $10 \mathrm{ft} \# 4$ & 20.230 & 0.366 & 0.305 & 0.061 & 0.171 & 0.545 \\
\hline \multicolumn{2}{|c|}{ Average } & 0.286 & 0.196 & 0.081 & 0.171 & 0.545 \\
\hline
\end{tabular}

From the provided data it can be noted the average eccentricity due to initial imperfections along column length is above the limit proposed by Zureick (1998) for every tested column length at $50 \%$ of the ultimate load except in the case of the $10 \mathrm{ft}$ columns. Negative values are a direct result of the mid-height lateral deflection being greater than the measured total eccentricity from stress relationships. These negative values are considered invalid and therefore are not included in the average values displayed in the final row of each table. The percent difference between the limit $(\mathrm{h} / 700)$ and the calculated ' $\mathrm{e}_{\mathrm{imp}}$ ' ranges from $8-33 \%$. Total eccentricity at $50 \%$ of the ultimate load was well within the prescribed $h / 220$ limit for each column length, with the $6 \mathrm{ft}$ columns coming nearest to surpassing it.

At the lower loading stage (25\% of Ult.) the calculated eccentricities for initial imperfections along the column length commonly fell beneath the limit state of $h / 700$, as is outlined below. 
Table 5-38 6ft Column Eccentricity (25\% Ult. Load)

\begin{tabular}{|c|c|c|c|c|c|c|}
\hline $6 \mathrm{ft}$ Samples & $\begin{array}{c}25 \% \text { Ult. } \\
\text { Load }\end{array}$ & $\begin{array}{c}\mathbf{e}_{\text {total }}=\mathbf{e}_{\text {def }}+ \\
\mathbf{e}_{\text {imp }}\end{array}$ & $\mathbf{e}_{\text {def }}$ & $\mathbf{e}_{\mathrm{imp}}$ & $h / 700$ & $h / 220$ \\
\hline Sample ID & (kip) & (in) & (in) & (in) & (in) & (in) \\
\hline $6 \mathrm{ft} \# 1$ & 16.955 & 0.236 & 0.000 & 0.236 & 0.103 & 0.327 \\
\hline $6 \mathrm{ft} \# 2$ & 18.170 & 0.374 & 0.047 & 0.327 & 0.103 & 0.327 \\
\hline $6 \mathrm{ft} \# 3$ & 18.193 & 0.236 & 0.068 & 0.168 & 0.103 & 0.327 \\
\hline $6 \mathrm{ft} \# 4$ & 19.477 & 0.385 & 0.010 & 0.375 & 0.103 & 0.327 \\
\hline $6 \mathrm{ft} \# 5$ & 18.450 & 0.302 & 0.060 & 0.242 & 0.103 & 0.327 \\
\hline \multicolumn{2}{|c|}{ Average } & 0.307 & 0.037 & 0.270 & 0.103 & 0.327 \\
\hline
\end{tabular}

Table 5-39 8ft-6in Column Eccentricity (25\% Ult. Load)

\begin{tabular}{|c|c|c|c|c|c|c|}
\hline $\begin{array}{c}\mathbf{8 . 5 f t} \\
\text { Samples }\end{array}$ & $\begin{array}{c}\mathbf{2 5 \%} \text { Ult. } \\
\text { Load }\end{array}$ & $\begin{array}{c}\mathbf{e}_{\text {total }}=\mathbf{e}_{\text {def }}+ \\
\mathbf{e}_{\text {imp }}\end{array}$ & $\mathbf{e}_{\text {def }}$ & $\mathbf{e}_{\text {imp }}$ & $\mathbf{h} / 700$ & $\mathbf{h} / \mathbf{2 2 0}$ \\
\hline Sample ID & (kip) & (in) & (in) & (in) & (in) & (in) \\
\hline $8.5 \mathrm{ft} \mathrm{\# 1}$ & 10.265 & 0.071 & 0.000 & 0.071 & 0.146 & 0.464 \\
$8.5 \mathrm{ft} \mathrm{\# 2}$ & 11.915 & 0.122 & 0.026 & 0.096 & 0.146 & 0.464 \\
$8.5 \mathrm{ft} \mathrm{\# 3}$ & 13.198 & 0.113 & 0.000 & 0.113 & 0.146 & 0.464 \\
$8.5 \mathrm{ft} \mathrm{\# 4}$ & 8.017 & 0.154 & 0.053 & 0.101 & 0.146 & 0.464 \\
$8.5 \mathrm{ft} \# 5$ & 15.414 & 0.267 & 0.000 & 0.267 & 0.146 & 0.464 \\
\hline \multicolumn{2}{|c|}{ Average } & $\mathbf{0 . 1 4 5}$ & $\mathbf{0 . 0 1 6}$ & $\mathbf{0 . 1 3 0}$ & $\mathbf{0 . 1 4 6}$ & $\mathbf{0 . 4 6 4}$ \\
\hline
\end{tabular}

Table 5-40 9ft Column Eccentricity (25\% Ult. Load)

\begin{tabular}{|c|c|c|c|c|c|c|}
\hline 9ft Samples & $\begin{array}{c}25 \% \text { Ult. } \\
\text { Load }\end{array}$ & $\begin{array}{c}\mathbf{e}_{\text {total }}=\mathbf{e}_{\text {def }}+ \\
\mathbf{e}_{\text {imp }}\end{array}$ & $\mathbf{e}_{\text {def }}$ & $\mathbf{e}_{\mathrm{imp}}$ & $h / 700$ & $h / 220$ \\
\hline Sample ID & (kip) & (in) & (in) & (in) & (in) & (in) \\
\hline $9 \mathrm{ft} \# 1$ & 9.575 & 0.075 & 0.000 & 0.075 & 0.154 & 0.491 \\
\hline $9 \mathrm{ft} \# 2$ & 9.692 & 0.158 & 0.045 & 0.113 & 0.154 & 0.491 \\
\hline $9 \mathrm{ft} \# 3$ & 8.735 & 0.315 & 0.051 & 0.264 & 0.154 & 0.491 \\
\hline $9 \mathrm{ft} \# 4$ & 10.556 & 0.249 & 0.000 & 0.249 & 0.154 & 0.491 \\
\hline $9 \mathrm{ft} \# 5$ & 8.454 & 0.158 & 0.019 & 0.139 & 0.154 & 0.491 \\
\hline \multicolumn{2}{|c|}{ Average } & 0.191 & 0.023 & 0.168 & 0.154 & 0.491 \\
\hline
\end{tabular}


Table 5-41 10ft Column Eccentricity (25\% Ult. Load)

\begin{tabular}{|c|c|c|c|c|c|c|}
\hline $\begin{array}{c}10 \mathrm{ft} \\
\text { Samples }\end{array}$ & $\begin{array}{c}25 \% \text { Ult. } \\
\text { Load }\end{array}$ & $\begin{array}{c}\mathbf{e}_{\text {total }}=\mathbf{e}_{\text {def }}+ \\
\mathbf{e}_{\text {imp }}\end{array}$ & $\mathbf{e}_{\text {def }}$ & $\mathbf{e}_{\mathrm{imp}}$ & h/700 & $h / 220$ \\
\hline Box Section & (kip) & (in) & (in) & (in) & (in) & (in) \\
\hline $10 \mathrm{ft} \# 1$ & 7.730 & 0.125 & 0.000 & 0.125 & 0.171 & 0.545 \\
\hline $10 f t \# 2$ & 0.529 & 0.787 & 0.000 & 0.787 & 0.171 & 0.545 \\
\hline $10 \mathrm{ft} \# 3$ & 8.576 & 0.201 & 0.074 & 0.127 & 0.171 & 0.545 \\
\hline $10 \mathrm{ft} \# 4$ & 10.109 & 0.184 & 0.140 & 0.044 & 0.171 & 0.545 \\
\hline \multicolumn{2}{|c|}{ Average } & 0.170 & 0.071 & 0.099 & 0.171 & 0.545 \\
\hline
\end{tabular}

The differences between the calculated eccentricity at $25 \%$ and $50 \%$ are predominantly driven by the amount of lateral deflection at mid-height. At $50 \%$ of the ultimate load, the percentage of measured deflection with respect to failure deflection ranged from 5-17\% among the column lengths. However, at $25 \%$ of the ultimate load this range was reduced significantly to below $5 \%$ for each column length. In the case of the 8ft-6in and $9 \mathrm{ft}$ columns little deflection was experienced until after $50 \%$ of the ultimate load was reached, signifying that the limit state of $h / 700$ should be checked at a stage where an initial change in deflection occurs for this particular method of calculation. Furthermore, in selective cases within the sample media for a given column length the limit is met, verifying that a limit within the range of the provided $h / 700$ is acceptable upon further research

\subsubsection{Eccentricity due to Initial Imperfections (Southwell)}

Wong and Wang (2007) utilized the Southwell method described previously (5.1.1 Critical Buckling Strength by Southwell) to determine the critical buckling strength of GFRP composite columns at elevated temperatures. In their research, initial imperfections along the column length are presented as the intersection of the Southwell plot and the negative x-axis (deflection). The absolute value of this quantity is then taken as the amount of out-of-straightness 
present in the column during testing. A graphical representation of a Southwell plot identifying an initial column imperfection is provided below.

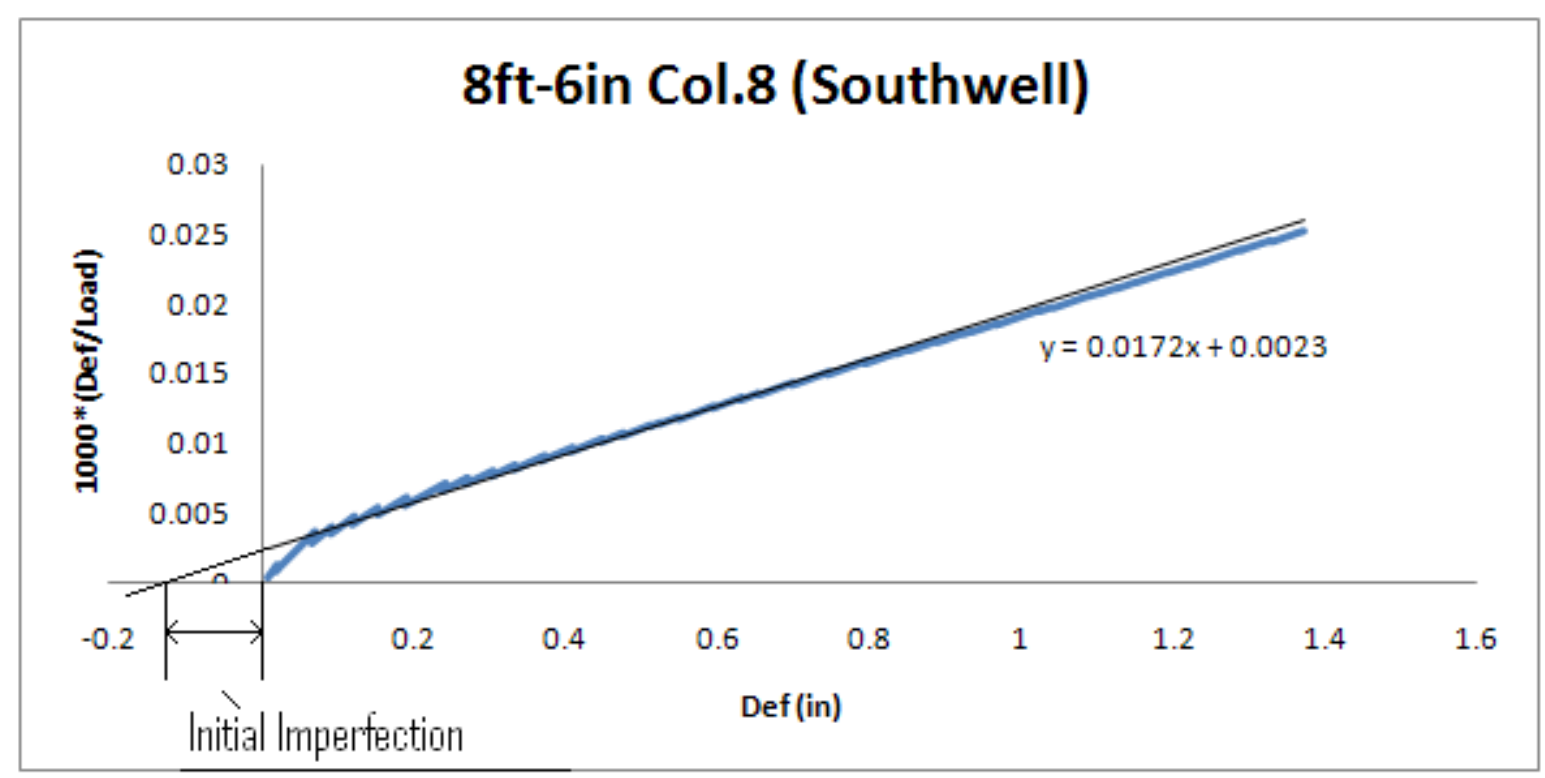

Figure 5-8 Column Initial Imperfection (Southwell)

Utilizing the method described by Wong and Wang (2006) average values for initial column out-of-straightness have been tabulated for each length of the hollow box columns along with their corresponding $h / 700$ limit as proposed by Zureick (1998).

Table 5-42 Average Column Imperfections (Southwell)

\begin{tabular}{|c|c|c|}
\hline $\begin{array}{c}\text { Column } \\
\text { Length }\end{array}$ & $\mathbf{e}_{\text {imp }}$ (in) & $\mathrm{h} / 700$ Limit \\
\hline $6 \mathrm{ft}$ & 0.205 & 0.103 \\
$8 \mathrm{ft}-6 \mathrm{in}$ & 0.096 & 0.146 \\
$9 \mathrm{ft}$ & 0.114 & 0.154 \\
$10 \mathrm{ft}$ & 0.166 & 0.171 \\
\hline
\end{tabular}

As evident in the Table 5-45, each of the column lengths tested met the required limit of $h / 700$ for initial imperfections, with the exception of the $6 \mathrm{ft}$ columns. A similar trend was observed at a loading of $25 \%$ of the ultimate discussed previously in the stress analysis. Further conclusions are drawn regarding this analysis in the ensuing Chapter. 


\subsection{Global vs. Local Buckling (LRFD Draft Spec)}

The predominant failure mechanism witnessed within the full length testing consisted of global buckling as a result of excessive load induced lateral deflection. Distinguishing between local and global failure was achieved by utilizing design equations for nominal axial stress presented in the current draft of the LRFD Design Manual for the use of FRP composites in structural applications. It is stated that for cross sections consisting of either square or rectangular tube sections the nominal critical stress be taken as the minimum of the Equations 5.17 \& 5.18, where Equation 5.17 represents the global failure stress and Equation 5.18 pertains to local buckling failure as noted below

$$
\begin{gathered}
F_{c r}=\frac{\pi^{2} E_{L}}{\left(\frac{K L}{r}\right)^{2}} \\
F_{c r}=\frac{\left(\frac{\pi^{2}}{6}\right)\left[\sqrt{E_{L} E_{T}}+v_{L T} E_{T}+2 G_{L T}\right]}{\beta_{w}{ }^{2}}
\end{gathered}
$$

where, $\beta_{\mathrm{w}}$ is the maximum width to thickness ratio, $v_{\mathrm{LT}}$ is Poisson's ratio associated with transverse deformation when compression is applied in the longitudinal direction and $\mathrm{E}_{\mathrm{T}}$ is the compression elastic modulus in the direction perpendicular to the pultrusion direction.

By equating Equations 5.17 and 5.18 to one another, the "critical length" where the transition between local and global buckling occurs can be calculated. Once the critical length is known a stress comparison, provided in Table 5-46, was made between actual failure stress of the columns tested in the present research and theoretical local/global buckling transition stress. 
Table 5-43 Transition between Local and Global Buckling

\begin{tabular}{|c|c|c|c|c|c|c|c|}
\hline \multirow{2}{*}{$\begin{array}{l}\text { Sample } \\
\text { ID }\end{array}$} & \multirow{2}{*}{$\begin{array}{c}\text { Critical Length } \\
\text { (ft) }\end{array}$} & \multicolumn{2}{|c|}{$\mathbf{F}_{\mathrm{cr}}(\mathrm{ksi})$} & \multirow{2}{*}{$\begin{array}{c}\text { Exp } \\
\text { Global } \\
\text { (ksi) } \\
\end{array}$} & \multirow[b]{2}{*}{$\mathbf{F}_{\text {cr.Global }} / \mathbf{F}_{\text {cr.Local }}$} & \multirow[b]{2}{*}{$\operatorname{Exp}_{\text {.Global }} / F_{\text {cr.Local }}$} & \multirow[b]{2}{*}{ \% Diff } \\
\hline & & $\begin{array}{c}\text { Local } \\
\text { Eq.5.22 }\end{array}$ & $\begin{array}{c}\text { Global } \\
\text { Eq. } 5.21\end{array}$ & & & & \\
\hline $6 \mathrm{ft}$ & 5.454 & 24.419 & 20.179 & 24.116 & 0.826 & 0.988 & 16.327 \\
\hline $8 \mathrm{ft}-6 \mathrm{in}$ & 5.472 & 29.637 & 12.282 & 18.905 & 0.414 & 0.638 & 35.034 \\
\hline $9 \mathrm{ft}$ & 5.472 & 29.637 & 10.955 & 14.008 & 0.370 & 0.473 & 21.796 \\
\hline $10 \mathrm{ft}$ & 5.472 & 29.637 & 8.873 & 11.883 & 0.299 & 0.401 & 25.329 \\
\hline
\end{tabular}

From Table 5-46 it can be noted that each of the columns lengths tested surpassed the “critical length” for local buckling, signifying failure due to global buckling. Experimental stress was computed by combining a concentric axial stress (P/A) with an additional bending stress (Pec/I), where eccentricity is represented by the $h / 700$ proposed by Zureick (1998). The experimental global buckling stress for each column length fell below the local buckling stress limit (Equation 5.18), providing further validation of global buckling failure.

All material properties where derived from mechanics of materials principals specifically the "Rule of Mixtures.” An effective length factor $(\mathrm{K})$ of 0.75 was used for each column length. 


\section{CHAPTER 6 Conclusions and Recommendations}

An extensive investigation into the prediction of critical buckling strength of pultruded GFRP composite columns was conducted in an effort to determine an adequately accurate failure load(s) criteria. The present research included both a review of published literature and laboratory tests dealing specifically with pultruded GFRP composite columns of varied length and cross section. Secondary analysis based on coupon and "pure” compression test specimens (12” long) data were also evaluated to accurately establish laminate mechanical properties while also serving as means of comparison with full-length samples. In addition to the strength prediction methods proposed in the literature, a strain energy density failure model previously created for GFRP composite coupons by researchers at WVU-CFC, was modified and applied to test specimens of the component level and produced promising strength prediction results over a range of column lengths. Furthermore, a design example was derived to establish a comparison with the current draft of the proposed LRFD composite design manual in an effort to evaluate accuracy of the manual’s suggested methodology for evaluating critical buckling strength.

\subsection{Evaluation of Mechanical Properties}

Composite materials present several complexities in structural analysis due to the anisotropic nature of their material properties. Developing an easy and accurate way of calculating mechanical properties commonly used in structural design is of benefit to both the manufacturer and designer.

The current research dealt with GFRP composites comprised of solely unidirectional fibers and CSM, significantly simplifying the evaluation of mechanical properties. Modulus of elasticity was tested for both the coupon and component levels in an effort to draw a correlation 
between coupon and full cross section samples. Utilizing the SACMA SRM 1R-94 (Modified ASTM D695) test procedures for evaluating coupons and the 4-phase loading technique described in Chapter 4, it was shown that both procedures are accurate accounts of measuring MOE with little deviation shown between the two methods. The resulting test data also compared well with theoretical mechanics and materials calculation methods, specifically the "Rule of Mixtures" technique, further verifying the accuracy of each test.

Designated shear modulus values for each of the column lengths tested were derived from theoretical applications along with three point bending tests conducted in the laboratory. A larger variation existed between each of the tests when compared with the MOE values, therefore, each method and its prescribed value were used in strength prediction calculations (5.1.3 Critical Load Proposed by F. Engesser).

\subsection{Commonalities within Data Analysis}

Several significant stress-strain/deflection trends were observed within the different column lengths under axial loading. Stress-strain relationships were primarily trilinear in nature, with a noticeable initial slope change at approximately 3,000 mircostrain. This phenomenon is likely attributed to internal slipping or delamination of the continuous strand mats within the composite. Global buckling effects were easily identified in load-deflection diagrams when the test specimen would experience an increase in deflection without a substantial increase in applied loading.

Bending effects are amplified by minor eccentricities accredited to initial imperfections. These imperfections are attributed to manufacturing defects from either miss alignment of fibers or crookedness of the column due to residual stress built up from non-uniform cooling. Miss 
alignment of the column during test set-up can enhance P- $\Delta$ effects during loading. For each of the column lengths tested the total eccentricity calculated from the combined stress (axial and bending) relationships discussed in Chapters 4 and 5, proved to be fairly consistent. In certain cases the calculation of initial imperfections along the column length resulted in values slightly greater than that of the limit proposed by Zureick (h/700).

Additional analysis utilizing Wong and Wang's (2007) account for initial imperfections along the column length provided a better correlation with Zureick's proposed $h / 700$ limit. During this effort, each of the tested column lengths fell below the limit $(<\mathrm{h} / 700)$ with the exception of the $6 \mathrm{ft}$ long columns. It is important to note that the failure data provided by Southwell analysis for the $6 \mathrm{ft}$ columns presented the largest variability between experimental failure and predicted failure. Consequently, initial imperfections as described by Wong and Wang (2007) directly incorporate the Southwell plot for each column validating the fact that the 6ft columns surpass the $h / 700$ limit.

Total eccentricity including the effects of creep, eccentricity of loading, and initial out-ofstraightness, and fiber misalignment shall be limited to $h / 220$, as suggested by Zarghamee (2010). Each of the tested column lengths under this study were well within the bounds of the limit at $25 \%$ and $50 \%$ of the ultimate failure load, even though several accounts for initial imperfections calculated through stress analysis proved greater than the previously discussed $h / 700$ limit. This suggests that the $h / 700$ limit can be further increased $(h / 500-h / 600)$, while simultaneously satisfying the total eccentricity limit of $h / 220$. 


\subsection{Strength Prediction}

Prediction of failure strength was evaluated for each of the different column lengths and corresponding cross sections utilizing several models presented in the literature. Differences between the methods included: accounting for initial imperfections created during manufacturing, the response of shear deformation during loading, empirical correlations, and effective length considerations. A summary of average failure load for the hollow box sections calculated from each prediction method is tabulated below with subsequent conclusions proceeding.

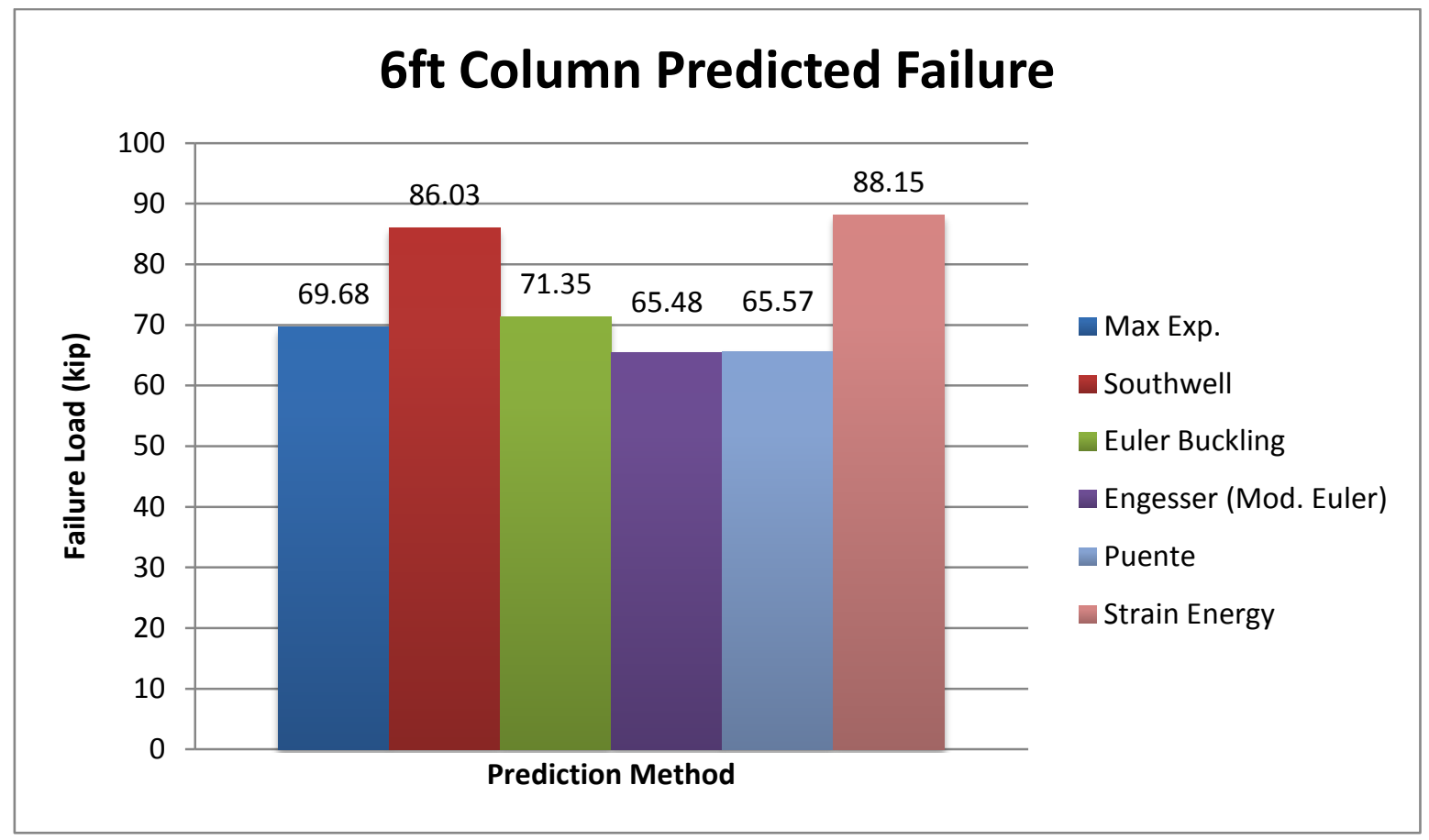

Figure 6-1 Predicted Failure (6ft Columns) 


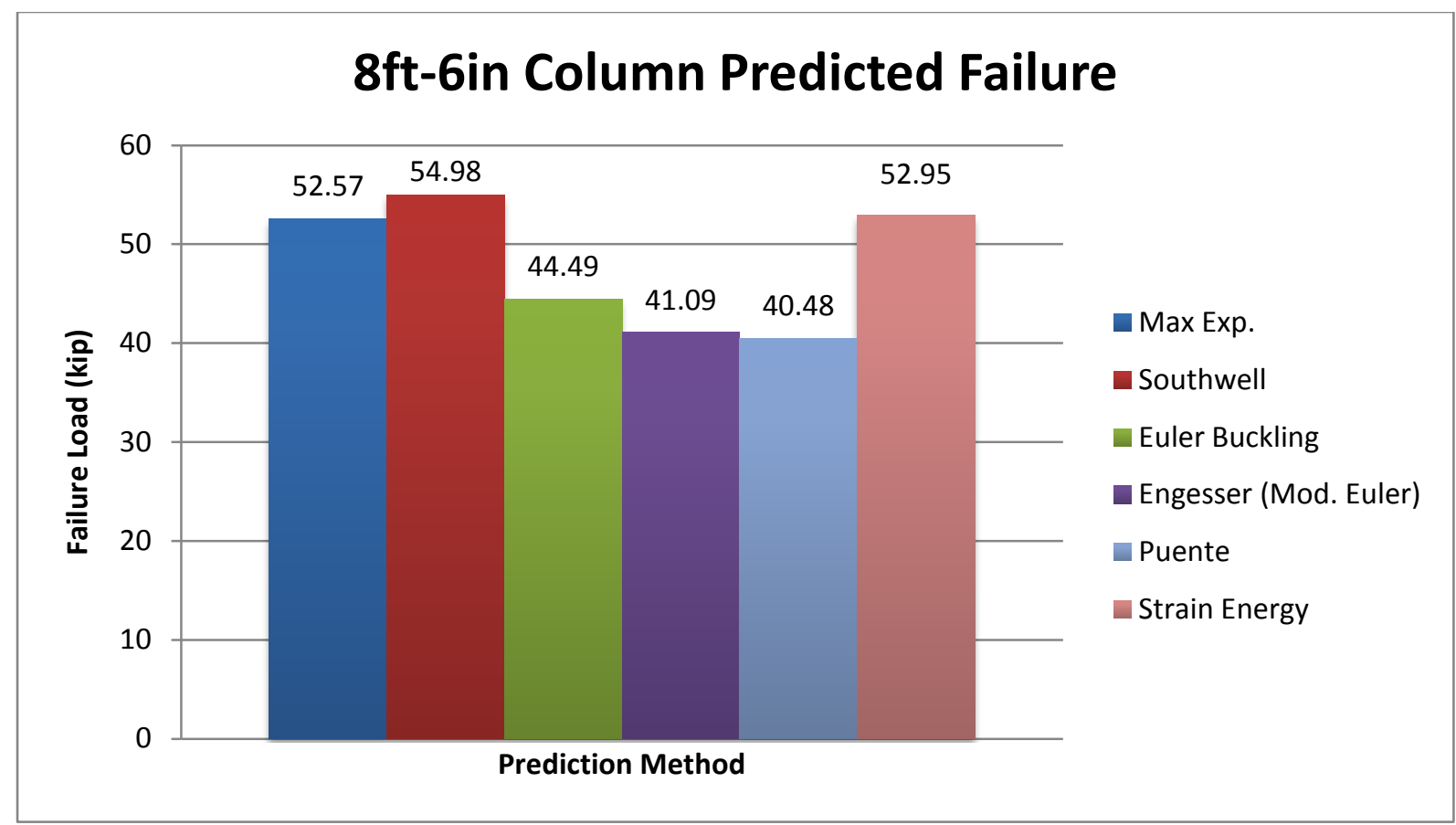

Figure 6-2 Predicted Failure (8ft-6in Columns)

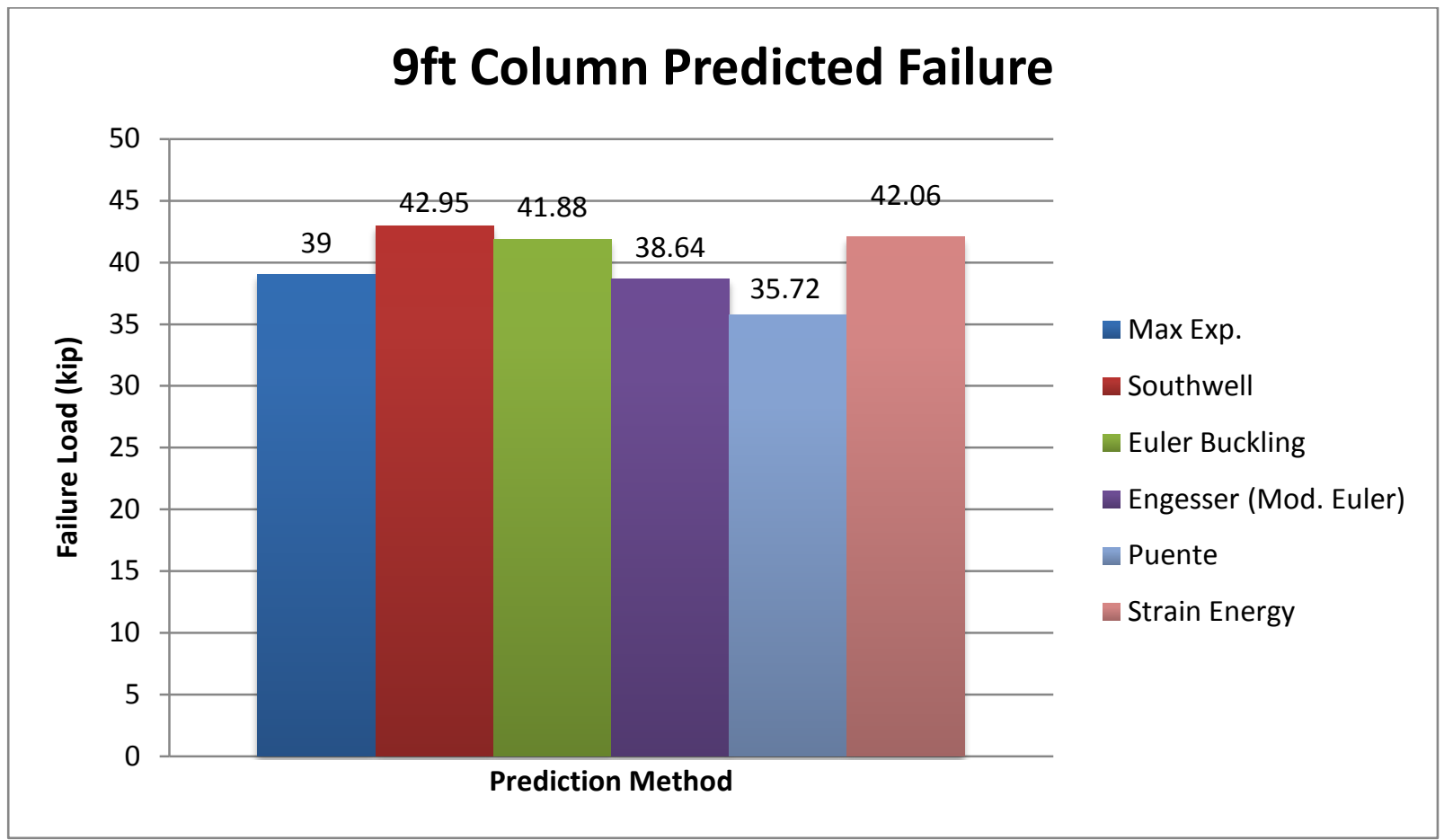

Figure 6-3 Predicted Failure (9ft Columns) 


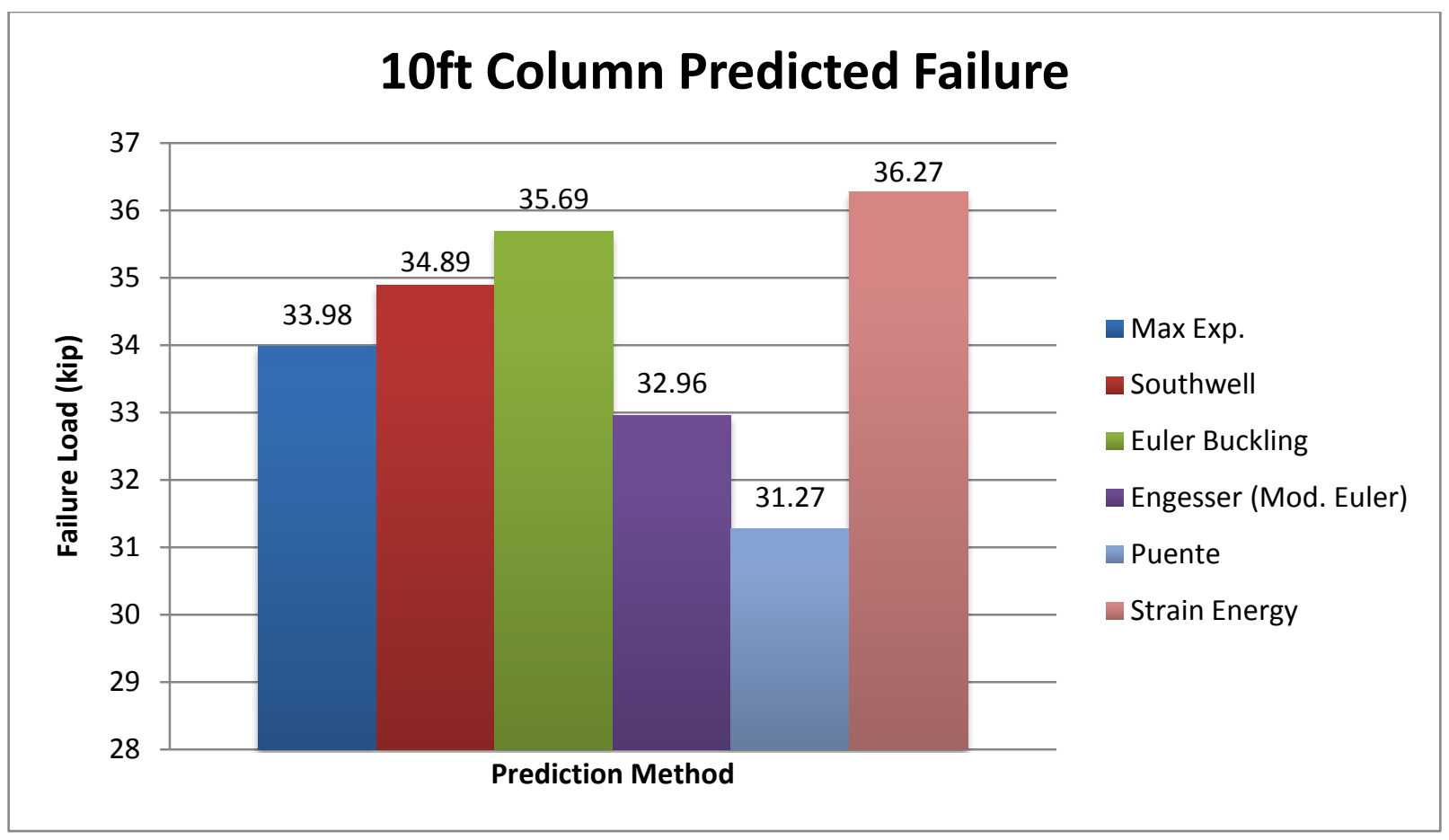

Figure 6-4 Predicted Failure (10ft Columns)

Consistency among the different theories tested in terms of over or under predicting the failure load was observed between each of the column lengths, the degree at which the prediction was off showed slightly more variance especially in the case of the $6 \mathrm{ft}$ columns. From the analysis of both the coupon and component data obtained from $6 \mathrm{ft}$ column samples, it can be concluded that the variance between the test data of the $6 \mathrm{ft}$ columns and the other $8 \mathrm{ft}-6 \mathrm{in}$, $9 \mathrm{ft}$ and $10 \mathrm{ft}$ long column test data is likely a result of different mechanical properties attributed to fiber volume fraction or different percent of cure of FRP used during manufacturing. Burn out test of coupon samples cut from the $6 \mathrm{ft}$ columns provided the necessary evidence of this conclusion by yielding a fiber volume fraction of 33\%, which is significantly less than the fiber volume fraction of 39-41\% typically used by BRP Inc.

Southwell prediction became more accurate as the column length increased. This did not come as a surprise since it is calculated based off load-deflection data and as the column length increased the amount of load induced deflection also grew. It shall be noted that properly 
accounting for experimental error present during the initial loading greatly impacts the accuracy of the method's ability to predict failure. In the case of the $6 \mathrm{ft}$ columns where little overall deflection was experienced, this phenomenon had even greater impact on the results (see section

\subsubsection{Critical Buckling Load by Southwell).}

Euler buckling and Engesser's modified Euler buckling equation accounting for shear deformation, provided very accurate accounts of failure. The percent difference between predicted and experimental failure was below $10 \%$ for every column length other than the $6 \mathrm{ft}$ columns where it was $12 \%$. Selection of appropriate effective length factors based on the support conditions is essential, since effective length is a function of the Euler buckling equation. The current research utilized support conditions which restrain the column ends with a mechanism somewhere between fully fixed and pin-pin, therefore, effective length factors were selected from a range of 0.5-1.0, with the overall column lengths' effect on rigidity during loading also accounted for.

Puente’s et al (2006) empirical equation derived from member slenderness slightly under predicted failure for each column length. The percent difference between experimental and predicted failure fell within a range similar to that of the other methods. However, local buckling loads are needed in order to calculate full length column capacity, making Puente's equation less than ideal for a designer.

Strength prediction by the strain energy density model developed for composite coupons by previous researchers at WVU-CFC required modifications for bending effects experienced during full scale column loading, which are discussed in further detail in Chapter 5.

The model's accuracy was extremely consistent among the different column lengths tested, with the exception of the $6 \mathrm{ft}$ columns having a slightly higher deviation between 
predicted and experimental failure. For the 8ft-6in, 9ft, and 10ft columns the percent difference between the two loads was near $10 \%$, showing a very promising correlation between its ability to predict failure with specimens of varied length (see Tables 5-31 thru 5-34).

In an effort to test each of the prediction methods ability to estimate strength based on cross section type, $6 \mathrm{ft} \mathrm{W}$-Flange columns of varied flange width were evaluated. Due to the lack of mid-height lateral deflection experienced during loading, the 6" flanged sections presented in Chapter 4 were not evaluated for each prediction method, therefore, the following table provides failure information for the 3" flanged sections only.

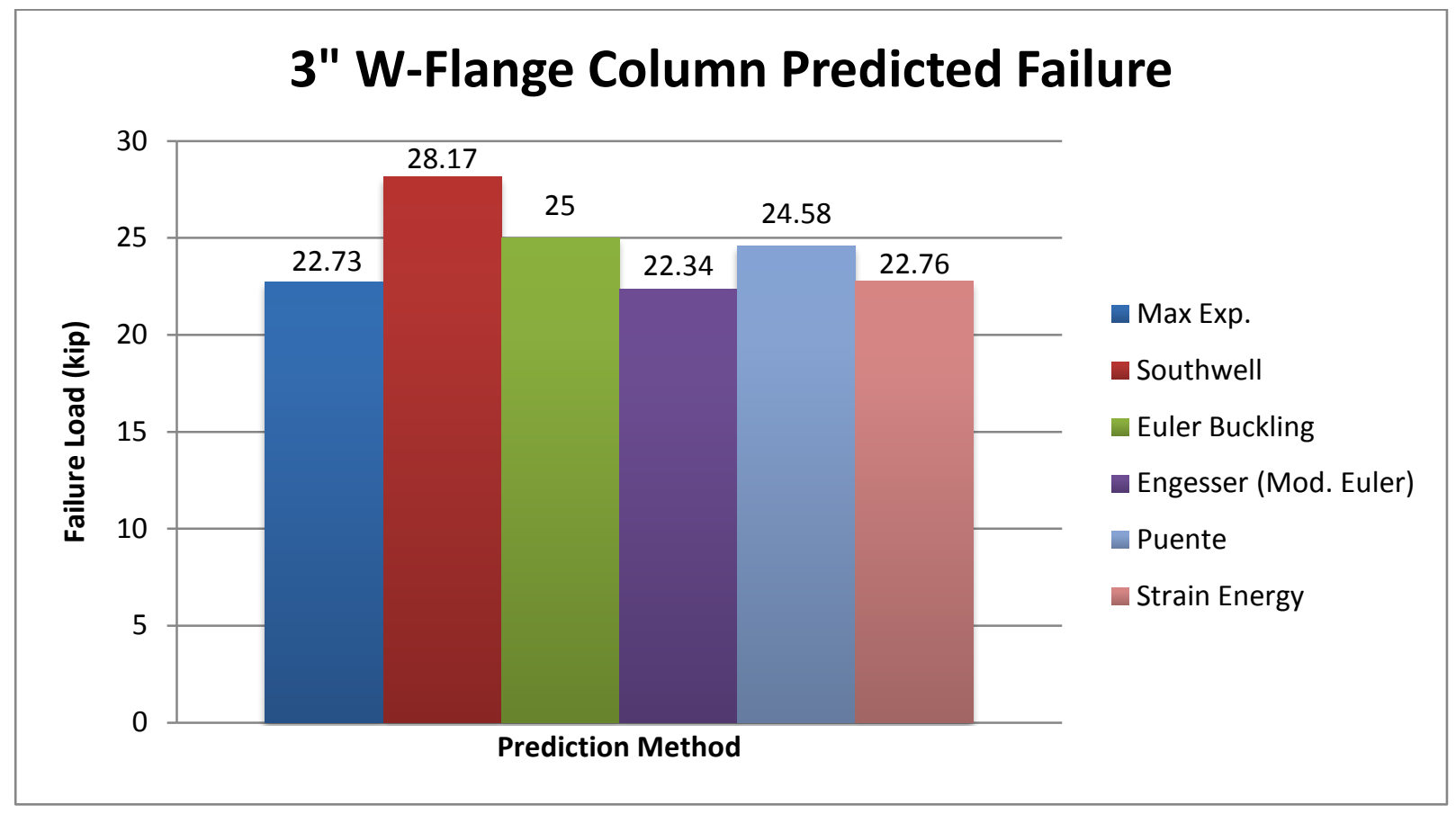

Figure 6-5 Predicted Failure (3" Flange)

As noted in Figure 6-5 a similar trend between predicted and experimental failure strength was observed for each method, in terms of open versus closed cross sections. Significantly more deflection was developed during loading in the case of the wide flange members due to the presence of a weak axis bending. Effective length factors were also taken at 
values closer to 0.5 when required, due to the deformed shape resembling more closely that of a fixed-fixed system.

\subsection{Recommendations}

To firmly draw a conclusion on which model displays the best accuracy and precision further testing is required.

The strain energy density model developed herein, showed promising results for pultruded GFRP composite columns with a vinyl ester matrix system, over the range of column lengths tested. However, in order to develop a universal model extensive testing is needed, to eliminate several of the assumptions made regarding, residual strain effects, void content of specimens, and bi-axial effects. Additional analysis regarding the assumption that GFRP composites follow a logical progression of failure is also required, since the corresponding stress and stiffness changes caused by distress and damage at each phase of the failure progression are being directly linked with changes in strain energy.

In this particular strain energy density model stress-strain relationship exhibited a curve with three distinct slope changes, allowing for the coefficients $\mathrm{K}_{1}, \mathrm{~K}_{2}, \mathrm{~K}_{\mathrm{E} 1}, \mathrm{~K}_{\mathrm{E} 2}$, etc. to be easily obtained following the same procedure outlined by Vadlamani (2007) for GFRP coupon composites with multidirectional reinforcing. Validity of this trend needs to be established for columns containing, different fiber volume fractions, fiber orientation, resin systems, and manufacturing processes. Although consistency over a range of column lengths was identified, a similar trend for different cross sections still needs to be established through additional analysis.

Variances in effective length need to be more firmly established by testing columns under well defined support conditions such as fully fixed or pin-pin, in order to more accurately 
determine each models' susceptibility to boundary conditions. The strain energy density model does not directly incorporate boundary conditions in the calculation of predicted failure however, changes in a columns stress-strain response may occur under different support conditions, resulting in different, ' $\mathrm{K}_{1}, \mathrm{~K}_{2}, \mathrm{~K}_{\mathrm{E} 1}, \mathrm{~K}_{\mathrm{E} 2}$, etc' values.

Theoretical accounts for strain energy need to be addressed further, more specifically in the case of combining strain energy due to bending to the pure axial compressive strain energy. A better account for eccentricity during loading is thus required.

Puente's, et al (2006) empirical approach to evaluating critical design strength provided a decent correlation between predicted and experimental failure for both open and closed cross sections. However, due to the local buckling strength being required in the analysis, Puente's, et al (2006) method is limited in terms of applicability for designers. Variances in local buckling strength are greatly impacted by fiber geometry, fiber volume fraction, manufacturing process, and matrix systems, resulting in the unlikelihood of data being readily available for a designer without subsequent laboratory testing.

Euler buckling and Engesser's modified Euler buckling equation provided consistent results for both closed and open cross sections of varied length. Additional W-Flange sections need to be evaluated to further validate the present research. Specific support conditions (pin-pin, fully fixed) must also be implemented in order to determine the two methods' accuracy when changes in effective length are experienced.

A decent correlation is made between characteristic values of experimental and Southwell data derived from ASTM D7290-06 as noted in Table 6-1 below, however, the necessity of experimental data limits the Southwell method's applicability for designers. Columns of shorter length and larger cross section do not provide accurate results due to the lack of mid-height 
lateral deflection a direct result of a failure mode approaching local buckling (see section 5.1.1.2 Wide Flange Sections).

Table 6-1 Characteristic Values of Southwell Method (ASTM D7290-06)

\begin{tabular}{|c|c|c|c|c|}
\hline \multirow[b]{2}{*}{$\begin{array}{c}\text { Sample } \\
\text { ID }\end{array}$} & \multicolumn{2}{|c|}{ Southwell } & \multicolumn{2}{|c|}{ Experimental Data } \\
\hline & $\begin{array}{c}\text { Confidence } \\
\text { Factor } \\
\Omega\end{array}$ & $\begin{array}{c}\text { Characteristic } \\
\text { Value } \\
\text { (kip) }\end{array}$ & $\begin{array}{c}\text { Confidence } \\
\text { Factor } \\
\Omega\end{array}$ & $\begin{array}{c}\text { Characteristic } \\
\text { Value } \\
\text { (kip) }\end{array}$ \\
\hline $6 \mathrm{ft}$ & 0.864 & 55.84 & 0.882 & 46.37 \\
\hline $8 \mathrm{ft}-6 \mathrm{in}$ & 0.910 & 39.77 & 0.880 & 33.58 \\
\hline $9 \mathrm{ft}$ & 0.921 & 32.93 & 0.896 & 27.16 \\
\hline $10 \mathrm{ft}$ & 0.700 & 13.10 & 0.886 & 24.92 \\
\hline
\end{tabular}

The current research suggests that prediction utilizing Euler buckling or the modified Euler buckling equation proposed by Engesser yields the most accurate results in terms of average percent difference for the range of column lengths tested. As noted in Table the strain energy prediction model provides more consistency in terms of over/under predicting the failure for each column length. However, due to the need for additional testing to validate assumptions made within the model, it cannot currently be implemented into design. Therefore, if specific support conditions for a particular design application are known it is suggested through the current analysis that the Euler buckling equation be utilized to yield the most accurate results.

Table 6-2 Average \%Diff with Respect to Experimental Data (Hollow-Box)

\begin{tabular}{|c|c|c|c|c|}
\hline Sample ID & $\begin{array}{c}\text { Euler } \\
\text { (kip) }\end{array}$ & $\begin{array}{c}\text { Engesser } \\
\text { (kip) }\end{array}$ & $\begin{array}{c}\text { Puente } \\
\text { (kip) }\end{array}$ & $\begin{array}{c}\text { Strain Energy } \\
\text { (kip) }\end{array}$ \\
\hline $6 \mathrm{ft}$ & 2.52 & -6.22 & -6.07 & 21.10 \\
$8 \mathrm{ft}-6 \mathrm{in}$ & -13.91 & -23.34 & -25.20 & 4.29 \\
$9 \mathrm{ft}$ & 6.88 & -0.93 & -9.18 & 7.28 \\
$10 \mathrm{ft}$ & 2.69 & -5.37 & -11.06 & 4.25 \\
\hline AVG & $-\mathbf{0 . 4 6}$ & $\mathbf{- 8 . 9 6}$ & $\mathbf{- 1 2 . 8 8}$ & $\mathbf{9 . 2 3}$ \\
\hline
\end{tabular}


Eccentricity due to initial imperfections along the column height should be limited to no greater than $h / 500$, where ' $h$ ' is the column height in inches. The limit of $h / 700$ recommended by Zureick (1998) could not be consistently met for the two methods of analysis performed as noted in Table 6-3. However, the limit of $h / 700$ only accounts for initial imperfections attributed to out-of-straightness across the column length. Additional imperfections that require consideration are misalignment of fibers/fabrics, and residual stress concentrations from non-uniform curing. Consideration of these aforementioned imperfections provides validation of why the $h / 700$ limit was not consistently met in the data presented herein.

Table 6-3 Eccentricity Due Initial Imperfections (50\% Ult. Load)

\begin{tabular}{|c|c|c|c|c|}
\hline Column Length & $\mathrm{e}_{\text {imp }}$ (exp) & $\mathrm{h} / 700$ & $\mathrm{~h} / 600$ & $\mathrm{~h} / 500$ \\
\hline $6 \mathrm{ft}$ & 0.130 & 0.103 & 0.120 & 0.144 \\
$8 \mathrm{ft}-6 \mathrm{in}$ & 0.159 & 0.146 & 0.170 & 0.204 \\
9ft & 0.208 & 0.154 & 0.180 & 0.216 \\
$10 \mathrm{ft}$ & 0.081 & 0.171 & 0.200 & 0.240 \\
\hline
\end{tabular}

Zarghamee's suggestion of limiting total eccentricity due to the effects of creep, eccentricity of loading, and initial out-of-straightness, to $h / 220$ proved to be an accurate account of the total eccentricity developed during testing in the current research over the ranges of column lengths evaluated at both $25 \%$ and $50 \%$ of the ultimate load.

Limiting the service load for design to $2 / 7 \mathrm{P}_{\text {cr }}$ is plausible if aesthetic issues regarding overly deflected columns are of concern. However, the current research proves that failure is not reached until well after the limit of $h / 220$ is met (50\% of Ultimate Load), leading to the possibility for an increased service load for design. Further analysis is therefore required before an adjustment to the $2 / 7 \mathrm{P}_{\mathrm{cr}}$ can be made. 


\section{REFERENCES}

Barbero, E. J. (1998). Introduction to Composite Material Design . Philadelphia , PA: Taylor \& Francis, INC. .

Barbero, E. J., \& Tomblin, J. (1994). A Phenomenological Design Equation for FRP Columns. Thin-Walled Structures , 117-131.

Dutheil, J. (1966). Verifica delle aste compresse: Principi fondamentali. Construzioni Metalliche , 266-275.

Gere, J. M. (2004). Mechanics of Materials (6th Edition ed.). Belmont, CA: Brooks/ColeThomson Learning .

Gere, J. M., \& Timoshenko, S. P. (1984). Mechanics of Materials (2nd ed.). Monterey, California , USA: Brooks/Cole Engineering Division.

Goodman, J., \& Gilksman, J. (1969). Structural evaluation of long boron composite column. Composite Materials: Testing and design , ASTM STP 460, 460-469. West Conshohocken, PA.

Hashem, Z. A. (1993). Structural Behavior of Plastic Composite Columns. University of Texas at Arlington. Arlington : University of Texas at Arlington.

Hewson, P. (1978). Buckling of pultruded glass fibre-reinforced channel sections. Composites , 9 (17) , 56-60.

Hutchinson, J. (2001). Shear Coefficients for Timoshenko Beam Theory. Journal of Applied Mechanics , 68, 87-92.

Lackey, E., Vaughan, J., Gupta, S., Rawls, S., \& Wimbrow, W. (2007). Comparison of Compression Test Methods for Pultruded Composites. Composties \& Polycon (pp. 1-18). Tampa: American Composites Manufacturers Association. 
Lee, D., \& Hewson, P. (1978). The use of fiber-reinforced plastics in thin-walled structures.

Stability Problems in Engineering Structures and Components (pp. 23-55). New York: T.H. Richards and P. Stanley.

Maquoi, R. a. (1978). Mise en equation des nouvelles courbes europeenes de flambement. Construzioni Metalliche , 1 , 17-30.

Nagaraj, V., \& GangaRao, H. (1997, August ). Static Behavior of Pultruded GFRP Beams. Journal of Composites for Construction , 120-129.

Puente, I., Insausti, A., \& Azkune, M. (2006, November/December). Buckling of GFRP Columns: An Empirical Approach to Design. Journal of Composites for Construction , 529-537.

Roberts, T. M., \& Masri, H. M. (2003). Section Properties and Buckling Behavior of Pultruded FRP Profiles. Journal of Reinforced Plastics and Composites , 22 (14), 1305-1317.

Southwell, R. (1932). On the Analysis of Experimental Observations in Problems of Elastic Stability (Vol. 135). London: Proceedings of the Royal Society of London.

Vadlamani, D. (2007). Strain Energy Density Based Failure Criterion for GFRP Coupons Under Tension and Bending. West Virginia University , Department of Mechanical and Aerospace Engineering . Morgantown: West Virginia University.

Winter, G. (1960). Lateral Bracing of Columns and Beams. ASCE Transaction, Paper No. 3044 , 116-136. ASCE.

Wong, P., \& Wang, Y. (2007, September 12). An experimental study of pultruded glass fibre reinforced plastic channel columns at elevated temperatures. Composite Structures (81) , 84-95. Manchester, United Kingdom: Elsevier. 
Zarghamee, M. S. (2010, April 21). Column Design of Serviceability Loads. Development of ASCE Standard for Load and Resistance Factor Design of Pultruded FRP Structures . Simpson Gumpertz \& Heger .

Zureick, A. (1998). Progress in Durability Analysis of Composite Systems. In K. Reifsnider, D. Dillard, \& A. Cardon (Ed.), Polymer Composites for Infrastructure, (pp. 181-184). Blacksburg. Zureick, A., \& Scott, D. (1997, November ). Short-Term Behavior and Design of FiberReinforced Polymeric Slender Members under Axial Compression. Journal of Composites for Construction , 140-149. 


\section{APPENDIX A - Data Analysis Figures}

Included in this appendix are additional plots of load-deflection, stress-strain, Southwell's method, and stress-strain regression analysis, for each of the testing methods described in the text.

\section{Full-Length Load Deflection Diagrams for Hollow Box Sections}
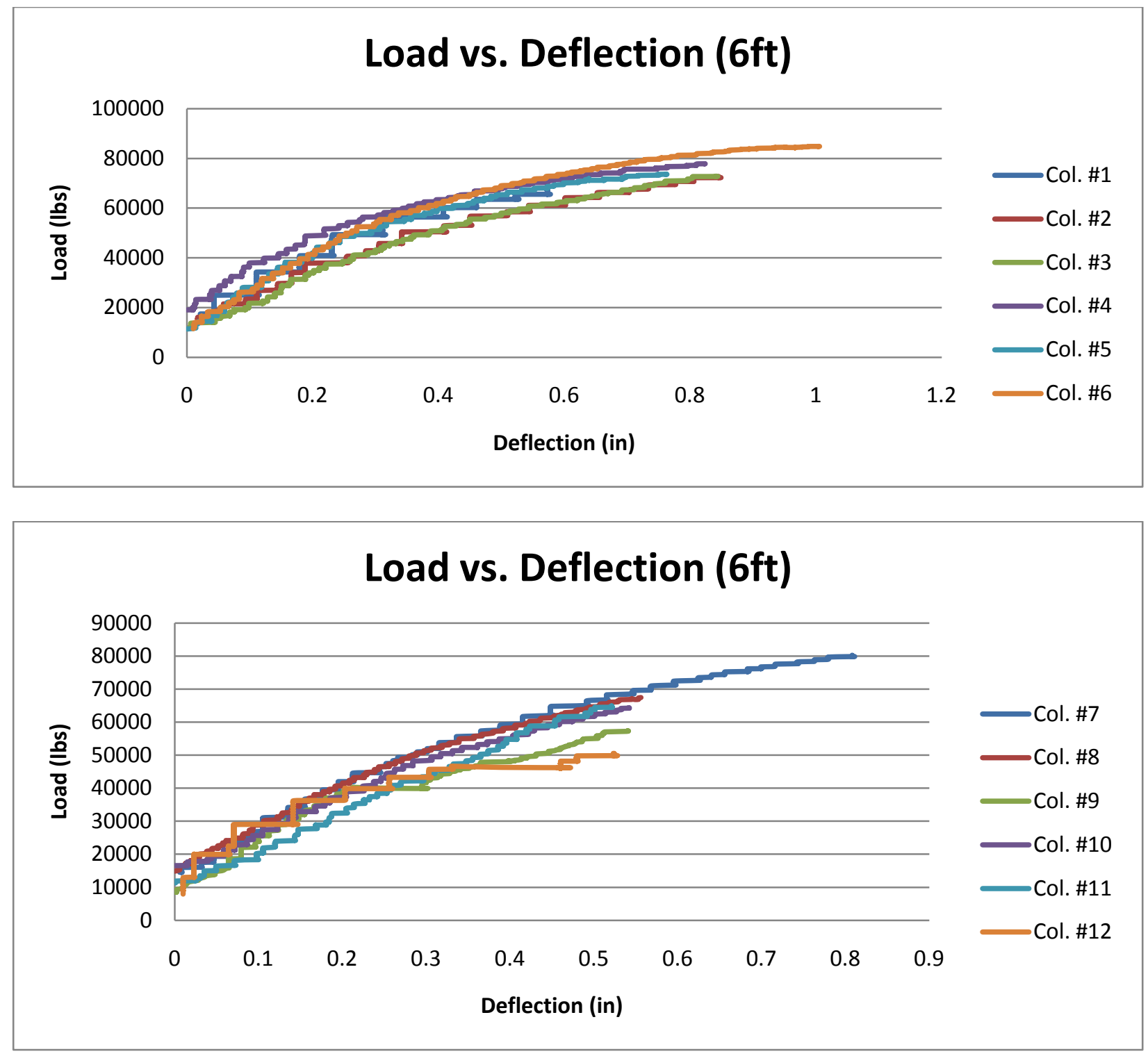

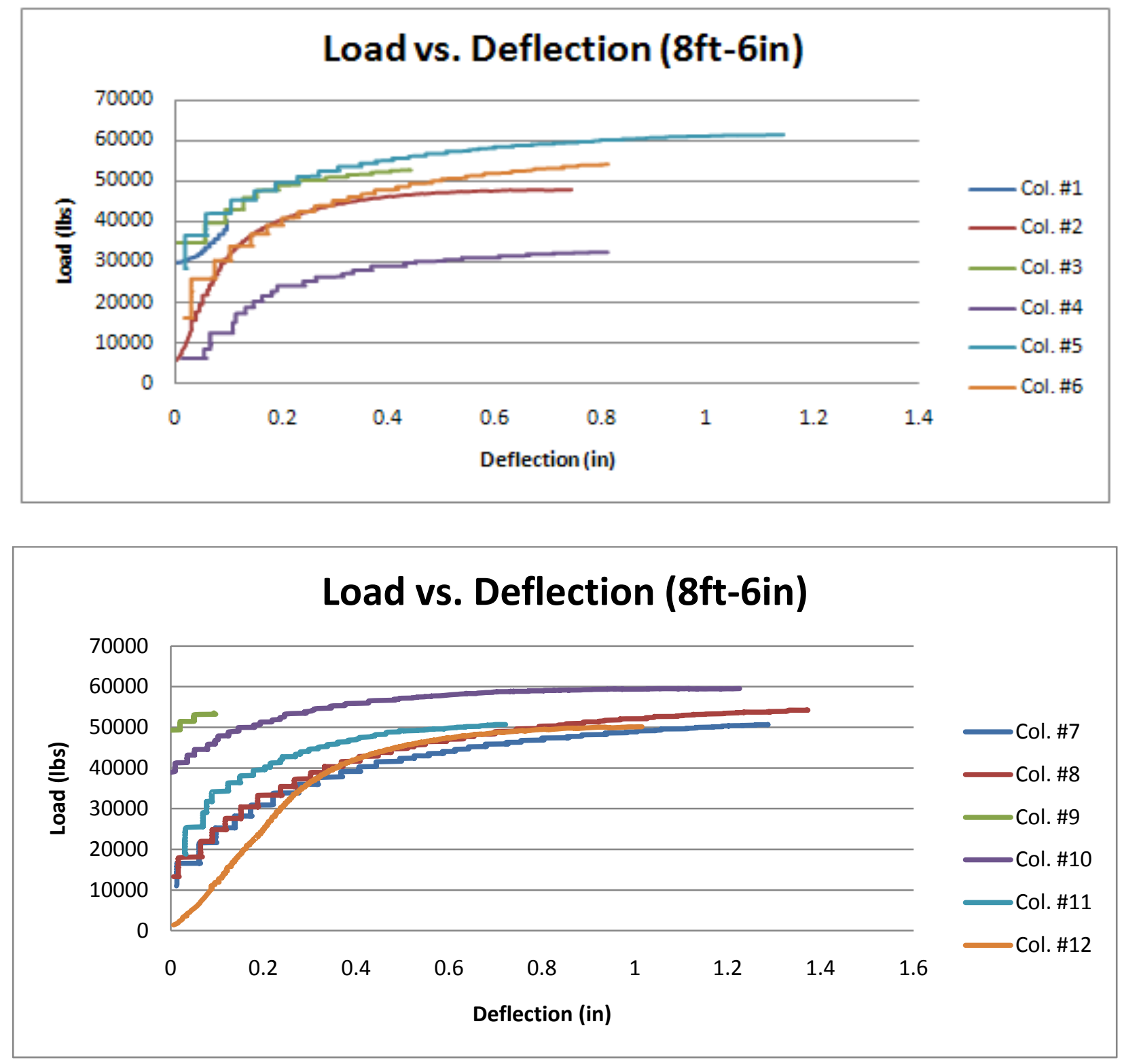

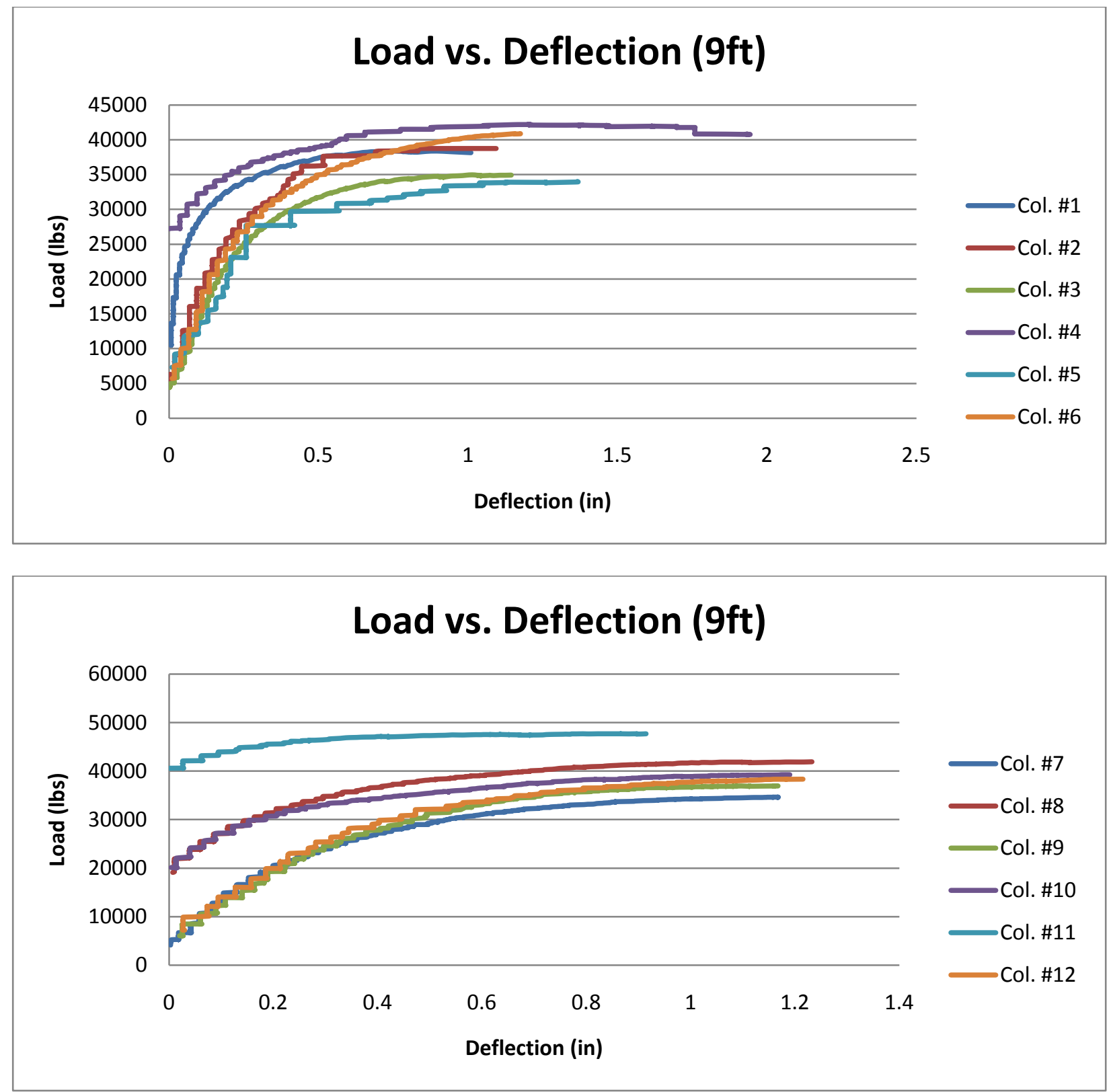

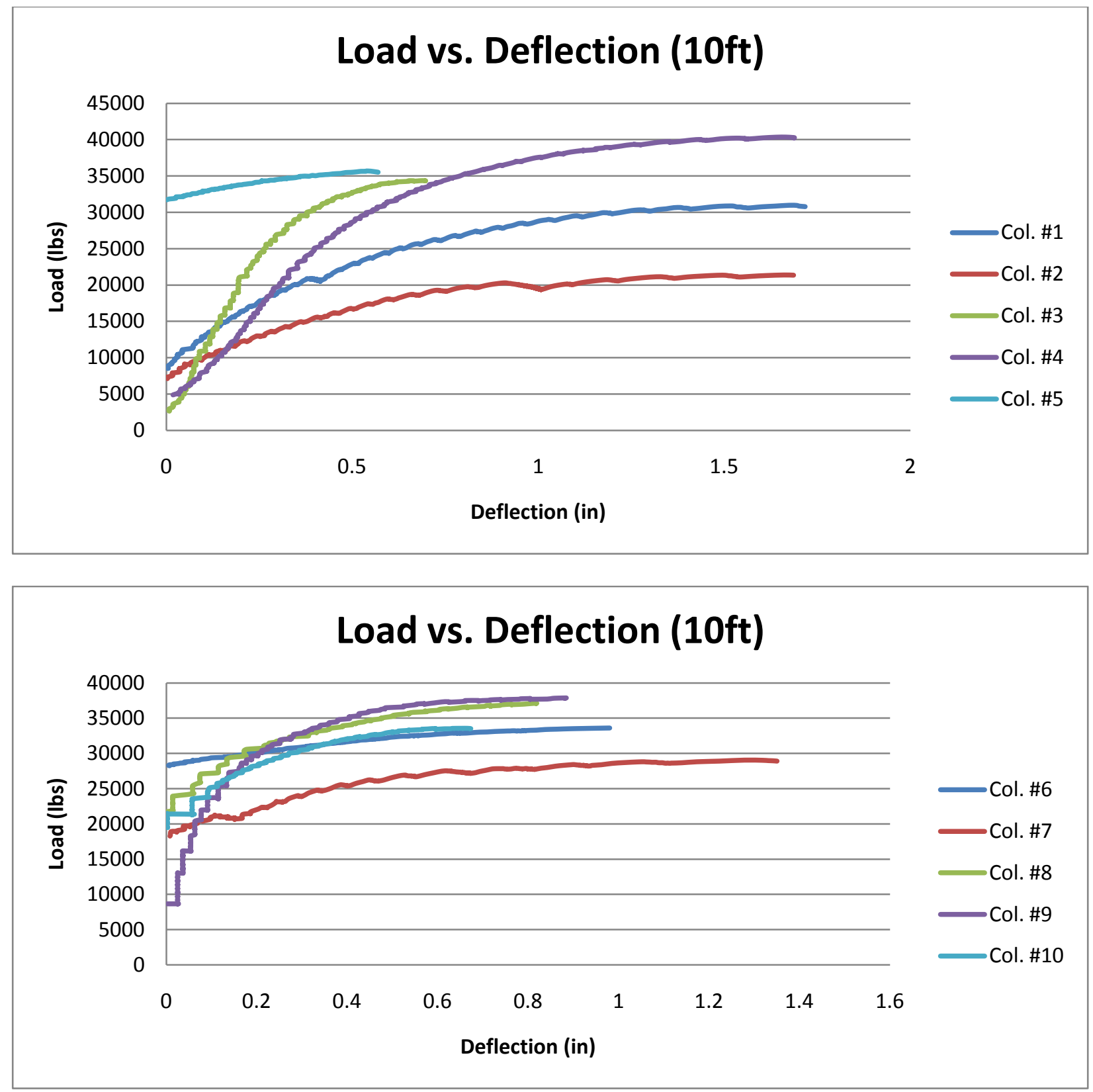
Stress-strain plots of 1ft "Pure” Compression Tests (Hollow Box Sections)
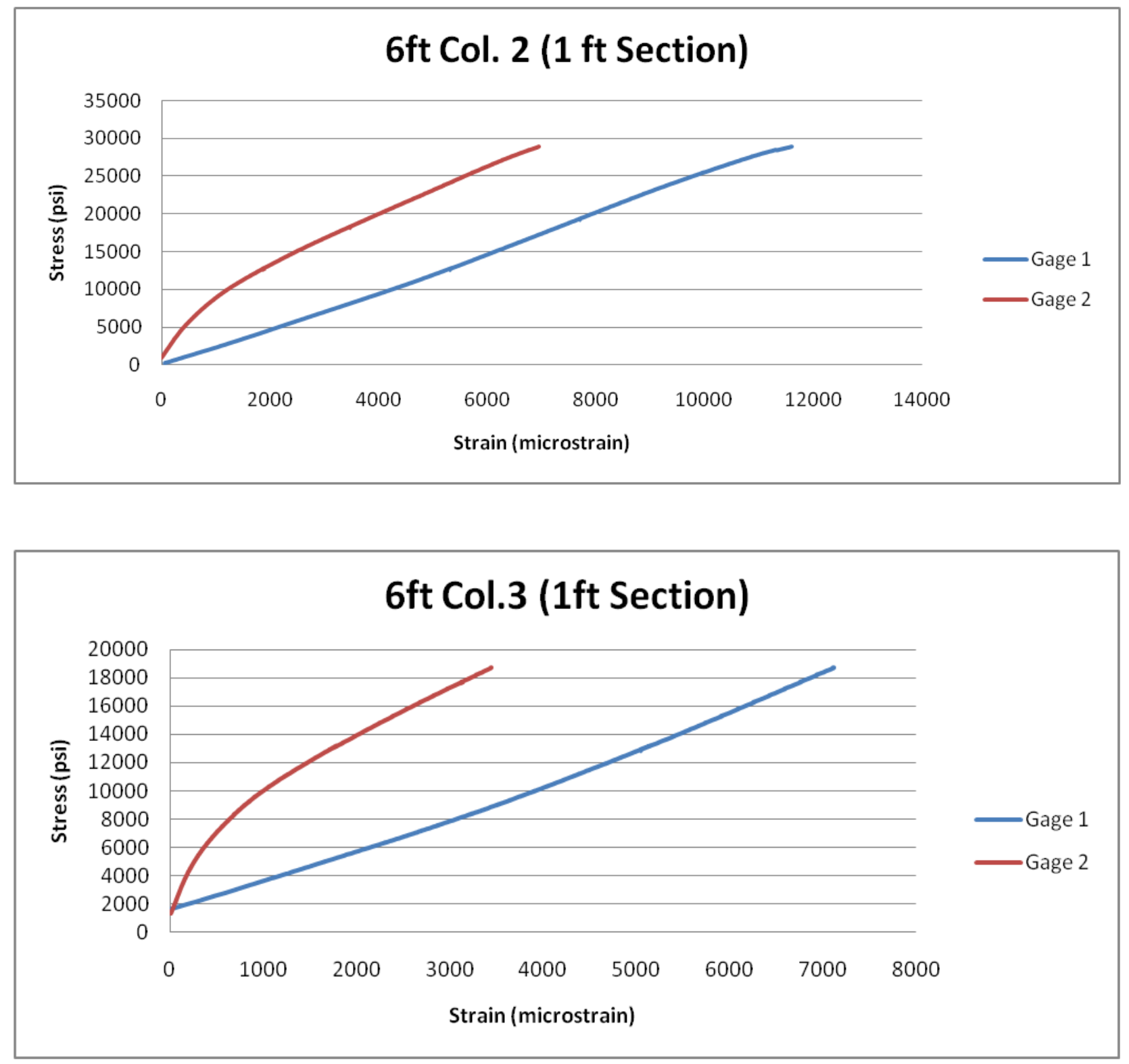

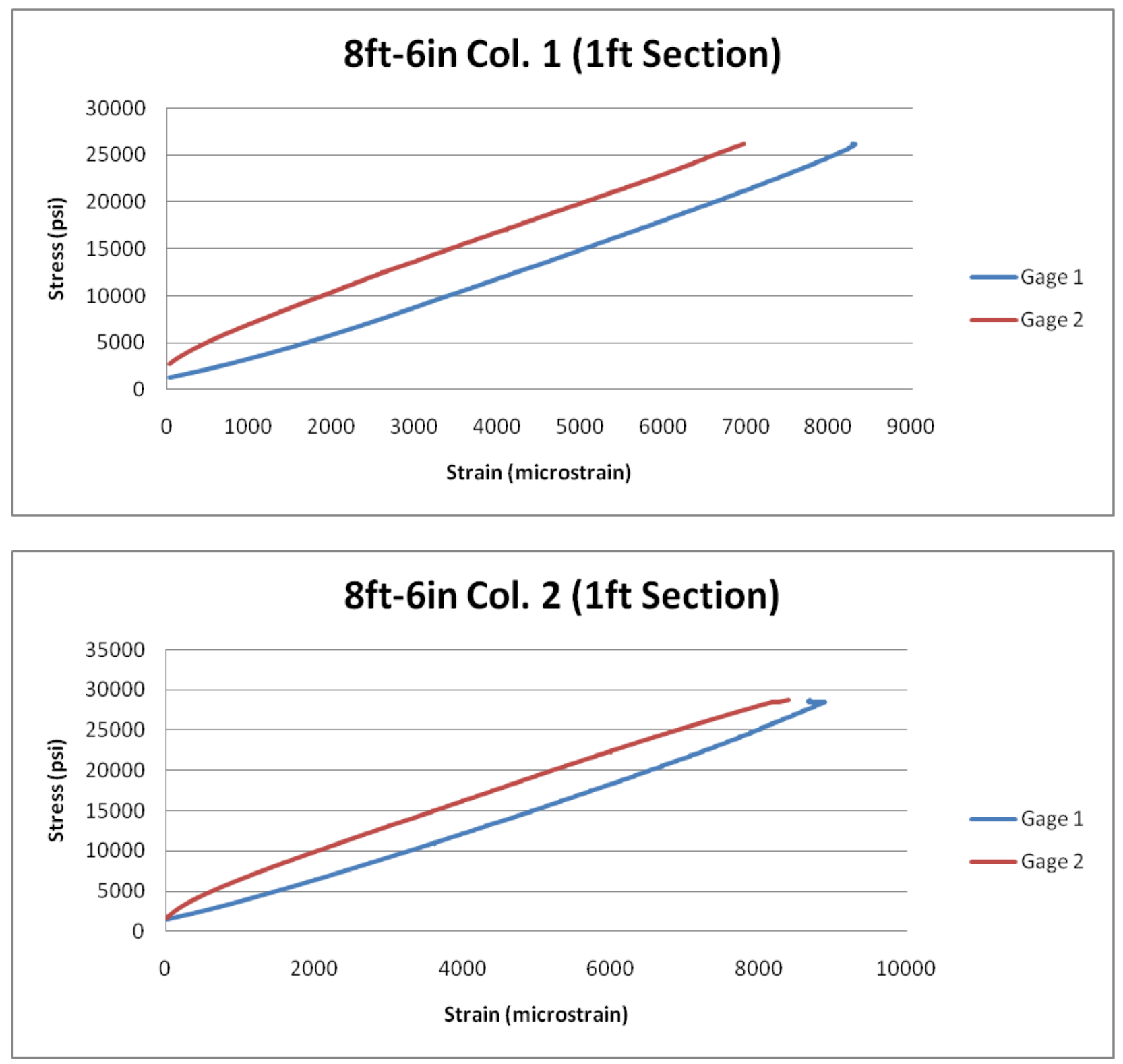

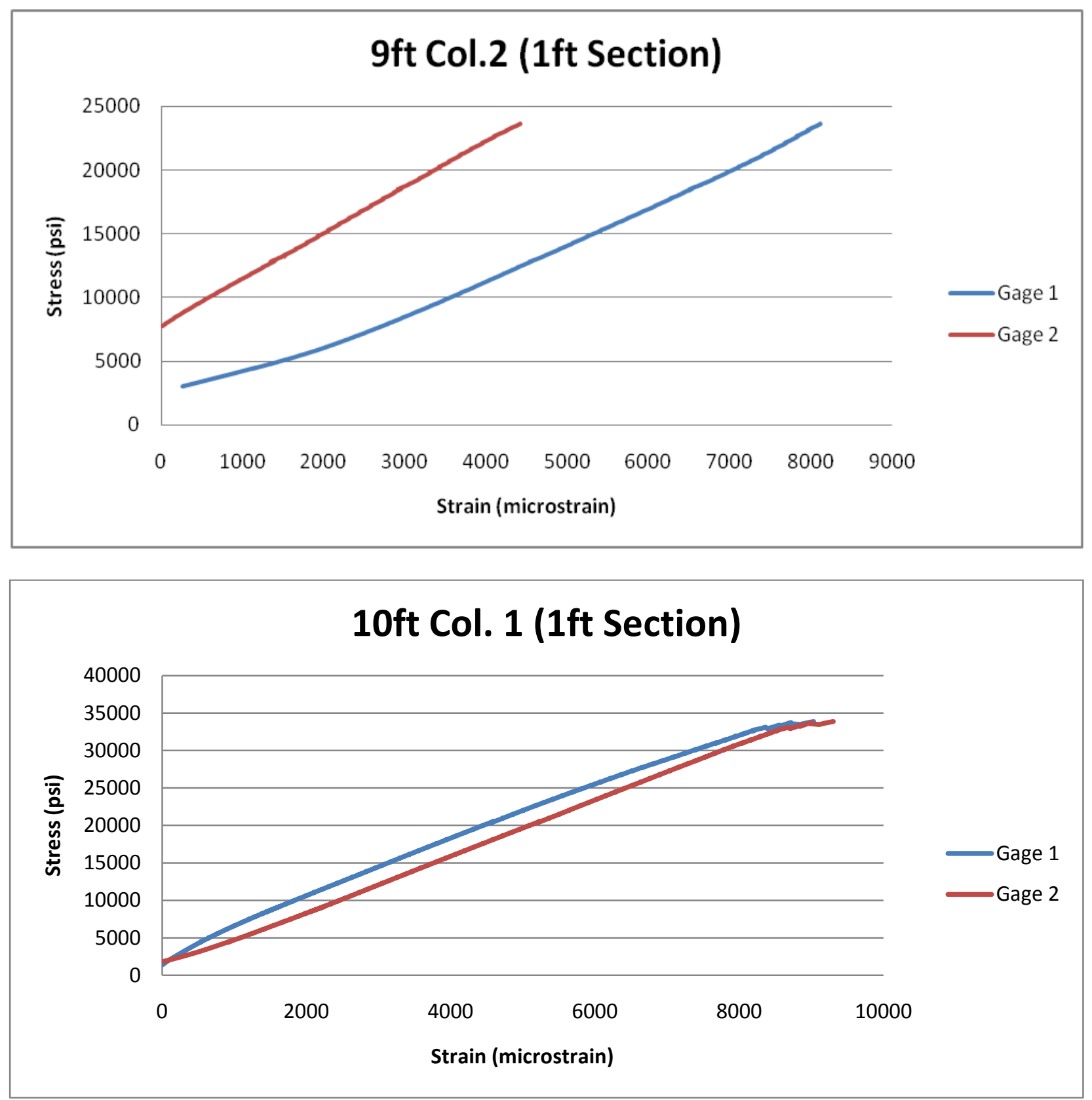


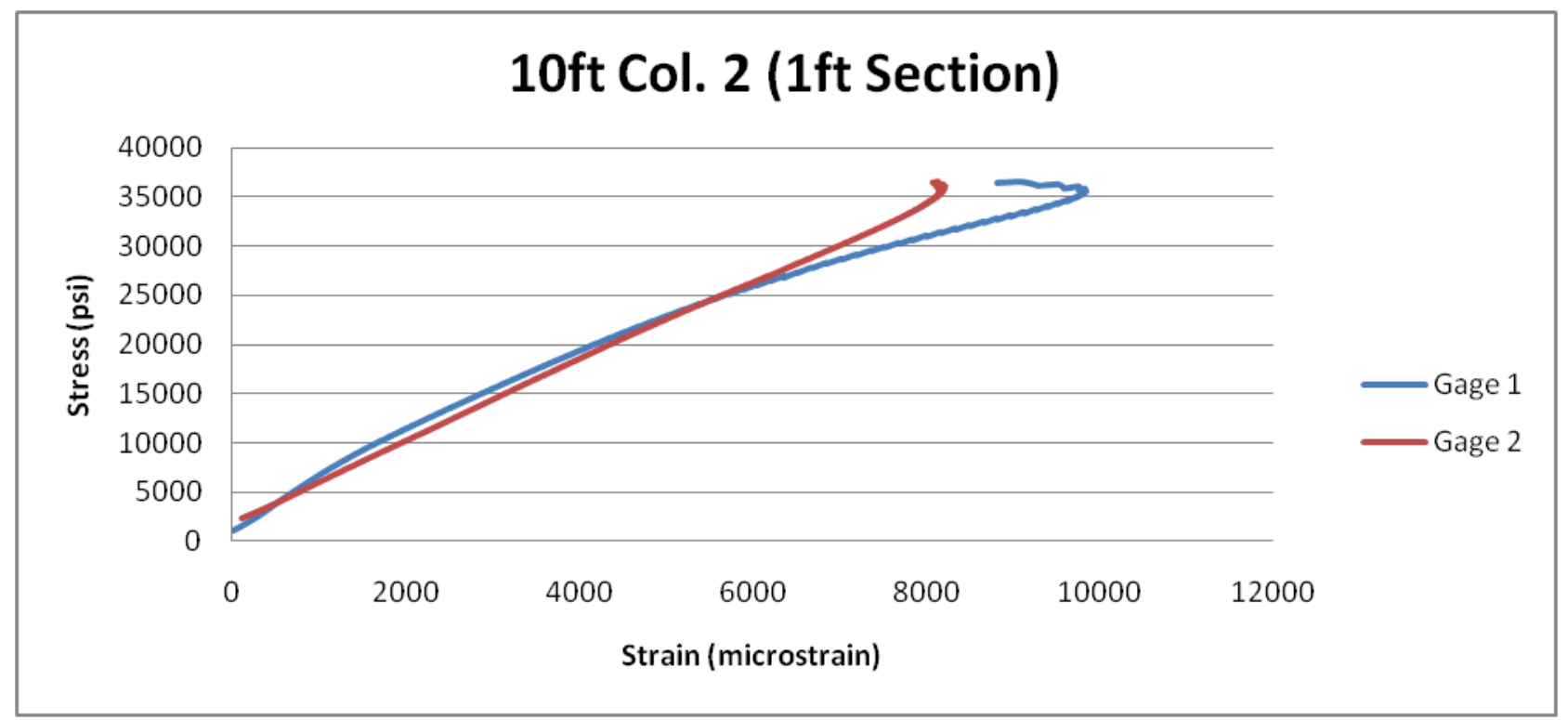

Stress-strain plots of 1ft "Pure” Compression Tests (WF Sections)

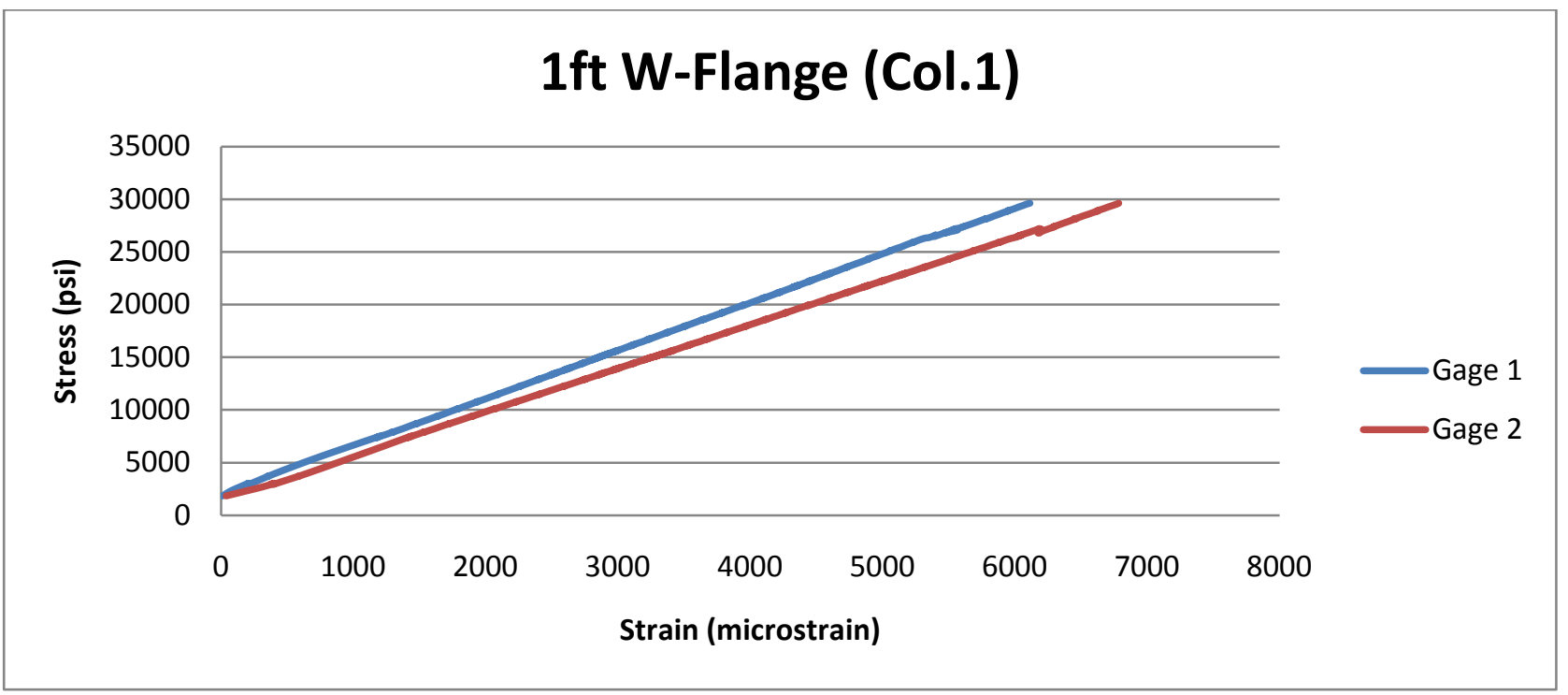



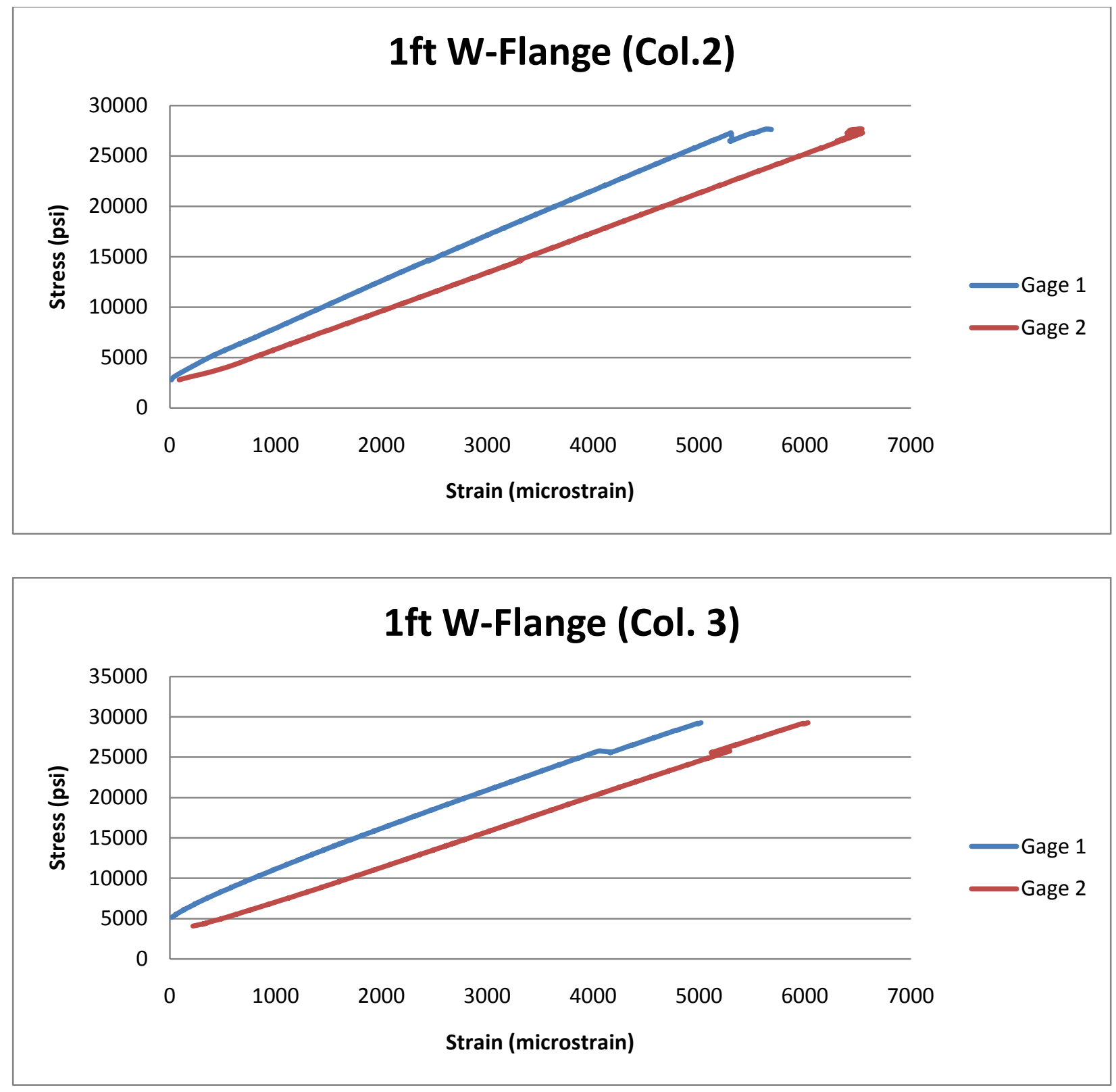
Southwell Plots of Full-Length Columns (Hollow Box Section)
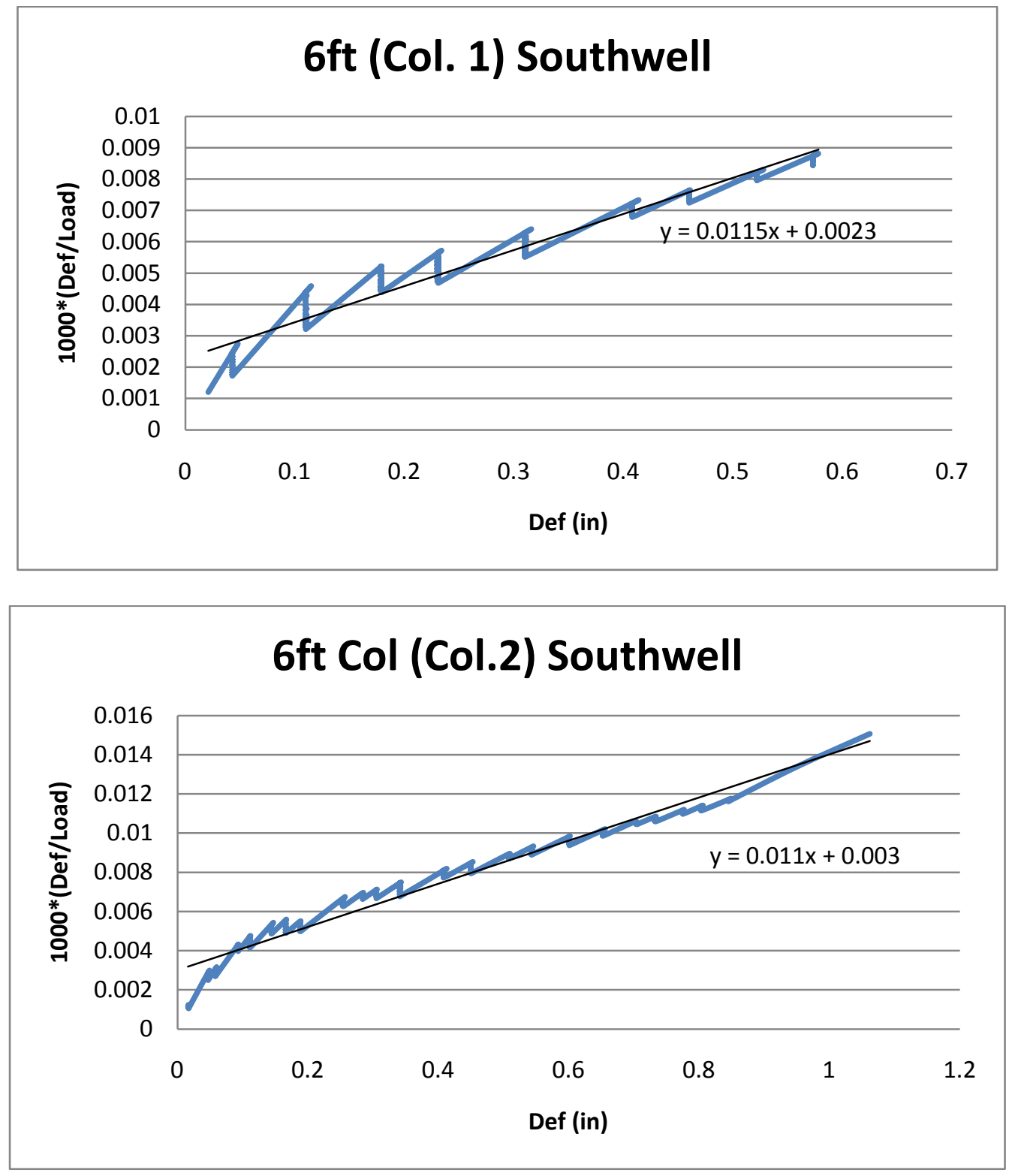

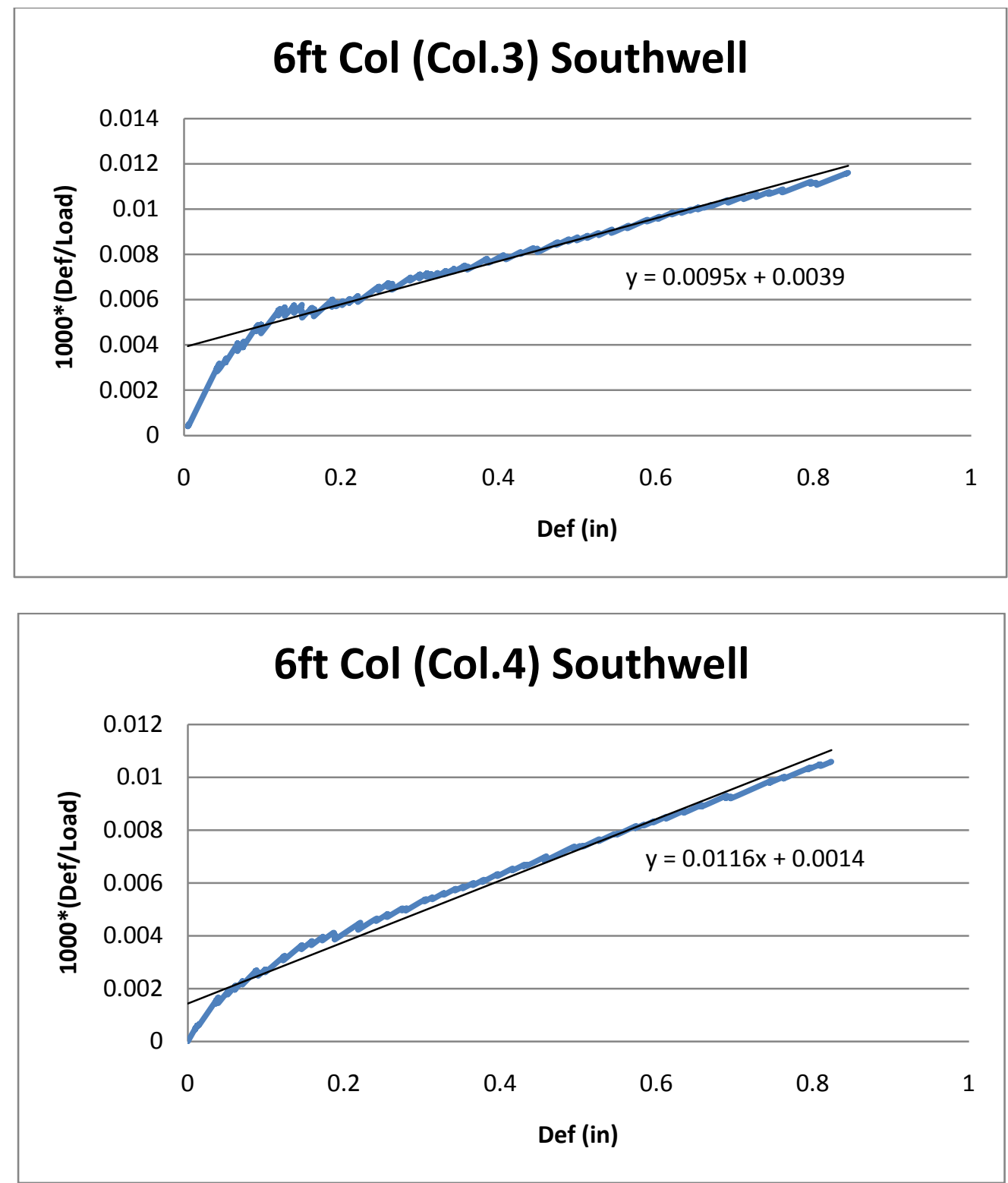

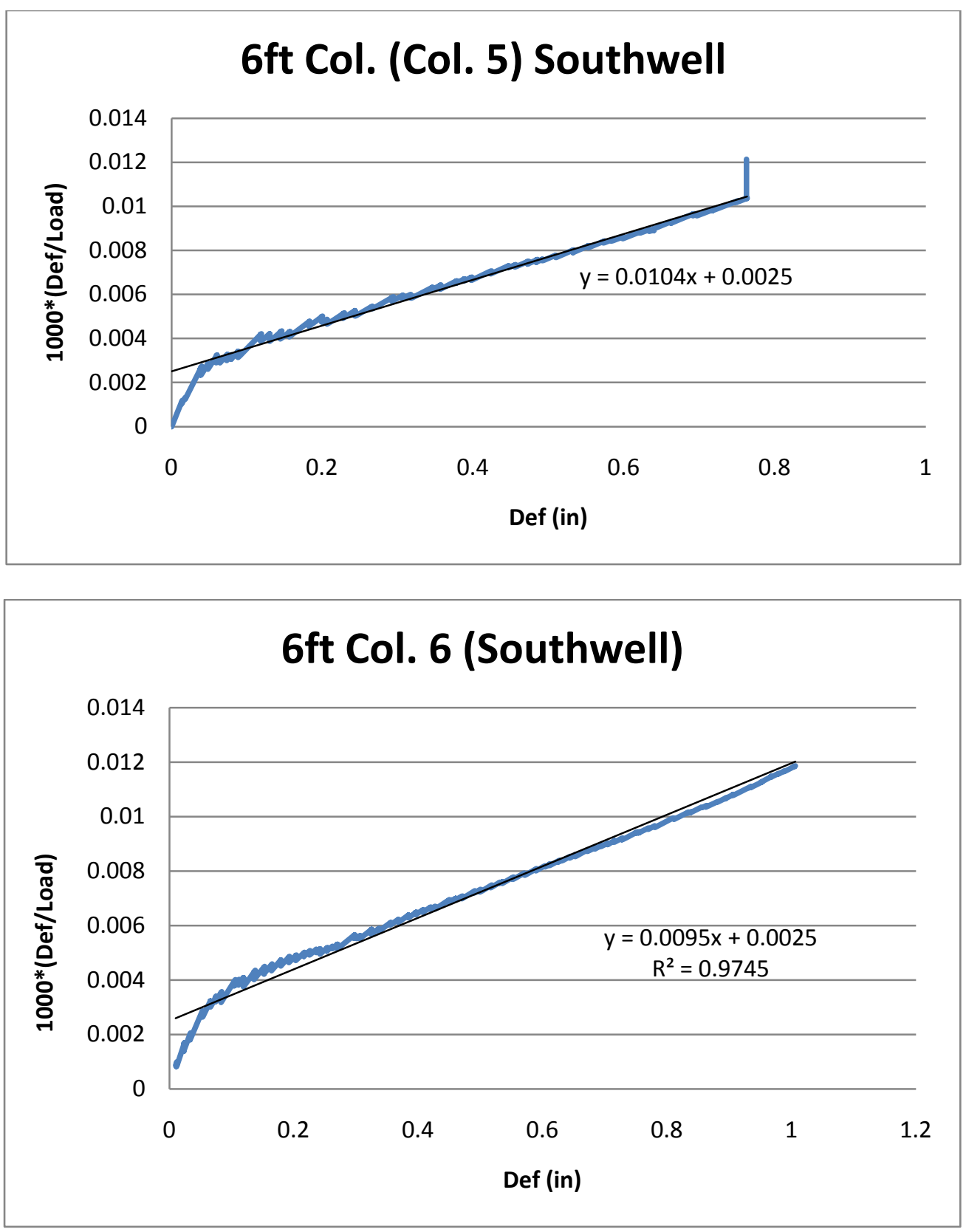

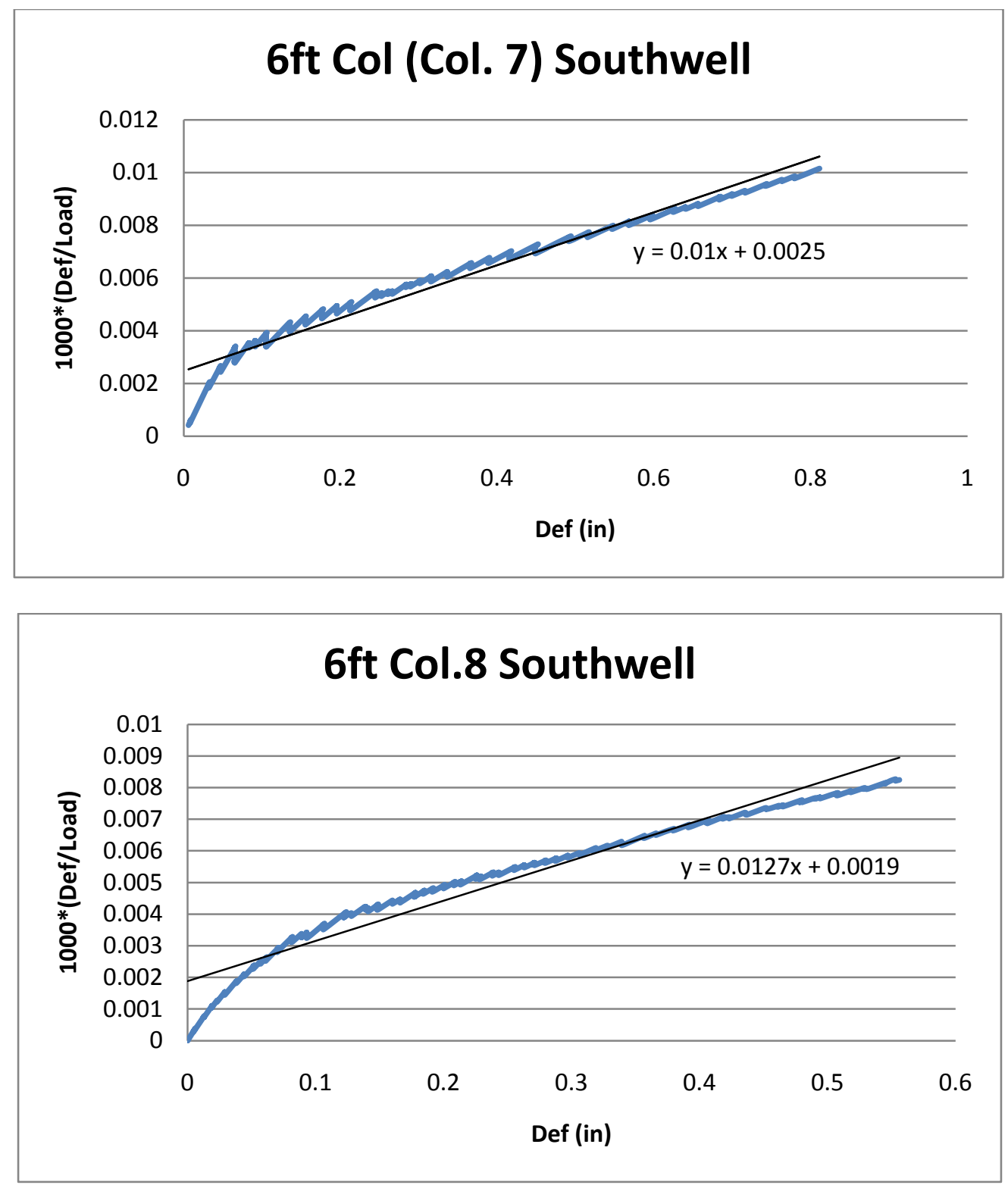

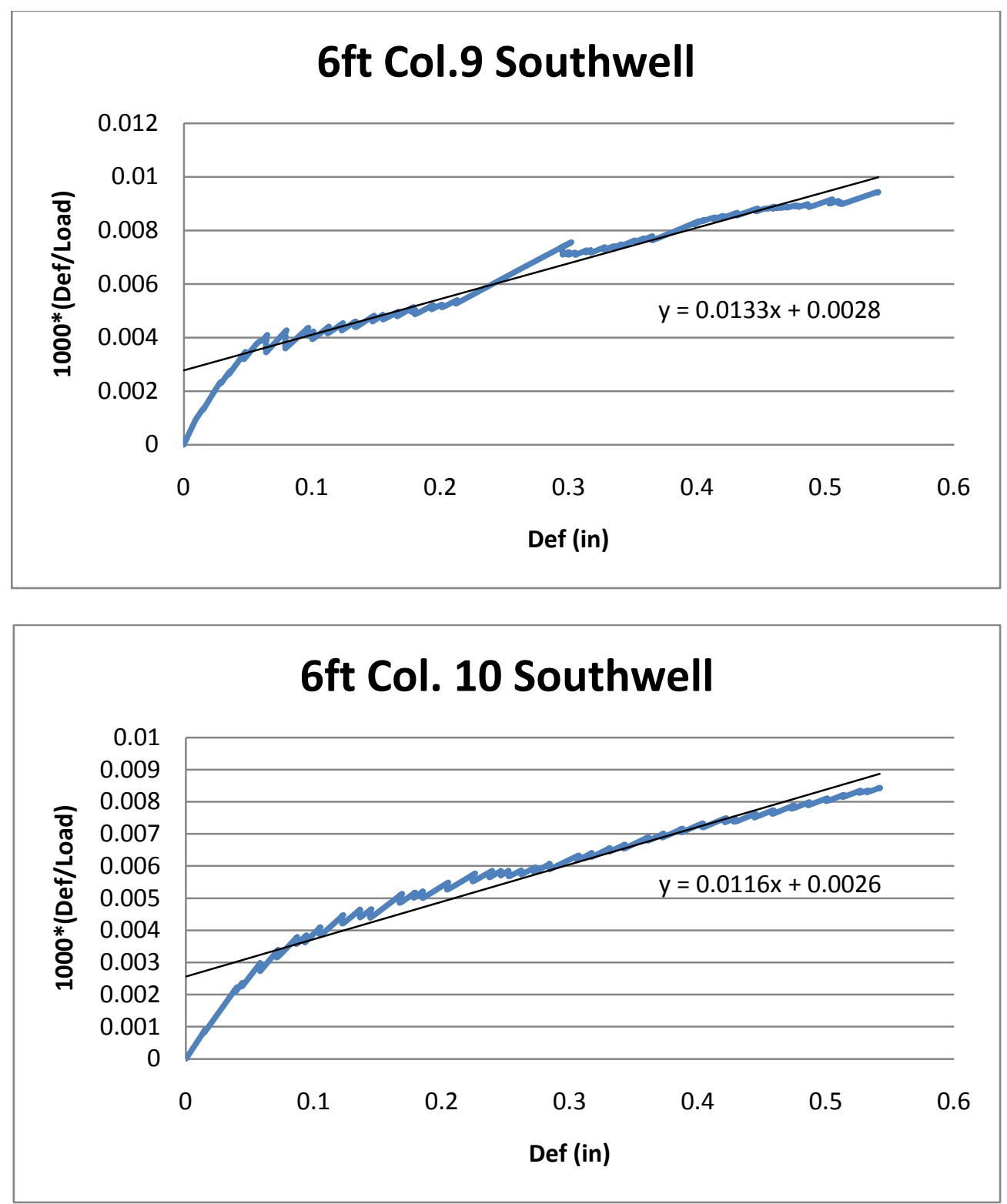

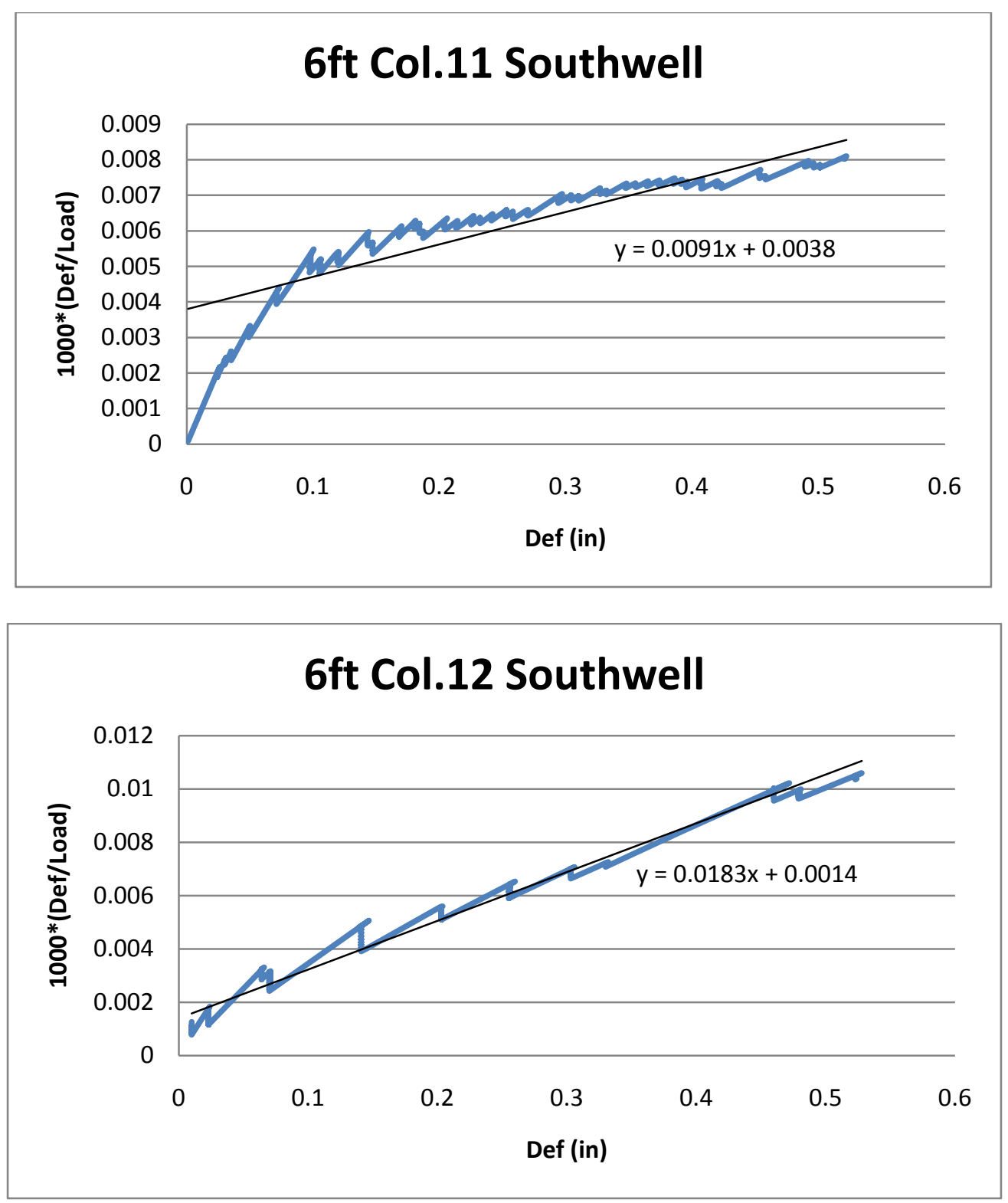

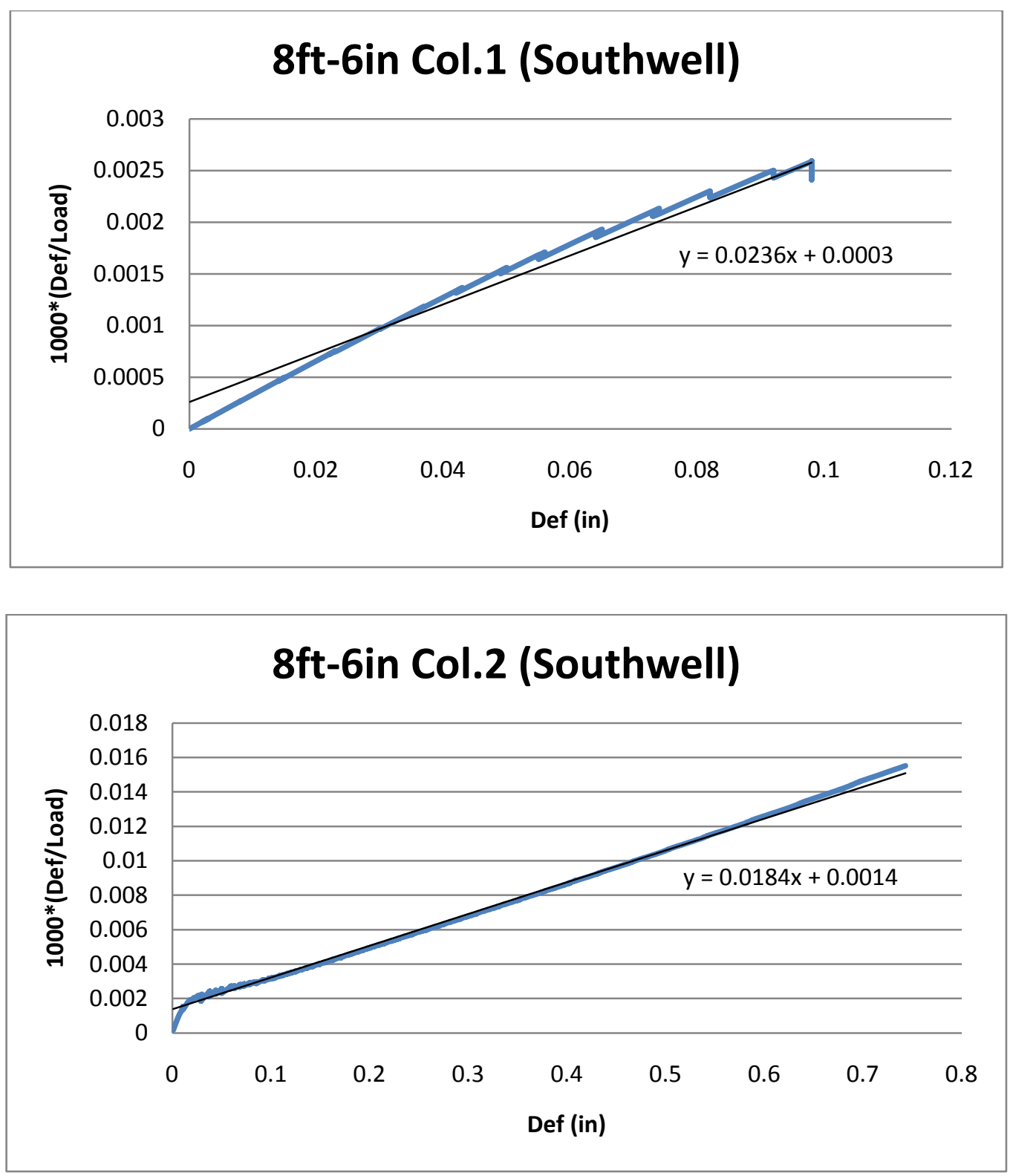

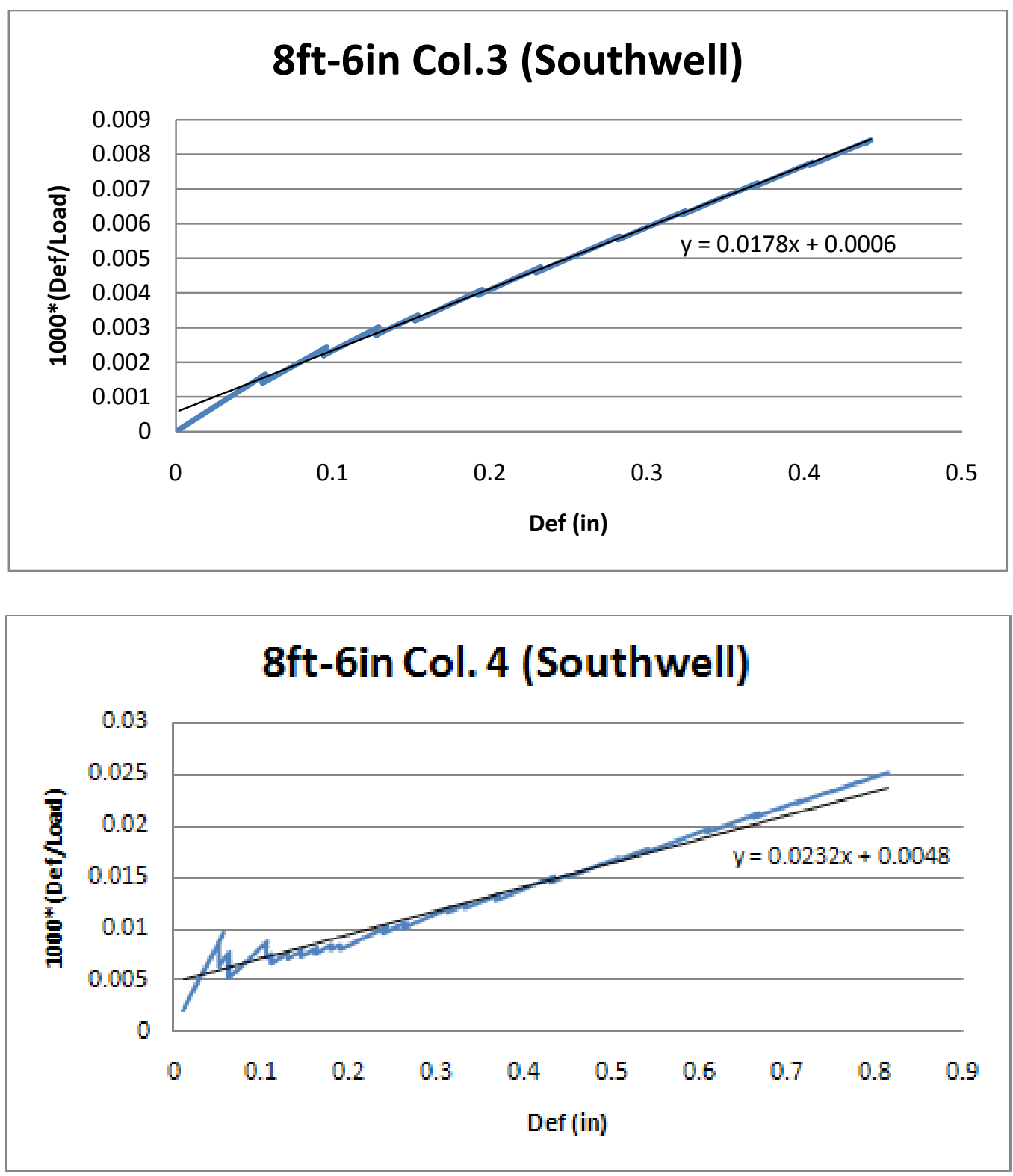

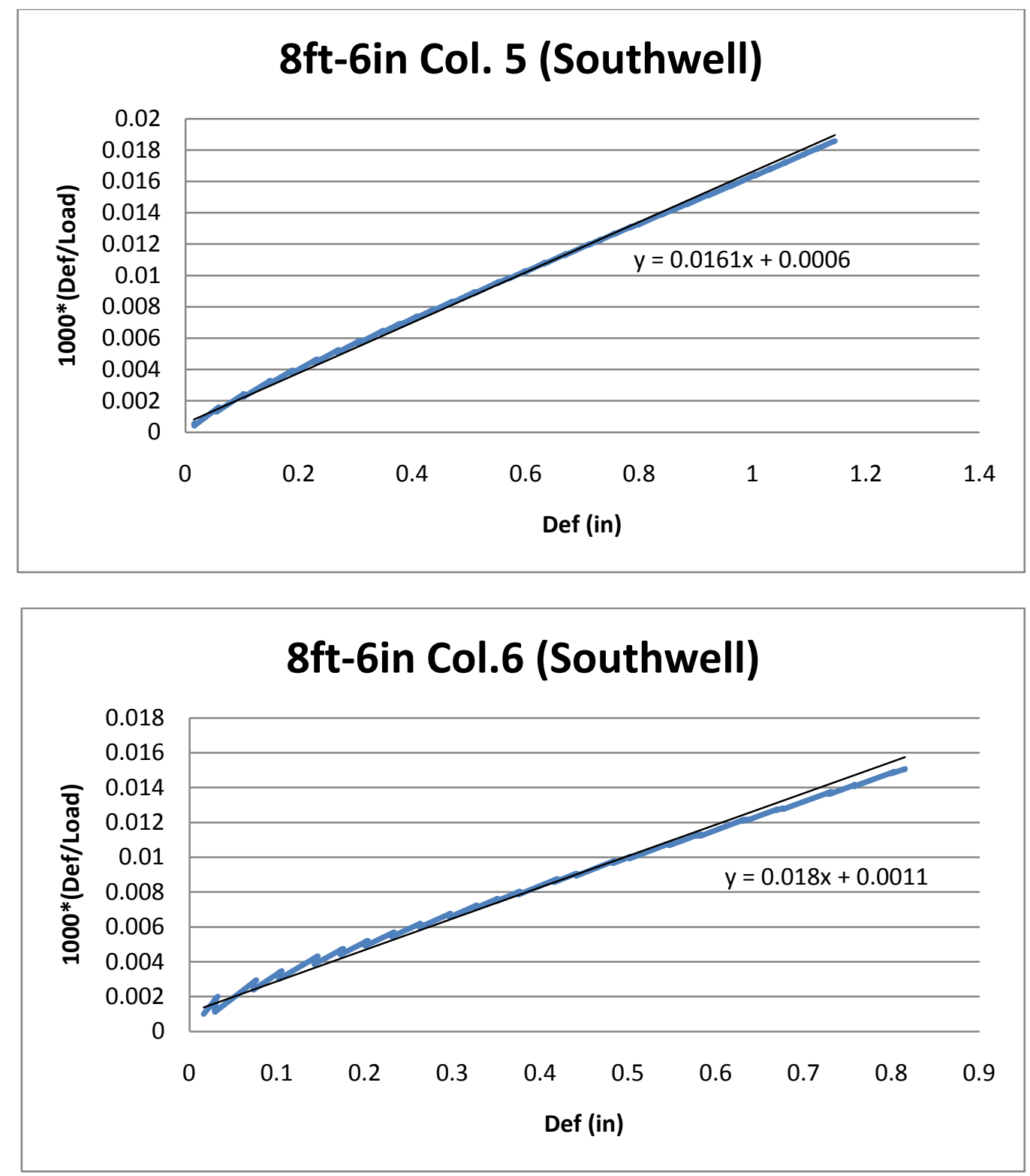

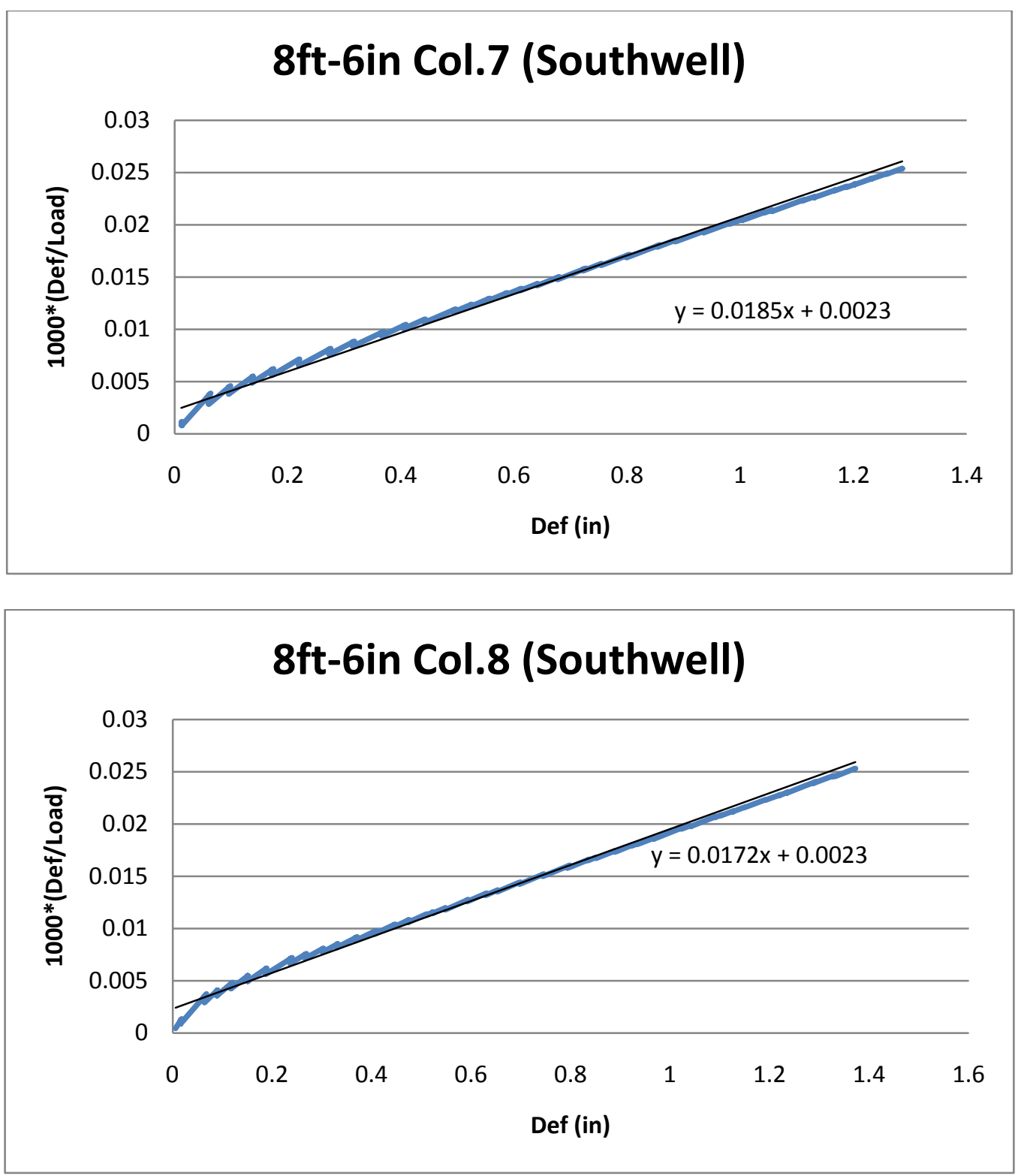

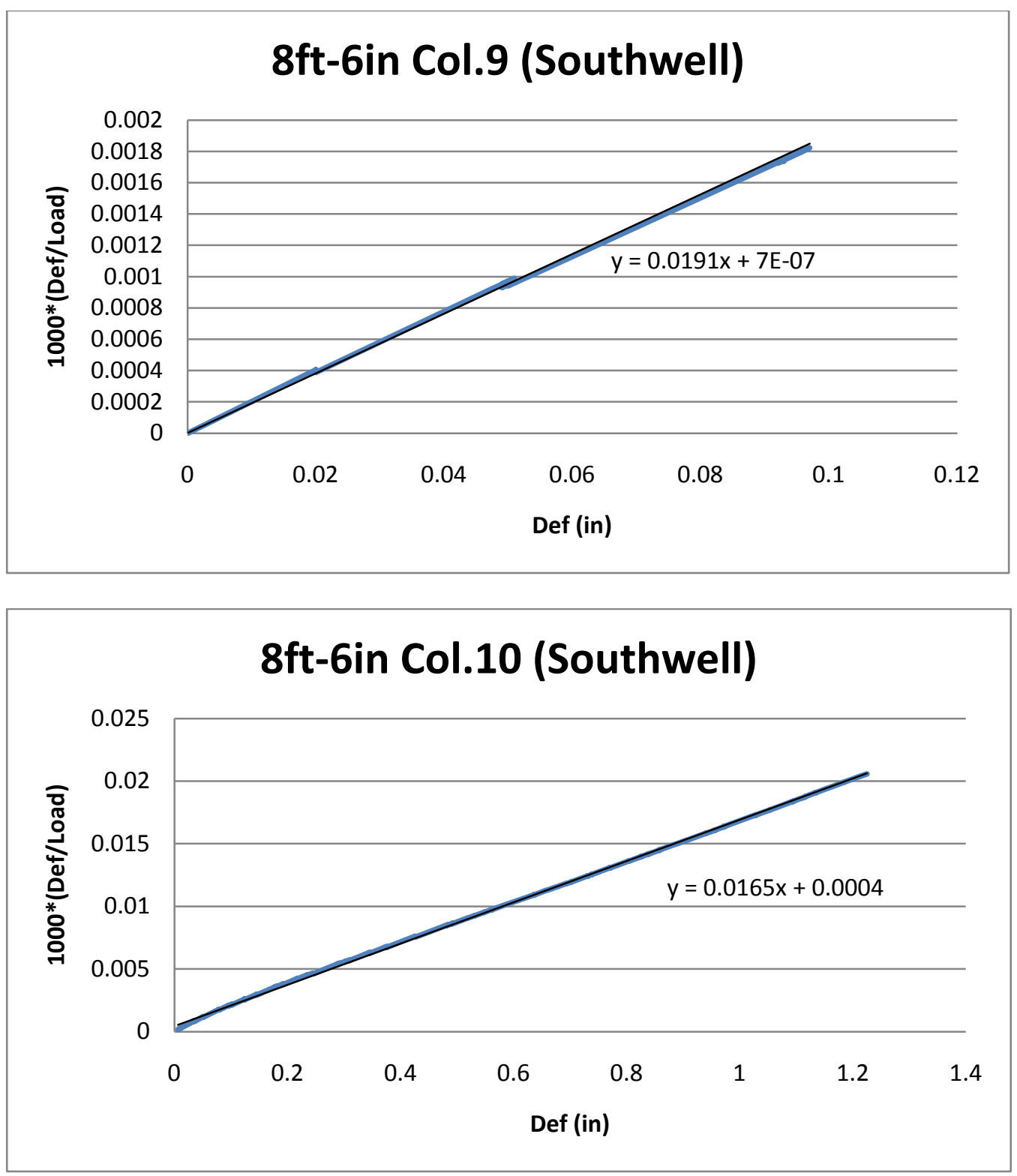

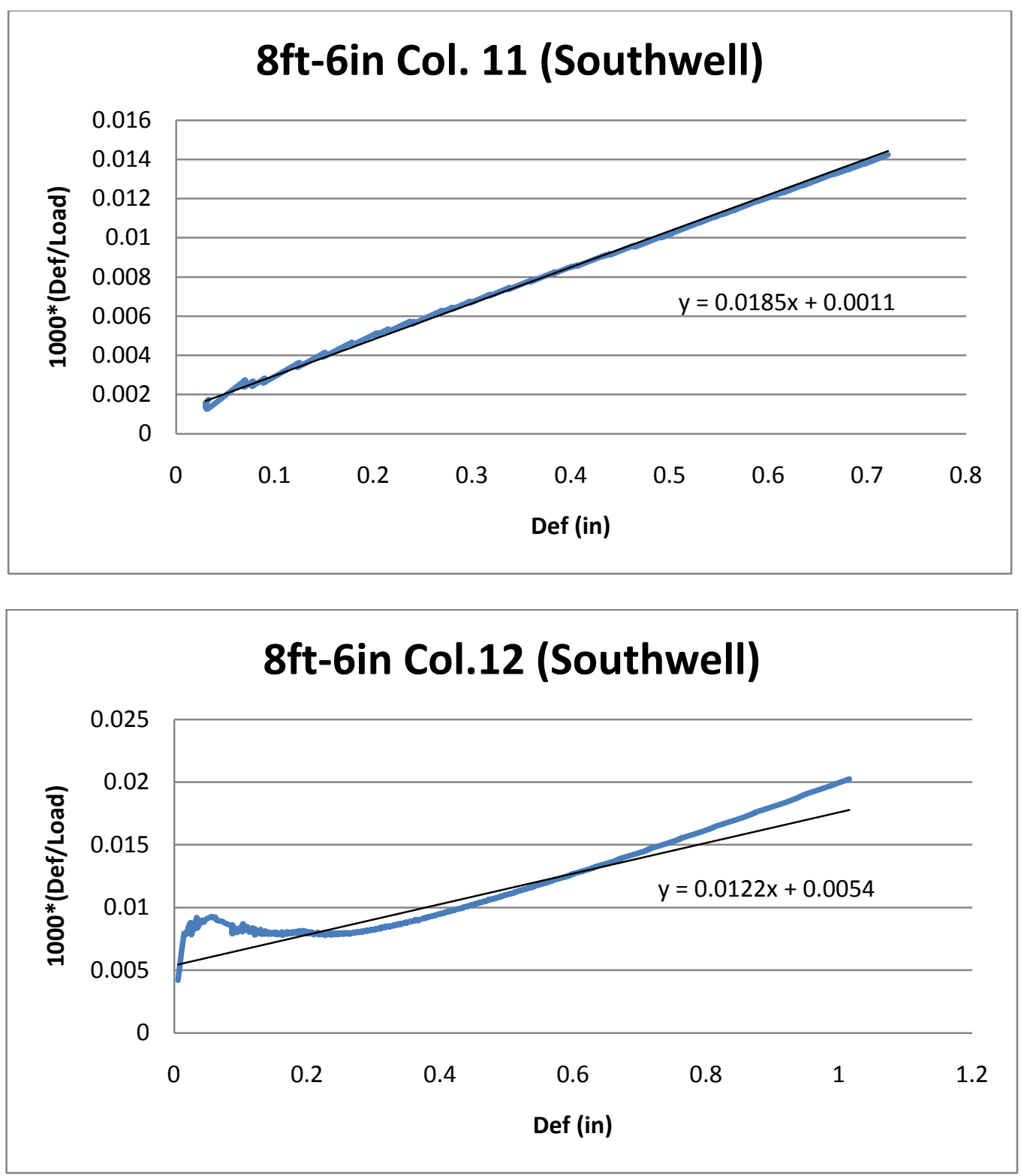

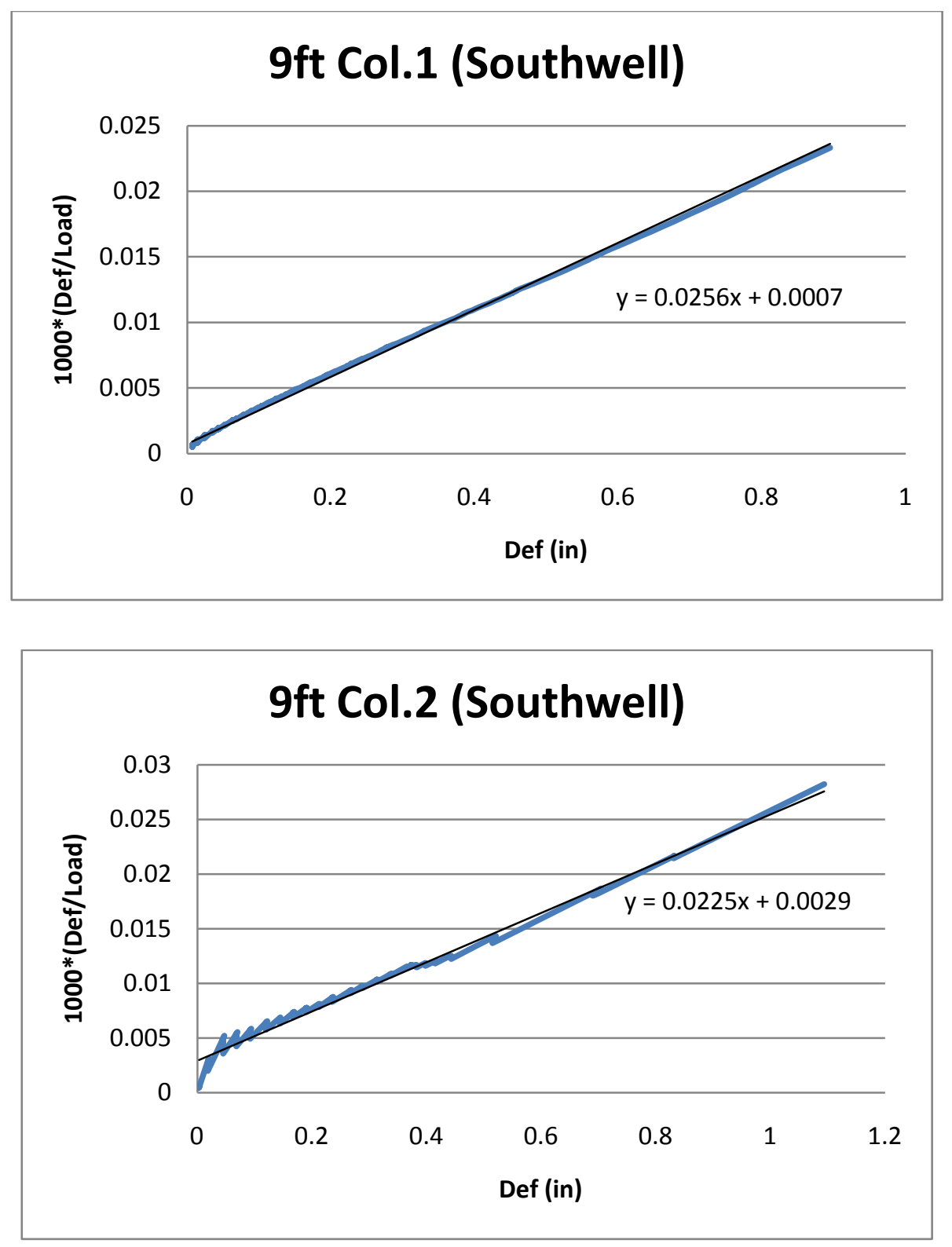

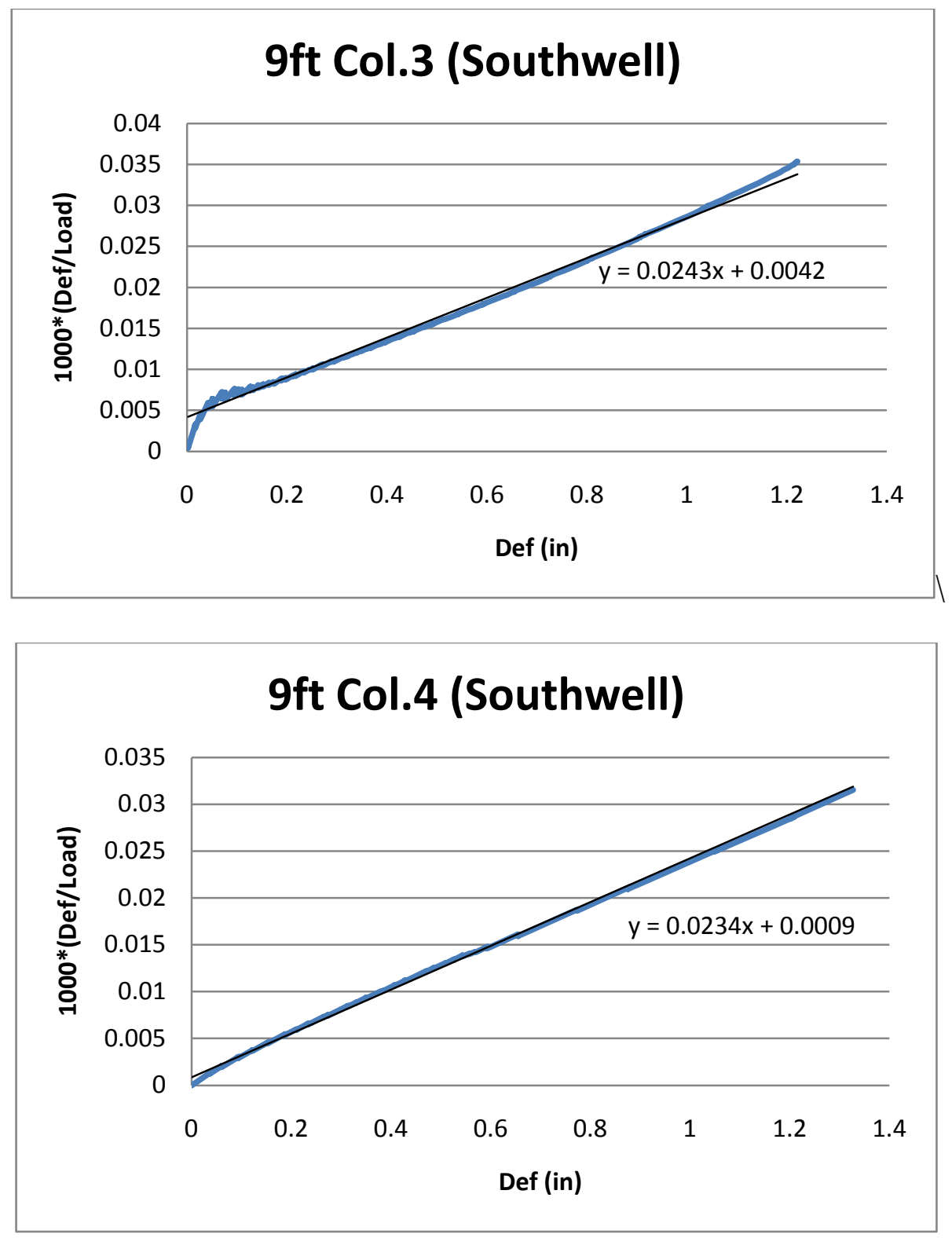

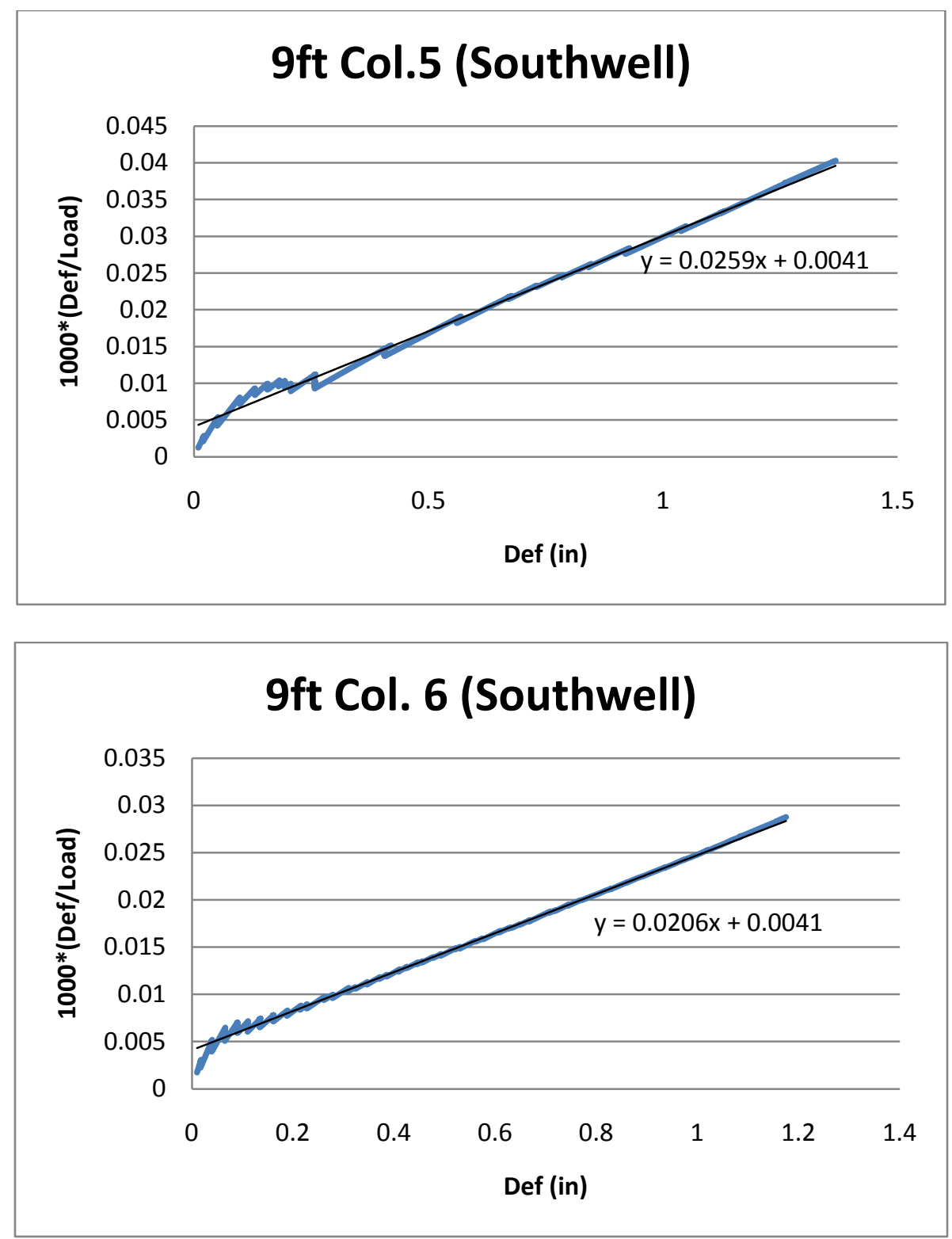

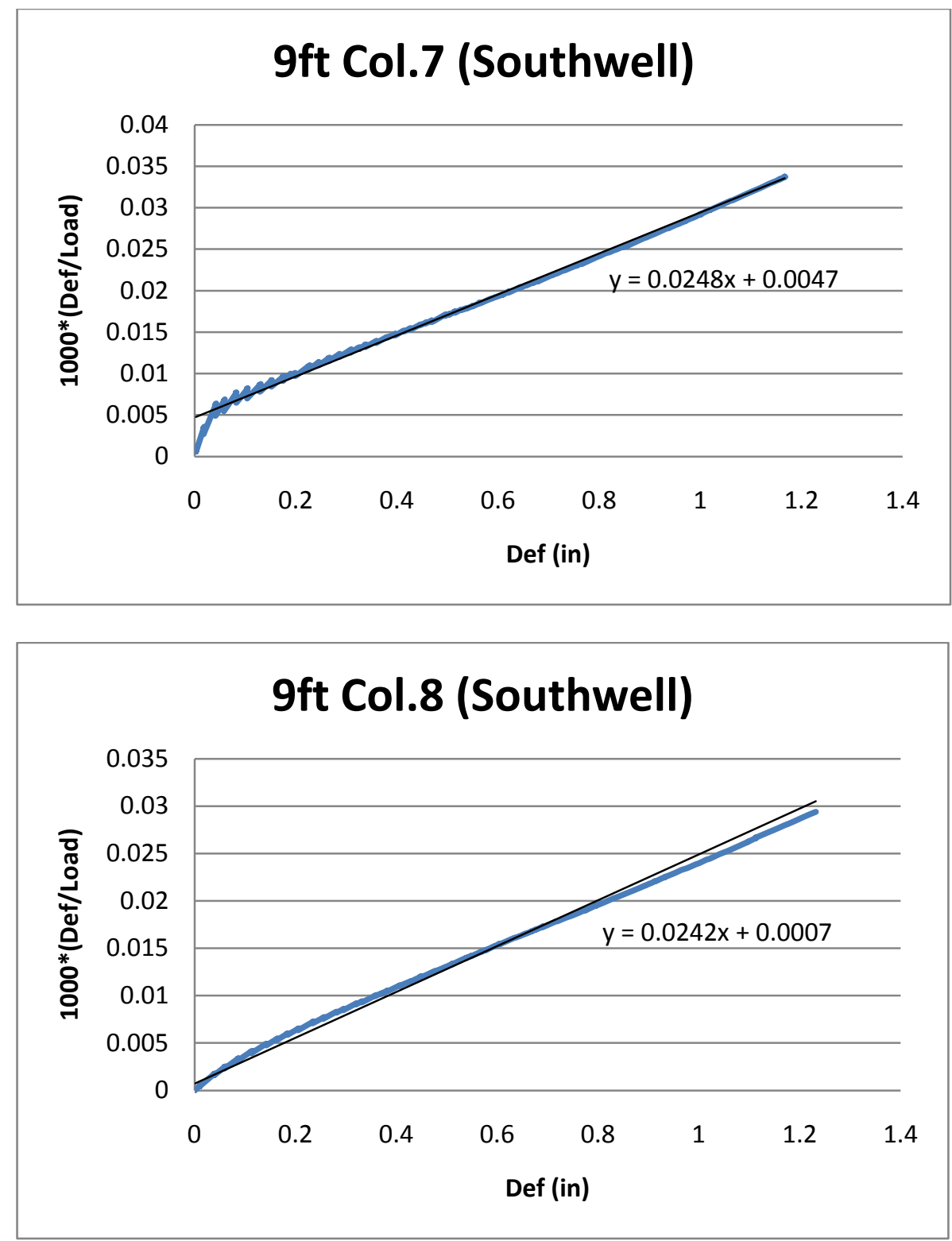

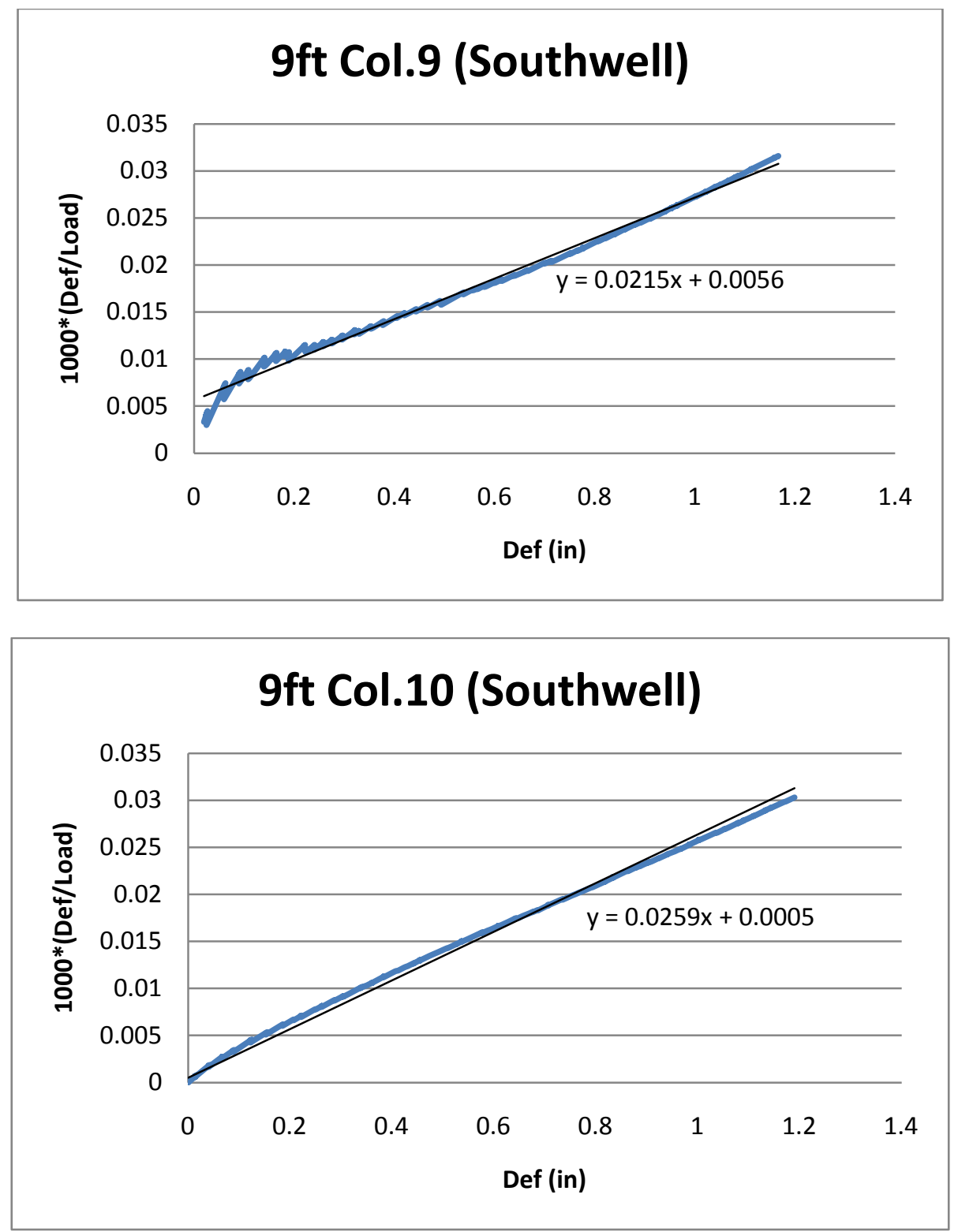

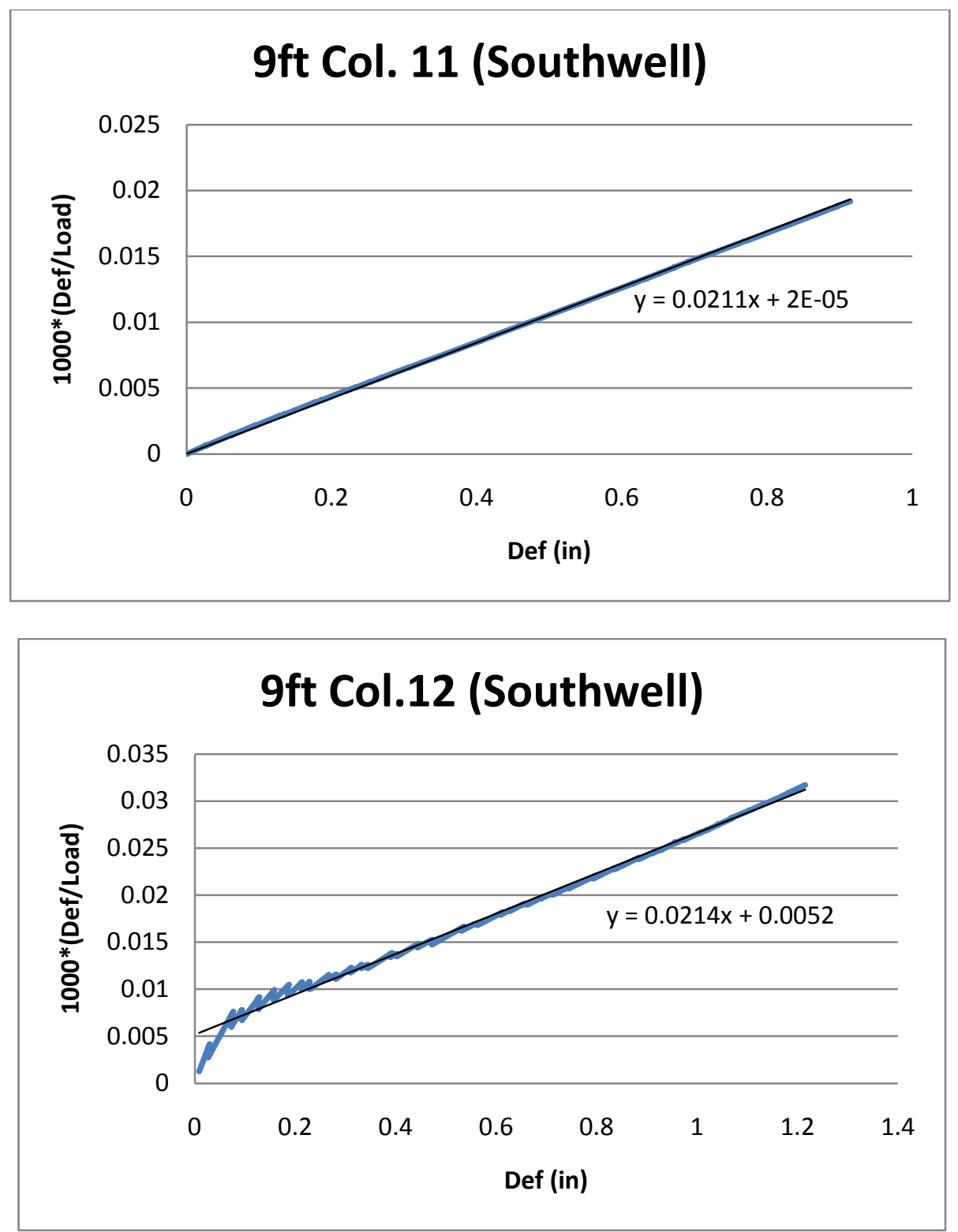

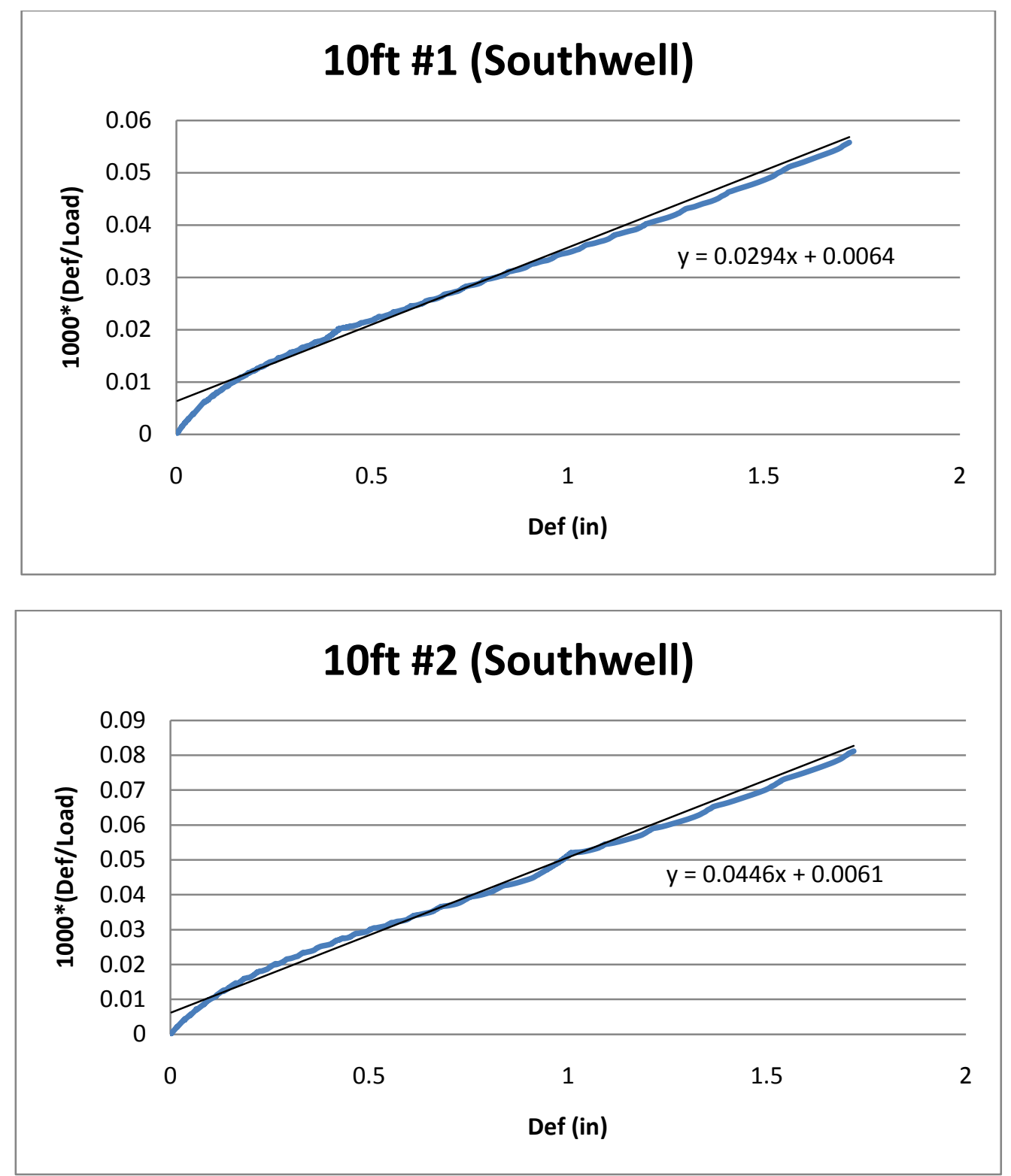

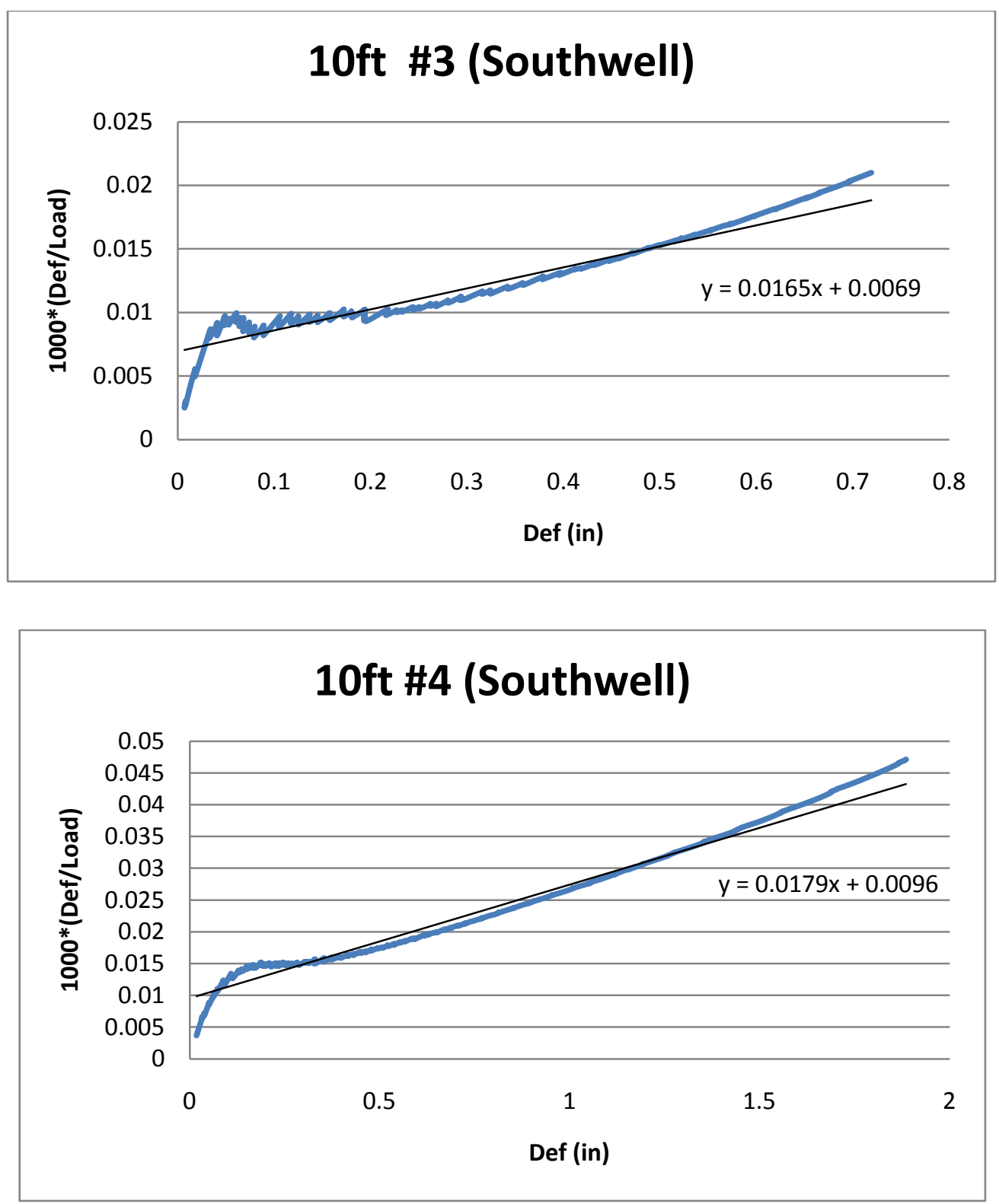

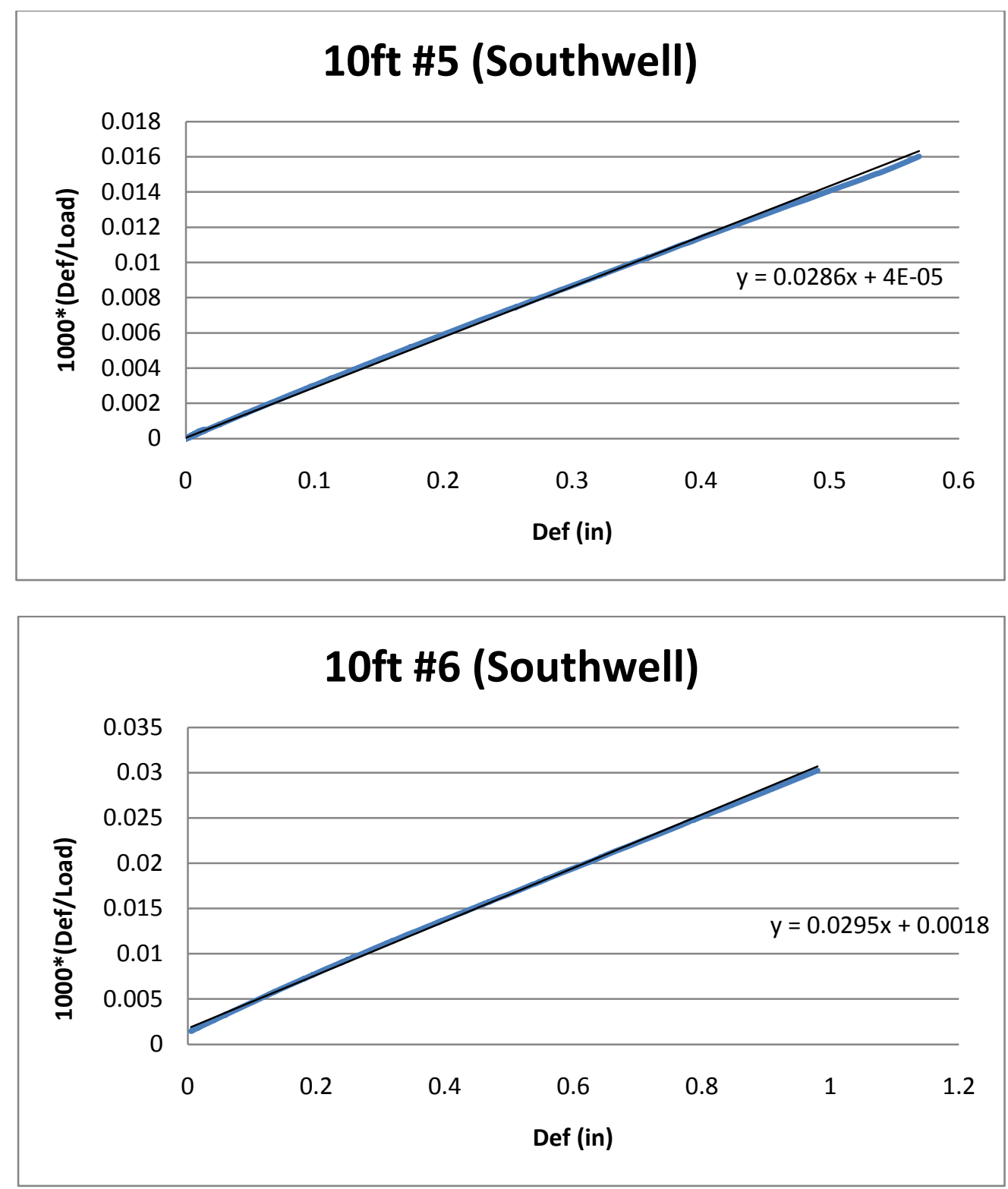

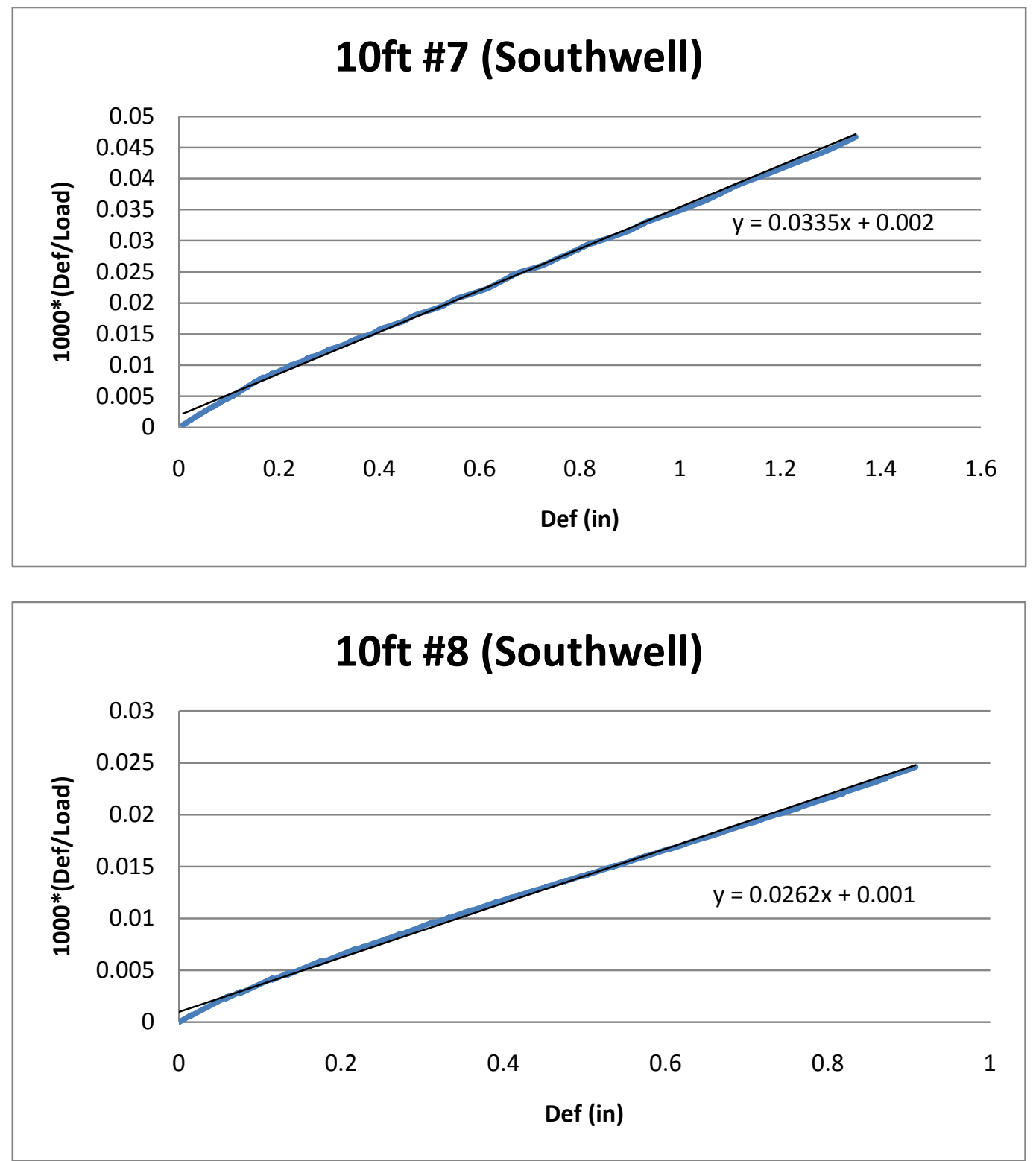

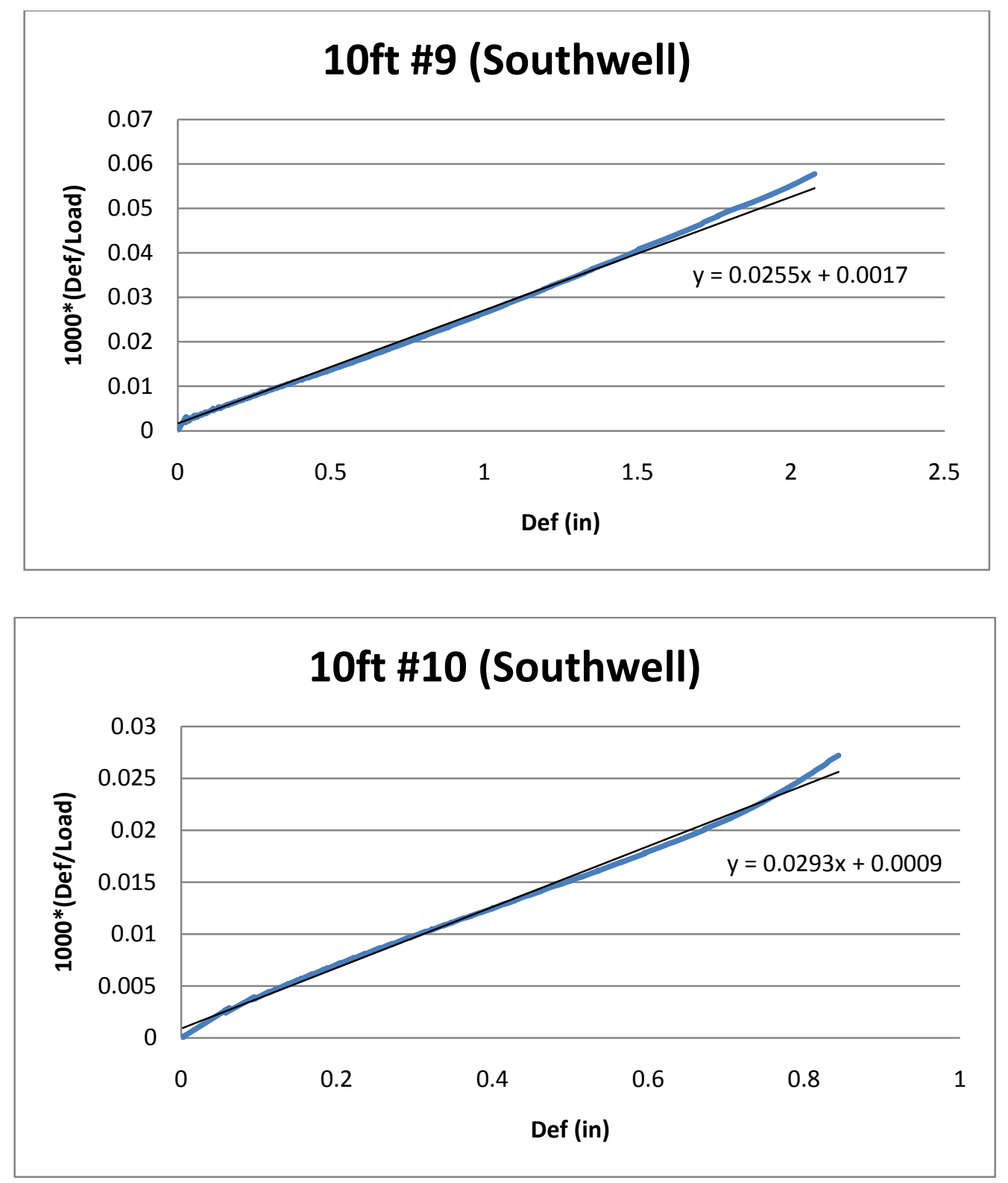
Southwell Plots of Full-Length Columns (WF Section)
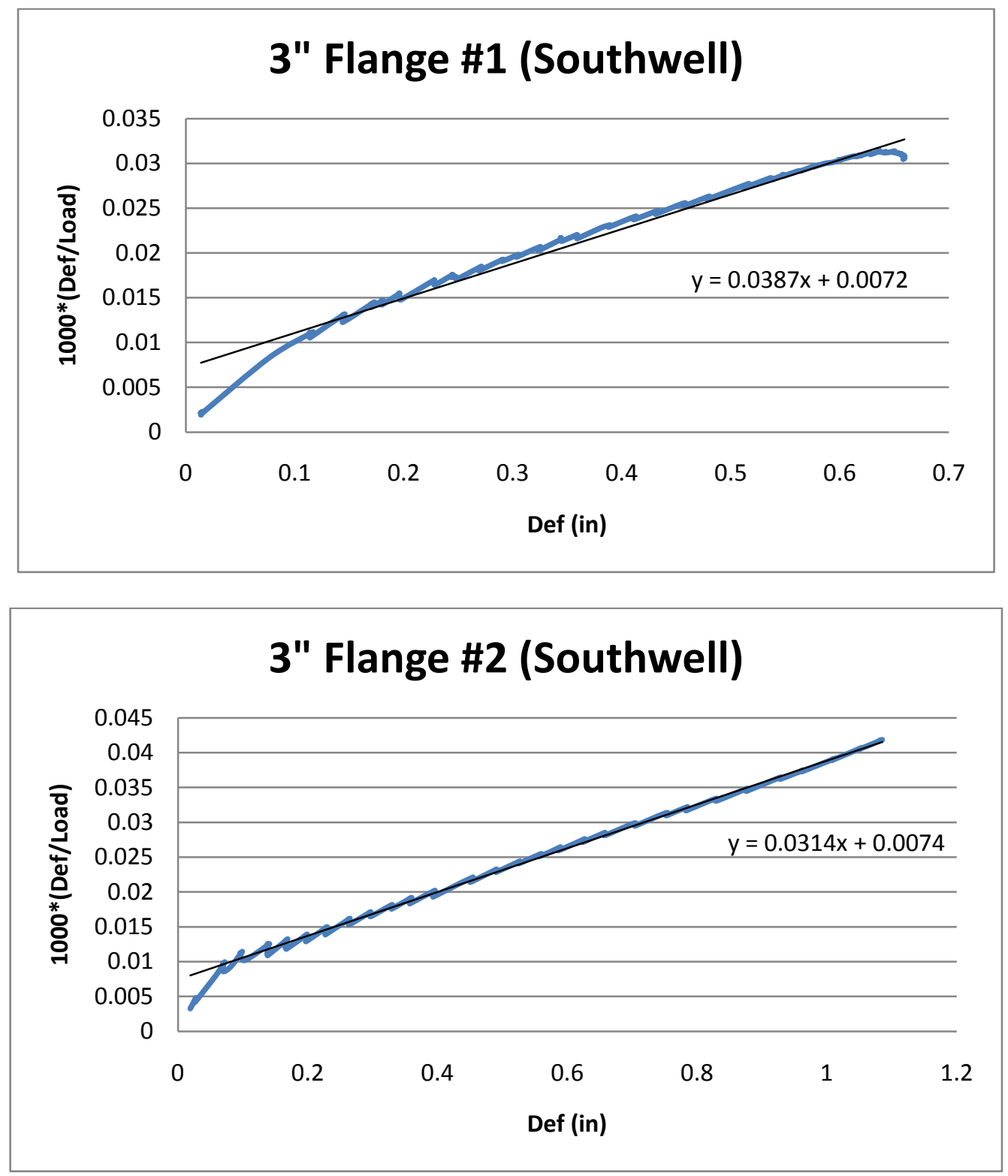


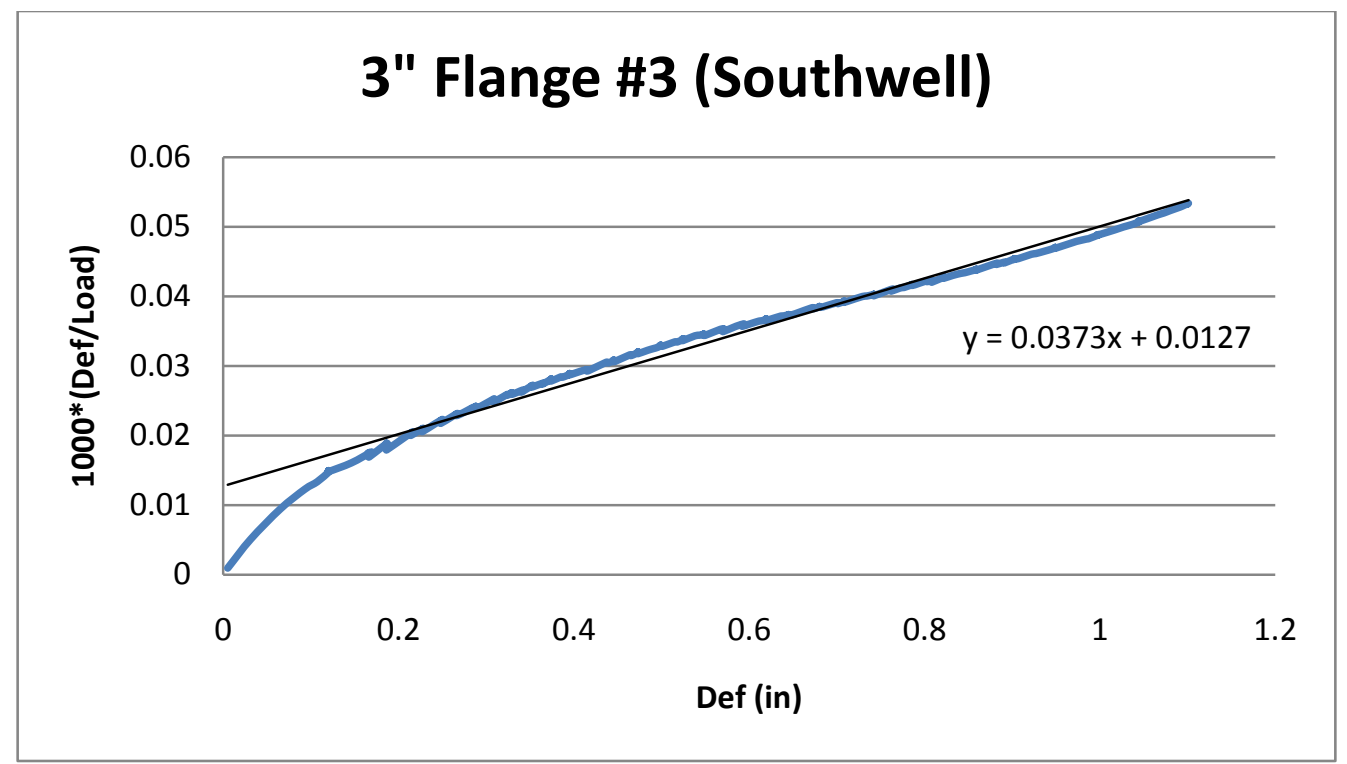

Full-Length Hollow Box Stress-Strain Regression Plots (Strain Energy)

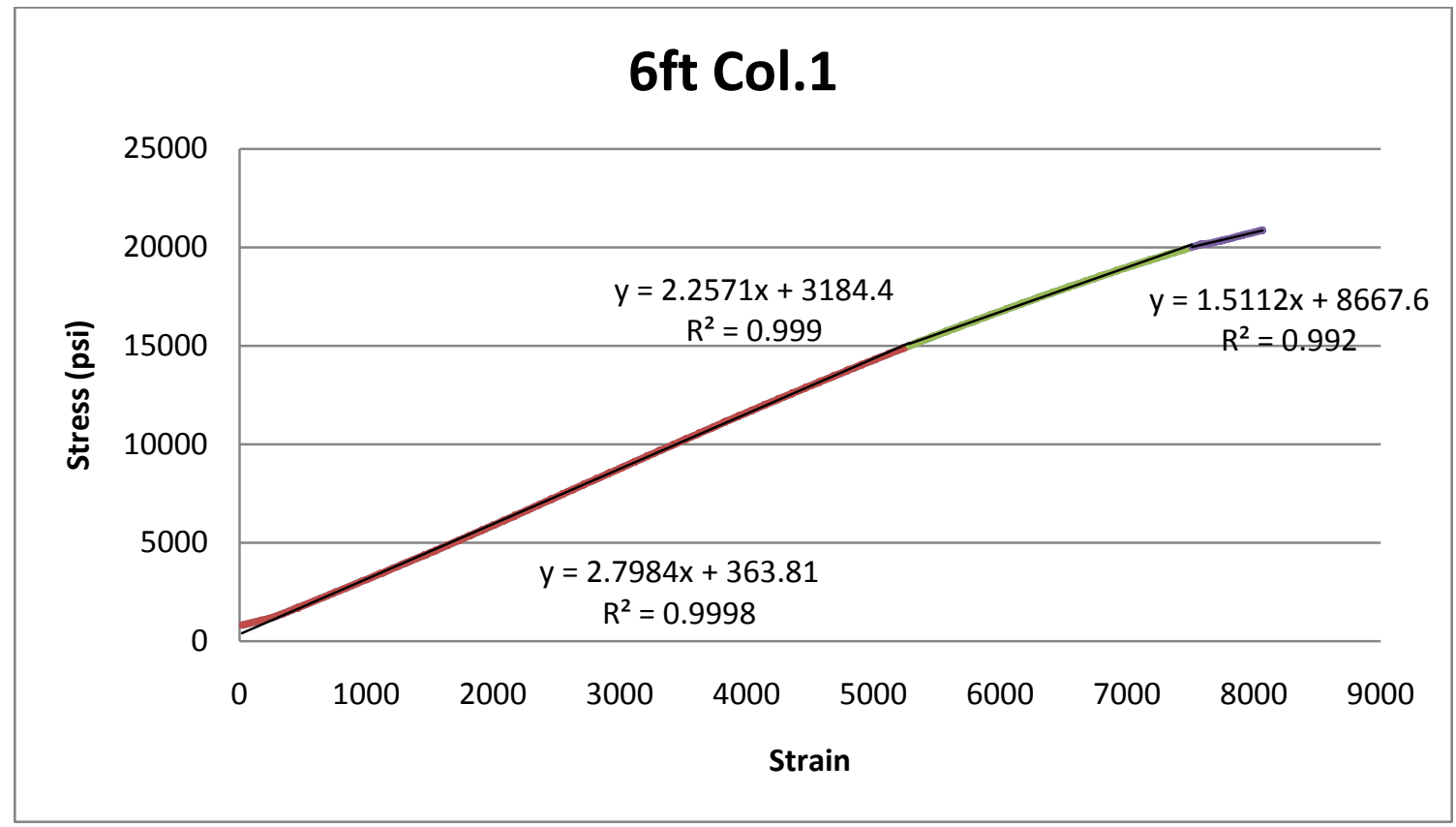



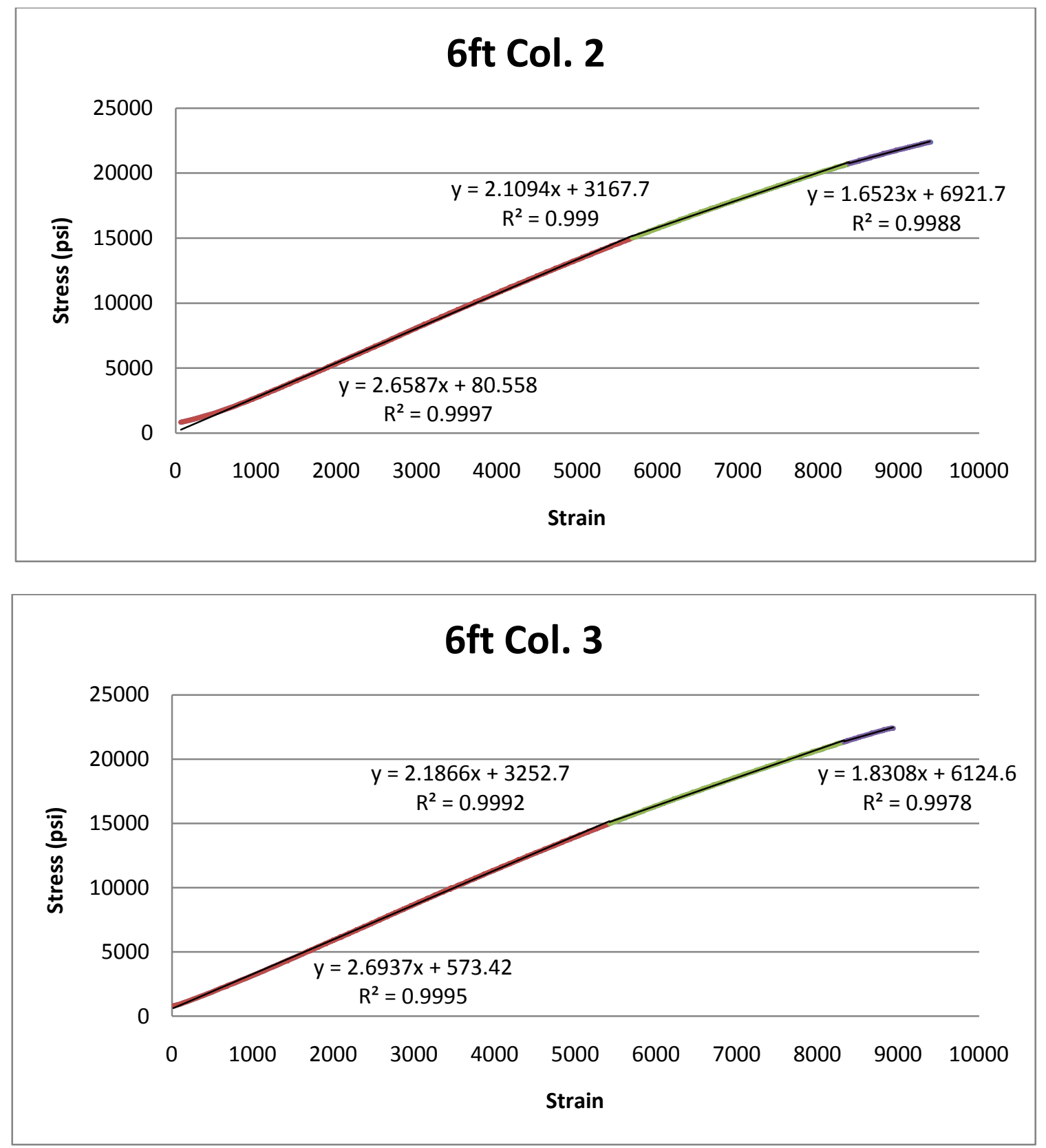

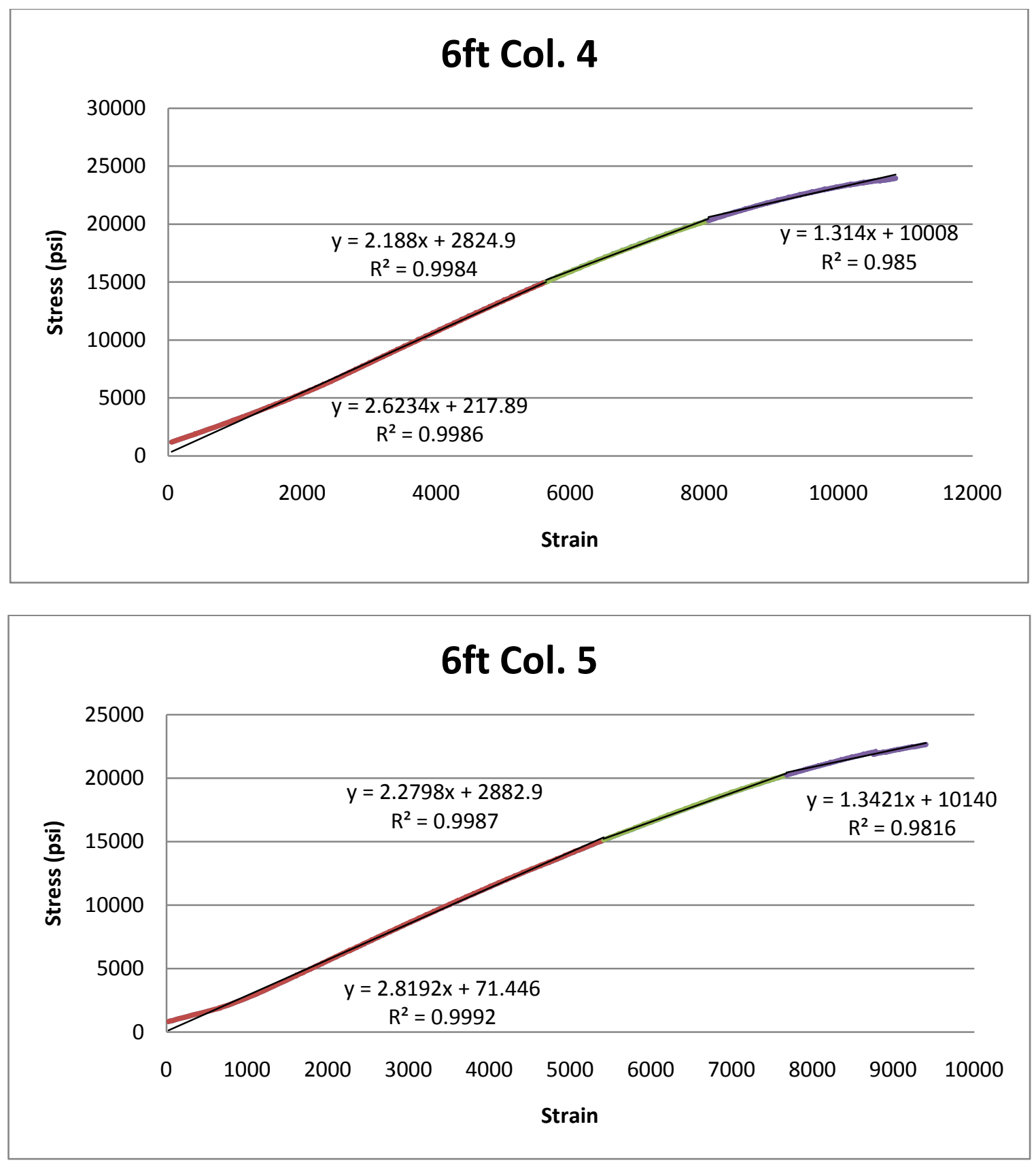

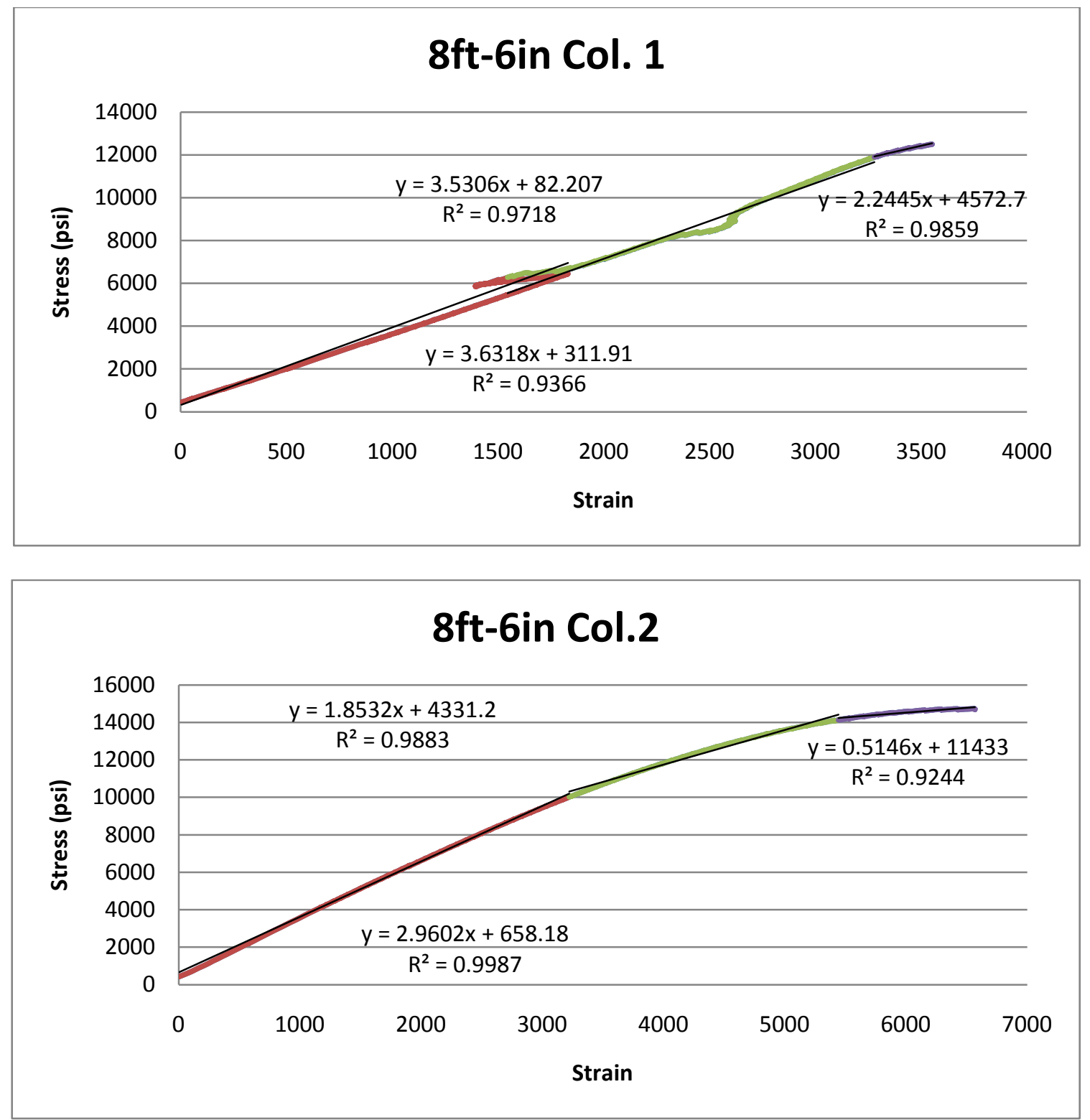

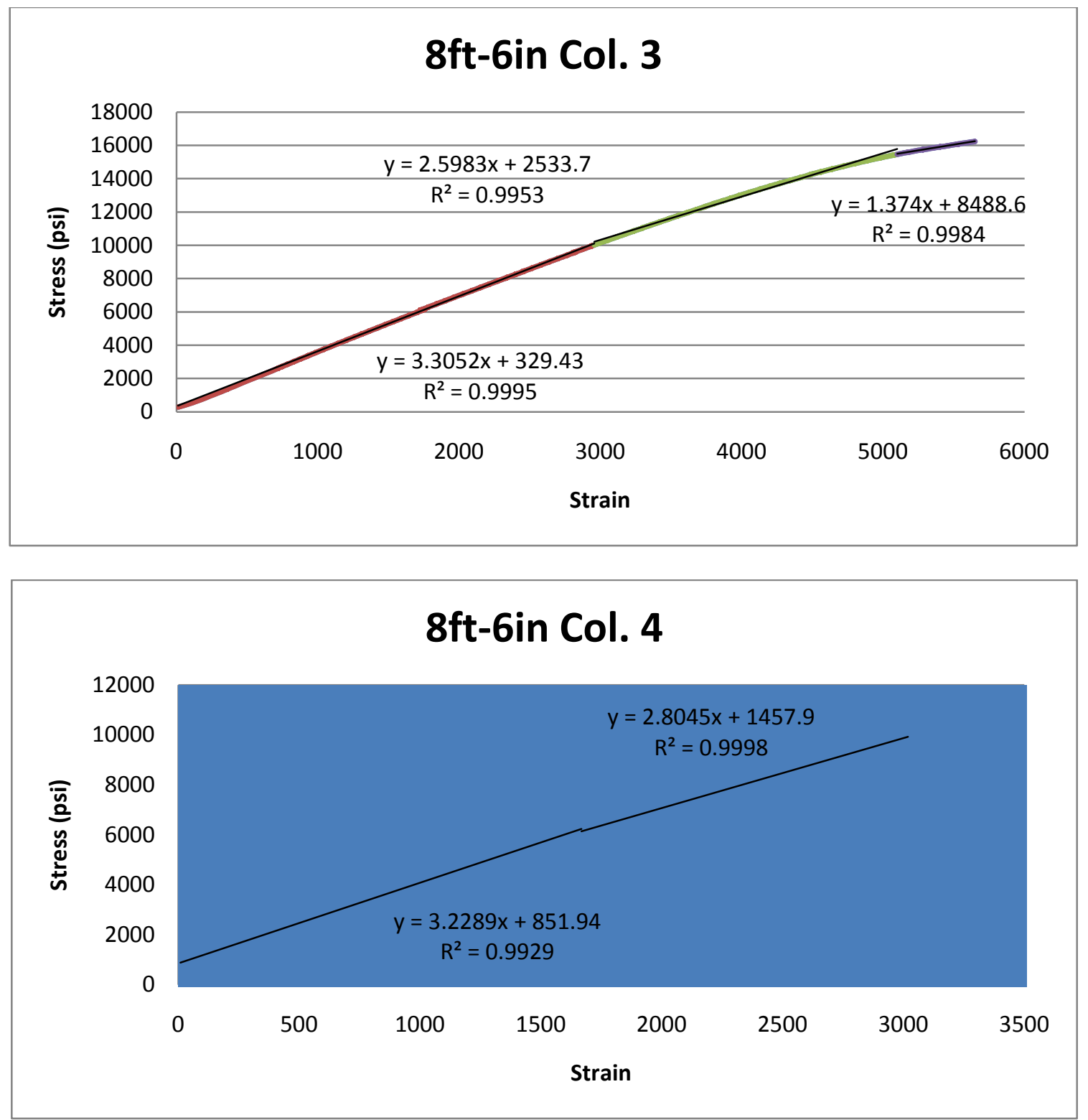

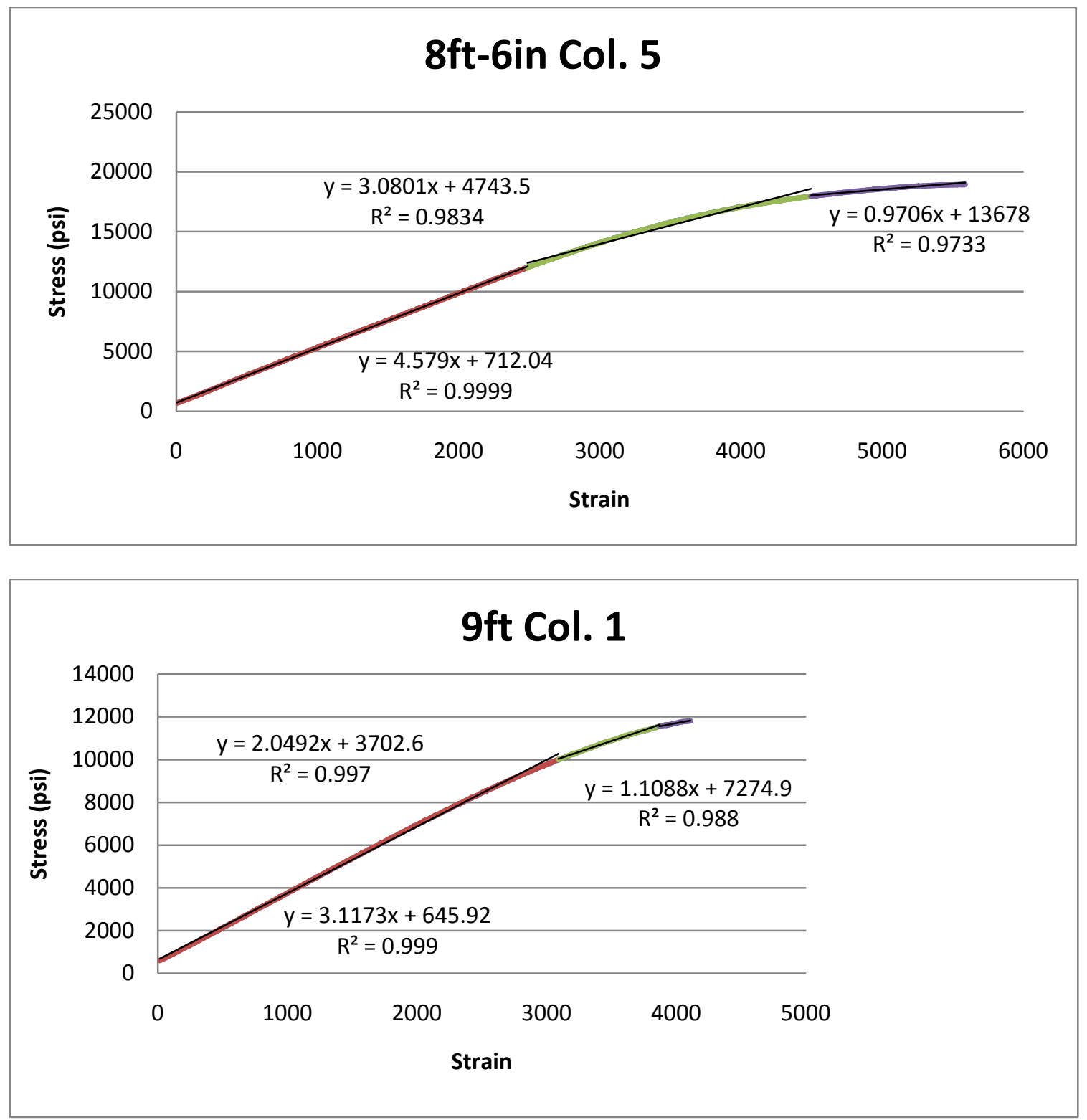

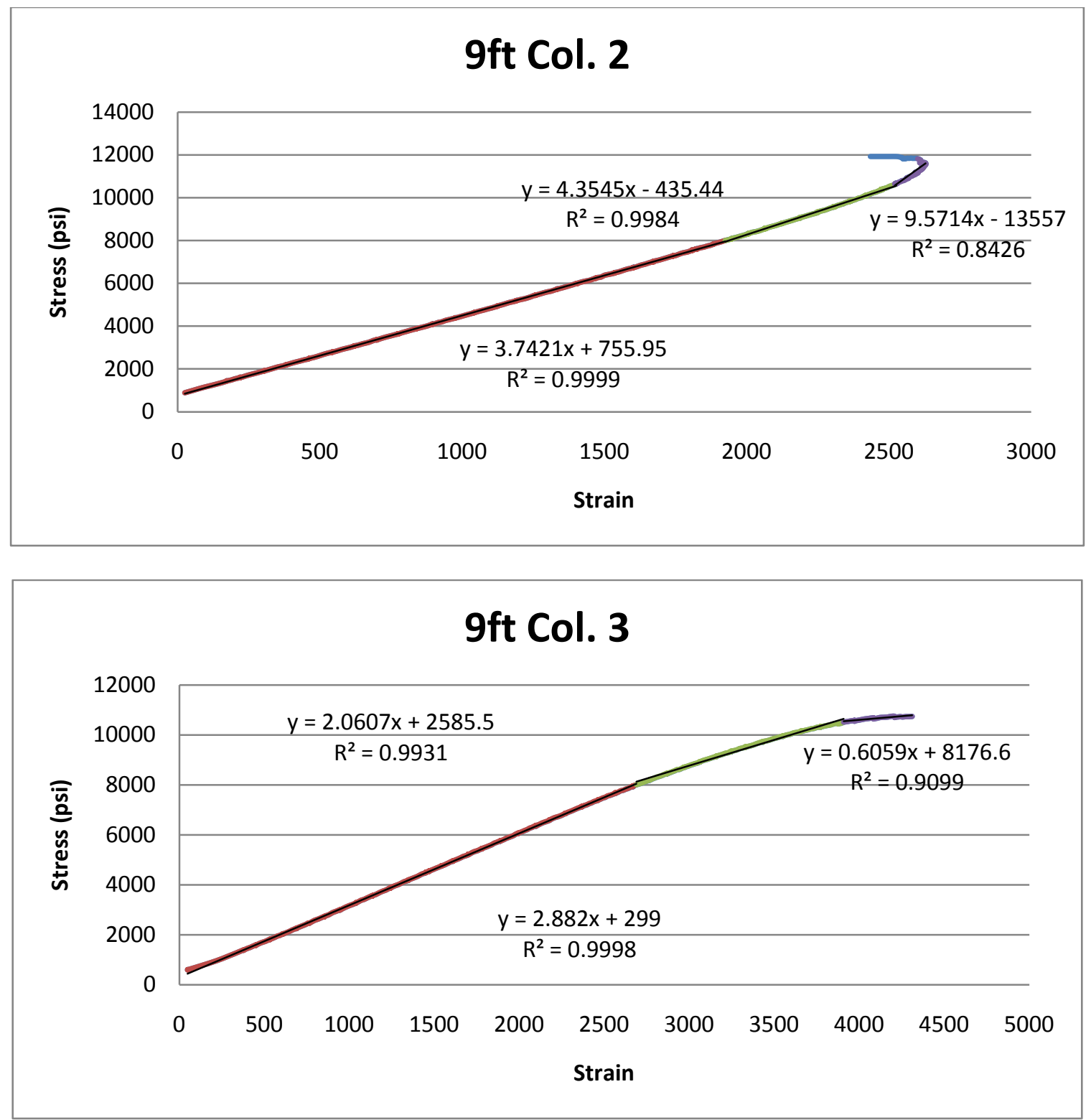

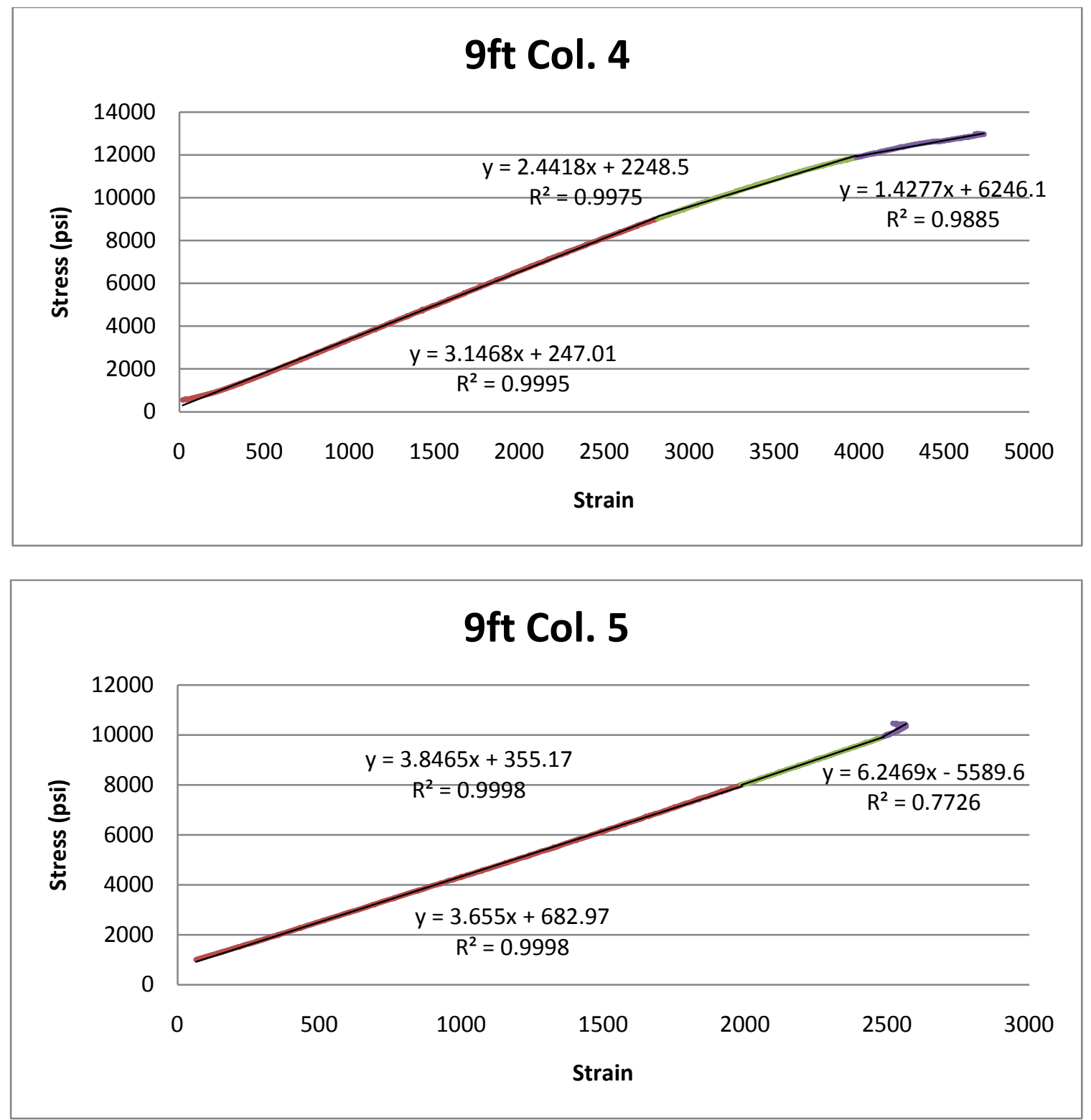

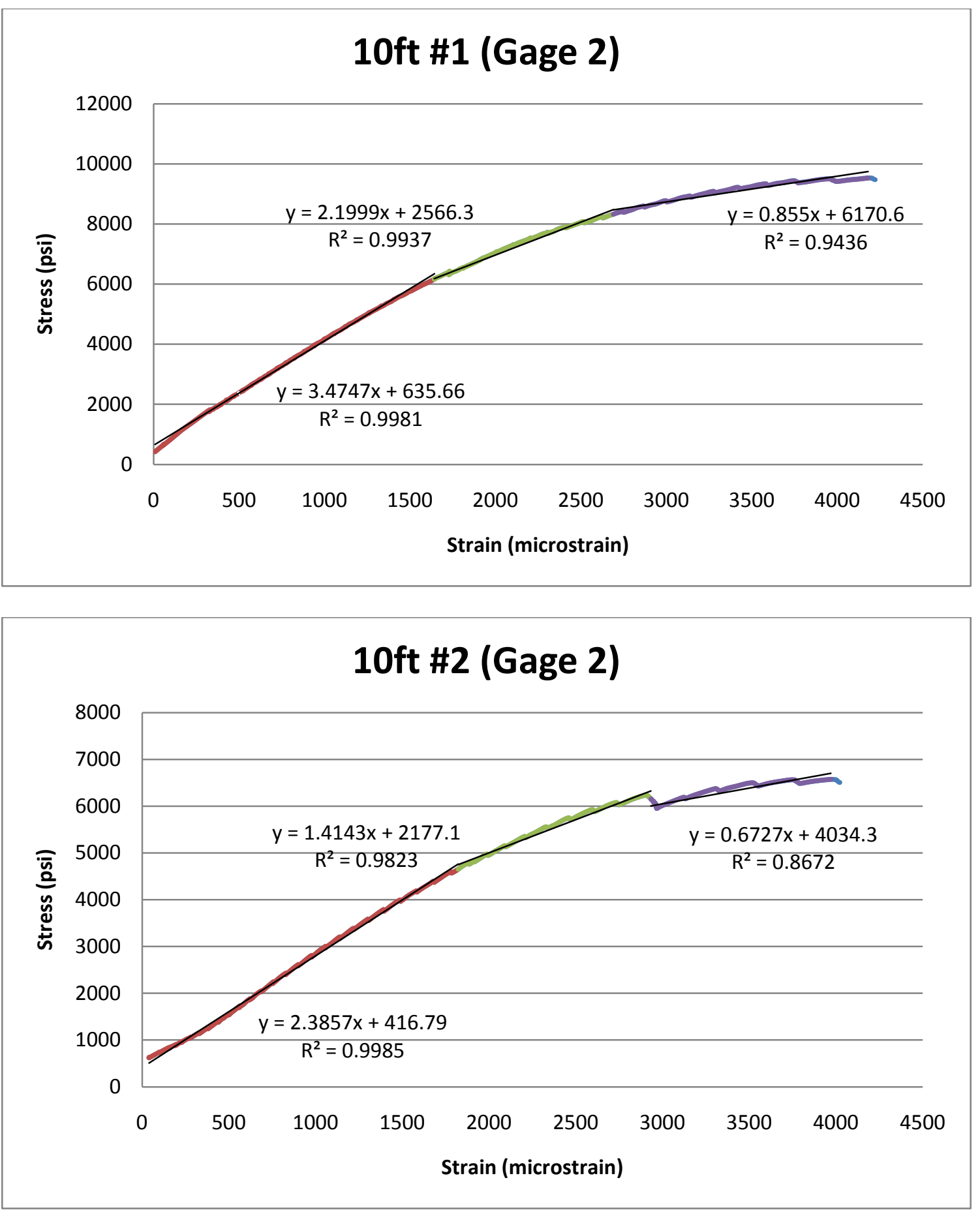

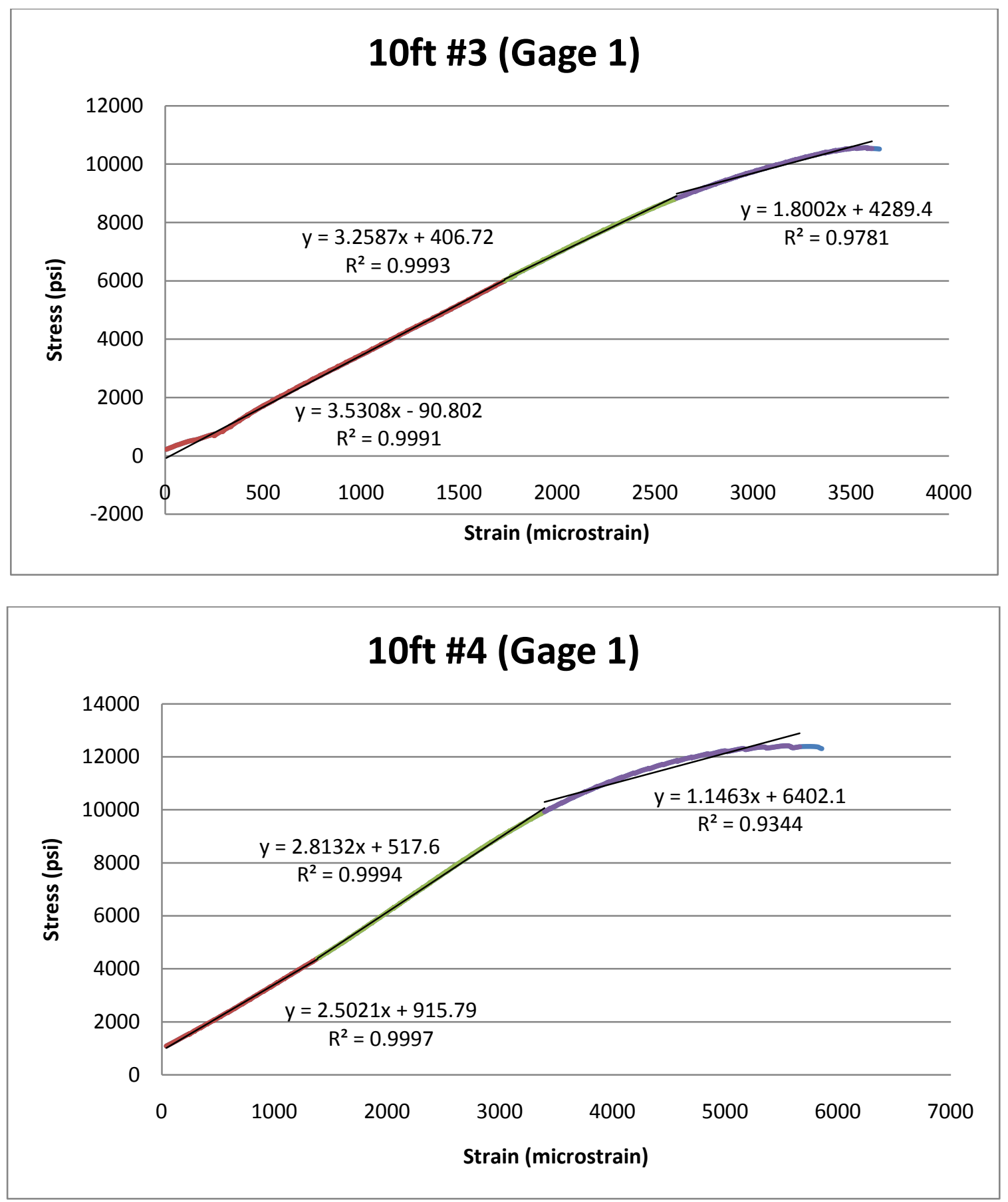


\section{APPENDIX B - Design Example}

Included in this appendix is a design example for structural elements (struts) within a truss subjected to axial compressive loading.

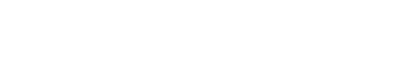
Hegen 


\section{Compression Members}

Struts $(13,15,17)$

$\mathrm{P}_{\text {u.strut }}:=1 \mathrm{kip}$

$\mathrm{E}_{\mathrm{L}}:=3.0 \cdot 10^{6} \mathrm{psi}$

$\mathrm{F}_{\mathrm{L}}:=33000 \mathrm{psi}$

$\mathrm{G}_{\mathrm{LT}}:=7000 \mathrm{psi}$

$\mathrm{E}_{\mathrm{T}}:=1 \cdot 10^{6} \mathrm{psi}$

$v_{\mathrm{LT}}:=.35$

$\phi_{\text {c.local }}:=.80$

$\phi_{\text {c.global }}:=.70$

$\lambda:=.75$
$\mathrm{L}:=15 \mathrm{ft} \quad$ Length of Member

Required axial strength due to facotred loads (Struts)

Longitudinal Compressive MOE from coupon testing (Creative Pultrusions)

Longitudinal Compressive strength from coupon testing (Creative Pultrusions)

In-plane shear modulus (Creative Pultrusions)

Transverse Compressive MOE from coupon testing (Creative Pultrusions)

Poisson's Ratio longitudinal direction (Creative Pultrusion)

Resistance factor for failure under compression (local)

Resistance factor for failure under compression (global)

Time effect factor (assumed from Table 2.3-1)

Determine the factored critical stress

Trail Cross-Section

$3^{\prime \prime} \times 25^{\prime \prime}$ Sq. Tube

$\mathrm{A}_{\mathrm{g}}:=2.74 \mathrm{in}^{2}$

$\mathrm{r}:=1.13 \mathrm{in} \quad \mathrm{b}:=3 \mathrm{in} \mathrm{t}:=.25 \mathrm{in}$

$\mathrm{K}:=1 \quad$ Effective Length Factor for pin-pin conditions

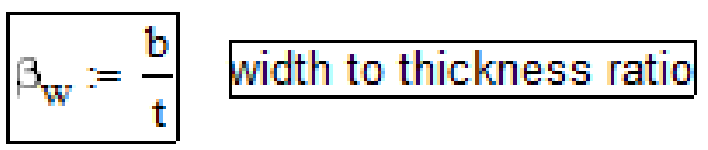

$\phi \mathrm{F}_{\text {cr.local }}:=\phi_{\mathrm{c} . \text { local }} \frac{\frac{\pi^{2}}{6} \cdot\left(\sqrt{\mathrm{E}_{\mathrm{L}} \cdot \mathrm{E}_{\mathrm{T}}}+\nu_{\mathrm{LT}} \cdot \mathrm{E}_{\mathrm{T}}+2 \cdot \mathrm{G}_{\mathrm{LT}}\right)}{\beta_{\mathrm{w}}{ }^{2}} \quad \phi \mathrm{F}_{\mathrm{cr} \cdot \text { local }}=19154.808 \cdot \mathrm{psi}$

$\phi \mathrm{F}_{\text {cr.global }}:=\phi_{\mathrm{c} . \text { global }} \cdot \frac{\pi^{2} \cdot \mathrm{E}_{\mathrm{L}}}{\left(\frac{\mathrm{K} \cdot \mathrm{L}}{\mathrm{r}}\right)^{2}} \quad \phi \mathrm{F}_{\mathrm{cr} . \text { global }}=816.829 \cdot \mathrm{psi}$

$\phi \mathrm{F}_{\mathrm{cr}}:=\mid \begin{aligned} & \phi \mathrm{F}_{\text {cr.local }} \text { if } \phi \mathrm{F}_{\text {cr.local }}<\phi \mathrm{F}_{\text {cr.global }} \quad \phi \mathrm{F}_{\mathrm{cr}}=816.829 \cdot \mathrm{psi} \\ & \phi \mathrm{F}_{\text {cr.global }} \text { otherwise }\end{aligned}$

$\phi \mathrm{P}_{\mathrm{n}}:=\phi \mathrm{F}_{\mathrm{cr}} \cdot \mathrm{A}_{\mathrm{g}} \quad$ Nominal axial compressive strength $\quad \phi \mathrm{P}_{\mathrm{n}}=2.238 \cdot \mathrm{kip}$

Check Limit State

$\lambda \phi \mathrm{P}_{\mathrm{n}}:=\lambda \cdot \phi \mathrm{P}_{\mathrm{n}}$

$\lambda \phi \mathrm{P}_{\mathrm{n}}=1.679 \cdot \mathrm{kip}$

Strength provided $:=\mid \begin{aligned} & \text { "sufficient" if } \mathrm{P}_{\mathrm{u} \text {.strut }} \leq \lambda \phi \mathrm{P}_{\mathrm{n}} \\ & \text { "insufficient" otherwise }\end{aligned}$

Strength ${ }_{\text {provided }}=$ "sufficient"

Strength provided.2 $=\mid \begin{aligned} & \text { "sufficient" if } \lambda \phi \mathrm{P}_{\mathrm{n}} \leq .7 \cdot \lambda \cdot \mathrm{F}_{\mathrm{L}} \cdot \mathrm{A}_{\mathrm{g}} \\ & \text { "insufficient" otherwise } 164\end{aligned}$

Strength provided.2 $_{\text {= "sufficient" }}$

$3^{\prime \prime} \times .25 " \mathrm{Sq}$. Tube 